\title{
Faking good, bad, and ugly: malingering in forensic psychiatric inpatients
}

Citation for published version (APA):

Cima - Knijff, M. J. (2003). Faking good, bad, and ugly: malingering in forensic psychiatric inpatients.

[Doctoral Thesis, Maastricht University]. Universiteit Maastricht. https://doi.org/10.26481/dis.20030528mc

Document status and date:

Published: 01/01/2003

DOI:

10.26481/dis.20030528mc

Document Version:

Publisher's PDF, also known as Version of record

\section{Please check the document version of this publication:}

- A submitted manuscript is the version of the article upon submission and before peer-review. There can be important differences between the submitted version and the official published version of record.

People interested in the research are advised to contact the author for the final version of the publication, or visit the DOI to the publisher's website.

- The final author version and the galley proof are versions of the publication after peer review.

- The final published version features the final layout of the paper including the volume, issue and page numbers.

Link to publication

\footnotetext{
General rights rights.

- You may freely distribute the URL identifying the publication in the public portal. please follow below link for the End User Agreement:

www.umlib.nl/taverne-license

Take down policy

If you believe that this document breaches copyright please contact us at:

repository@maastrichtuniversity.nl

providing details and we will investigate your claim.
}

Copyright and moral rights for the publications made accessible in the public portal are retained by the authors and/or other copyright owners and it is a condition of accessing publications that users recognise and abide by the legal requirements associated with these

- Users may download and print one copy of any publication from the public portal for the purpose of private study or research.

- You may not further distribute the material or use it for any profit-making activity or commercial gain

If the publication is distributed under the terms of Article $25 \mathrm{fa}$ of the Dutch Copyright Act, indicated by the "Taverne" license above, 
FAKING G00D, BAD, AND UGLY;

malingering in forensic psychiatric inpatients 
M J CIMA, HEERLEN 2003

OMSLAGONTWERP \& LAYOUT: designocima w, ww.designocina.com

DRUK: Drukkerij Groeneveldt BV, Landgraaf

ISBN $908077152 \times$

NUR 776 


\title{
FAKING GOOD, BAD, AND UGLY; malingering in forensic psychiatric inpatients
}

\author{
PROEFSCHRIFT
}

ter verkrijging van de graad van doctor aan de Universiteit Maastricht. op gezag van de Rector Magnificus, Prof. dr. A. C. Nieuwenhuijzen Kruseman, wolgens het besluit van het College wan Decanen, in het openbaar te verdedigen op woensdag 28 mei 2003 om 14:00 uur

door

Maaike José Cima-Knijff 


\section{PROMOTOR:}

Prof. dr. H. L. G. J. Merckelbach

\section{BEOORDELINGSCOMMISSIE:}

Prof. dr. H. F. M. Crombag (voorzitter)

Dr. M. Jelicic

Prof. dr. J. Jolles

Dr. F. Koenraadt (Uniwersiteit Utrecht)

Prof. dr. C. de Ruiter (Universiteit van Amsterdam) 


\section{CONTENTS}

INTRODUCTION

1. MALINGERING IN FORENSIC PSYCHIATRIC INPATIENTS

Introduction 10

Forensïc instruments 10

$\begin{array}{ll}\text { Background } & 17\end{array}$

Research questions

2. STRUCTURED INVENTORY OF SIMULATED SYMPTOMS:

THE GERMAN VERSION OF THE STRUCTURED INVENTORY OF MALINGERED SYMPTOMATOLOGY: SIMS.

Summary 36

Introduction $\quad 36$

Methods $\quad 40$

Results $\quad 42$

Discussion $\quad 49$

3. I CAN"T REMEMBER YOUR HONOR: OFFENDERS WHO CLAIM AMNESIA 53

Summary

Introduction $\quad 54$

Crime related amnesia $\quad 56$

The legal context $\quad 59$

What science says 61

$\begin{array}{ll}\text { Tests } & 68\end{array}$ 
Diagnostic accuracy

Conclusion

4. PERSONALITY TRAITS OF PSYCHIATRIC PRISON INMATES WHO CLAIM AMNESIA

Summary 80

Introduction 80

Methods 82

Results 86

Discussion 89

5. CLAIMS OF DISSOCIATIVE AMNESIA IN GERMAN AND DUTCH FORENSIC PATIENTS

Summary 94

Introduction 94

Methods 98

Results 99

Discussion 101

6. THE CONNECTION BETWEEN TRAUMA AND DISSOCIATION 105

Sunmary 106

Introduction $\quad 106$

The link between trauma and dissociation 108

Inconsistencies 110

Correlates of the DES and their implications 112 
Causal connection

Self-report of trauma

Pseudo-memories.

Discussion

7. THE OTHER SIDE OF MALINGERING: SUPERNORMALITY

Summary

Intraduction

Item construction

Results

Discussion

8. IT WASN'T ME: ATTRIBUTION OF BLAME FOR CRIMINAL ACTS IN PSYCHIATRIC OFFENDERS

Summary

Introduction

Methods

Results

Discussion

9. GENERAL DISCUSSION

$\begin{array}{ll}\text { Introduction } & 160\end{array}$

Case $1 \quad 160$

Case 2 164

Case 3 166 
4 CONTENTS

case 4

Direction for future research

Final remarks

SUMMARY

SAMENVATTTNG

ZUSAMMENFASSUNG

REFERENICES

DANKWOORD

CISRRICULUM VITAE

235

LIST OF PUBLICATIONS 


\section{INTRODUCTION}

"It comes as no surprise that psychopaths make good impostors....

In most cases they select professions in which the requisite skills are easy to fake, the jargon is easy to Learn, and the credentials are unlikely to be easily checked. If the profession also places a high premium on the ability to manipulate others, or to "lay on the hands," so much the better. Thus psychopaths find it easy to pose as financial consultants, ministers, counsellors and psychologists." 1

In the present dissertation, deceptive behaviour of criminal psychiatric patients is studied from the perspective of the context in which it occurs. In other words, the prevalence of different types of deceptive behaviours may be dependent on the precise goals that people may want to achieve. An example will help to clarify this proint. An adult who has a lengthy history of antisocial behaviour and who is facing a long prison sentence will undoubtedly may have a good reason to feign insanity in an attempt to awoid a long and harsh incarceration and/or to make a sympathetic impression on triers of fact. Time spent in a mental hospital seems less difficult than being sent to prison, particularly if the individual has prior experiences with incarceration. A period in a mental institution is seen as "easier time". However, a criminal psychiatric patient, who already serwes time in a mental insticution, may be motivated by different factors. Exhibiting signs of mental illness may prolong his stay in the mental hospital; thus, deception may take the form of feigning normal behaviour and denying psychopathology when there is an actual illness or condition that may warrant treatment.

As the term malingering is commonly used to refer to "fakking bad", we coined the term "supernormality" to refer to the deliberate fabrication or gross exaggeration of

\footnotetext{
Hore (1999) pp. 108
} 
healthy features (i.e., faking good). Developing instruments to detect malingering and supernormality is a challenge to forensic psychology. This dissertation is about faking good, faking bad, and how to detect these phenomena. In order to detect these phenomena, it is important to develop instruments that have sufficient sensitivity and specificity. On the other hand, the faking good or faking bad must be ugly enough to detect it by means of self-report scales.

The first chapter gives an outline of what is known about the prevalence and measurement of personality traits associated with malingering in criminal psychiatric settings. From this review, the main research questions are derived.

In chapter 2 to 8 , empirical findings are presented. Chapter 2 presents the result of a study addressing the validity of a German version of an instrument measuring malingered symptomatology. The psychometric merits of this instrument are evaluated.

Chapter 3 presents a critical review of clinical, experimental, and psychometric literature pertaining to several forms of crime-related amnesia. Difficulties surrounding expert testimonies about this phenomenon are also discussed.

Chapter 4 addresses the results of a study on personality traits associated with claims of amnesia in criminal psychiatric patients. More specifically, the study focuses on the issue as to what extent amnesia in these patients is malingered. A follow-up study to investigate the relationship between amnesia for crime and recidivism is discussed in chapter 5 . Amnesia is commonly seen as a dissociative symptom. Dissociation is often considered a psychological defence mechanism used by victims of traumatic events such as sexual abuse, physical punishment, or emotional abuse. Problems with the causal interpretation of childhood trauma as the primary antecedent of dissociative symptoms are explored in chapter 6 . In particular, the possibility that other factors may be of importance in the development of such symptoms is considered in detail. 
A newly developed questionnaire, termed Supernormality Scale (Supernormalität Skala: SNS) is introduced in chapter 7. This scale intends to detect faking good tendencies. The psychometric properties of this test are evaluated and results are critically discussed. The relationship between supernormality and attribution of blame for criminal activity is also addressed in this study.

Chapter 8 sought to measure attributional styles among offenders with regard to their criminal activities. The contribution of certain blame attributions (e.g., external attributions; mental element attributions) to the development of deceptive behaviour is also examined.

Finally, in chapter 9, forensic judgement based on clinical experience is critically reviewed. Two case studies are presented to illustrate this critique and to show how one can do better. Chapter 9 also discusses research avenues for future studies. 

CHAPTER 1

Malingering in forensic psychiatric inpatients 


\section{INTRODUCTION}

This chapter describes the theoretical background of the current dissertation. More specifically, issues like different forms of deceptive behawours, psychopathy, blame attribution, crime-related amnesia, and dissociation are discussed. A brief review of the relationship between mental illness and violent behaviour is also provided. In addition, the connection between psychopathy and malingering of major mental fllness, as well as the relationship between dissociation and trauma is briefly addressed. On the basis of the background information provided in this chapter, the research questions addressed in the following chapters are formulated.

\section{FORENSIC INSTRUMENTS}

When a prosecutor or judge wants to determine whether a defendant is not guilty by reason of insanity, he or she has to answer the following three questions (Mooij, 1995): 1) did the defendant suffer from a psychiatric disorder at the time of the crime event? 2) and if so, what was the nature and extent of this disorder? and 3) is there a causal relationship between the disorder and the crime event. In order to answer these questions, the judge appoints 2 experts. According to standing criminal law", one of them has to be a psychiatrist, but nobody knows why exactly this is a sound principle (Crombag, Van Koppen \& Wagenaar, 1994). Of course, psychologists and psychiatrists who are asked to report to the court. should have had proper training in the forensic field. However, some sceptics (de Ruiter \& Hildebrand, 2002) argue that this is rarely the case.

In the Netherlands, the precise content of forensic psychological examinations are rarely discussed in court (Kelk, 1999). However, according to de Ruiter (2000), forensic examinations differ in three respects from regular diagnostic routines used

Wetboek 5 artikel 37 lid 2 ; antikel $37 b$ lid 2

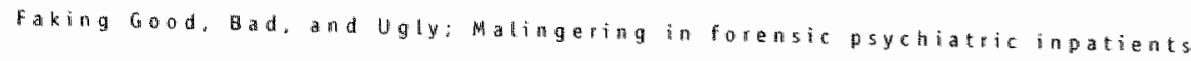


in psychiatric hospitals. First, forensic psychological assessment differs from nomal. clinical practice in that it is not the defendant who asks for an examination. More specifically, the involuntary aspect is contrary to the nature of the relationship between psychologist and patient, a relationship in which a patient consults with a psychologist on the basis of trust generated by the psychologist. To the extent that the psychologist may provide the court with a negative portrait of the defendant, the defendant may try to make a favourable impression, showing even deceptive or manipulative behaviour. Because of this, tests in which such deceptive behaviour is controlled for are to be preferred, as are tests in which measurements are not obvious to the defendant, such that manipulations of test responses is difficult or even impossible (de Ruiter, 2000).

A second point in which forensic assessment differs from routine clinical work, is the nature of personality pathology, which is fairly common among forensic patients (Kröber \& Lauf, 2000). That is, manipulative and/or deceptive behaviours may not only occur because of the circumstances (e.g., test situation), but may also be directly related to the nature of the persionality pathology. The majority of personality disorders seen in forensic settings are antisocial, narcistic, and borderline personality disorders (Greeven, 1997), which are often referred to as cluster B disorders of the DSM-IV (APA, 1994). Pathological lying and manipulation are core features of patients with psychopathic personality characteristics. of course, these features undermine the validity of self-reports and therefore the forensic psychologist is well-advised to use collateral information such as file information and hetero-anamnestic data (de Ruiter \& Greeven 1999).

Thirdly, psychologists working in the forensic field are often asked to provide the court with an indication about the chance that the defendant will re-offend in the future. Questions regarding risk taxation have lead to the development of certain risk assessment instruments in Canada and the United States (Quinsey, Harris, Rice \& Cormier, 1998; Hanson \& Bussière, 1998; Monahan \& Steadman, 1994). Based 
upon extensive empirical work, these tests have been refined and translated for Dutch purposes (e.g., PCL-R; HCR-20; Philippe, de Ruiter, Hildebrand \& Bouman, 2000; Hare, Vertommen, van den Brink \& de Ruiter, in press). When conducting risk assessments, the forensic psychologist is well-advised to employ instruments that tap important risk factors of criminal behaviour, such as impulsivity, lack of empathy, psychopathy, and aggression regulation (de Ruiter, 2000). Self-report questionnaires should only be used when they contain built-in items controlling for deception (Gacono \& Meloy, 1994). Unstructured clinical interviews of the sort commonly conducted in psychiatry lead to unreliable diagnoses in forensic samples and most of the time, unreliability takes the form of underestimating pathology (Zimmerman \& Mattia, 1999). However, semi-structured interview methods like for instance the "Structured Clinical Interview for DSM-IV Axis I disorders" or "Structured Interview for Disorders of Personality-IV" are valuable tools suitable for forensic evaluations, because of their full criteria analysis (de Ruiter, 2000). Despite their availability, these tools are rarely used by professionals. Psychologists and psychiatrists often base their judgements on clinical experience alone (Borum \& Grisso, 1995). However, research literature clearly indicates that clinical prediction leads to less adequate results compared to prediction based on measurement of factors that are known to be related to criminal behaviour (Lidz, Mulvey \& Gardner, 1993).

So far, our discussion focussed on how forensic work differs from routine clinical work and how forensic psychological evaluations can best be done. As to the specifics of how forensic assessments are factually conducted, Borum and Grisso (1995) surveyed psychological test usage among forensic psychologists $(n=51)$ and psychiatrists $(n=42)$. They report no differences between psychologists and psychiatrists in terms of their perceptions of the importance of psychological testing for the assessment of criminal responsibility, though psychologists ordered and conducted more tests than did psychiatrists. Overall, about two thirds of 
practitioners indicated that psychological tests are important for the assessment of criminal responsibility. Meanwhile, only $25 \%$ of forensic experts conducting criminal responsibility assessments stated that psychological testing is essential (Borum \& Grisso, 1995). With respect to specific forensic instruments, $46 \%$ of the psychologists in the Borum and Grisso (1995) study reported never using them, and another $20 \%$ reported that they rarely used them. An even greater percentage of psychiatrists (i.e., 91\%) reported never or rarely using forensic assessment instruments.

Durat, Jabotinsky-Rubin, and Ginath (1993) noted that $84.4 \%$ of the insanity assessments in Israel are carried out in inpatient settings. Further, psychological testing is done in only $15.5 \%$ of the forensic evaluations and almost $40 \%$ of the reports are based on data collected during a 1-day observation (Durat et al., 1993). Given the widespread failure to use well calibrated instruments, it may come as no surprise that clinicians seem not to be able to identify malingerers from genuine patients. In his famous study, Rosenhan (1973) had healthy subjects malinger psychotic symptoms during the intake interview. All of them were admitted for hospital treatment because of severe mental illness. After admission, the "faking" patients were behaving normal again. However, clinicians still were not able to identify the participants as healthy individuals. More interestingly, when clinicians in a follow-up study were told before hand that for the next few weeks, they could expect malingerers coming to their hospital for experimental purposes, they falsely classified real patients as malingerers (Rosenhan, 1973). Enhancing the subjective expectancy to detect abnormalities has the opposite effect. Thus, a study by Renaud and Estess (1961) showed that every psychiatrist who had to interpret a case vigmette portraying a well-adjusted individual, nevertheless diagnosed mental disorder in this case due to a priori expectancies about pathology. This tendency to assume the presence of abnormality and then seek supportive evidence fosters 
"overpathologizing", that is the misclassification of healthy individuals as abnormal (Faust \& Ziskin, 1988).

Why psychologists and psychiatrists should not make judgement based on their clinical experience alone, is also nicely demonstrated by studies showing that professional clinicians do not in fact make more accurate clinical judgements than da laypersons (Faust \& Ziskin, 1988). For instance, high school students and professionals who both reviewed the same case material for making predictions about violent behaviour experienced similar difficulties and also weighted data in a similar way. This suggests that both groups relied on common assumptions about potentially violent individuals or shared cultural stereotypes about such individuals. When judgement rests on conventional beliefs or stereotypes rather than empirical knowledge, professionals are unlikely to surpass laypersons (Faust \& Zisikin, 1988). Furthermore, there is almost no evidence that a select group of professionals with extensive experience or special qualifications performs better than other professionals. That is, the amount of clinical training and experience are unrelated to judgement accuracy (Goldberg, 1968). In a study by Faust, Guilmette, Hart, Arkes, Fishburne, and Davey (1988), in which neuropsychologists evaluated test protocols of individuals so as to determine the presence, location, and cause of brain damage, no significant relations were obtained between judgemental accuracy and education or experience. In contrast, actuarial methods for diagnosis and prediction, which eliminate the human judge and base conclusions solely on empirically established frequencies, consistently outperform professionals and laypersons (Meehl, 1996; Sawyer, 1966). With the possible exception of the Minnesota Multiphasic Personality Inventory (MMPI; Rogers, 1984), which is sensitive to the exaggeration or simulation of disorders, few actuarial procedures directly address forensic questions like, for example, the detection of malingering. Plainly, it is important to develop, calibrate, and validate actuarial tests in order to meet these forensic purposes. 
On a related note, clinical judgement is often not sensitive to forensically relevant sources of error (de Ruiter \& Hildebrand, 2002). Reliance on clinical judgement alone is therefore especially problematic in the criminal context. The point here is that the central actors in a criminal context are suspects rather than patients. While the clinical context is preoccupied with false negatives (misclassifying a sick patient as healthy), the forensic context is (or at least should be) preoccupied with false positives: misclassifying a healthy and innocent individual as a mad and therefore dangerous perpetrator. Basically, the presumption of innocence dictates that convicting an innocent person is worse than acquitting a guilty suspect. Indeed, criminal law contains an elaborated set of rules that aim at reducing the risk of such false positive errors. Thus, in the legal context, specificity is important and perhaps even more important than sensitivity (Rassin \& Merckelbach, 1999). However, the work of clinicians (e.g., psychotherapists) is aimed at promoting the well-being of their patients (Adshead, 1997). In fact, curing and palliation the most important purpose of clinical activity. Given the obligation to act in the best interest of their patients, therapists will act so as to maximize the detection of pathology. In other words, they will give high priority to sensitivity over specificity when diagnosing and treating symptoms (Rassin \& Merckelbach, 1999). Given this state of affairs, the clinician who is working in a legal context is well-advised to rely on actuanal tests so as to counter his/her natural tendency to produce false positives.

Apart from their different heuristics, clinical and legal professionals also seem to have a different concept of truth. In court, factual evidence is important, while in clinical context, the question of whether or not, say, sexual abuse took place is often considered to be not really important. The fact that the patient believes he/she was abused is reason enough to talk about the event (McNulty \& Wardle, 1994). Although clinical and legal heuristics are difficult to reconcile, the fact remains that in court, judges and juries have to depend on expert testimonies given by psychologists and psychiatrists. 
With respect to the qualification of those who offer expert testimony in insanity defence trials, there is considerable variability in background of evaluators (Farkas, DeLeon \& Newman, 1997). The absence of unified standards for forensic examiners can potentially lead to problems with respect to the quality of their expert testimonies and mental health reports in insanity defence trials (Lymburner \& Roesch, 1999). Reichlin, Bloom, and Williams (1993) examined reports that were used by court in evaluating insanity defendants. The results of this study raise serious concerns, because as much as $17 \%$ of the mental health reports relied upon by court, had not been prepared for the purpose of evaluating criminal responsibility.

Apart from the fact that clinicians seldomly employ actuarial methods, important issues like malingering are often ignored or trivialized by them. For example, Gerson (2002) opined in his recent review that pure malingering is rare. Similarly. Hall and Poirier (2001) state in their book that it is a mistake to believe that the insanity defence is easily "faked". But how do they know? Is it their clinical experience that tells them this? In the words of the famous forensic specialist David Faust (1995; p. 255): "Doctor, each time you've been fooled, you don't know it, do you?"

Since deceptive behaviour may not be important in psychiatric settings, it follows that the issue of malingering is also seriously underestimated when clincians operate in the legal domain. As discussed earlier, the clinician's role in a forensic hospital is most of the times not strictly clinical, one therefore should take the issue of malingering in the forensic context seriously. Meanwhile, studies demonstrate that judgements of malingering based on clinical experience do not outperform Judgements of laypersons (Faust \& Ziskin, 1988).

To sum up, then, two urgent research issues can be formulated on the basis of the titerature reviewed above. The first has to do with the development and validation of psychometrically sound tests for forensic purposes. The second has to do with the phenomenon of malingering. Most chapters of the current dissertation address both 
issues. More precisely "they facus on tests to detect faking bad and faking good in the forensic context.

\section{BACKGROUND}

\section{MENTAL ILLNESS AND VIOLENCE}

In approximately $1 \%$ of the 40.000 annual criminal cases in which Dutch courts decide to incarcerate, defendants are classified as not (fully) guilty by reason of insanity (Huls, Schreuders, ter Horst-van Breukelen \& van Tulder, 2000). Figure 1. I shows how this figure has been decreasing and is now increasing over the years (up to 1999).

Forensic psychiatric patients represent a straightforward problem to society. Thus institutions that hospitalise such patients permanently face highly complex decisions that have to be made about these patients. These decisions concern such widely diverse issues as conditional hospital release, the danger of potential recidivism, and expert testimony about insanity. Up to this very day, such decisions are mainly guided by psychiatrists" and psychologists" intuitive clinical experience. Accordingly, to a large extent this field is characterized by a lack of clear standards and criteria. On the other hand, over the past few years, forensic psychological testing has made considerable progress. That is, there are now good and valid tests available (e.g., SIRS, MMPI-2, SIMS, M Test; Rogers, 1997) to identify psychiatric disorders in forensic patients and to differentiate them from malingering (simulation) of psychiatric symptoms. Also, there is now a substantial corpus of knowledge about the symptoms and disorders that represent high risk factors for violent recidivism (e.g., hyperactivity, impulsivity, attention deficit, aggressiveness, antisocial behaviour, psychopathy: Loeber \& Farrington, 1998). While relevant tests and instruments have largely been developed in the USA and Canada, it is obvious that they aiso bear strong relevance to continental forensic psychiatry. 
18 CEAPTER

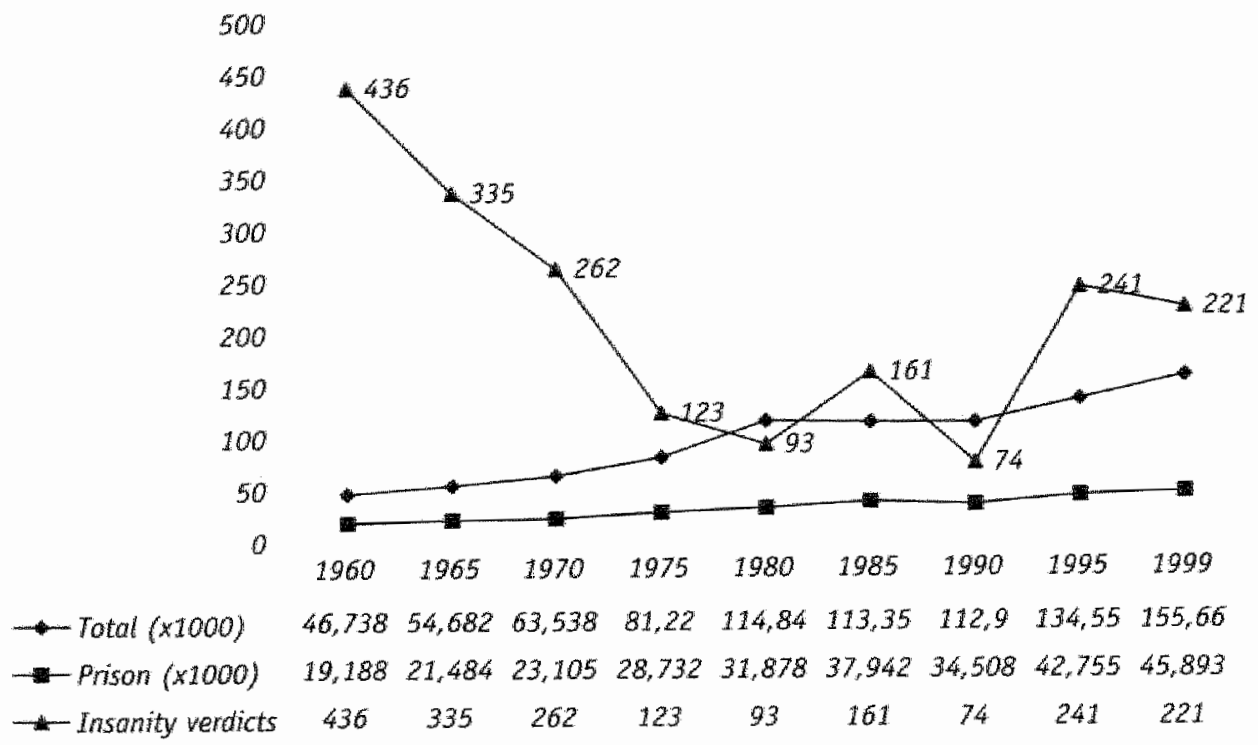

Figure 1.1: Overview of criminal cases appearing in count (i.e., totot), number of prison incarcerations (i.e., prisan), and court decisions inwolving insanity werdicts, aver the last 40 years. ${ }^{3}$

The main focus of this dissertation is the status of psychiatric symptoms in criminal offenders. Broadly formulated, the question is whether crimes are conducted because of mental illness, or does malingering of psychiatric symptoms appear after crimes have been committed. Clinical intuition suggests that violence is closely linked to mental illness. Many studies have explored this relationship, both in community and institutional settings (for example see Link \& Stueve, 1994; Link, Stueve \& Phelan, 1998; McNiel, 1994; McNiel \& Binder, 1994; Silva, Leong, Weinstock \& Klein, 1995; Taylor, Leese, Williams, Butwell, Daly \& Larkin, 1998). In general, this research shows that there are different models that one might

\footnotetext{
"Based upon data of the WODC (Huls, Schreuders, ter Horst-wan Breuketen \& wan Tulder, 2000)
} 
consider. According to Junginger (1996), much of the violent behaviour observed in mentally ill people is not randon but is motivated and directed by psychotic symptoms. In his study, the most violent behaviour among psychiatric patients was in keeping with the content of their delusions and hallucinations. In line with this, there is some evidence that specific symptoms can predict violence. While some authors (e.g., Swanson, 1994) argue that a diagnosis of sctizophrenia is a predictor for the occurrence of violent behaviour, most studies (e.g., Nijman, 1999: Bartels, Drake, Wallach \& Freeman, 1991) convincingly demonstrate that it is not mental illness per se which brings about criminality, but the specific presence of delusions and hallucinations.

However, there are also authors who believe that there is no relationship between mental illmess and violent behaviour. By this view, psychiatric symptoms and criminality have little or nothing in common (e.g., Monahan \& Steadman, 1983). These authors base their argument on studies in which the association between criminality and psychiatric symptoms disappeared once factors such as, age sexe, and social status were controlled for. Furthermore, in a meta-analysis conducted by Bonta, Law, and Hansson (1998) on predictors of recidivism among offenders with major mentall disorder, clinical characteristics were not related to subsequent violent behaviour (see also Appelbaum, Robbins \& Monahan, 2000). Yet another approach to this issue assumes that the connection between mental illness and violent behaviour is, at least in part, a by-product of some offenders malingering psychiatric symptoms to avoid criminal responsibility. This approach is based on the following considerations (e.g., Hare, 1995):

$\checkmark$ Violent crimes are often committed by offenders with psychopathic or/and antisocial personality characteristics.

$\checkmark \quad$ Such personality characteristics also induce malingering of psychiatric symptoms. 
$\checkmark$ These personality characteristics are related to poor executive functioning and impulsive behaviour.

\section{DECEPTION}

In general, deceptive forms of behaviour can take rather mild forms such as occasional "fibs" or lies, or they can be more extreme such as chronic lying. deliberate feigning of physical or emotional distress, cheating or conning others out of money, or making false allegations (e.g., of sexual abuse; McCann, 1998). The term deception is actually a more palatable reference to lying, which is defined as "an assertion of something known or believed by the speaker to be untrue, with intent to deceive" (Ekman, 1985; Sigmon \& Snyder, 1993). An older view of malingering, referred to as the "pathogenic model" (Rogers, 1990a, 1990b), treats malingering as a symptom of genuine mental illmess acting als a defence against the disintegration of the very condition that is feigned (e.g., Eissler, 1951). As to the prevalence of malingering major mental illiness in forensïc hospitals, results are highly inconsistent; Prevalence rates vary from as low as 10 of 353 patients (3\%; Roman, Tuley, Villanueva \& Mitchell, 1990), 9 out of 79 patients (12\%; Hankins, Barnard \& Robbins, 1993), and 15.7\% of the patients (Rogers, Sewell \& Goldstein, 2994), to as high as 18 of 36 patients (50\%; Gacono, Meloy, Sheppard, Speth \& Roske, 1995). Table 1.1 shows some typical examples of studies concerned with prevalence rates of malingering.

Rogers (1990a) outlined 3 different models of matingering. The first model (i.e., the pathogenic modely postulates that malingering is an attempt to control psychotic and neurotic processes by consciously reproducing underlying psychopathology. The tension inherent to this model between unconscious illness and conscious production of symptoms exemplifies the difficulties in formulating sharp boundaries between the conscious/unconscious and voluntary/imvoluntary dimensions which are necessary to classify malingerers as individuals who consciously and purportedly 
report false symptoms. DSM-IV (APA, 1994) adopts a criminal model of malingering, which stresses a wilful antisocial motivation which is reminiscent of nineteenth century views. The implicit assumption of this model is that socially deviant individuals are likely to fabricate illness when they have to appear in court. This model proposes that psychopaths are not sensitive to either social convention or criminal law and therefore they tend to feign mental disorders so as to obtain unearned and undeserwed rewards (Rogers et al., 1994). Finally the adaptational model assumes that malingering is a creative attempt, at least from the feigner's perspective, to succeed in highly adversarial circumstances. This model is based on decision theory, which assumes that an individual will malinger if doing so will result in a positive or favourable outcome in adverse circumstances. By this view, malingering is an option selected because it is "adaptive" in that it brings about the desired goal sought by the individual. Germane to this issue is Walters' (1988) observation that prison inmates modify their self-report to fit the adversarial nature of a forensic evaluation and to achieve desired goals.

As mentioned earlier, deception in clinical assessment and treatment will have quite different significance to the clinician and the forensic examiner. More specifically, in climical settings, the ultimate goal is to understand and treat psychological symptoms and to reduce suffering. In contrast, in forensic settings, the uttimate goal is to gather and collect uncontaminated data. Based on this consideration, it should come as no surprise that the preferred models of malingering will vary as a function of the particular role one assumes and the setting in which one functions. However, given the different tests available by now, there is no reason to base judgement about malingering on clinical experience alone. The next paragraph gives a brief overview of various tests that intend to differentiate malingering from genuine psychopathology.

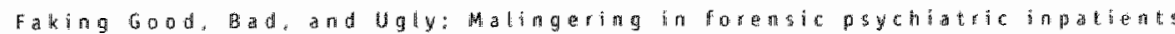


TESTS. Clinical litewature suggests that malingerers often report fantastic or preposterous symptoms (Rogers, 1984). Based on the Structured Interview of Reported Symptoms (SIRS). Rogers (1990b) found that feigners were likely to endorse several improbable symptoms, which were almost never reported by psychiatric samples or other controls. Research on the MMPI-2 (Bagby, Gillis \& Dickens, 1990) has suggested that the validity index, consisting of absurd items, may be a valuable tool in identifying simulators. In addition, there is some evidence from the M Test (Gillis, Rogers \& Bagby, 1991) that an overendorsement of improbable symptoms may be indicative of feigning psychosis. The SIMS (Smith \& Burger, 1997), the German version of which is addressed in the next chapter, shows promising results in correctly discriminating controls from malingerers. As is the case with many forms of psychopathology (e.g.o dissociation: Chu, 1988), researchers also assume that malingering and defensiveness are part of a continuum that is characterized by malingering at the one end and defensiveness at the other (Rogers, 1997). Consequently, patterns of item endorsement gradually will shade into malingering or defensiveness as one moves across this continuum. Given this continuum, one can develop scales to assess both types of response sets, with high scores reflecting malingering and low scores reflecting defensiveness. Examples of such scales are the validity scales of the MMPI-2 (Roger, 1997), the M Test, and Wiggins (1959) Social Desirability (Wsd) questionnaire. However, the presence of malingering or defensiveness does not rule out actual psychopathology. A person who actually has a specific mental disorder atso may malinger or be defensive about the presence of other forms of psychopathology (Rogers, 1997). It has been suggested that psychopaths may be specifically good at malingering a mental disorder (Clark, 1997). This idea is further discurssed later on. 
Table 1.1 Some examples of studies that loaked at the prevalence of malingering

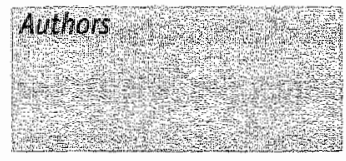

Comell \& Hawk (1989)

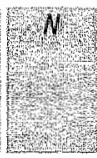

314 Pre-trial defendants

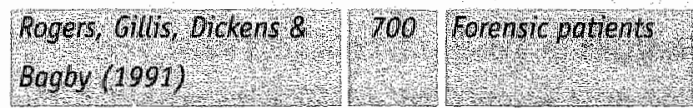

Grossman \& Wasyliw (1988)

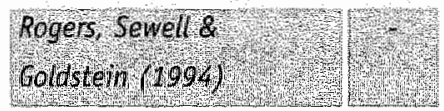

Heilburn, Bennett, White
49 Pre-trial

defendants

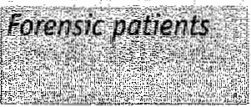

159 Forensic patients

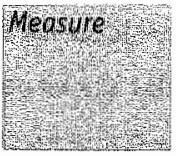

Review of records
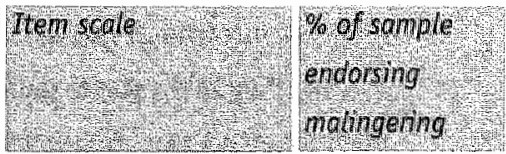

8

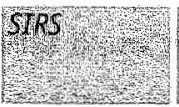

MMPI

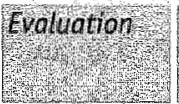

MMPI
Dichotamous items

14.0

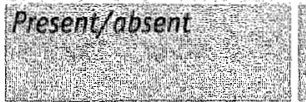

Dichotomous items

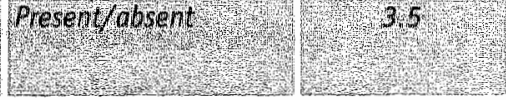

15.

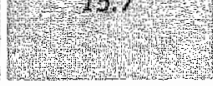

9 \& Kelly (1990)

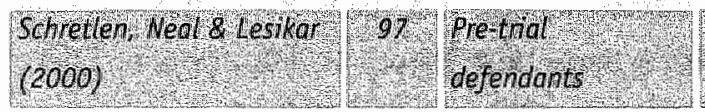

\section{PSYCHOPATHY}

Impulsivity is a hallimark feature of criminal behaviour, as it is one of the DSM-IV criteria for antisocial personality disorder (APD). It also figures prominently in descriptions of a concept closely related to APD, namely psychopathy (Hare, 1991). APD as well as psychopathy are often preceded by conduct disorder (CD) in childhood, which in turn is often preceded by oppositional defiant disorder $(000$; Lahey \& Loeber, 1997; Lynam, 1996; Frick, 1998). A typical childhood disorder related to impulsivity is the hyperactivity/impulsive type of attention-deficit hyperactivity disorder (ADHD), which constitutes a risk factor for adult criminal behaviour (Babinski, Hartsough \& Lambert, 1999). Over the past few years, the study of possible genetic or biological mechanisms involved in the development and persistence of criminal behaviour has boomed. According to Barratt (1993), 
impulsivity involves a neural system which includes primarily pathways between the orbitofrontal cortex, selected limbic system nuclei (especially the basolateral amygdala), basal ganglia nuclei, and the cerebellum. Impulsivity refers to a lack of contral over the expression of thoughts into actions. In many studies, the forebrain, especially the orbitofrontal cortex, has been found to be implicated in inhibitory control (neurophysiological) over other cortical and subcortical nuclei and in behavioural control (Schlag \& Scheibel, 1967).

A large body of research suggests that participants with a diagnosis of psychopathy differ from controls in various ways, for example, in terms of neuropsychological functioning (e.g., Newman, 1998). In the United States, the Psychopathic Checklist (PCL; Hare, 1980), Psychopathic Checklist Revised (PCL-R; Hare, 1991), and Psychopathic Checklist Screening Version (PCL-SV; Hart, COX \& Hare, 1996) have become important psychological tools for taping into personality traits associated with antisocial behaviour. Factor analyses indicate that the PCL-R has two separate factors (Hare, 1991: Harpur, Hakstian \& Hare, 1988; Harpur, Hare \& Hakstian, 1989). One (Factor 1) reflects certain affective and interpersonal traits (e.g., superficial charm, lack of remorse, deceitful behaviour) while the other (Factor 2) mainly reflects antisocial traits (e.g., impulsivity, irresponsibility, poor behavioural control).

Self-control, free will, volition, inhibition, and executive functions of the brain are all relevant concepts related to the control of thoughts and behaviour (Monahan \& Steadman, 1994). According to Barratt (1994), the trait of impulsivity is significantly related to one form of aggression, which he labelled "impulsive aggression", a term that has also been used by others (e.g. Coccaro, 1989). The term refers to a group of common characteristics that define the overlap between impulsivity and certain forms of aggression. These common characteristics include a genetic predisposition, acting without thinking, low serotonin levels, and an inability to control certain behaviours even though one intends to do 50 (Barratt. 
1994). There is evidence that serotonin levels are partially genetically mediated, which could account for the genetic predisposition noted above. The term 'executive function" refers to a complex cognitive construct that encompasses the set of processes that underlie flexible goal-directed behaviour (e.g., planning, inhibitory control, attentional flexibility, working memory). Poor executive functions may be preceded by developmental disorders during brain maturation (Hughes, 2002). Executive functions are closely associated with the pre-frontal cortex, an area of the brain that becomes functionally mature very late in development, namely around adolescence (Golden, 1981; Rakic, Bourgeois, Zecevic, Eckenhoff \& Goldman-Rakic, 1986; Diamond, 1988, 1991). In line with this, clinical evidence shows that people with damage to the pre-frontal cortex experience problems with a range of executive tasks involving planning, flexibility, organization, and working memory (Shallice, 1998; Stuss \& Benson, 1986). However, the neural and cognitive processes which underlie performance during executive function task have yet to be fully specified (Rabitt, 1997). As well, the causal pathways by which neural damage produces executive deficits are not well understood (Beveridge, Jarrold \& Pettit, 2002).

The process of normal development of executive function begins in young children (DeLoache \& Brown, 1984; Rakic, et al., 1986; Hughes, 1998). Numerous studies have shown that compared to normal children, children with a variety of neurodevelopmental disorders perform more poorly on tasks that place denands on executive functions (Pennington \& Ozonoff, 1996). For example, children with ADHD demonstrate clear executive deficits (Diamond, Prevor, Callender \& Druin, 1997; Pennington \& Ozonoff, 1996). Furthermore, according to Raine (1993), damage to the pre-frontal cortex can result in impulsivity, loss of self-control, immaturity. altered emotionality, and the inability to modify behaviour, which can all in turn facilitate aggressive acts. This author also noted that neuropsychological studies involving antisocial, violent offenders have revealed strong evidence of impaired pre-frontal functioning in this group. Tabel 1.2 shows some biological parameters 
involved in the development of violent behaviour. Different clinical neuroscience paradigms are beginning to converge on the conclusion that there is a significant brain basis to APD over and above contributions from the psychosocial environment, and that these neurobehavioral processes are relevant to understanding manifestations of violence in society (Raine, 1993). However, neuroscience studies on criminal behaviour are expected to make only further progress, once some key concepts referring to the behaviour one wants to explain are better understood. We now turn to these concepts: psychopathy, malingering, and dissociation.

Table 1.2: Bialogical parameters involved in the development and persistence of criminal behoviour:

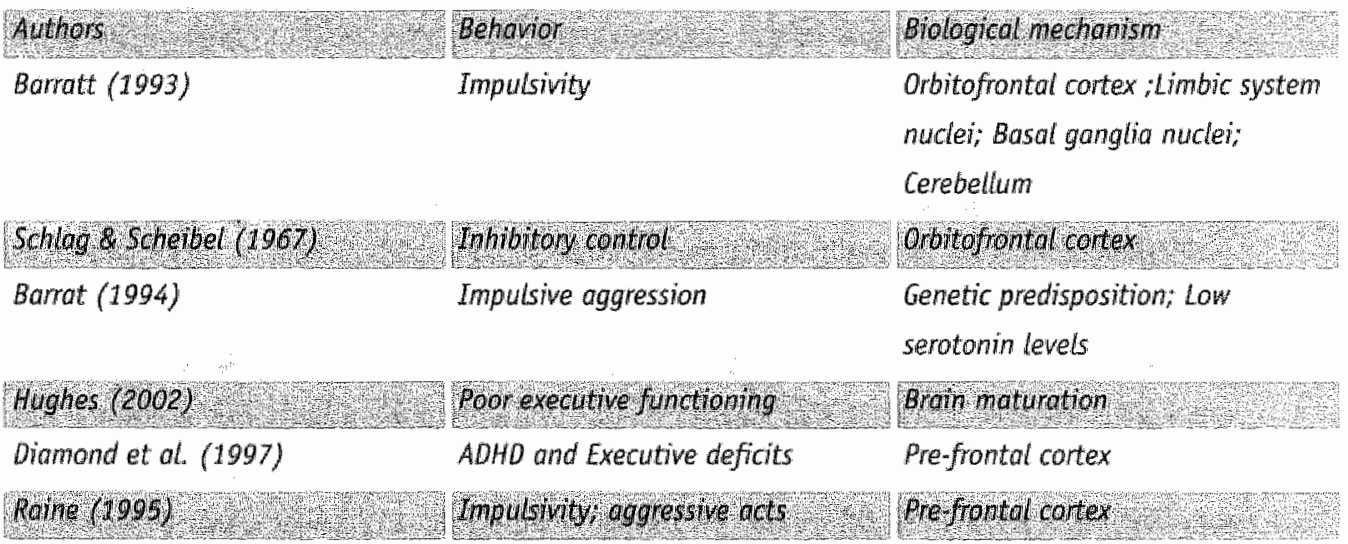

PSYCHOPATHY AND MALINGERING. Psychopathy, psychopathic disorder, and antisocial personality disorder reflect conditions that share several common characteristics (Stalenheim \& von knorring, 1996), like impulsivity, rule-breaking, and reckless or irresponsible behaviour (Raine, 1993). It is a long-held clinical belief that persons who exhibit personality features indicative of psychopathy are particularly likely to engage in a variety of conning and deceptive behaviours. (Sierles, 1984). In fact, "pathological lying" and "conning/manipulation" are 2 of 
the 20 criteria on Hare's (1991) PCL-R mentioned earlier. In the United States, this instrument is regarded by many health professionals as the gold standard for identifying psychopathy in forensic settings. Apart from a general tendency toward deception, it has also been argued that psychopathic individuals are specifically and dispropontionately at risk to engage in matingering, such as the fabrication of psychotic symptoms in order to be admitted to psychiatric facilities or to avoid prosecution for a crime (Edens, Buffingtion \& Tomicic, 2000). Some authors (e.g., Clark, 1997) argue that at least some psychopaths are not only more likely to feign, but are also especially talented at malingering and dissimulation, given their endogenous tendencies toward deception and manipulation. However, other studies suggest that persons diagnosed with APD (Rogers, Kropp. Bagby \& Dickens, 1992) or psychopathy (Roger, 1997) are not significantly better at feigning mental illness than are prison inmates without these diagnoses. Because recent literature suggest that the relationship between psychopathy and malingering is not so robust and direct as has previously been thought (e.g., Rogers, 1997; Poytress, Edens \& Watkins, 2001), we were interested in the relationship between psychopathy and "faking good". Meanwhile, there are no suitable instruments for measuring "faking good" and so a first step was to develop a scale for this purpose (i.e., supernormal behaviour in forensic patients). This issue will be further taken up in chapter 7 .

\section{BLAME ATTRIBUTION}

To be held criminal responsible, a person must have freely chosen to commit a criminal act, knowing that this act was criminal. This is the so called mens rea principle (e.g., Crombag, 2002). An evaluation of self-control and free choice by the defendant is central to the determination of criminal responsibility. Intact selfcontrol and choice at the time of the alleged crime often lead courts to hold the defendant responsible. Conversely, impaired self-control may result in exculpation or mitigation of responsibility for the offence (Hall \& Poirier, 2001).

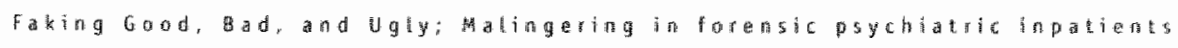


Forensic settings aim at creating a therapeutic atmosphere and in this context, feelings of responsibility and remorse are crucial to therapeutic progress. It may well be the case that for certain individuals, the legal interpretation of criminal responsibility and personal feelings about responsibility do not match. For instance, a defendant may attribute his criminal behaviour to a mental disorder not because he himself believes this to be the case but rather to reduce his responsibility in the eyes of others (e.g.e court, therapists, family). Criminals may use other types of attribution as well. For example, they may attribute their offences to external circumstances or they may rely on intermal attributions, which lead to feelings of remorse. Furthermore, features such as empathy and remorse are items used in risk taxation and prognoses of recidivism of offenders. To evaluate such attributions, one should make use of objective and validated tests. Gudjonsson's (Gudjonsson \& Singh, 1989a) Blame Attribution Inwentory is an interesting and promising tool in this respect. The psychometric properties of the German version of this scale are discussed in chapter 8 .

TYPE OF CRIME AND BLAME ATTRIBUTION. Perhaps because of its obvious implications for criminal proceedings, researchers have shown considerable interest in factors influencing attribution of responsibility (Fishbein \& Ajzen, 1973). Literature suggests that there is a relationship between certain crime types and certain blame attributions. For instance, violent offenders seem to attribute their criminal behaviour significantly more often to mental aberrations than do sexual or non-violent offenders (Gudjonsson \& Singh, 1988; Gudjonsson \& Petursson, 1991a). As mentioned before, research on criminal responsibility has also extended beyond the strict confines of the general psychological literature, with researchers attempting to identify brain dysfunctions associated with criminal behaviour. Specifically, using Positron Emission Tomography (PET), Raine, Buchsbaum, Stanley, Lottenberg. Abel, and Stoddard (1994) studied brain functioning in insanity 
defendants who had committed homicide and matched controls. Results indicted that murderers who are pleading insanity are characterized by a specific pre-frontal dysfunction. As mentioned before, pre-frontal dysfunction is associated with loss of inhibition, risk-taking, rule-breaking behaviour, emotional outbursts, loss of selfcontrol, and poor social judgement. Thus, it is not unreasonable to assume that such deficits may predispose an individual toward violence. However, the danger with this type of explanation is that it becomes in court a sort of "biological defence strategy" to reduce crime responsibility. However, biological predisposition does not necessarily indicate loss of control. We will return to this issue in the final chapter.

\section{DISSOCIATIVE AMNESIA}

What was called "psychogenic" ammesia in the third revised edition of the DSM (DSM-III-R; APA, 1987) has been renamed dissociative amnesia in DSM-IV (APA, 1994). Most published cases of dissociative amnesia are characterized by a sudden onset of memory impairments for autobiographical events and knowledge (Kanzer, 1939; Schacter, Wang, Tulving \& Freedman, 1982; Wong, 1990). Some researchers have postulated that dissociative amnesia develops following acute traumatic events accompanied by extreme emotional arousal (Kopelman, 1987). Criminal offenders often claim amnesia for their crimes (see for example table 1.3). As will be explained in more detail later on (i.e., chapters 3 to 5), when an offender claims amnesia, the crime event itself is often interpreted by experts as a traumatic experience for the offender. However, there may be other and perhaps more plausible causes for offenders' self-reports of amnesia. First, there is a distinction between organic and dissociative (also called functional) amnesia (Schacter, 1986). Organic amnesia refers to pathological forgetting as a result of irreversible (ii.e., lesions) or reversible (i.e., intoxication) brain damage. Perhaps one of the most interisively studied manifestation of organic amnesia is known as the amnesic 
syndrome. This is a chronic and debilitating loss of memory that exists in conjunction with relatively normal intellectual functioning (Schacter, 1986). It has also been demonstrated that high doses of alcohol and other drugs can produce memory deficits in normal subjects (e.g., Birnbaum \& Parker, 1977; Eich, 1980). An extreme example of this is alcoholic 'blackout', which occurs when a person is amnestic for an episode of intoxication (Goodwin. Crane \& Guze, 1969; Goodwin. Othmer, Halikas \& Freeman, 1970; Lisman, 1974; Tarter \& Schneider, 1976). Dissociative amnesia differs from organic amnesia insofar as it occurs in the absence of detectable brain pathology. The most frequently mentioned cause of dissociative amnesia is emotional shock produced by traumatic events (Schacter, 1986). Finally, feigned (i.e., malingered) amnesia refers to a condition in which amnesia claims are consciously fabricated (e.g., Schacter, 1986; Loewenstein, 1991; Kopelman, 1995; Kihlstrom \& Schacter, 1995).

In the clinical context, it may not be relevant to examine the precise causes of amnesia. Thus, differentiating between organic, dissociative, or malingered amnesia may not be that important to most clinicians. Things are different in the legal domain. Here, triers of fact often associate organic ammesia and sometimes even dissociative amnesia with automatic behaviour during the crime. In a legal context. automatism refers to behaviour that is executed involuntarily and without consciousness or intention (Schacter, 1986). The significance of automatism for the attribution of criminal responsibility has been spelled out clearly by Martin (1981): "Voluntary conduct is essential for criminal liability. If a person's badily movements are not subject to the control of his will, there is no voluntary conduct. Automatism has now become the term used to denote unconscious involuntary behoviour" (pp. 22-23). However, amnesia that is claimed here and now does not necessarily imply automatic behaviour at the time of the crime (Hopwood \& Snell, 1933). Nevertheless, many clinicians firmly believe that amnesia indicates 
automatism during crime and therefore reduced criminal responsibility (Barbey. 1990).

According to Carlisle (1991), dissociative amnesia is one of the most frequent symptoms during a violent criminal act. Accordingly, many clinicians working in the forensic field do not seem to be interested in investigating the status of claims of amnesia. Mast of the time, such claims are interpreted by them as dissociative amnesia supporting a plead of diminished responsibility (e.g., Barbey, 1990). It would be a step forward if forensic professionals would take into account the possibility of feigning in cases were criminals claim amnesia. However, in order to do 50, one would need instruments for evaluating the credibility of amnesia claims. In chapter 3, we address this issue at length. In the final chapter, we will return to this issue by focussing on some case studies.

Table 1.3: Examples of studies addressing the prevalence of crime-related amnesia

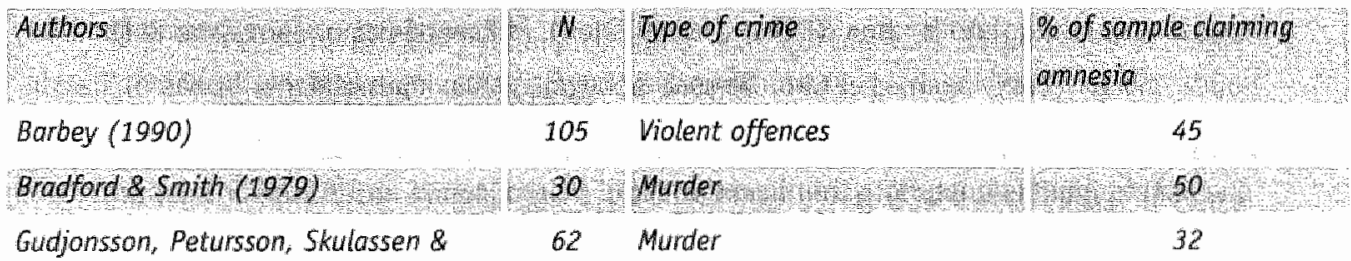

Sigurdardottir (1989)

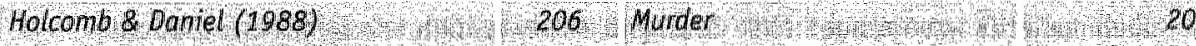

Leitch (1948)

51 Murder or Manslaughter 31

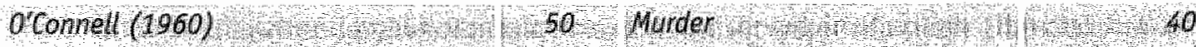

Panwatiker, Halcomb \& Menninger $\quad 105$ Violent offences 23

(1985)

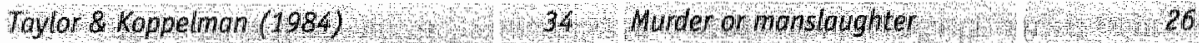


DISSOCIATION AND TRAUMA. AS it is true for Freudiain repression, the concept of dissociation refers to a defence mechamism. More specifically, it has been assumed that dissociation functions so as to make detachment from emotional impact of a traumatic event possible (Classen, Koopman \& Spiegel, 1993; van der Kolk \& van der Hart, 1989). Not surprisingly, it is commonly believed that dissociation is a defence or coping strategy acting in response to overwhelming events from which no physical escape is possible (e.g., Allen, 1993; Braun, 1988; Putnam, 1989; Spiegel, 1994; Spiegel \& Cardena, 1991). Dissociation occurs on a continuum from daydreaming to more pathological forms such as Multiple Personality Disorder (Chu, 1990). Although it has been claimed that the relationship between dissociation and trauma is a robust and direct one (e.g.. Classen et al., 1993: Putnam, Carlsen, Ross, Anderson, Clark, Torem et al., 1996; Brunner, Resch, Parzer \& Koch, 1997; Resch, Brunner \& Parzer,1998), some studies have come up with results that are difficult to interpret in terms of a simple trauma-dissociation model (e.g., DiTomasso \& Routh, 1993; Nash, Hulsey, Sexton, Harralson \& Lambert, 1993; Merckelbach, Dekkers, Wessel \& Roefs, 2003; Merckelbach, Muris \& Rassin, 1999; Merckelbach, Rassin \& Muris, 2000d; Merckelbach, Devilly \& Rassin, 2002b). This issue will be discussed in more detail in chapters 3 and 6 . The results presented in these chapters make it clear that there is no direct relationship between dissociation and traumatic childhood experiences.

Some authors have argued that men with extreme high levels of dissociations can be readily found in prison (Snow, Beckman \& Brack, 1996). As a study of Cima, Merckelbach, Klein, Schellbach-Matties, and Kremer (2001) showed, there is some truth to this, but the dissociative symptoms of the criminals in their study were not related to self-reports of childhood abuse. Amnesia is, of course, a prominent dissociative symptom. In chapters 3, 4, and 5 we will discuss the alternative hypothesis that such symptoms have to do with the tendency to feign. If this hypothesis is correct, then one might expect certain internal and external blame 
attributions for crime of offenders who score high on simulation, an issue that is taken up in chapter 8.

\section{RESEARCH QUESTIONS}

From our review of the literature presented above, the main research issues of the present dissertation can be derived. More specifically, the following questions will be addressed in the chapters to follow:

$\checkmark \quad$ Is the Structured Inventory of Malingered Symptomatology (SIMS; Smith \& Burger, 1997) a reliable and valid instrument for measuring malingering? (chapter 2)

$\checkmark$ How prevalent are claims of crime-related amnesia in forensic settings? (chapters 4 and 5)

$\checkmark$ How should one interpret such claims? (chapters 3, 4, and 5)

$\checkmark$ Are there certain personality traits that go together with claims of crimerelated amnesia? (chapter 4 )

$\checkmark \quad$ Is there a relationship between crime-related amnesia and prior convictions in criminal psychiatric inpatients (chapter 5), as one would expect if crimerelated ammesia is, indeed, strategic behaviour.

$\checkmark$ Do traumatic event precede the development of dissociative symptoms? (chapter 6)

$\checkmark$ Is the Supernormality Scalle (SNS; Cima, Merckelbach, Hollnack, Butt, Kremer, Schellbach-Matties \& Muris, accepted pending revision) a reliable and valid instrument for measuring supernormality? (chapter 7)

$\checkmark \quad$ Do blame attributions for crime depend on type of crime and/or malingering tendencies? (chapters 7 and 8) 


\section{CHAPTER 2}

*The German version of the Structured Inventory of Malingered Symptomatology (SIMS) as a screening tool for the detection of malingering

"This chapter is in press as: Cima, M., Hollnack, S., Kremer, K. Knouer, E., Schellbach-Matties, R. Klein. B. \& Merckelbach, H. Strukturierter Fragebogen Simulienter Symptome: Die deutsche Version des "Structured Inventory of Malingered Symptomatology: SIMS". Nervenarzt. 


\section{SUMMARY}

The current chapter addresses the psychometric qualities of the German Version of the Structured Inventory of Malingered Symptomatology (SIMS), a self-report measure of malingering. The SIMS was administered to a heterogeneous sample of forensic patients $(n=62)$ and undergraduate students $(n=204)$. Within the student sample, some undergraduates were instructed to feign certain pathological conditions, while others were asked to respond honestly to the SIMS items. Findings indicate that the German version of the SIMS demonstrates adequate test-retest stability and internal consistency. In the patient sample, the SIMS was found to be strongly correlated with manipulative and antisocial personality features. More specifically. SIMS scores were raised in sexual delinquent patients with an antisocial. personality disorder. Our findings support the idea that the SIMS is a valuable screening tool for malingering of psychiatric symptoms.

\section{INTRODUCTION}

Malingering is defined as the deliberate fabrication or gross exaggeration of psychological or physical symptoms (Resnick, 1997). In forensic settings, malingering is estimated to occur in about $16 \%$ of the patients, which suggests that it is not a trivial problem (Rogers, Sewell \& Goldstein, 1994). Motives for malingering within the criminal justice system may include exculpation or delay of pending criminal charges, mitigation of sentencing, or serving an easy time in a psychiatric facility (Resnick, 1997). As to clinical treatment of forensic patients, malingering may provide therapists with a pessimistic view of treatment gains. In light of these considerations, it is important to develop sensitive instruments for detecting malingering.

Fatk 
Meanwhile, in the literature, the consensus is that inalingering is difficult to detect (Smith, 1997). In general, three approaches for the detection of malingering have been proposed. The first relies on widely used intelligence or personality measures (see for a review. Schretlen, 1988). The rational behind this approach is that malingerers will respond in an aberrant manner to standardized assessment devices (e.g., "near miss" responses, inconsistent scores across repeated administrations). Some of these standardized toals contain validity scales to tap such deviant response styles. The Minnesota Multiphasic Personality Inventory (MMPI; Hathaway \& Mckinley, 1983) is an example of an assessment tool with validity indices. One of these is the F-scale. However, research examining the efficacy of the F scale for the detection of malingering has produced mixed results (Green, 1988).

Interview techniques and observational strategies constitute a second approach to the detection of malingering. For example, Resnick (1984, 1993) noted that malingerers display several distinct characteristics during interviews. The Structured Interview of Reported Symptoms (SIRS; Rogers, Bagby \& Dickens, 1992) is a good example of a standardized interview technique that capitalizes on these characteristics. However, such interview techniques have certain practical limitations. That is, they are time consuming and require trained interviewers. The third approach involves the use of self-report instruments specifically designed for the detection of malingering. Examples of such tests are the "coin-in-hand" test (see Cochrane, Baker \& Meudell, 1998) and the M-test (e.g., Grow, McVaugh \& Eno, 1980), which aim at the detection of malingered amnesia and malingered schizophrenia, respectively. A limitation of these tools is that they focus on a narrow range of symptoms. The Structured Inventory of Malingered Symptomatology (SIMS; Smith \& Burger, 1997) is a promising self-report tool that addresses a broad range of symptoms that are sensitive to malingering.

The SIMS is a 75 -item true-false test which intends to provide a brief screening measure of mallingering in an easily administered format. Items were drawn from 
two different sources. First, questions were selected from existing measures such as the MMPI, SIRS, and the Wechsler Adult Intelligence Scale-Revised (WAIS-R). These measures have demonstrated some utility in detecting malingering in past research (Smith, 1997). The selected items were then edited so as to tap various malingering strategies (e.g., approximate answers) and to increase their sensitivity to the feigning of particular conditions. Second, additional items were developed to reflect the qualitative characteristics of malingerers noted in previous research (e.g.. Resnick, 1984; Rogers, 1984; Seamons, Howell, Carlisle \& Roe, 1981). All items were then organized into five scales of 15 questions each designed to tap commonly malingered conditions, namely low intelligence (LI), affective disorder (AF), neurological impairment $(\mathbb{N})$, psychosis (P), and amnestic disorder (AM). Certain items have a bizarre content (e.g. " When I hear voices I feel as though my teeth are leaving my body") or refer to unrealistic symptoms (e.g*. "I have pain in my body which seem to feel like bugs crawling under the surface of my skin"). Other items explicitly allude to a certain syndrome (e.g.r depression) in such way that specialist recognize that highly atypical symptoms are listed (e.g., "The more depressed I get, the more I want to eat"). Still, other items contain an option for "near good" responses (e.g., "There are six days in a week"). Answers indicating malingering are summed to abtain a Total SIMS score. Scores can also be summed across each of the 5 subscales.

A first study addressing the psychometric properties of the SIMS (Smith \& Burger, 1997) relied on 476 students assigmed to a developmental and cross-validational sample. Within each sample, participants were assigned to either a control (i.e., honesty responding) condition or various instructed malingering conditions. The Total SIMS score proved to be the most efficient indicator of malingering. It accurately identified $95.6 \%$ of the simulators (sensitivity) and $87.9 \%$ of the honesty responding participants (specificity). Individual SIMS scales varied in terms of their sensitivity from a low of $74.6 \%$ for the AF subscale to a high of $88.3 \%$ for the AM

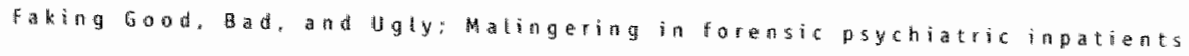


subscale. Even though subscales proved less successful to detect malingering, the authors concluded that they might provide qualitative information as to the particular syndrome that participants try to feign.

Rogers, Hinds, and Sewell (1996) investigated the efficacy of the SIMS to detect the presence of feigned response patterns in an adolescent patient sample. A total of 53 participants completed the SIMS under honest and malingering conditions. Relatively high sensitivity (i.e., $87 \%$ ), but modest specificity (i.e. $62 \%$ ) was found. Because of its accessibility, sensitivity, and brevity, the authors recommended the SIMS as a screening measure.

When evaluating the usefulness of a diagnostic measure, not only sensitivity and specificity are important accuracy parameters, but also Positive Predictive Power (PPP) and Negative Predictive Power (NPP) should be considered (see for technical definitions, table 2.3). PPP and NPP make probability estimates about individuals. More specifically, they refer to the likeihood that a person with a score above the cut-off is a malingerer (PPP) and the likelihood that a person with a score below cut-off is a honest responder (NPP). In the study of Rogers et al. (1996), a cut-off score of 16 on the Total SIMS yielded a PPP of $87 \%$. Although this value is acceptable for a screening device, it also implies that there is a small subgroup of high scoring honest responders who will be misclassified as malingerers. Rogers et al. (1996) reported a NPP of $94 \%$ for this cut-off point, which suggests that the SIMS produces relatively few false negatives.

Using a mix sample of undergraduates and psychiatric inpatients $(\mathbb{N}=298)$. Merckelbach and Smith (2003) found sensitivity, specificity, and Positive Predictive Power (PPP) rates for the SIMS that were all relatively high ( $>.90$ ) indicating that the SIMS is effective in detecting simulated symptomatology.

So far, research about the diagnostic accuracy of the SIMS heavily relied on normal participants instructed to feign certain pathological conditions. As a matter of fact, no study systematicailly looked at SIMS performance of forensic patients. With these

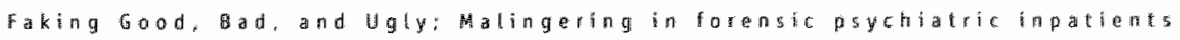


considerations in mind, we made a German translation of the SIMS. The purpose of the present study was to gather psychometric information about the German SIMS in normal and forensic psychiatric patients. More specifically, we examined Total SIMS scores as well as SIMS subscale scores in a sample of undergraduate students instructed to feign certain conditions. Their performance was compared to SIMS data gathered in a forensic inpatient sample and a sample of undergraduates instructed to respond honestly. We recruited a forensic inpatient sample as it is plausible to assume that the forensic setting is an important domain for the SIMS. In the words of Heilbrun $(1992 ;$ p. 226$)$ : "the closer the fit between a given individual and the population and situation of those in the validation research, the more confidence can be expected in the applicability of the results".

\section{METHODS}

\section{PARTICIPANTS}

The sample consisted of 286 participants of whom 204 were undergraduate students (98 men) and 62 were forensic inpatients (all men). The student sample was recruited from undergraduate courses in psychology, medicine, theology, and computer technology at the University of Bonn, Germany. The mean age of this sample was 24.4 years $(S D=6.3)$. The psychiatric sample was recruited from the Forensic Inpatient Hospital Düren, Germany. Their mean age was 38.5 (SD $=10.9$ ). Twenty patients had committed murder, while the remaining patients had been convicted for sexual offences (22 patients), aggressive criminal acts (10 patients), theft, fraud and arson (10 patients). As to their psychiatric diagnoses, a majority of the patients (60 patients; 96\%) met DSM-IV (American Psychiatric Association, 1994) criteria for one or more personality disorders, in particular disorders of the cluster B type. Forty-one patients $(66 \%)$ had more than one Axis I diagnosis. Psychotic disorders were the most common Axis I diagnoses (31 patients; $50 \%$ ).

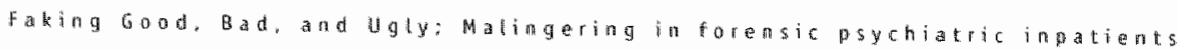


Also common were substance abuse (27 patients; 44\%). mood disorders (17 patients; $27 \%$ ), and anxiety disorders (18 patients; $29 \%$ ). Seventeen patients had a diagnosis of paraphilias $(27 \%)$. Patients volunteered to participate in several test sessions.

\section{MEASURES}

During one individual session, patients completed the German version of the Structured Inventory of Malingered Symptomatology (SIMS; Smith \& Burger, 1997). During a second session, the patient group completed the 567-item Minnesota Multiphasic Personality Inventory (MMPI-2; Hathaway \& Mckinley, 1983).

In the current study, we only looked at patients' scores on the validity scales of the MMPI-2. More specifically, we examined to what extent these scores correlated with SIMS scores. Significant correlations between these measures would provide additional evidence for the concurrent validity of the SIMS. Extensive hospital records of all 62 patients were available. Patients records were subjected to close inspection to reach an independent assessment as to indications for malingering. These indications involved a history of exaggeration of symptoms or manipulation through feigning somatoformic disorders, depressives moods, or claiming amnesia. Ratings were made by two medical doctors, who were blind as to the patient's SIMS or MMPI-2 status. Indications for malingering based on hospital records were scored in a dichotomous fashion ( 1 = indications for malingering absent; 2 = indilcations for malingering present).

\section{PROCEDURE}

Undergraduate students volunteered to complete the SIMS in groups of approximately 25 individuals. Students were assigned to one of 6 conditions. Five of them involved instructed malingering of symptoms, white one condition served as control condition (i.e., honest responding). The 5 instructed malingering conditions 
corresponded to the 5 subscales of the SIMS: Low intelligence $(n=27)$, affective disorder $(n=31)$, neurological impairment $(n=27)$, psychosis $(n=29)$, and amnesia $(n=21)$. Participants in the malinger conditions first received a detailed instruction. Depending on the precise condition, instructions were either to imagine themselves detained on a serious assault charge and to simulate a specific disorder so as to avoid a serious sentence, or being a victim of a car accident and feigning a disorder in a litigation procedure (see, for similar procedures, Smith \& Burger, 1997; Merckelbach \& Smith, 2003). Participants in the control condition were asked to complete the SIMS in a forthright and self-disclosing manner. Criminal psychiatric patients completed the SIMS along with the MMPI-2, under standard (i.e., honest responding) instructions.

\section{RESULTS}

\section{RELIABILITY}

In a separate pilot study, we evaluated the test-retest stability of the German SIMS version. A sample of 18 undergraduates ( 4 wamen; mean age $=21.6$ years) completed the SIMS twice, with a 6-weeks interval in between. These undergraduates were asked to respond honestly to the SIMS items. Mean Total SIMS scores on the first and second occasion were $8.3(S D=6.7)$ and $7.6(S D=6.8)$. respectively. The Pearson product-moment correlation between SIMS scores obtaired during the first and second administration was 0.97 , indicating excellent stability of SIMS scores.

To obtain psychometric information about the intermal consistency, we examined SIMS scores of the 69 honestly responding undergraduates in the control condition. The internal consistency (Conbrach alpha coefficient) for the Total SIMS scale was 0.80 , which indicates acceptable internal consistency. 
Figure 2.1 shows the frequency distribution of Total SIMS scores of undergraduates in the control condition. Skewness and kurtosis parameters indicate that scores follow a relatively normal distribution (skewness $=.15 ; \mathrm{SE}=.29$; kurtosis $=-.99$; SE $=.57)$. The mean Total SIMS score in this subsample was $8.1(S D=3.8)$. There were no differences in Total SIMS scares between men and women, means being 7.9 (SD $=$ $3.8)$ and $8.8(S D=4.1)$, respectively $[\mathrm{t}(67)<1.0]$. None of the participants in this condition had a total score exceeding the cut-off point of 16 recommended by Rogers et at. (1996).

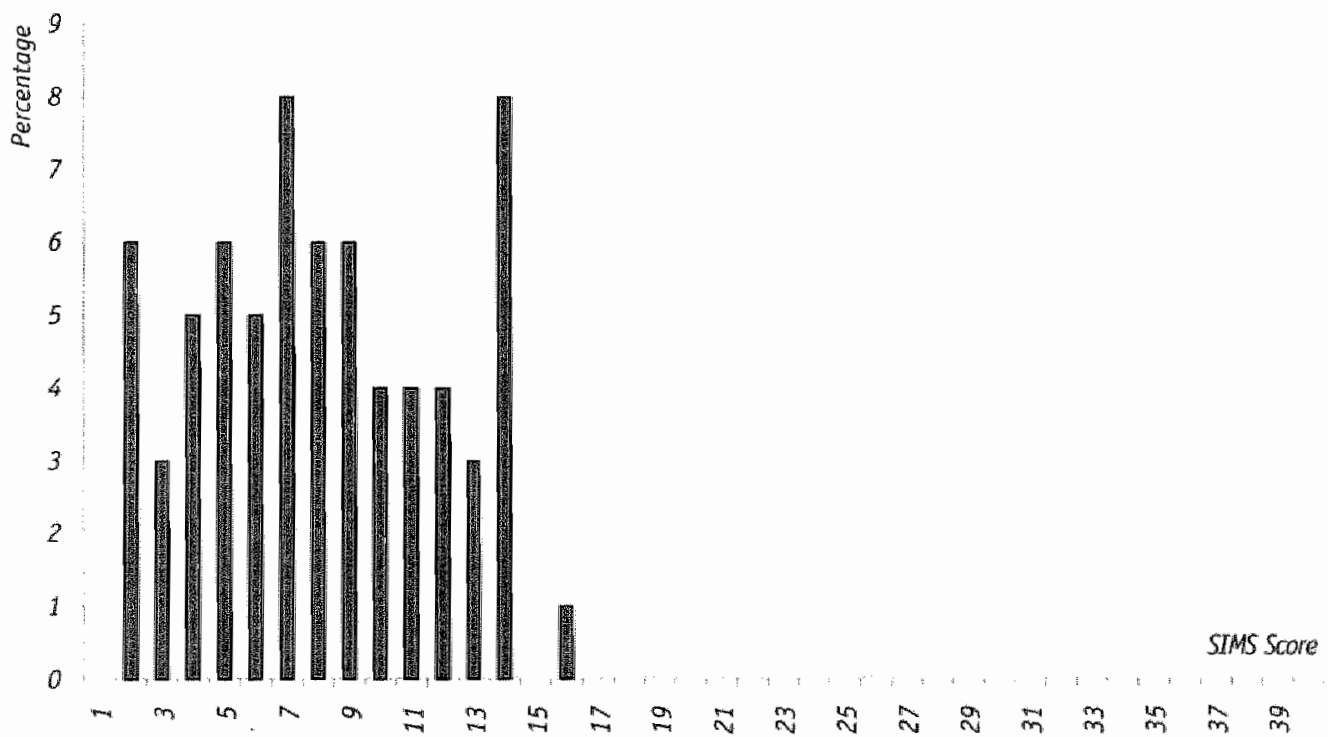

Figure 2.1: Distribution (proportion of total subsample; 17 69) of Total S7MS scores of honestly responding control participants. 


\section{VALIDITY}

To examine the validity of the SIMS, 7 groups were compared to each other. Group 1 $(n=69)$ consisted of honestly responding control participants (cf. supra). Groups 2 through 6 consisted of undergraduates who were instructed to feign a certain type of pathology on the SIMS $(n=135)$. There were 5 different instructed matingering conditions, each one corresponding to one of the SIMS subscales (LI, AF, N, P, and AM). Group 7 involved 62 criminal psychiatric patients.

Table 2.1 shows mean scores of honestly responding control participants, instructed malingering participants, and criminal psychiatric patients. A one-way Analysis of Variance (ANOVA) was conducted to evaluate differences between the three groups. The three groups differed significantly with regard to their mean Total SIMS scores: $F(2,241)=103.4, p<.001$. The strength of the association between instructed malingering and higher Total SIMS scores, as assessed by $\eta 2$, was moderately strong, with the group factor accounting for $46 \%$ of the wariance in Total SIMS scores. Follow-up tests were conducted to evaluate pairwise differences among the groups. Because variances within the three groups ranged from 14.75 to 185.50 , we choose to perform post-hoc Dunnett's $C$ tests. Patients had higher SIMS scores than honestly responding controls $[t(129)=4.29, p<0.01]$, whereas they had lower SIMS scores than the instructed malingering group $[t(195)=8.59, p<0.01]$. As well, honestly responding controls had significantly lower Total SIMS scores than instructed malingerers $[\mathrm{t}(202)=13.74, \mathrm{p}<0.01]$. As can be seen in Table 2.1, none of the controls had a Total SIMS score exceeding the cut - off of 16 , while $86 \%$ of the instructed malingerers and $27 \%$ of the patients scored in this range. 
Table 2.1. Mean Total SIMS scores, range of Total SIMS scores, and \% of subsample scoring above the cut-off: (1) in the control sample $(n=69)$. (2) the instructed matingering sample ( $n=135)$, and(3) the patient group $(n=62)$

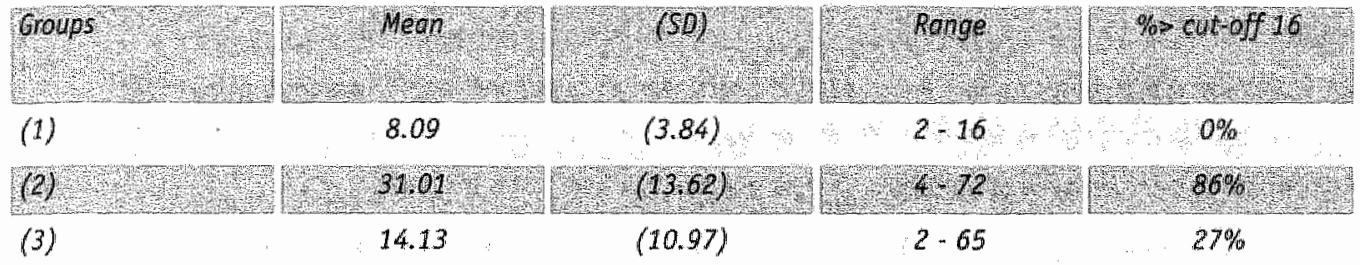

The control group had lower total SIMS scores than the instructed low intelligence group $[t(94)=14.44, p<0.01]$, the instructed affective disordier group $[t(98)=17.32$, $p<0.01]$, the instructed neurological deficits group $[\mathrm{t}(94)=6.74, \mathrm{p}<0.01]$, the instructed psychosis group $[t(96)=24.44, p<0.01]$, and the instructed ammesia group $[t(88)=12.19, p<0.01]$.

Table 2.2 shows mean Total SIMS and SIMS subscale scores of the various instructed malingering subsamples. We conducted a 5 (conditions) $\times 5$ (SIMS subscales) ANOVA with repeated measures on the last factor. The main effect of condition $[F(4,130)=$ 8.83, $\mathrm{p}<0.01]$ indicated that the conditions differed significantly with regard to their mean STMS scores. The main effect of scale $[F / 4,130)=58.98, p<0.01]$ makes plain that on the whole, some subscales (e.g., AF) had higher mean scores than other subscalles (e.g., LI). Finally, the significant condition $X$ scale interaction $[F(16,520)=17.36, p<0.01]$ shows that scalles were differentially sensitive to the various malinger instructions. Thus, the low intelligence group had the highest score on the LI subscale, the depression group had the highest score on the AF subscale, the neurological impairments group had the highest score on the $\mathrm{N}$ subscale, and the ammesia group had the highest score on the AM subscale. However, on the amnesia subscale, instructed amnesia participants were outperformed by instructed psychosis participants. By and large, this patterm supports the idea that SIMS 
subscales can provide qualitative information about the type of syndrome a participant is trying to malinger (Smith \& Burger, 1997; Merckelbach \& Smith, 2003).

Table 2.2: Scores on SIMS subscales of undergraduates instructed to malinger low intelligence ( $L I ; n=27)$. depression (AF; $n=31$ ), neurological impaiments $(N ; n=27)$, psychosis $(P ; n=29)$, and amnesia $(A M$; $n=21)$. Standard deviations appear between parentheses. Graups are columns and scales are rows.

\begin{tabular}{|c|c|c|c|c|c|}
\hline \multirow[t]{2}{*}{ Total } & 39.79 & 26.00 & 22.41 & 30.03 & 35.22 \\
\hline & $(9.06)$ & $(10.15)$ & (16.69) & $(8.88)$ & $(14.46)$ \\
\hline p & $\begin{array}{l}9.96 \\
(8.86)\end{array}$ & $\begin{array}{l}(1.86) \\
(1.80)\end{array}$ & $\begin{array}{l}304 \\
(4-27)\end{array}$ & $\begin{array}{l}2,48 \\
278)\end{array}$ & $\begin{array}{r}5,33 \\
(4.20)\end{array}$ \\
\hline \multirow[t]{2}{*}{$A M$} & 10.21 & 8.48 & 4.22 & 6.65 & 7.74 \\
\hline & $(3.89)$ & $(4.06)$ & $(4.20)$ & $(3.91)$ & $(4.24)$ \\
\hline N & $\begin{array}{l}741 \\
(3) \\
(3)\end{array}$ & $(3,5)^{6}$ & $\begin{array}{l}6.19 \\
(4.40)\end{array}$ & $\begin{array}{l}8.23 \\
(2.87)\end{array}$ & $\begin{array}{l}6.89 \\
(3.86)\end{array}$ \\
\hline \multirow[t]{2}{*}{$A F$} & 8.31 & 6.95 & 6.19 & 10.87 & 6.78 \\
\hline & $(2.42)$ & $(2.87)$ & $(3.80)$ & $(1.64)$ & $(2.72)$ \\
\hline & $\begin{array}{r}7.9 \\
(247)\end{array}$ & $\begin{array}{l}2.95 \\
(2.96)\end{array}$ & $\begin{array}{l}2.78 \\
(3.72)\end{array}$ & $\begin{array}{r}1.67 \\
(1.65)\end{array}$ & $\begin{array}{r}8.52 \\
(3.58)\end{array}$ \\
\hline
\end{tabular}

\section{DIAGNOSTIC ACCURACY/PARAMETERS}

Data of honestly responding controls, instructed malingers and patients were pooled in order to calculate sensitivity, specificity, positive and negative predictive power (PPP and NPP). We knew for certain that of the total sample of 266 participants, $135(51 \%)$ had malingered a certain syndrome. Using the cut-off score of $16,87 \%$ of the malingerers were identified correctly (sensitivity), while $86.7 \%$ of the non- 
malingerers were classified correctly (specificity). The Positive Predictive Power (PPP) was 0.87 . In other words, the probability that someone with a Total SIMS score of 17 or higher was an instructed malingerer was $87 \%$. Sensitivity, specificity, PPP, and NPP rates are given in table 2.3. The specificity of $86.7 \%$ implies a false alarm rate of $13.3 \%$. In other words, $13.3 \%$ of the participants who did not receive an instruction to malinger nevertheless had Total SIMS scores exceeding the cut-off point. A closer look at these participants revealed that all of them were forensic psychiatric inpatients.

Table 2.3: Classification and accuracy indices for the pooled data $(N=266)$.

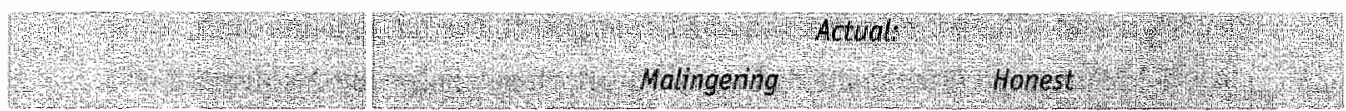

Predicted:

$\begin{array}{rlr}\text { Malingering } & 117(C P) & 17(F P) \\ \text { Honest } & 18(F N) & 114(C N)\end{array}$

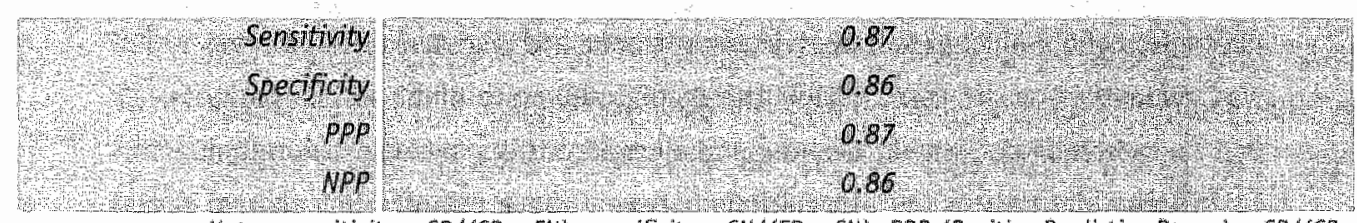

Notes: sensitivity $=C P /(C P+F N)$; specificity $=C N /(F P+C N) ; P P P$ (Positive Predictive Power $)=C P /(C P$

$+F P) ; N P P$ (Negative Predictive Power) $=C N /(F N+C N)$.

\section{PATIENTS}

Within the subsample of patients $(n=62), 17$ patients $(29 \%)$ had Total SIMS scores above the cut-off of 16 . Of these 17 patients, $11(65 \%)$ were classified as malingerers by the independent raters who inspected hospital records. Of the 45 patients with Total SIMS scores below 17, $6(13 \%)$ patients were classified as malingerers by the independent raters. This difference is significant $\left[\chi^{2}(1)=13.34\right.$, $p<.01]$. Furthermore, correlation analysis showed that the Total SIMS scores of the 
patient sample were significant related to the MMPI F-scores $(r=.43, p<.01)$. As expected, the correlation between $K$-scale scores, tapping the opposite feature of simulation (i.e., dissimulation) and Total SIMS scores was negative and reached borderline significance; $r=-.23, p=.09$. Also, the L-scale scores did not correlate with the SIMS-total score, $r=.03, p=.83$, indicating that malingering as measured with the SIMS can be distinguished from pathological lying. MMPI-2 F-scale scores of patients with a Total SIMS score of 17 or more were significantly higher than those of patients with a Total SIMS score below this cut-off $[\mathrm{t}(60)=4.11, p<0.01]$. To explore whether patients with Total SIMS scores above cut-off might have certain traits in common, we looked at their hospital fites, and more specifically, at their diagnoses and the sort of crime they had committed. The 17 patients with above cut-off SIMS scores could be divided into twa subgroups. Subgroup 1 consisted of 5 (29\%) patients who had an acute psychotic decompensation. Note, however, that of the 45 patients with below cut-off SIMS scores, $26(58 \%)$ patients were diagnosed with a psychotic disorder. If the SIMS would be extremely sensitive to real psychosis, one would expect that these patients had elewated SIMS scores, which was evidently not the case. Within the second subgroup of 12 (71\%) patients, 11 had an antisocial personality disorder and all except three, were sexual delinquents. To test the strength of the associations between above cut-off SIMS scores, sexual. delinquency, and antisocial personality disorder, a 2 (sexual delinquency versus other crimes) $\times 2$ (antisocial personality versus other diagnoses) contingency table was made. Table 2.4 shows the frequency (and proportion) of patients with elevated SIMS scores $(\geq 17)$ in the 4 resulting cells. As can be seen, this frequency was the highest in sexual delinquents with an antisocial personality disorder. Indeed, the proportion of raised SIMS scores in this cell was higher than that in sexual delinquents without antisocial personality $\left[\chi^{2}(1)=4.2, p<0.05\right]$ or in patients with an antisocial personatity who committed an other type of crime $\left[x^{2}(1)=3.7\right.$. $p<0.05]$.

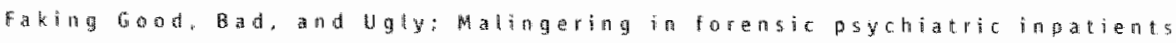


Toble 2.4: Frequency and proportions (of $n=62$ ) of patients with above curt-off SIMS scores in sexual delinquency group and "other crimes" group with and without antisocial personality disorder (APD).

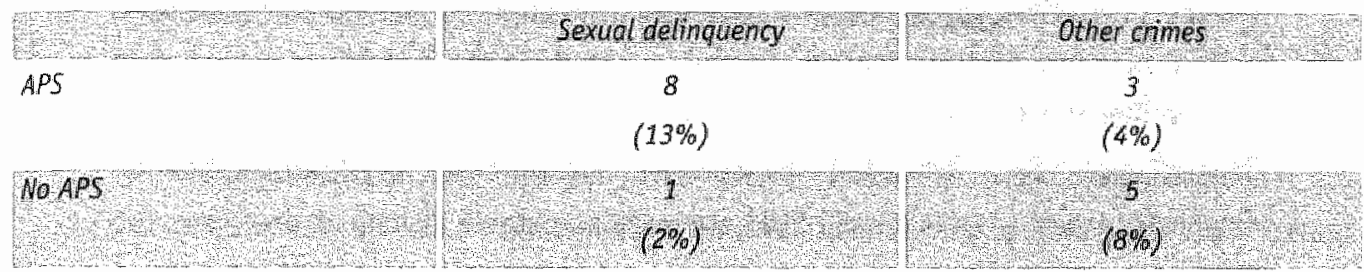

\section{DISCUSSION}

The SIMS was designed as a brief screening measure for detecting malingering. The results presented above show that this ambition stands up to empirical testing. To begin with, the SIMS possesses adequate reliability in terms of test-retest stability and internal consistency. Secondly, the SIMS has predictive validity in the sense that certain categories of individuals who are known to exhibit malingered characteristics (i.e., people who were instructed to feign a certain syndrome) display higher scores on this scale than do control individuals. Thirdly. the SIMS demonstrates concurrent validity in that it correlates with amother index of malingering (i.e., MMPI-2- F scale) as well as with independent raters' assessment of malingering indications in patients' hospital records. Taken together, the current results indicate that the SIMS is a psychometrically sound research and screening instrument.

This cautious optimism about the usefulness of the SIMS is further strengthened by the relatively high sensitivity, specificity, PPP, and NPP rates that we found for the SIMS in the current study. All these diagnostic accuracy parameters were above .85 , which replicates earlier findings by Smith and Burger (1997), Edens, 0tto, and Dwyer (1999), and Merckelbach and Smith (2003). Note that these previous studies 
were mainly based on undergraduates who completed the SIMS under honest or feigning conditions. With the exception of the small-scale study by Rogers et al. (1996) that relied on adolescent offenders, no study to date looked at SIMS performance in a forensic context. Indeed, our study is the first in which such data were systematically gathered. Our results make plain that in a mixed sample of honest responders, instructed malingerers, and forensic psychiatric patients, diagnostic accuracy rates for the SIMS are quite acceptable as long as one views the SIMS as a screening instrument rather than an instrument that aims at providing a definite diagnasis as to the malingering status of an individual patient (Smith, 1997; Rogers et al., 1996; Merckelbach \& Smith, 2003).

In their study on undergraduates, Edens et al. (1999) found some indications that the SIMS might be sensitive to genuine psychopathology. More precisely, these authors found elevated SIMS scores in students who reported current psychopathological distress. Accordingly, Edens et al. (1999; p. 395) concluded that "use of the SIMS in forensic contexts should still be considered with caution, given the potential for high false positive rates". On the other hand, Merckelbach and Smith (2003) noted that the raised Total SIMS scores of depressive or anxious undergraduates only seldomly exceed the recommended cut-off paint of 16 . The current study adds some further insights to this important issue. All 17 false positive SIMS protocols were from forensic psychiatric patients. Furthermore, according to the independent judges, more indications for malingering were found in the record of these 17 false positive patients than in the records of patients with Total SIMS scores below the cutting point. As well, MMPI F-scale scores of false positive patients were significantly higher than those of the patients with SIMS scores below the cut-off. So, the question arises to whether the forensic patients with SIMS scores exceeding the cut-off of 16 were truly misclassified as malingerers by the SIMS. Interestingly, 8 of these 17 patients ( $47 \%$ ) had a combination of an antisocial personality and sexual delinquency, a combination that was less common 
$(13 \%)$ in the patients with SIMS scores below the cut-off. Chi-Square tests suggested that it is the combination of the antisocial personatity and sexual delinquency that might contribute to elevated SIMS scores.

It is true that Rogers (1990) found a comparable prevalence of antisocial personality among bona fide patients and malingerers. This implies that notwithstanding the suggestions in the DSM-IV (APA, 1994), antisocial personality per se is not intimately linked to malingering. However, the current results show that further examination of malingering phenomena in sexual delinquents with antisocial personality is clearly warranted. In any case, the idea that this category of patients might show a pronounced tendency to feign psychiatric symptoms has prima facie plausibility. It might well be the case that patients in this category justify their sexual deviant behaviour and preferences by strategically enacting and manipulating psychiatric symptoms.

If we assume that at least 11 of the 17 patients with Total SIMS scores above the cut-off were malingerers, the percentage false positives drops to $6 \%$, while sensitivity, specificity, PPP all increase to even higher levels $(0.88,0.94$, and 0.95 , respectively). All in all, this pattern underlines the utility of the SIMS as a screening instrument for detecting malingered psychopathology.

Two limitations of the present study should be acknowledged. First, whatever way one uses to calculate the base rate of malingering in our study (the $51 \%$ base rate formed by undergraduates instructed to feign symptoms or the $5.4 \%$ base rate comprising instructed undergraduates plus patients for whom there were indications of malingering), it is unrealistically high. Note that Rogers et al. (1994) estimated the base rate of malingering in forensic settings to be $16 \%$. Note further that diagnostic accuracy parameters like the PPP and NPP critically depend on such base rates (e.g. Merckelbach \& Smith, 2003). Thus, it is conceivable that the diagnostic accuracy of the SIMS declines when studies would use a more realistic base rate of malingering. Clearly, this issue requires further research. Secondly, our forensic 
patient sample was heterogeneous and although we found indications that SIMS scores are raised in some patients, but quite normal in others, it would require a large sample of forensic patients to determine whether SIMS scores are specifically linked to distinct features of forensic patients. Again, this issue deserves systematic study. Notwithstanding these limitations, our study supports the idea that the SIMS is reliable and walid screening tool. 


\section{CHAPTER 3}

*I can't remember Your Honour: Offenders who claim amnesia

*This chapter appeared as: Cima, M., Merckelbach, H., Nijman, H., Knaver, E., \& Holliack, 5. (2002). I can't remember Your Honour: Offenders who claim amnesia. German Joumal of Psychiaty 5 24-34. 


\section{SUMMARY}

Persons who claim memory loss for the crime they are charged with, represent a problem for the legal system. When such claims emerge, the court often relies on expert testimonies. Mental health professionals who act as experts in these cases, often assume that the memory loss is caused by a combination of strong emotions and abundant substance use (e.g., alcohol). It is also common to gather arguments for such an interpretation by interviewing the offender or suspect. However, discriminating between different kinds of amnesia requires the use of sophisticated tests and tasks. By reviewing clinical, experimental, and psychometric literature, this chapter addresses several forms of crime-related amnesia and discusses the difficulties that arise when expert testimony about this phenomenon is given. It also emphasizes the importance of techrical knowledge about diagnostic quality parameters. A review of the literature shows that dissociative amnesila is not the only or even the most prevallent form of offender amnesia. Experts should at leasit take the possibility of other forms of amnesia (i...., organic amnesia; malingered amresia) into account. Expert testimonies about crime-related amnesia should not rely exclusively on interviews or archival data. Rather such testimonies results require tests and tasks combined with good diagnostic interviews.

\section{INTRODUCTION}

It is not uncommon that offenders claim memory loss (i.e., ammesia) for their crime. As a matter of fact, $25-45 \%$ of criminals found guilty of homicide claim amnesia for the event (e.g., Kopelman, 1995). In cases where suspects claim crime-related amnesia, the court often asks for an expert testimony. Triers of fact seem to assume that an expert is able to differentiate between various kinds of genuine amnesia, as well as between genuine amnesia and simulated amnesia. According to Schacter

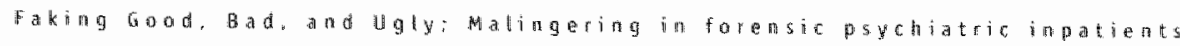


(1986), there are two obvious legal reasons as to why it is important to explore crime-related amnesia. To begin with, amnesia raises the issue of automatism, which refers to criminal behaviour that is executed unconsciously and without intent. The issue of automatism is, of course, critical for legal responsibility. We will return to the difference between "sane" and "insane" automatism later on. Secondly, amnesia raises the issue of competency to stand trial. An accused who has no memory of the crime event can not plead in his or her own cause, simply because he or she is unable to inform his or her counsel (Schacter, 1986). Thus, such a person might be incompetent to stand trial.

In a study of Merckelbach. Cima, and Nijman (2002a) popular beliefs about crimerelated amnesia were inwestigated. The authors describe a typical but real crime case in which an offender, after a night out with heavy use of alcohol and coke stabbed someone to death. The offender clained amnesia for the homicide. The court appointed a mental health professional in order to give expert testimony about the ammesia of the offender. Based on two interviews, this expert concluded that the crime-related amnesia was a result of "the high level of alcohol and drug use". This case was administered to 5.4 lay persons. They were asked whether they thought that genuine amnesia would be a plausible scenario in this type of crime. The majority of them $(82 \%)$ indicated that it was a plausible scenario. A majority $(76 \%)$ also felt that the court was very wise to appoint a forensic expert. As well, respondents had very strong opinions about the origin of the amnesia. A large majority of the respondents $(70 \%)$ felt that alcohol, cocaine, strong emotions or a combination of these are responsible for the offender's amnesia. Apparently, offenders who claim crime-related amnesia do not need to worry that their claim meets widespread disbelief. Merckelbach and associates (2002a) wondered whether this has to do with the way in which they presented this case. They construed a version of the case in which the offender claimed to remember "every second of the stabbing" extremely good. Having read this version, a new sample of respondents $(\mathbb{N}=54)$ were asked 
whether they could also imagine the opposite, mamely an offender developing amnesia for the stabbing incident. Again, the large majority $(74 \%)$ thought that it is perfectly possible that an offender develops complete amnesia for his crime. The idea that strong emotions, alcohol and/or drugs may affect offenders in such way that they fully forget what they have done is apparently widespread.

The ideas of lay people about crime-related amnesia would be of little or no concern to us, were it not that judges and layers are lay people who have to decide about the plausibility of claims of crime-related amnesia. One would argue that these triers of fact rely on expert testimony precisely to overcome their lack of technical knowledge. On the other hand, in cases of claimed amnesia, mental health professionals who act as expert witnesses often rely on notions and assumptions that come dangerously close to that of lay people. In the sections that follow, we first discuss the prevalence rates and different manifestations of crime-related amnesia. We then move on to the Legal significance of amnesia claims. Next, we focus of on several crucial discriminations that experts have to make in cases where - such claims emerge: Thus, the expert has to differentiate between dissociative amnesia, feigned (i.e., simulated amnesia), and organic amnesia. He/she also has to consider critically the precise role that alcohol plays in this category of cases. Following a detailed examination of these issues, we turn to diagnositic and psychometric topics. We will argue that there exists powerful tools to discriminate between various forms of crime-related amnesia. We conclude with a consideration of the specialized knowledge that these seemingly simple tools require.

\section{CRIME-RELATED AMNESIA}

Offenders who claim amnesia for their crime are by no means rare. In an older study of Leitch (1948), 51 murderers were interviewed and $14(27 \%)$ of them claimed amnesia for their crime. Taylor and Kopelman (1984) replicated this study by

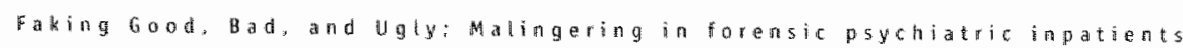


interviewing 34 murderers: $9(26 \%)$ of them claimed amnesia. In a more recent study, Gudjonsson, Petursson, Skulason, and Sigurdardottir (1989) investigated 64 convicted criminals. This time, $21(32 \%)$ claimed amnesia for there crime. As a rule of thumb, 20 to $30 \%$ of offenders of violent crimes, claim amnesia for their crime. While these claims are often raised in the context of murder or manslaughter cases, there are other crime categories in which claims of amnesia do occur. For example, claims of amnesia regularly occur in sexual crime cases (Bourget \& Bradford, 1995), domestic violence cases (Swihart, Yuille \& Porter, 1999), and fraud cases (Kopelman, Green, Guinan, Lewis \& Stanhope, 1994).

In the literature, all kinds of taxonomies have been proposed to distinguish between different types of amnesia (e.g., Schacter, 1986; Loewenstein, 1991; Kopelman. 1995; Kinlstrom \& Schacter, 1995). Most taxonomies agree that at the very least. three amnesia types should be considered: dissociative amnesia (formerly termed psychogenic or functional amnesia), organic amnesia, and feigned amnesia ("malingered amnesia"). Dissociative amnesia for criminal behaviour is thought to originate from extreme emotions that accompany such behaviour. Several authors have argued that dissociative amnesia is characteristic for crimes that are unplanned, involve a significant other, and are committed in a state of strong agitation (e.g., Loewenstein, 1991; Kopelman, 1995). The idea behind this is that extreme levels of arousal during the crime may hamper memory retrieval at a later point in time. Thus, a falure in so called retrieval processes would underlie dissociative ammesia such that the offender who subsequently has come to his senses. finds it impossible to access memories stored during a moment of turbulence. A term often used in the Anglo-Saxon literature to describe amnesia as a consequence of strong emotions (e.g., rage) is "red-out". In the words of Swithart et al. (1999): "Apparently, an individual can get so angry with his/her intimate partner that $s$ /he can severely beat or kill that partner and then not remember doing 
so: that is, they can experience a red-out resulting in circumscribed amnesia" (p. 200). Later on, we will discus the merits of this interpretation.

organic amnesia is always caused by a neurological defect. This defect may be structural (e.g., epilepsy, brain trauma), but it may also be momentarily such as in the case of alcohol- or drug intoxication. Kopelman (1995) assumes that memory loss in organic amnesia has to do with storage-problems rather than retrievalproblems: due to an epileptic seizure, brain damage or intoxication, offenders would not be able to store their memories in the first place, which would eventually lead to a total "blackout" for their crime.

A number of authors have emphasized that excessive alcohol use often contributes to dissociative amnesia for crime (Kopelman, 1995; Bourget \& Bradford, 1995; Swihart et al., 1999). Bower's (1981) "state-dependent memory theory" is often invoked to account for the combination of dissociative amnesia and alcohol (Swihart et al., 1999). In short, this theory states that when memories are stored in an exceptional context (strong emotion and/ or under the influence of alcohol). subsequent retrieval of these memories is facilitated when a similar context is reinstated. However, in a different context (e.g., when one is relaxed and sober), the pertinent memories would be inaccessible and so, dissociative amnesia would occur. The case of Sirhan Sirhan, who was held responsible for the murder of Robert Kennedy, is often presented as an example of state dependent memory. Sirhan claimed that he was unable to remember the murder. However, when he was hypnotized and brought into an agitated state, he suddenly said to remember the details of the murder.

As for feigned amnesia, offenders may malinger amnesia for a crime in an attempt to obstruct police investigation and/or to avoid responsibility for their acts. In an older study. Hopwood and Snell (1933) found that $20 \%$ of the offenders who claimed amnesia were malingerers. However, there are good reasons to believe that the rate of malingering is actually much higher (see below). The literature provides

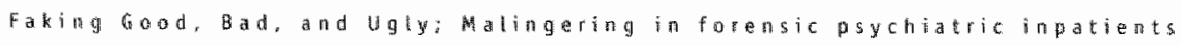


strong examples of defendants who feigned amnesia in order to gain tactical advantage in legal procedures. Our favourite example is that of Rudolf Hess, who at the start of the "Neurenberg" trials, claimed to be amnestic for his Third Reich period. A group of prominent psychiatrists examined Hess and concluded that his amnesia was genuine. When it became clear to Hess that the amnestic role confers a disadvantage in the sense that one cannot respond to allegations, he suddenly announced during one of the trials sessions that he had fooled the psychiatrists and feigned his amnesia (Gilbert, 1971; for a somewhat different interpretation see Picknett, Prince \& Prioir, 2001).

\section{THE LEGAL CONTEXT}

Does it matter legally when defendants claim crime-related amnesia? For the Anglom Saxon situation, Parwatikar, Holcomb, and Menninger (1985) noted that: "no court has found a defendant incompetent to stand trial solely because of amnesia" (p.202) (see also Hermann, 1986). And, indeed, in Anglo-Saxon countries, amnesia does not figure in the listing of disorders that regularly lead to "not guilty by reason of insanity" trial outcomes (Lymburner \& Roesch, 1999). Typically, such outcomes involve schizophrenia and mood disorders, especially in combination with alcohol or drug use. Still, according to some leading Anglo-Saxon commentators, claims of amnesia may have far-reaching legal implications (e.g., Bradford \& Smith, 1979). Meanwhile, it is not amnesia per se, but what amnesia reveals about the state of the defendant at the mament he committed his crime. More speciffically, amnesia may indicate a state of "automatism" "which refers to unconscious, non-intentional, and therefore uncontrollable behaviour. In the literature, eccentric examples of "automatic" crimes conmitted during sleepwalking, epileptic seizures, or hypoglycaemia states, abound. 
In countries like Canada and Australia, automatism has been divided into "sane" and "insane" automatism. For both types of automatism, it is assumed that the mens rea (i.e., "wicked mind") aspect of the crime, is at stake (Hermann, 1986). "Sane" automatism refers to a crime committed by someone who is essentially healthy, but who is in a temporary state of madness due to some external agent (e.g., insulin). such a scenario may lead to acquittal. "Insane" automatism refers to a crime originating from structural brain dysfunction. The prototypical example is the man who killed his neighbour during an epileptic seizure (Fenwick, 1993). Such a scenario can lead to a "not guilty by reason of insanity" verdict. Kopelman (1995) notes that "automatic" crimes always fall prey of amnesia. However, the opposite does not hold: when a defendant claims crime-related amnesia, it does not necessarily imply that the crime came about automatically (Kalant, 1996). Curiously enough, this is nevertheless what the German Bundesgerichtshof seems to think, because it argued that "a verified ammesia for the criminal act - alone or in combination with other factors - is a sign of an emotionally based disorder of consciousness" (BGH 4 Str 207/87; see also Barbey, 1990).

Another point that is important to stress is that the distinction between controlled behaviour. "sane" automatism, and "insane" automatism is more problematic tham it at first glance may appear. Referring to several case examples. McSherry (1998) showed that this distinction is highly dependent on arbitrary judgements made by expert witnesses: it just depends on what a forensic expert is willing to consider as a structural brain dysfunction. She described two similar cases of domestic murder. Due to expert witness testimonies, one case was classified as "sane" automatism leading to full acquittal, whereas the other case was classified as an example of "insane" automatism. leading to a "not criminally responsible" verdict and admission to a psychiatric hospital. 


\section{WHAT SCIENCE SAYS}

Lay persons ideas about what is possible do not by definition have to be wrong. However, for a trial judge who is confronted with a defendant claiming amnesia, the issue of what is possible is less interesting. To the extent that the judge appreciates expert witness testimonies, he will mostly benefit from an expert who educates him about the type of ammesia that the defendant is suffering from and how this diagnostic judgement was reached. For the expert witness, it is very difficult to differentiate between dissociative, organic or feigned amnesia on the basis of interviews with the defendant. This has to do with the fact that simulators can give a compelling imitation of someone with a dissociative or organic amnesia. It is only on the basis of psychological tests and tasks, that an expert will be able to identify simulators. Nevertheless, our impression is that mental health professionals acting as experts in cases of amnesia, often use interviews with the defendant as the sole source for making their diagnostic judgements. This state of affairs is hardly surprising: the average mental thealth professional is not a memory specialist and has no specialized knowledge about tests that might be helpful in discriminating between dissociative, organic, and feigned amnesia. Below, we will take a closer look at this distinction.

\section{DISSOCIATIVE VERSUS FEIGNED AMNESIA}

Dissociative amnesia is defined as "an inability to recall important personal information, usually of a traumatic or stressful nature, that is too extensive to be explained by ordinary forgetfulness" (American Psychiatric Association, 1994: p. 477). A number of authors have argued that the term dissociative amnesia is quite confusing (Pope, Hudson, Bodkin \& Oliva, 1998; Kopelman, 1995). It not only suggests that the cause of the memory loss is a dissociation between consciousness and memory, it also assumes that memory loss for emotional trauma does exist. 
Although lay people find it wery plausible that an emotional provocative event tike murder can lead to memory loss (cf. supra), specialists have not yet reached a consensus about this. For example, some authors (e.g., Kopelman, 1995) opine that dissociative amnesia does exist and their most important argument is that defendants who claim amnesia often themselves inform the police about the crime: "This makes an account of amnesia as simulation to avoid punishment less plausible" (p.435; for a similar reasoning, see Porter, Birt, Yuille \& Herve, 2001). However, this argument is not very convincing. A defendant who knows that there is a vast amount of forensic evidence against him, may argue that he will make a more sympathetic impression on triers of fact when he simulates amnesia than when he provides them with a lucid description of the crime details. Thus, Sadoff (1974) argues that mosit cases of dissociative amnesia are actually feigned. There are three good reasons to take his point seriously.

The first is that there is quite some knowledge about the psychological characteristics of those who claim dissociative amnesia for a crime. Older studies reported that criminals who raise such claim can be distinguished from other criminals by their relative Low intelligence and their hysterical traits (O'Connel, 1960; Parwatikar et al., 1985). In this context, hysterical traits refer to manipulative behaviour, including the terndency to feign symptoms ( $0^{\prime}$ Connel, 1960).

While the concept of hysteria has largely disappeared from psychiatric vocabulary. the findings of more recent studies in this domain point in the same direction. For example, Lynch and Bradford (1980) reported that claims of amnesia are often raised by defendants with an antisocial personality disorder. A hallmark feature of this disorder is, of course, manipulative behaviour (Porter et al. 2001). Similarly, Cima, Merckelbach, Hollnack, and Knauer (in press b) noted that criminals who claimed amnesia had low intelligence and displayed antisocial personality features. The picture emerging from these studies is that defendants who claim dissociative 
amnesia often rely on a simple form of denial in an attempt to minimize their responsibility.

A second reason to critically consider claims of dissociative amnesia is that the idea of amnesia for crime is based on the dubious assumption that "the majority of crimes which are followed by amnesia are those accompanied by strong emotional. reactions" (Hopwood \& Snell, 1933, p.32). According to this interpretation, strong emotions lead to repression or, to use a more recent notion, to dissociation and this would produce "retrieval"-problems. If this line of reasoning is correct, one would expect that, for example, victims of concentration camps also display amnesia for the horrifying events they have experienced. However, this is not the case (e.g., Kuch \& Cox, 1992; Yehuda, Elkin, Binder-Brynes, Kahana, Southwick, Schmeidler \& Giller, 1996). On a related note, eyewitnesses of extreme violence seldomly develop amnesia for the events they witnessed (Porter et al., 2001). In short, the notion that people may develop amnesia for events that are accompanied by strong emotions is very controversial (Pope et al., 1998) and, therefore, it is wise to consider dissociative amnesia as a rare phenomenon.

A third reason to be sceptical about claims of dissociative amnesia is that recent pisychiatric literature shows that a nontrivial minority of people tend to feign a variety of symptoms and tend to confabulate stories if this serves their interests. For example, it is estimated that as much as $20 \%$ of closed-head injury patients pursuing financial compensation exaggerate their symptoms (Binder \& Rohling, 1996). Likewise, in the United States hundreds of Vietnam veterans with Post Traumatic Stress complaints have never even served in Vietnam (Burkett \& Whitley, 1998). When motor wehicle accidents victims feign neurological complaints and when military personnel invent a complete autobiography to qualify for disability payments, why should the criminal who simulates amnesia be a rarity? Let's put it in a different way: lay persons as well as many expert witnesses tend to view dissociative amnesia as the rule and feigned amnesia as the exception. Given the 
considerations discussed above, we think that it would be wise to reverse these probability estimates. This conclusion is further supported by studies in which normal subjects were instructed to play the role of a murderer who during interrogation is confronted with abundant evidence. The most frequently chosen strategy of these subjects is to claim amnesia for the criminal act and to attribute it to an internal force that they cannot control (Spanos, Weekes \& Bertrand, 1986; Merckelbach, Devilly \& Rassin, 2002b).

\section{THE ROLE OF ALCOHOL}

As mentioned earlier, excessive alcohol or drug use is often said to precede criminal acts for which later dissociative amnesia is claimed. At least, that is what criminals who claim such memory loss tell researchers and expent witnesses. The "statedependent memory" hypothesis is often invoked to explain the apparent link between alcohol and amnesia (Swihart et al., 1999), but a close look at the literature shows that this hypothesis is not based on solid evidence. For example, in a study of Wolf (1980), a substantial amount of alcohol was given to criminals who had committed murder under the influence of alcohol and who claimed to be amnestic. The "state-dependent memory" hypothesis would lead one to predict that alcohol would produce complete disappearance of the amnesia, but this is not what happened. While under the influence of alcohol, subjects maintained that they could not remember the crime details.

Admittedly, the phenomenon of "alcohol-blackout" does exist. However, this phenomenon is best wiewed as an organic form of amnesia resulting from an excessive amount of alcohol consumed within a very short time span (e.g., 5 glasses of whisky or 20 glasses of beer within 4 hours; Goodwin, 1995). Even when subjects consume such a large dose, only some of them will develop an "alcoholblackout". Furthermore, in most cases where dissociative amnesia is claimed, alcohol doses do not reach such an extreme level. This suggests that in these cases, 
defendants" reference to alcohol or drug use may fulfil a different function, namely that of the "partial excuse for the essentially inexcusable" (Room, 2001: p. 194). That is, for those who have seriously violated the law, an appeal to alcohol- or drug intoxication may give an explanation for the crime that has been committed as well as for the memory loss that is claimed. The example of the Canadian Supreme Court shows that courts are not insensitive to such "intoxification defence" "In the case of a rapist, who argued not to remember the crime because he was in a state of alcohol. intoxication, this Court ruled that the crime had been committed in a state of "drunken automatism" (Kalant, 1996). Lay persons not only seem to have strong opinions about the plausibility of dissociative amnesia, they also have strong opinions about the behavioural- and memory- effects of alcohol or drugs. Again, these opinions are not always in line with what is actually known about these effects.

\section{THE ROLE OF EXPECTATIONS}

Experiments show that the behavioural effects of alcohol are to a great extent guided by expectancies that people have about these effects: "Things that are believed real are real in their consequences" (Thomas \& Thomas, 1928: p. 572). A straightforward procedure to demonstrate this phenomenon is the so-called "balanced placebo design". The crux of this design, is that some subjects are given a non-alcoholic drink that they believe to contain alcohol, whereas other persons consume an alcoholic drink that they believe is a non-alcoholic refresthment. Under these circumstances, extravert behaviour, tension reduction, and other positive as well as negative effects that people associate with alcohol do not depend on actual alcohol intake, but on the belief that one has consumed alcohol (Critchlow, 1986). This finding underlines that people have strong ideas about the effects of alcohol which in turn may affect their behaviour. 
Is it possible that a similar expectancy effect occurs in cases of dissociative amnesia? In other words, is it possible that some defendants claim amnesia for their crime because they assume that this is a probable autcome, given the traumatic character of the ewent and the use of alcohol? The case of Gudjonsson, Kopelman, and Mackeith (1999) demonstrates that such an imaginary amnesia does exist. In this case, a defendant was convicted for the murder of a little girh. During the police interrogations, he could not remember anything of the crime. Experts interpreted this as a manifestation of dissociative amnesia, a scenario in which the defendant himself started to believe. Yet, later on, it became clear that he was innocent.

Germane to the issue of expectancies is also an experiment of Christianson and Bylin (1999). These authors gave their subjects a case vignette of a murder and subjects were instructed to identify themselves with the offender. Next, one group of subjects was told to play the role of an amnestic offender during a task that consisted of a series of questions about the case. The control group was encouraged to perform as best as they could on this task. After a week, subjects returned to the lab and, again, answered questions about the case. This time, all subjects were instructed to perform as well as they could. During the first testing session, subjects who played an amnestic role gave fewer correct answers than the control group. This is not remarkable: it only shows that the "amnestic" subjects took their role seriously. However, during the one-week follow-up test session ex-simulators were still performing under the level of control subjects. This is remarkable: apparently, "playing" amnesia has memory-undermining effects. It is not too far-fetched to assume that expectancies are the driving force behind this effect. That is, people who initially play the role of an amnestic person, may have a strong expectation that they will perform poorly on subsequent memory tasks. This, in turn, may give rise to a "self-fulfilling prophecy" when the person is given such a memory task. This phenomenon is also known from studies on placebo's. Subjects who receive a placebo in combination with the story that it is a memary-undermining substance, 
Later on perform less well on memory tasks than do control subjects (Kvavilashvili \& Ellis, 1999). To sum up, then, a defendant who claims memory loss is often classified by experts as someone with a dissociative amnesia, but there are at least two alternative interpretations that should be considered: matingered amnesia and imaginary amnesia.

\section{ORGANIC VERSUS FEIGNED AMNESIA}

Unlike dissociative amnesia, organic amnesia is a relative unproblematic phenomenon. In many cases, organic amnesia will be a persistent symptom of traumatic brain injury, or closed-head injury. Note that in this context, the word trauma has a completely different meaning. In the psychiatric literature, it refers to a major emotional event (e.g., a crime), whereas in the neurological context it refers to the external causes (accidents, drugs, fights) of acute brain damage (Hacking, 1995). Even in cases of mild traumatic brain injury, acute loss of consciousness and subsequent Post Traumatic Amnesia (PTA) may occur. PTA refers to disoriented behaviour and serious memory problems immediately after the incident that caused the brain injury. When loss of consciousness exceeds 30 minutes and PTA duration is longer than 24 hours, the traumatic brain injury is said to be severe (Faust, 1996).

Regardless of whether the brain injury is mild or severe, in the period after the PTA, the patient usually reports all kinds of complaints that vary from concentration difficulties to depressive feelings. These complaints are sometimes referred to as the "post-concussion" syndrome, but this impressive term suggests more clarity than the neurological literature really offers. For example, Lees-Haley, Fox, and Courtney (2001) noted that most symptoms associated with this syndrome are surprisingly aspecific and are also highly prevalent among people who never sustained a brain injury. However, inability to recall important details of the events surrounding the trauma (the incident, the fight) - organic amnesia - is a rather specific symptom of 
the post-concussion syndrome. According to the 19th century French memory psychologist Theodule Ribot (Haber \& Haber, 1998), organic amnesia follows a course that is now known as Ribot's law. More specifically, this Law refers to the phenomenon that organic amnesia pertains to the traumatic incident itself and events that immediately preceded and/or followed it, rather than events that toke place long before the trauma. If such older memories have nevertheless become inaccessible, they will return sooner in the weeks following the trauma than more recent memories that have become inaccessible. Eventually, the amnesia will largely disappear, and will be limited to the traumatic event itself and the few seconds that preceded it.

There are reasons to believe that the vague and aspecific symptoms of the postconcussion syndrome are sensitive to simulation. This is mostly the case in civil law suits, in which, for example, vehicle accident victims require financial compensation. In such cases, it is relatively easy to feign aspecific symptoms (Youngjohn, Burrows \& Erdal, 1995). Meanwhile, organic amnesia is considerably more difficult to simulate, - at least for lay persons -, precisely because it has such a typical course. That is, organic amnesia requires the specific sequence of trauma, loss of consciousness, PTA, memory loss relating to recent rather than old memories. and memory recovery in such a way that older memories come back more readily than more recent ones. When a person claims an organic amnesia for a traumatic event (e.g., accident) that does not fit with this sequence, there is every reason to be sceptical and to consider the possibility of feigned amnesia.

\section{TESTS}

When a defendant claims crime-related amnesia, how should an expert witners determine what type of ammesia the defendant suffers from? One possibility is that the defendant has sustained brain injury and consequently developed organic 
amnesia. The expert may explore this possibility by examining if and how the defendant" s amnesia disappears over time. If the defendant's amnesia follows Ribot's law, that information might be crucial for the defendant's counsel. Consider the example of the defendant charged with murder. If the defendant has an organic amnesia and it can be shown that this amnesia originates from the victim hitting the defendant on his head before he was murdered, then a self-clefence interpretation of the murder case might be considered.

Another possibitity is that a defendant believes that he suffers from amnesia. As far as we know. there is no valid test to explore this possibility. However, with the findings of Kvavilashvilt and Ellis (1999) in mind, the expert might consider giving the defendant a placebo along with the instruction that it is a memory-enhancing drug. In a way, such a manipulation is deceptive, but on the other hand, it is highly similar to forensic hypnosis, because in hypnosis expectancies also play a key role.

A third possibility is that a defendant feigns his amnesia. Again, this possibility needs to be scrutinized and this can be done in either of two ways.

\section{SYMPTOM VALIDITY TESTING}

The first way is to subject the defendant to a so-called Symptom Validity Test (SVT), With this method, it is possible to identify defendants who simulate amnesia (Frederick, Carter \& Powel, 1995; Denney, 1996). Basically, SVT procedures consist of a farced-choice recognition test. During SVT, the defendant is asked a series of dichotomous (true-false) questions about the crime and the circumstances under which it took place. The defendant is instructed to guess in case he does not know the right answers because of his amnesia. Typically, 15 to 100 items are presented, each followed by a two-alternative forced-choice recognition. Typical questions asked in the SVT are for example "Did the offender use a pistol or a knife?"; "Was the person known to sell ecstasy or crack?"; "Was the victim black or white?"; and "Was the street made of cobblestones or asphalt?". With any number of items, 
chance performance (guessing) can be determined fairly precisely. This has to do with the fact that, purely random responding will result in about $50 \%$ of the answers being correctly answered. Individuals who perform significantly below chance, avoid correct alternatives, which mean that they have knowledge about the correct answers, and this implies that they feign memory impairment. SVT is based on binomial statistics and this has the clear advantage that one can quantify memory performance." Thus, one can determine the exact chance that someone with genuine memory loss gives only 3 right answers to 15 true-false questions. On the basis of chance such a person should have 6,7 or 8 correct answers. The chance that someone with memory loss produces only 3 correct answers, is smaller than $5 \%$ (see footnote; the exact chance can be calculated as follows: $z=(3+.5-(15 \times .5))$ $\sqrt{ }(15 \times .5 \times .5)=2.1$, which corresponds to a $p$-value of $\leq 0.02)$.

Several case studies have been reported in which suspected (Frederick \& Carter, 1993; Frederick, Carter \& Powel, 1995) or confirmed (Denney \& Wynkoop, 1995) malingerers showed a response pattern in which their performance fell below chance. One study (Denney, 1996) presents three cases within the criminal forensic setting. To evaluate the assumption that the procedure actually conforms to probability standards of the binomial theorem, this author used a normative sample of 60 adults who had no prior knowledge of events in question. Results of this study showed that the SVT procedure is rather robust and can handle variability in the probability of several items. Although the more questions created the more reliable the test and the more test variance it will contain (Crocker \& Algina, 1986), the results of Denney (1996) suggests that even with a test of only 10 items, the varied item probability had little practical effect on the test. The mean correct answer of a control sample $(\mathbb{N}=60)$ for each case was either the same as the hypothesized mean

\footnotetext{
The Binominal formula is as follows: $z=[(x \pm .5)-N p)]$ f Npq, in which $z$ is the test statistic (value and corresponding $p$ can be looked up in a table), Wis the number of items, $x$ the number of correctly answered items, $p$ the chance for a correct answer when one has to guess (idealy .5) and $q$ is $1-p$.
} 
or where in the positive direction. For example, in one of the cases described, the defendant answered only 7 of 29 questions correctly $(z=-2.6, p<0.005)$ which suggests that such a performance would only occur less than 5 times out of 1000 by chance alone. The control sample results of this case showed a mean of 15.83 (SD = 2.77) and a range from 8 to 23. Moreover, the distribution of item probabilities appeared quite symmetrical suggesting that much of the variability is due to random chance.

Some researchers have argued that a clever defendant who attempts to simulate amnesia will readily recognize the rationale behind SVT. By this view, defendants would quickly realize that they have to perform at chance-Level (half of the answers correct and the other half incorrect). A recent study by Merckelbach, Hauer, and Rassin (2002c) tested this idea. In this study, 20 students were instructed to steal an emvelop with some money. Next, students were told to simulate amnesia in a way that would convince experts. To explore how well the SVT could identify this feigned amnesia, students took 15 true-false items SVT. More than half ( $57 \%$ ) of the student. sample had less than 4 correct answers and, thus, they were identified as malingerers. The other students succeeded in performing at chance-level and thus, seemed to be able to simulate in a convincing way. However, post-experimental interviews with the subjects made it clear that only a minority of them were able to verbalize the rationale behind SVT.

Given the fact that a majority of students can not beat the SVT, the efficacy of the SVT in identifying malingering should be considerably better with less educated defendants who simulate amnesia. This is especially true if the number of SVT questions is increased. The Merckelbach et al. (2002c) experiment relied on a relatively small number of test items (i.e., 15). However, with more SVT items, say 30 , it becomes more and more difficult for defendants to monitor whether one still performs at chance-level. And even when defendants perform at chance-level, there is an appropriate test to examine whether the pattern of correct and incorrect 
answers is random (as it should be in the case of genuine amnesia) or structured (as is the case in a strategic attempt to perform at chance level) (Cliffe, 1992). A discussion of this "runs"-test falls beyond the scope of this article, but the principle behind it can be summarized as follows. Suppose you have a coin and on 15 consecutive trials you throw head, while on the next 15 consecutive trials you throw tail. That would be nicely at chance-level. However, there must be something wrong with the coin, because too few so-called "runs" have been made (namely 2) to assume that the pattern of heads and tails is random. The same is true for some forms of SVT performance at chance-level. Those who during a SVT of 30 true-false items, answer the first 15 items correctly and the last 15 items incorrectly, perform precisely at chance level, but are identified as malingerers by the "runs"-test. So, even when the results fall within the predictable random range and distribution, but the response pattern shows that the first half of the test is answered correctly and the second half is not, it indicates a non-random response pattern. To detect malingerers one should not only test the binomial significance of true and false answers, but also whether the sequence of the true and false answers is at random. SVT does not require much technical facilities. All one needs is a pencil, a paper. and basic knowledge of statistics. It is essential, though, that the correct and incorrect alternatives are first evaluated by a panel of naif subjects. When this panel. judges the incorrect alternatives as more plausible than the correct alternatives, it is possible that someone with a genuine amnesia performs below chance-level. In the clinical or forensic setting, this method of control might prove umwieldy and extremely time consuming. Nevertheless, with this restriction in mind, we would like to recommend the SVT to experts who have to examine cases in which defendants claim amnesia. 


\section{SELF-REPORTS}

A second way to examine claims of amnesia, is provided by selfareports questionnaires that capitalize on the tendency of malingerers to exaggerate their memory complaints (Smith, 1997). In this context, a promising questionnaire is the Structured Inventory of Malingered Symptomatology (SIMS; Smith \& Burger, 1997: see for a German translation: chapter 2). The SIMS consists of 75 dichotomous (i.e., true-false) items that can be grouped into 5 subscales, each subscale containing 15 items. Subscales correspond to symptoms domains that are sensitive to malingering and include low intelligence (LI), affective disorder (AF), neurological impairment $(N)$. psychosis (P), and amnestic disarder (AM). Items of the subscales refer to bizarre experiences (e.g., "At times. I've been unable to remember the names or faces of close relatives so that they seem like complete strangers") or to unrealistic symptoms (e.g., "When I can't remember something, hints do not help"). Other items explicitly allude to a certain syndrome (e.g., amnesia) in such way that specialists recognize that highly atypical symptoms are listed (e.g., "My past and important events became a blur to me almost overnight" $)$. The idea is that malingerers will exaggerate and in doing so, will endorse bizarre, unrealistic, and atypical symptoms. Answers indicating malingering are summed to obtain a Total SIMS score.

So far, a number of studies have looked at the accuracy with which the SIMS detects malingered symptomatology (Rogers, Hinds \& Sewell, 1996; Smith \& Burger, 1997; Edens, Otto \& Dwyer, 1999). Although these studies came up with promising results, one should note that with the exception of the study by Cima and colleagues (chapter 2) all studies relied on laboratory set-ups. In this type of study. undergraduate students are instructed to feign in a convincing way. certain psychiatric symptoms (e.g., amnesia). Performance of these instructed malingering groups on the SIMS is then compared to the SIMS scores of control (ii.e., uninstructed) groups responding honestly. It is evident that this approach is subject 
to a number of limitations, not the least of which is that for undergraduates instructed to malinger symptoms there are hardly any risks or incentives. Nevertheless, so far the results with the SIMS are encouraging in that subjects instructed to feign, say, amnesia can be identified with a high degree of precision. For example, Merckelbach and Smith (2003) reported that more than $90 \%$ of the subjects instructed to malinger amnesia are identified by the SIMS (sensitivity) and more than $90 \%$ of the control subjects are classified by the SIMS as honest respondents (specificity).

In the one study that systematically looked at SIMS performance of forensic patients (chapter 2), a German translation of the SIMS was administered to a sample consisted of 266 participants of whom 204 were undergraduate students ( 98 men) and 62 were forensic inpatients (all men). The German SIMS showed excellent stability (0.97) as well as acceptable consistency (Cronbach alpha coefficient = $0.80)$. None of the participants in the control sample $(69$ honestly responding healthy subjects) had al total score exceeding the cut-off point of 16 recommended by Rogers et al. (1996), while $86 \%$ of the instructed malingerers $(n=135)$ and $27 \%$ of the forensic patients scored in this range.

Data of honestly responding contrals, instructed malingers and patients were pooled in order to calculate sensitivity, specificity, positive and negative predictive power (PPP and NPP). Using the cut-off score of $16,87 \%$ of the malingerers were identified correctly (sensitivity), while $86,7 \%$ of the non-malingerers were classified correctly (specificity). The Positive Predictive Power (PPP), which is explained in the next section, was 0.87 . In other words, the probability that someone with a Total SIMS score of 17 or higher was an instructed malingerer was .87 . The specificity of $86.7 \%$ implies a false alarm rate of $13.3 \%$. In other words, $13.3 \%$ of the participants who did not receive an instruction to malinger nevertheless had Total SIMS scores exceeding the cut-off point. A closer look at these participants revealed that all of them were forensic psychiatric inpatients.

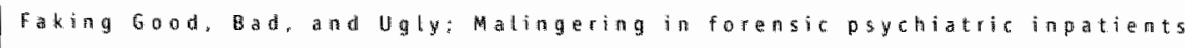




\section{DIAGNOSTIC ACCURACY}

Our discussion so far makes plain that experts who at the request of the court have to evaluate a case in which crime-related amnesia is claimed, can and should do more than just interviewing the defendant. The SVT as well as the SIMS are examples of tests that can be applied in this type of cases. Other tests and tasks that can be of help are extensively discussed in Rogers (1997) and Hall and Poirier (2001).

Selection and actual use of tests in amnesia cases should be guided by scientific literature and, more specifically, by what this literature tells the experts about diagnostic accuracy. Experts usually focus on sensitivity and specificity of diagnostic measurements. In this context, sensitivity refers to the percentage of malingerers who are correctly classified by the test, while specificity refers to the percentage of honestly responding controls who are correctly identified. The idea that a diagnostic instrument is valid if research shows that its sensitivity and specificity circle around $90 \%$ seems widely accepted by experts, but is misleading. An example taken from Rosenfeld, Sands, and van Gorp (2000) may illustrate this point. Suppose, there is a questionnaire that intends to detect simulated amnesia and suppose that this instrument has been tested in a laboratory study that involved 50 subjects simulating amnesia and 50 honestly responding subjects (control group). Let us further assume that the results of this study showed that 45 of the 50 simulators were identified by this questionnaire (sensitivity $=90 \%$ ), while 48 of the 50 control subjects were classified correctly (specificity $=96 \%$ ). So, sensitivity and specificity rates are excellent, but this does not mean that the test is valid. The point is that these rates were obtained with a particular base-rate of malingering, namely $50 \%$ ( $50 \%$ of the subjects were simulating amnesia). When one lowers this base-rate to, say, $10 \%$ (10 subjects simulate versus 90 subjects respond honestly), diagnostic accuracy of the test will drop dramatically, although its sensitivity and specificity remain the same. Table 3.1 shows this effect. With a base-rate of $50 \%, 45$ of the 
malingerers are correctly identified and 2 honestly responding subjects are misclassified as malingerers. However, with a base-rate of $10 \%$, there are 9 correctly classified malingerers and 4 honest subjects who are misclassified. A good measure to capture these proportions is the Positive Predictive Power (PPP). PPP is concerned with the classification of individual and this is what matters in a legal context. PPP pertains to the probability that an individual with a score that exceeds the cut-off does have the diagnose (in this case, feigned amnesia). With a base-rate of $50 \%$, the PPP of our fictitious instrument is $45 / 45+2=96 \%$. However, with a base-rate of $10 \%$, the PPP of this instrument drops to $9 / 9+4=69 \%$. In other words, with such a base-rate, the probability is only 2 out of 3 that someone who has an above-cut-off score does, indeed, simulate amnesia. The take-home message of this example is that applying tests in order to identify simulated amnesia, requires technicat knowledge about diagnostic quality parameters (sensitivity, specificity, and PPP) of these tests. This is essential, because only when the expert possesses. such technical knowledge and communicates it to the court, trial judges become aware of strengths and limitations of diagnostic evaluations in amnesia cases. 
Tabel 3.1: Sensitivity and specificity of a diagnostic instrument and how they relate to bose-rate. Values between parentheses show what happens when the base-rate of malingering drops to 10\%: 10 subjects malinger and 90 perform honestly. $C P=$ correct pasitive, $F P=$ false positive, $F N=$ false negative and $C N$ $=$ correct negative. Sensitivity $=C P /(C P+F N)$; specificity $=C N /(C N+F P) ;$;PP (Positive Predictive Power) $C P /(C P+F P)$

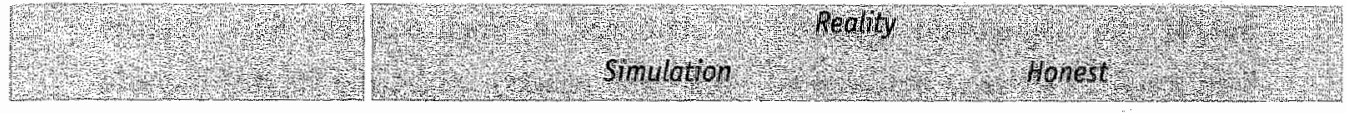

Test:

Malingering $45(C P)$

(9)

Honest
$2(F P)$

$48(\mathrm{CN})$

(86)

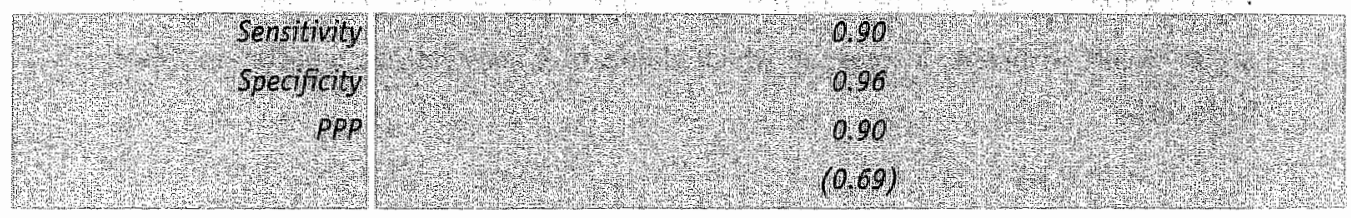

\section{CONCLUSION}

It is not uncommon that defendants claim amnesia for a crime of which they are accused. Mental health profersionals who serve as expert witnesses in such cases often assume that this type of memory loss is the joint effect of strong emotions (i.e., dissociative amnesia) and excessive drug or alcohol use. It is also common to seek arguments for this interpretation by interviewing the defendant. In this article, we explained why this approach is dubious. Dissociative amnesia is not the only or even the most prevalent form of crime-related amnesia. Experts should at least take the possibility of other forms of ammesia into account. These other types involve simulated, imagined, and organic amnesia. The diagnostic differentiation between these types of amnesia can not take place solely on the basis of interviews. 
Professionals should use objective measures as opposed to relying on clinical judgement alone. Tests (e.g., the SIMS) and tasks (e.g., the SWT) are required to make this differentiation. As with interviews, the use of only one test is not sufficient in determining between the different types of amnesia. No one should be diagnosed as malingerer solely on the basis of one test. Instead, proper diagnosis entails the appropriate synthesis of information from multiple data sources (structural interviews, observation, other test results), especially in the forensic setting. Statistically based procedures, when used prudently and in conjunction with multiple data source should counteract inherent weaknesses of clinical judgement alone. Although these tests and tasks may seem simple, their use requires sophisticated knowledge about diagnostic quality parameters. Many psychologists and psychiatrists will not possess this knowledge and therefore their competence to act as expert witnesses in cases in which claims of crime-related amnesia are raised is doubtful. 
CHAPTER 4

${ }^{*}$ Characteristics of Psychiatric Prison Inmates Who Claim Amnesia

*This chapter is in press as: Cima, M., Merckelbach, H.* Hollnack, S. \& Knawer, E. Characteristics of psychiatric prison inmates who claim amnesia. Personality and Individual Differences. 


\section{SUMMARY}

In the current chapter, we explored characteristics of psychiatric prison inmates who claim amnesia for their crimes. More specifically. we examined differences in intelligence, psychopathology, executive functions, and malingering tendencies between psychiatric prison inmates who claimed amnesia $(n=17)$ and those who did not $(n=45$ ). Findings indicate that lowered levels of intelligence and relatively poor performance on executive (i.e., frontal lobe) tasks accompany claims of amnesia. As well, those who claimed amnesia displayed heightened scores on an instrument intending to measure malingering. This pattern supports the view that such claims must be treated with scepticism.

\section{INTRODUCTION}

It is not uncommon that offenders claim memory loss (i.e., amnesia) for their crime. As a matter of fact, 25-45\% of criminals found guilty of homicide claim amnesia for the event (Kopelman, 1995). In only a handful of these cases, brain dysfunctions may account for reports of amnesia. Some authors have argued that in the legal domain, the most common form of amnesia is simulated amnesia (Sadoff, 1974; Schacter, 1986; chapter 3). For example, Parwatikar, Holcomb, and Menninger (1985) argued that one obvious motive for offenders to feign amnesia is to avoid or reduce punishment. On the other hand, Kopelman (1995) has pointed out that even though criminals may claim amnesia, they often themselves report their crimes to the police. According to Kopelman (1995), this would argue against the view that all claims of ammesia for crime can be accounted for in terms of malingening. This author assumes that when extreme emotions accompany a criminal act, genuinely dissociative (i.e., psychogenic) amnesia for crimes may occur (see, for a similar position, Porter, Birt, Yuille \& Hervé, 2001; Swihart, Yuille \& Porter, 1999).

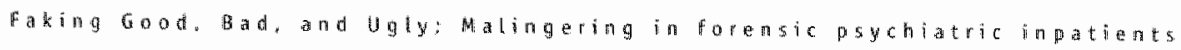


Surprisingly few studies have looked at personality characteristics of individuals claiming amnesia for their crimes. In an early study, O'Connell (1960) suggested that low intelligence is related to claims of amnesia. This author argued that because of its simplicity, claims of amnesia might constitute an attractive defence manoeurre for low intelligent people. Parwatikar et al. (1985) argued that depressive symptoms often accompany amnesia for crime. Taylor and Kopelman (1984) reported a similar finding , but these authors remind us of the possibility that in some cases, depression might be a reaction to the crime. In one of the most systematic studies to date, Gudjonsson, Hamnesdottir, and Petursson (1999) administered individual difference measures to criminats who claimed amnesia for their violent offences and control criminals. These authors noted that amnestic offenders score relatively high on introversion and relatively tow on impulsivity. However, o'Connell (1960) and Parwatikar et al. (1985) found that hysterical personality characteristics are rather prevalent among offenders claiming amnesia. To the extent that hysteria implies extravert and impulsive behaviour, this finding is difficult to reconcile with the results reported by Gudjonsson and associates. Another prominent feature of hysterical personality is manipulative behaviour and this, of course, is also an important aspect of psychopathy. In the words of Porter and co-workers (2001; p.36): "Psychopaths use a high degree of manipulation, deception, and malingering relative to other offenders and would be likely to use a false claim of amnesia if any personal gains were anticipated."

Some traits (e.g.. low intelligence, hysteria) that have been found to be typical for offenders claiming amnesia fit nicely with a malingering interpretation, while other traits (e.g., depression, introversion, low impulsivity) ascribed to this group seem to be more consistent with the idea that highly arousing events such as crimes may cause memory dysfunction. Meanwhile, the view that traumatic events might produce complete amnesia has not gone unchallenged. For example, Porter and associates (2001) noted that most witnesses to extreme violence have good rather 
than impared memories for the events. Likewise. Merckelbach, Dekkers, Wessel, and Roefs (2003) reported that concentration camp surwors only rarely develop dissociative mansia for ther tramatic experiences.

Awhough research has come up with conflicting findings about the personality characteristics of criminats who clam amnesia, there is consensus about two issues. Firsty, is a wet-estabhished fact that clams of ammesia more often pertain to violent Grimes than to non-wiolent crimes (e.g., Taylor \& Kopelman. 1984). Secondly, crime-retated ammesia is often associated with atcohol and/or drug intoxication during the crime (e.g.. Gudjomsson et al., 1999).

To the extent that claims of crime-retated amnesia are a form of feigning, one would expect that they are raised by individuats who have relatively low IO's, psychopathic features, impulsivity manfesting itself in poor executive (i.e., frontal lobe) functions, and heightened scores on malingering scales. The present study explored whether such a constellation of features is typical for psychiatric prison inmates who claim amnesia. Since all these patients had been invotved in legal proceedings, extensive and detailed patient records were available. Information about claims of ammesia was obtained by having an independent and blind rater inspecting these records.

\section{METHODS}

\section{PATIENTS}

Participants were 62 inmates of a German psychiatric correctional institute. All were men. Their mean age was 38.5 years $(S D=10.9)$. Twenty patients had committed murder, while the remaining patients were convicted for sexual offences (22 patients), aggressive criminal acts (10 patients), or theft and arson (10 patients). As to their psychiatric diagnosis, a majority of the patients (60 patients; $96 \%$ ) met DSM-IV (American Psychiatric Association, 1994) criteria for one or more personality 
disorders, in particular disorders of the cluster B type (e.g., antisocial personality, hysterical personality). Forty-one patients $(66 \%)$ had more than one Axis I diagmosis. The most common Axis I diagnoses were psychotic disorders (31 patients; $50 \%$ ). Also common were substance abuse ( 27 patients; $44 \%$ ), mood disorders (17 patients; $27 \%$ ) and anxiety disorders (18 patients; $29 \%$ ). Seventeen patients had a diagnosis of paraphilias $(27 \%)$. Patients volunteered to participate in several test sessions.

For all patients, extensive hospital records were available. Patients' records, including psychotherapists' notes and summaries of police interviews, were subjected to close inspection to establish whether patients claimed amnesia for the crime that lead to their conviction. Seventeen patients (24\%) claimed ammesia for their crimes. Of these 17,6 patients $(35 \%)$ had committed murder, 5 patients $(30 \%)$ were sexual delinquents, while the remaining 6 (35\%) had been convicted for bodily harm or other forms of severe aggression (e.g., armed robbery). The frequency of violent offences was significantly higher in those claiming amnesia as compared to those who did not (100\% versus $36 \%$, respectively, $\chi 2(1)=20.58, p<0.01$ ). In 2 of the 17 amnestic cases, but none of the control cases, the court reasoned that extreme alcohol consumption before the crime had produced a temporary state of insanty.

\section{MEASURES}

IQ. As part of routine diagnostic screening, patients completed the German version of the Wechsler Adult Intelligence Scale (Wechsler, 1991: HAWIE-R; Hamburg. Wechsler Intelligenztest für Erwachsene Revision). The HAWIE-R consists of 11 subtests, of which 6 are designed to measure verbal $\mathrm{IO}$ and 5 measure performance Ia. A Total IO score can be abtained by summing across subtests and standardizing scores, using age and sex appropriate normi-tables. 
ANTISOCIAL PERSONALITY FEATURES. We counted the frequency of DSM-IV (American Psychiatric Association, 1994) defined antisacial personality disorder (APD) diagnoses among amnestic and control patients. Diagnoses were made by independent clinicians as part of routine screening. Patients were also administered the Psychopattic Check List Revised - Screening Version (PCL-SV; Hart, Cox \& Hare, 1996). The PCL-SV is a 12-item instrument, with each item rated on a 3-point scale (anchors: $0=$ feature absent; 2 - feature strongly present). Scores were obtained from two independent raters who evaluated a semi-structured interview with patients and their archival records. Scores of the two raters were averaged to calculate a Total PCL-SV score (Cronbach alpha $=0.78$ ), which ranges from 0 to 24 and reflects the degree of overall psychopathic symptomatology. Total PCL-SV scores exceeding the cut-off of 12 are considered to be an indication that follow-up screening for psychopathic symptoms is warranted (Hart et al., 1996).

IMPULSIVENESS. Patients completed the German version of the Barratt Impulsivity Scale Version 10 (BIS-10; Patton, Stanford \& Barratt, 1995). The BIS-10 is a 34-item self-report questionnaire designed to measure several forms of impulsivity. More specifically, the BIS-10 addresses (a) motor impulsivity (e.g.e "I do things without thinking") (b) cognitive impulsivity (e.g." "I make up my mind quickly"): (c) lack of planning (e.g., "I plan tasks carefully"). Items are answered on 4-point scales (anchors: 1 = rarely/ never ; $4=$ almost always/ always). After recoding atems with reversed scoring formats, a Total BIS-10 score (Cronbach's alpha $\approx 0.83$ ) was obtained by summing across items.

EXECUTIVE FUNCTIONS. Patients completed 4 tasks of The Behavioural Assessment of Dysexecutive Syndrome (BADS) test battery (Wilson, Alderman, Burgess, Emslie \& Evans, 1996). As in one of our previous studies (Cima, Merckelbach, Klein, Schellbach-Matties \& Kremer, 2001), we used the following 
BADS subtests: The Rule Shift Cards test, which measures cognitive flexibility: The Key Search test, which indexes the ability to plan and monitor effective search strategies; The Temporal Judgement test, which taps reasoning about time duration; and The Zoo Map test, which measures the ability to plan a route. For each task, a profille score ranging from 0 to 4 was given and these were summed to obtain a total. BADS score (Cronbach alpha $=0.76$ ), with lower scores indicating poorer executive (i.e. frontal) functioning.

MALINGERING TENDENCIES. Patients completed the German version of the Structured Inventory of Malingered Symptomatology (SIMS; Smith \& Burger, 1997; chapter 2). The SIMS is a self-report scale designed to detect malingering of psychiatric symptoms and/or cognitive impaiments. It consists of 75 items that can be grouped into 5 subscales, each subscale containing 15 items designed to tap commonly malingered conditions, like low intelligence and amnestic disorder. Certain items have a bizarre content (e.g., "When I hear voices I feel as though my teeth are leaving my body") or refer to low-frequency symptoms (e.g." "I have a pain in my body which seems to feel like bugs crawling under the surface of my skin"). Other items explicitly allude to a certain syndrome (e.g. depression) in such way that experts recognize that highly atypical symptoms are listed (e.g. "The more depressed I get, the more I want to eat"). Still other items contain an option for "near good" responses (e.g. "There are six days in a week"). Answers indicating malingering are summed to obtain a Total SIMS score (Cronbach's alpha $=0.81$ ). Previous studies recommended a cut-aff score of 16 for follow-up screening of malingering (e.g.. Rogers, Hinds \& Sewell, 1996),

\section{PROCEDURE AND DATA-ANALYSES}

Patients were given the PCL-SV interview items and the BIS-10, BADS, and SIMS during separate sessions, which all took place in a quiet room. Differences between 
those who claimed amnesia and those who did not were evaluated with two-tailed ttests and Chi-square tests. In case of significant differences, Cohen's (1992) d's were calculated. As our study was explorative in nature, we did not apply Bonferronicorrections.

\section{RESULTS}

Table 4.1 shows scores on the various parameters of patients who claimed ammesia $(n=17)$ and those who did not $(n=45)$. As can be seen, Total IQ was significantly lower in those who claimed crime-related amnesia than in those who did not: $t(60)$ $=2.47, p<0.05$ (two-tailed). In terms of effect size, this difference was moderate to large: $d=.70$. A more detailed analysis indicated that amnestic patients had significantly lower performance IO's than controls, means being $78.4(S D=10.5)$ and $91.1(S D=17.7)$, respectively, $t(60)=2.79, p<0.01(d=.79)$. Verbal Ia was also lower in those who claimed amnesia than in controls, means being 81.4 (SD $=$ 13.7) and $91.0(S D=18.8)$, but this difference only reached borderline significance: $t(60)=1.94, p=0.06(d=.55)$. 


\section{CHAPTER 4}

Table 4.1: Mean (SD's) IQ levels, frequency (\%) of APD (Antisocial Personality Disorder). mean (SD'S) PCL.SV (Psychopathy Checklist-Screening version) scores, mean (SD's) BIS-10 (Barrett Impulsiveness Scale-10) scores, mean (SD's) BADS (Behavioral Assessment of Dysexecutive Syndrome) scores, and mean (SD's) SIMS (Structured Invertory of Malingered Symptomatology) scores of amnestic $(n=17)$ and control $(n=45)$ patients.

\begin{tabular}{|c|c|c|}
\hline & 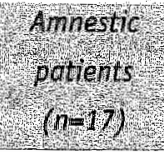 & $\begin{array}{l}\text { control } \\
\text { profients } \\
(n-3)\end{array}$ \\
\hline Total IO* & $78.5(10.4)$ & $90.8(19.5)$ \\
\hline APD & $12(71 \%)$ & $21(47 \%)$ \\
\hline Total PCL-SV & $13.3(4.0)$ & $13.1(3.8)$ \\
\hline rotal BIS 10 & $79.5(10.9)$ & $72,01129)$ \\
\hline Total BADS* & $6.1(2.6)$ & $8.3(3.2)$ \\
\hline
\end{tabular}

Twelve of the 17 amnestic patients (71\%) were diagnosed with an antisocial personality disorder versus 21 of the 45 controls ( $47 \%$ ). Thus, the frequency of this diagnosis was significantly higher in the former group $\left[\chi^{2}(1)=11.07, p<0.01\right]$, a difference that was in the moderate range $(d=.49)$. As for the $P C L-5 V, 10$ of the 17 amnestic patients (59\%) had a score of 13 or higher. However, about the same proportion of controls $(56 \%)$ obtained such a score. Indeed, there was no difference between amnestic and control patients with regard to their mean scores on the PCLSV: $\mathrm{t}(60)<1.0$.

Mean Total BIS-10 score for the total sample $(N=62)$ was $72.4(S D=12.3)$, which is significantly above $64.9(S D=10.19)$, the mean score of the general population (Patton et al., 1995): $\mathrm{t}(472)=4.97, \mathrm{p}<0.01$. Patients who claimed amnesia and contrals did not differ with regard to Total BIS - 10 levels: $t(60)<1.0$. 
Table 42: Pearson correlations between IQ, psychopathy (PCL-SV), impulsivity (BIS-10), executive functions (BADS), and matingering (SIMS) in patients claiming amnesia $(n=17)$.

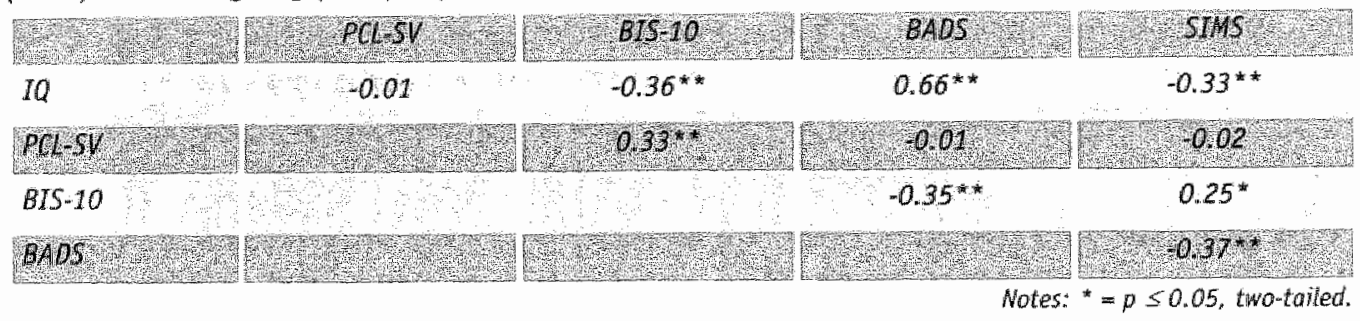

Total BADS scores of amnestic patients were below that of control patients, a difference that was significant $[t(60)=2.61, p<0.01]$ and moderate to large $(d=$ .72). To examine whether poor BADS performance of amnestic patients might be an artifact of their low IQ's, we conducted an Analysis of Variance (ANOVA) with patient groups as factor, BADS scores as dependent variable, and intelligence as covariate. This showed that amnestic patients had poorer executive functions than controls, even when the contribution of intelligence was controlled for: $F(2,59)=$ 23.73, $\mathrm{p}<0.01$. A similar result was obtained when performance IQ served as the covariate: $\mathbb{F}(2,59)=18.36, p<0.01$.

As to the SIMS, $53 \%$ of the ammestic patients and $18 \%$ of the controls scored above the clinical cut-off of 16 , a difference that is statistically significant $\left[\chi^{2}(1)=7.67\right.$, $p<0.01]$ and represents a moderate effect $(d=.42)$. However, while Total SIMS scores of amnestic patients were higher than those of controls, this difference failed to attain significance $[\mathrm{t}(60)=1.49, p=0.14]$.

To explore how the various measures were interrelated in the group of patients daiming amnesia, wè performed a set of Pearson product-moment correlations. As table 4.2 shows, lower intelligence was significantly related to higher impulsivity, poorer executive functions, and stronger malingering tendencies. Psychopathy was only significantly correlated with impulsivity. 


\section{DISCUSS10N}

The main findings of the current study can be summarized as follows. To begin with, in keeping with prevalence rates reported in earlier work (e.g., Kopelman, 1995), our study found that a nontrivial minority of psychiatric criminals (i.e., 27\%) claimed amnesia for their offences. As was the case in earlier studies (Taylor \& Kopelman, 1984; Kopelman, 1995), claims of amnesia were found to be fairly typical for those who had committed violent crimes. Secondly, in line with o'connell's (1960) suggestion, patients claiming amnesia had lower IO's than controls. Thirdly, a diagnosis of antisocial personality was more prevalent in patients claiming amnesia than in controls. Fourthly, patients claiming amnesia exhibited more evidence of executive dysfunctions and more frequently scored above the cut-off of a malingering scale (SIMS) than controls. This is reminiscent of a previous study (Cima et al., 2001), which showed that poor executive functions go hand in hand with self-reports of dissociative symptomatology. Fifthly, in contrast to what has been assumed by some authors (Porter et al., 2001), we found that psychopathy as. measured by the PCL-SV was equally distributed among those who claimed amnesia and those who did not. Two explanations for this finding suggest themselves. One is that in our sample, most instances of claimed amnesia involved genume memory loss. If true, one would not expect to detect a link between claims of amnesia and psychopathy (see Porter et al., 2001). However, we do not find this possibility very plausible given the raised SIMS scores of those who claimed amnesia. Another possibility is that malingered amnesia is different from the more subtle types of manipulative behaviour found among psychopathic individuals. Thus, it may well be the case that malingered amnesia is more typical for those with relatively low IQ's, while other and more subtle forms of deception are typical for psychopathic individuals with relatively normal or above normal IQ's. Interestingly, a recent study by Poythress, Edens, and Watkins (2001) also failed to find a link between 
psychopathic personality features and straightforward maltingering. Clearly, the precise links between types of malingering, IO, and psychopathy warrant systematic investigation. Although the prevalence of psychopathy (as indexed by PSC-SV scores $>18$ ) and borderline psychopathy (PCL-5V scores > 12) was equally distributed among amnestic and control patients, a clinical diagnosis of APD was more common among the former group. One explanation for this discrepancy might be that relative to controls, amnestic patients more often had committed violent crimes. Thus, it may well be the case that clinicians' diagnoses of APD was influenced by the type of crime that patients had committed.

By and large, our pattern of findings supports the idea that those who claim amnesia for their crimes have relatively low $\mathrm{IO}^{\prime} \mathrm{s}$, exhibit poor executive functioning and tend to feign and overendorse bizarre symptoms in certain domains (e.g., memory). Our correlational analysis further suggests that rather than being incidental correlates of claimed amnesia, these characteristics co-vary in a meaningful way. At the very least, this is consistent with a malingering interpretation of crime-related amnesia. More specifically. when offenders claim amnesia, the following scenario warrants serious attention. Because of their low intelligence, and lack of executive control, these individuals engage in violent behaviour and later try to avoid responsibility by claiming amnesia. Note that such an interpretation comes close to the positions taken by Sadoff (1974) and O'Connell (1960).

Three limitations of the current study deserve some comment. First, the present study relied on offenders with psychiatric complaints and, therefore, its results cannot be easily extrapolated to criminals who claim amnesia, but have no (other) psychiatric symptoms. Secondly, there are many characteristics and traits that are potentially relevant when one tries to understand the origins of amnesia claims raised by offenders and the current study addressed only a handful of them. For example, it would be informative to employ experimental tasks rather than self- 
reports to examine the precise contribution of impulsivity to claims of amnesia for violent behaviour. Likewise, many authors have taken it for granted that alcoholblackouts play a critical role in such claims (e.g., Swihart et al., 1999). But. again, evaluations of alcohol consumption by amnestic criminals are often based on their self-reports, which may have no other function than providing an excuse for the crime as well as the memory loss that is claimed (chapter 3). Clearly, the link between objective parameters of alcohol intoxication and amnesia warrants future study. Thirdly, and most importantly, the current study derived information about amnesia claims from patients" records and this information only pertained to criminal acts for which patients were currently sentenced. We have no guarantee that some patients in the control group had claimed amnesia for crimes that they committed earlier in their criminal career. Perhaps, then, differences between those who claimed amnesia and those who did not would have been more pronounced had we taken this point into account.

To sum up, our results show that low intelligence, executive dysfunction, and heightened scores on a malingering device accompany claims of amnesia. This pattern underlines the idea that such claims must be treated with scepticism. 



\section{CHAPTER 5}

*Claims of Crime-Related Amnesia in Forensic Patients.

* This chapter has been accepted pending revision as: Cima, M., Nijman, H., Merckelbach. H., Kremer, K. \& Hollnack,S. Claims of crime-related amnesia in forensic patients. Internationa! Joumal of Law and Psychiatry. 


\section{SUMMARY}

Many authors assume that crime-related amnesia arises from the stressful nature of crimes and/or drug intoxication at the time crimes are committed. The study described in this chapter examined prevalence and correlates of crime-related amnesia in a German $(n=180)$ and a Dutch $(n=128)$ sample of forensic inmates. More specifically, patients claiming amnesia and control patients were compared with regard to their intelligence, criminal backgrounds, and psychiatric diagnoses. In contrast to the popular stress-dissociation interpretation, stressful features of the crime were not found to be related to claims of amnesia. Neither alcohol or drug intoxication, nor psychotic episodes could fully account for claims of memory loss. Interestingly, ammesia claims were especially prevalent among recidivists. This suggests that such claims are the product of a learning process. Thus, it may well be that those who are familiar with the penal system may have experienced the advantages of claiming ammesia.

\section{INTRODUCTION}

It is not uncommon for perpetrators to claim amnesia for their crime (Kopelman, 1995). Although the precise prevalence of such claims among various categories of perpetrators is not known. the estimates that can be found in the literature are rather consistent. In an early study, Leitch (1948) noted that 16 out of 51 offenders $(31 \%)$ convicted of murder or manslaughter claimed amnesia for their crime. Guttmacher (1955) found that about $30 \%$ of the convicted murderers in his sample claimed that they could not remember their crimes. Likewise, o'Connell (1960) reported a $40 \%$ incidence of amnesia in his sample of perpetrators of homicides. In a more recent study. Taylor and Kopelman (1984) interviewed 203 men who had committed both violent and non-violent crimes. Of the 34 men who had committed 
murder or manslaughter, $26 \%$ reported amnesia for their crime. When the authors omitted these homicide cases, there were 120 perpetrators of violent crimes. Amnesia claims were raised by only $8 \%$ of them, whereas no amnesia claims were found in perpetrators of non-violent crimes. A similar pattern was reported by Gudjonsson, Petursson, Skulasson, and Sigurdardottir (1989) who interviewed 62 Icelamdic criminals. Amnesia was claimed by $32 \%$ of the offenders and was most common in perpetrators of homicides (see also Lynch \& Bradford, 1980).

As to the correlates of amnesia claims, $0^{\prime}$ Connell (1960) reported that $40 \%$ of the perpetrators who claimed amnesia had an average or higher than average I0 as compared to $83 \%$ in the non-amnestic group. Relatively low IO levels in patients claiming amnesia were also reported by Cima, Merckelbach, Hollnack, and Knawer (in press b; chapter 4). However, Taylor and Kopelman (1984) were not able to replicate the association between low IO and amnesia claims. One interesting finding in their study was that mean age of the amnestic offenders was significantly above that of the non-amnestic offenders.

In keeping with earlier work (Hopwood \& Snell, 1933; Lennox, 1943; Rasch, 1966; Gross \& Kaltenbäck, 1974; Bradford \& Smith, 1979), Taylor and Kopelman (1984) found a heightened frequency of alcohol abuse in offenders claiming amnesia. Similarly, in a study of Barbey (1990), 52\% of 98 offenders who claimed amnesila had a diagnosis of alcohol abuse. However, this author also pointed out that acute alcohol intoxication was only partially responsible for the claims af amnesia since alcohol dosages that had been consumed in these cases were rather low. Moreover, $16 \%$ of the offenders who did not claim amnesia were intoxicated at the time of the crime. Apart from low IQ and excessive alcohol use depressed mood and hysterical traits have been found to be associated with claims of crime-related amnesia (Hopwood \& Snell, 1933; Kopelman, 1987, 1995; Parwatiker, Holcomb \& Menninger, 1985; chapter 3). 
Basically, psychiatric literature offers three types of explanations for the phenomenon of crime-related amnesia (Cima, Merckelbach, Nijman, Knauer \& Hollnack, 2002; chapter 3). The first emphasizes the stressful nature of crimes, notably murder. Thus, Hopwood and Snell $(1933 ;$ p. 32) argued that most crimes are "accompanied by strong emotional reactions" and this would undermine memory for crimes. Follawing this line of argumentation, some recent studies assume that it is offenders" dissociative reactions during the crime that produce subsequent amnesia (e.g., Tanay, 1969; Porter, Birt, Yuille \& Herve, 2001). Atthough this stressdissociation account of crime-related amnesia sounds plausible, it is at odds with studies showing that most eyewitnesses to extreme violence have good rather than impaired memory for the events (e.g., Porter et al., 2001). Another point that is difficult to reconcile with the stress-dissociation account is that survivors of WW II concentration camps rarely report amnesia for their horrifying experiences in these camps (Kuch \& Cox, 1992; Merckelbach, Dekkers, Wessel \& Roefs, 2003).

A second type of explanation for crime-felated amnesia is based on the observation that many offenders who claim such amnesia also say that they were intoxicated at the time they committed the crime. This has inspired state-dependency accounts of crime-related amnesia (e.g., Eich, Weingartner, Stillman \& Gillin, 1975; Swihart, Yuille \& Porter, 1999). These accounts assume that when crime memories are encoded during an exceptional state (extreme agitation and/or intoxication). subsequent retrieval of these memories will remain difficult or even impossible as long as the original state is not reproduced. Attempts to test this idea have yielded disappointing results. A case in point is the study by Wolf (1980) who showed that inducing a state of intoxication in murderers who claimed amnesia did not lead to a return or recovery of crime memories. Katant (1996) drew attention to amother shortcoming of state-dependency accounts when he argued that the pharmacological action of alcohol is typically such that it progressively suppresses both memory processes and complex behaviour. Thus, it is highly unlikely that an 
alcohol-intoxicated person engages in complex criminal behaviour, but has no memory of this behaviour.

A third explanation assumes that most cases of crime-related amnesia are a form of malingering (Sadoff, 1974; Cima et al, 2002; Cima et al., in press b; chapters 3 \& 4). The idea here is that by feigning a memory deficit, offenders might minimize their responsibility for the crime they committed. Unlike stress-dissociation and state-dependency accounts, the malingering interpretation of crime-related amnesia has met with considerable scepticism. Thus, Kopelman (1995) pointed out that offenders who claim amnesia often themselves are the ones who informed the police about their crime. According to Kopelman (1995; p.435), "this makes an account of amnesia as simulation to avoid punishment less plausible". A similar point has been madie by Porter and associates (2001) who argued that offenders who claim amnesia may confess, but maintain their amnesia claims. On the other hand, Cima et al. (in press $b_{\text {; }}$ chapter 4) found that convicted offenders who maintain their amnesia claims display heightened scores on instruments tapping the tendency to endorse bizarre, atypical, and rare symptoms. This finding is in line with a malingering interpretation. Note, however, that convicted offenders" motive for maintaining their claim of amnesia may have little to do with attempts to minimize legal responsibility, but more 50 with attempts to come up with a plausible rationale for not being able to discuss crime details during, for example, therapeutic sessions.

With a few exceptions (e.g., Taylor \& Kopelman, 1984), langeuscalle studies examining the characteristics of criminals who claim amnesila are scarce. With this in mind, the current study explored demographic and psychiatric characteristics of a large sample of forensic patients who had been convicted and claimed amnesia for their index crime. More specifically, we tested the following predictions. First, the stress-dissociation account would lead one to expect that claims of amnesia are typically found among those who committed violent and spontaneous (i.e.w unmediated) crimes. Secondly, on the basis of the state-dependency view, one 
would anticipate that a diagnosis of psychosis and/ar substance abuse is rather common among those who claim amnesia. Thus, to the extent that agitated states are typical for psychotic and/or intoxicated individuals, one would expect that such disorders are intimately related to amnesia claims. Third, a malingering interpretation of amnesia claims would predict that such claims are typical for recidivists who have learned that claiming amnesia provides them with an opportunity to avoid discussions about their criminal career. The present study sought to test these predictions in a relatively large sample of German and Dutch forensic patients.

\section{METHODS}

\section{PATIENTS}

The sample consisted of 308 forensic malle inpatients. One-hundred-eighty of them were from high secure settings at the Forensic Clinic Düren, Germany, while 128 were from high secure settings at Forensic Psychiatric Hospital the Kijvelanden, the Nethertands. Mean age was 34.3 years $(S D=9.6)$. All patients had been convicted for serious crimes. That is, 103 patients had committed murder, attempted murder or manslaughter ( $33 \%$ ), while the remaining patients had committed sexual offences ( 86 patients or $28 \%$ ), grievous bodily harm (44 patients or $14 \%$ ), and armed robberies or arson ( 75 patients or $24 \%$ ). A majority of the patients (186 patients; 60\%) met DSM-IV criteria (American Psychiatric Association, 1994) for one or more personality disorders, notably disorders of the cluster B type. The most common Axis I diagnosis was substance abuse (156 patients; $51 \%$ ). Also common were psychotic disorders (111 patients; 36\%) and sexual disorders (50 patients; $16 \%$ ), while 25 patients had a diagnosis of mental retardation $(8 \%)$. 


\section{MEASURES}

Extensive hospital records of all 308 patients were available. Patients records, including psychotherapists' notes and police interviews were studied to establish whether patients had, during any point in time, raised a claim of amnesia for the index crime. When a patient had claimed amnesia for his crime, his records were evaluated for the presence of inconsistencies (e.g., retracting a claim of amnesia and replacing it by a full description of the crime), crime details provided by the patient, claims of intoxication during the crime, and evidence of neurological impairments (e.g., epilepsy, brain injury, meningitis). Records were also evaluated to determine whether or not the index crime had been premeditated.

For 201 patients $(65.3 \%)$, recent information about intelligence levels was available. In most cases, IQ had been determined with the WAIS-R test (Wechsler, 1991) during standard diagnostic evaluations. Patients claiming amnesia and those who did not were compared with regard to frequencies of DSM-IV Axis I and Axis II diagnoses. To explore whether claims of amnesia were more often raised in the context of violent crimes (e.g.. Kopelman, 1995), we looked at the frequency of certain crime types in those who claimed amnesia and those who did not. We also looked at the frequencies of prior convictions in both groups. Finally, patients claiming amnesia and controls were compared with regard to the age at which they had committed their index crime.

\section{RESULTS}

\section{FREQUENCY AND TYPE OF AMNESIA}

Seventy-two patients (23\%) claimed either total or partial amnesia for their crimes. of these 72 amnesic patients, 26 patients $(36 \%)$ said to have complete memory loss for their crime, without having been under the influence of alcohol or drugs during the crime. Seventeen patients $(24 \%)$ claimed to be unable to remember the crime, 
While file information suggested that they had been alcohol and/or drug intoxicated during the crime. Another 26 patients ( $36 \%$ ) claimed to have forgotten crucial parts of their crime (usually the most violent ones) or said they couldn't recall certain incriminating details. The remaining $3(4 \%)$ patients claiming amnesia suffered from serious neurological disorders that probably contributed to their memory loss (e.g. epilitepsy and brain trauma).

In the subsample of "amnestic" patients $(n=72), 24$ patients $(33 \%)$ had committed murder, 18 patients $(25 \%)$ were sexual delinquents, 8 patients $(11 \%)$ had committed grievous bodily harm, and 22 patients $(31 \%)$ were convicted for arson and/or theft. The records of 15 of the 72 patients (21\%) claiming amnesia provided strong evidence that the index crime had been premeditated (e.g., buying a knife at the evening before the murder toak place).

\section{AMNESIA CLAIMING PATIENTS VERSUS CONTROLS}

Table 5.1 provides demographic background variables and information about psychiatric diagnoses of patients claiming amnesia and patients who did not raise such claims (controls). As can be seen, patients who claimed crime-related amnesia were older than controls $[\mathrm{t}(306)=2.61, \mathrm{p}<0.01]$. However, the two groups had similar intelligence levels. Amnesia claiming patients had had significantly more prior convictions than controls [ $\mathrm{t}(306)=3.22, \mathrm{p}<0.01]$. On the other hand, it was not the case that homicide crimes were more prevalent among patients claiming amnesia than among controls $\left[x^{2}(1)<1.0\right.$, N5]. A closer look at crimes with fatal consequences revealed that such crimes had comparable rates among amnesia claiming patients and controls, means being $28 \%$ and $25 \%$, respectively $\left[x^{2}(1)<\right.$ 1.0, NS]. Neither did amnesia claiming and control patients differ with regard to their age at the time of the first offence for which they had been convicted.

As to psychiatric diagmoses, the frequency of substance abuse was higher among amnesia claiming participants than among controls $\left[\chi^{2}(1)=11.39, p<0.01\right]$. The two 
groups did not differ with regard to frequency of psychotic disorder $\left[x^{2}(1)=1.23, p\right.$ $=0.27]$ or personality disorder $\left[\chi^{2}(1)=1.69, p=0.19\right]$.

Table 5.1: Mean age, intelligence, number of prior convictions, and frequency of homicide crimes, diagnoses of substance abuse, psychotic disorder, and persanality disorder in patients claiming amnesia $(n=72)$ and control patients $(n=236)$.

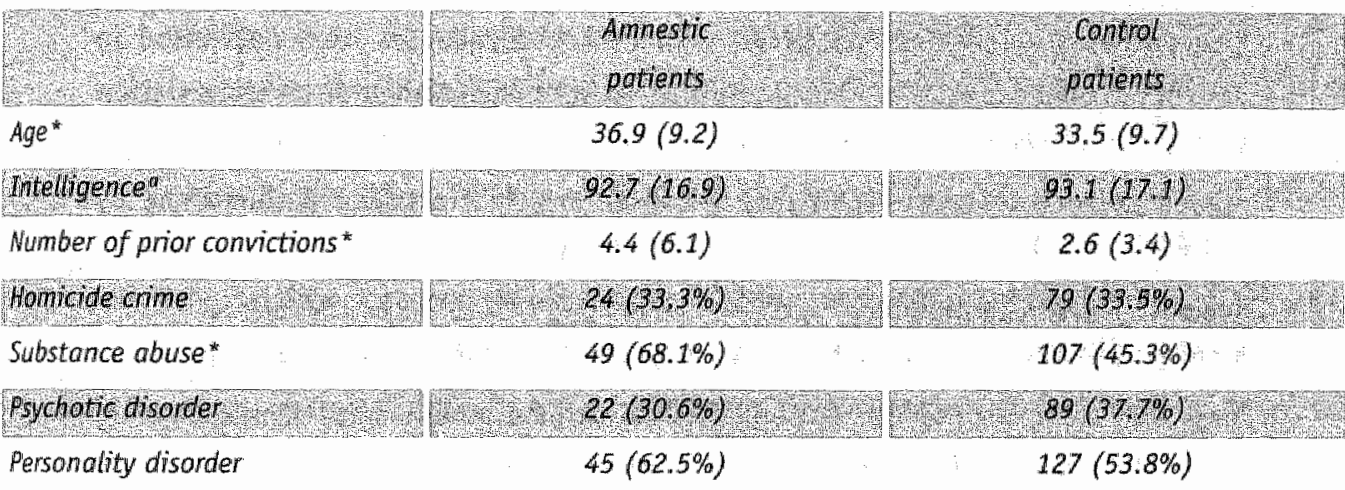

Notes: $=p-0.01$, two-tailed; $a=n$ 's are 60 for annestic group and 141 for control group.

\section{DISCUSSION}

The main findings of this study can be summarized as follow. To begin with, in line with earlier findings (e.g., Kopelmam, 1995; Annon, 1988), about a quarter of the perpetrators claimed aminesia for their index crime. Secondly, unlike the studies of O'Connell (1960) and Cima and colleagues (in press b; chapter 4), we found no evidence to suggest that amnesia-claiming patients had lower intelligence levels than control patients. Thirdly, in contrast to earlier research (Bradford \& Smith, 1979; Taylor \& Kopelman, 1984; Kopelman, 1995; Annon, 1988), we found no specific connection between claims of amnesia and homicide. Fourthly, perpetrators who claimed amnesia had significantly more prior convictions than controls. As well, 
perpetrators claiming amnesia were significantly older than controls, which is in line with the findings of Taylor and Kopelman (1984). Fifthly, as was the case in the Hopwood and Snell (1933) study, only a minority (20\%) of our psychotic patients claimed amnesia for their crime. Thus, we found no specific relationship between psychosis and claims of amnesia. Yet, patients claiming amnesia more often suffered from substance abuse disorder than controls.

Frequencies of homicides and crimes with fatal consequences were not raised in patients claiming amnesia. This is difficult to reconcile with a stress-dissociation view of crime-related amnesia. By this view, one would predict that amnesia is especially likely to occur in patients who were involved in crimes accompanied by extreme stress levels (e.g., "red outs"; Swihart et al., 1999). Our data do not provide evidence for this prediction.

Another interpretation of crime-related amnesila is the state-dependency view. According to this view, the combination of extreme arousal and alcohol or drug intoxication during the crime produces state-dependent encoding and subsequent retrieval problems when the perpetrator finds himself in a different state (e.g.* Swihart et al., 1999; Porter et al. 2001). The current data are consistent with a state-dependency account in as much as they show that substance abuse was more common among patients claiming amnesia than among controls. However, a closer look at the files of substance abuse disordered patients who claimed amnesia made it clear that only a minority of them (17 out of 49) had at the time of the index crime sufficiently high alcohol and/or drug levels to produce amnesia. Thus, patients' references to alcohol and/or drug intake at the time of the crime might. serve as an excuse for their offence and as a way for making their amnesia claim credible (Cima et all. 2002; chapter 3). Another observation that seems to run counter to the state-dependency view is our finding that there was no specific association between psychosis and clains of amnesia. To the extent that psychotic episodes represent extreme states, a state-dependency approach would predict that 
psychotic offenders have great difficulty remembering their offences. Although hints in this direction can be found in the literature (e.g., Taylor \& Kopelman, 1984), our study failed to obtain evidence for such a link.

The most pronounced difference between patients claiming amnesia and controls was that the former were older and had more prior convictions. Thus, it may well be that offenders who are familiar with the penal system have had more opportunities experiencing the advantages of claiming (partial) amnesia for their crime. For example, claiming amnesia may serve as a successful strategy for avoiding painful discussions about crime details during therapy sessions. More generally, if crimerelated amnesia is, indeed, part of a conscious strategy to minimize responsibility, recidivism rates might also be higher for criminals with such claims. Thus, the association between crime-related amnesia and prior convictions found in the current study suggests that it might be worthwhile for future studies to examine more systematically to what extent amnesia serves as a predictor of criminal recidivism.

In sum, then, the current study provides little or no support for the stressdissociation account of crime-related amnesia. Its findings also suggest that the state-dependency view accounts for omly a small minority of the cases. The fact that claims of amnesia are related to length of criminal career indicates that such claims are often the product of a learning process. We should emphasize, though, that our study relied on forensic patients. Therefore, mechanisms behind amnesia claims might be completely different in other populations (e.g., nonpsychiatric offenders). Nevertheless, we feel that the relationship between criminal career and amnesia claims warrants further study. 
CHAPTER 6

*The connection between Trauma and Dissociation: A critical approach

"This chapter was accepted pending revision as: Cima, M., Merckelbach. H., Hollnack, S. knauer. E. Der Zusammenhang zwischen Trauma und Dissoziation: Eine kntische Betrachtung. Fartschritte der Neurologie und Psychiatrie. 


\section{SUMMARY}

Dissaciation is often considered to be a psychological defence mechanism used by victims of traumatizing events (e.g., sexual abuse, physical punishment, or emotional abuse). Evidence for this view comes from studies that found a connection between self-reported traumatic childhood experiences and high levels of dissociation. However, there are some problems with this causal interpretation. The aim of the review presented in is to summarize evidence that casts doubts on the commonly voiced view that the connection between self-reported trauma and dissociation is a simple and rabust one. First, we briefly summarize studies that looked at the link between trauma and dissociation as well as studies that identified factors that may modulate this link. Second, we review studies that explored the psychological correlates of dissociation. Over the past few years, our kmowledge of these correlates has increased considerably. Some of these correlates (e.g., fantasy proneness, suggestibility, and frontal lobe dysfunction) are especially relevant because they may undermine the accuracy of retrospective reports of self-reported trauma. Finally, we conclude that the link between trauma and dissociation is more complex than many clinicians seem to assume. In particular, the possibility that dissociation acts as an antecedent of self-reported trauma warrants serious attention.

\section{INTRODUCTION}

In the Diagnostic and Statistical Manual of Mental Disorders (American Psychiatric Association, 1994) the core feature of dissociation is defined as a disruption in the usually integrated functions of consciousness, memory, identity, and perception of the environment. One widely used measure for assessing dissociative symptoms is the Dissociative Experiences Scale (DES; Bernstein \& Putnam, 1986). The DES is a

waking 600 , Bad, and Ugly: Malingering in forensic psyctiotic ingationts 
28-item self-report measure that asks respondents to what extent they are familiar with dissociative experiences. Typical examples of DES items are: "Some people have the experience of finding themselves in a place and having no idea how they got there. Mark the line to show what percentage of the time this happens to you" and "Some people have the experience of not being sure whether things that they remember happening, really did happen or whether they just dreamed them. Mark the line to show what percentage of the time this happens to youtr. The DES is also widely used in Germany (e.g.. Freyberger, Spitzer, Stieglitz, Kuhn, Magdeburg \& Bernstein-Carlson, 1998). Apart from the fact that the DES is a frequently used research instrument, it is also recommended as a screening tool for disorders that are thought to have a traumatic etiology (e.g.. Dissociative Identity Disorder, Dissociative Amnesia; Ross, 1997).

A recurrent theme in clinical literature is that traumatic experiences cause dissociative symptomatology. For example, Classen, Koopman, and Spiegel (1993) claim that dissociation allows traumatized victims to compartmentalize traumatic perceptions and memories and in this way, victims would be able to detach themselves from the full impact of the trauma. Thus, according to these authors, a straightforward consequence of trauma is the development of dissociative symptoms. Likewise, Putnam, Carlsen, Ross, Anderson, Clark, Torem et al. (1996) argued that elevated levels of dissociation are significantly associated with histories of antecedent trauma. According to the authors mentioned above, traumatic childhood experiences constitute a direct pathway to dissociative symptoms. This opinion is not exclusive to American authors. For example, German psychiatrists often believe that dissociative symptoms have traumatic backgrounds. In the words of Brunner, Resch, Parzer, and Koch (1997): "Wähend beim akuten Streß durch eine situationsspezifische Krise die Dissoziation als Abwehr-bzw. Bewältigungsstil in Erscheinung treten kann, kann sich auf der Symptomebene eine dissociativen Episode entwickeln, die vor allem Amnesien, Depersonalisationen und 
Derealisationen beinhalten kann. Hingegen karn eine chromische Streßbelastung auf dem Hintergrund pră- und posttraunmatischer Einflüsse zur Entstehung einer vulnerablen Persönlichkeit führen, die sïch weiter zu einer chronisch dissoziativen Störung bzw. Identitätsstörung entwickeln kann" (p. 313). Whereas this quotation sketches a prudent version of the causal relationship between trauma and dissociation, Resch, Brunner, and Parzer (1998) are obviously more certain when they argue that "Bei amhaltender Traumatisierung entwickelt sich schließlich ein dissoziatives Muster mit Amnesien, tranceartigen Zuständen, schnellen Wechsel von Stimmungen und Verhaltensweisen, Störungen der affektregulation, Aufmerksamkeits- und Gedächtnisbeeinträchtigungen als ein Abwehr- und Bewältigungsstil" ( $p$. 129).

The current article argues that the alleged trauma-dissociation link is more problematic than is often assumed. Our critical points have mainly to do with the empirical basis of the trauma-dissociation model. Evidence for the traumadissociation model mostly comes from results of cross-sectional studies, in which scores obtained with the DES are correlated with self-report measures of trauma. This article critically addresses the interpretation of these correlations.

\section{THE LINK BETWEEN TRAUMA AND DISSOCIATION}

A first point is that the trauma-dissociation model assumes a robust connection between traumatic experiences and dissociative symptoms. A number of studies have looked at this connection. For example, in their case report, Stibner, Voulkl, and Soyka (1989) concluded that "Aus den gesamten Informationen aus Lebens- und Krankheitsgeschichte der Patientin könnte die Anmahme einer frühen dissoziativen Entwicklung als Überlebensstrategie nach schweren psychosozialen Belastungsfaktoren mit andauerndem MiSbrauch durchaus plausibel erscheinen" (p. 443). The authors concluded that the patient's personality profile (e.g.,: "hohe Intelligenz,

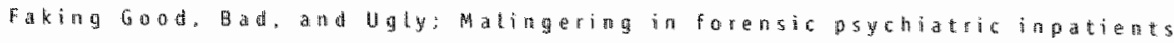


ungewöhnlich differenzierte affektive Schwingungs-fähigkeit, geprägter Lebensstil aber auch unberechenbares und aggressives Verhalten") suggested the presence of a Dissociative Identity Disorder.

Indeed, some studies do find high correlations between self-reported traumatic experiences and dissociative symptoms (for example $r=.72$; Nijman, Dautzenberg. Merckelbach, Jung, Wessel \& a Campo. 1999; $r=.40$; Zlotnick, Shea, Pearlstein, Simpson, Costello \& Begin, 1996). However, correlations of this magnitude have not been uniformly found. A case in point is a study by DiTomasso and Routh (1993) that retied on a large sample of undergraduate students $(N=312)$. Students were asked to complete self-report scales of sexual and physical abuse as well as the DES. The correlation between sexual abuse and the DES was .21, while that between physical abuse and the DES was .18. Due to the large sample size, these correlations attained significance, but their magnitude is, of course, everything but robust.

A second remark has to do with the assumption that the link between trauma and dissociation is a direct and simple one. It is easy to demonstrate that this assumption is doubtful. Consider the study of Nash, Hulsey, Sexton, Harralson, and Lambert (1993). These authors noted in a mixed sample of women with and without psychiatric complaints $(N=105)$ that women with a self-reported history of sexual abuse scored significantly higher on dissociation measures than women without such a history. This findings nicely fits with the idea that trauma is an important antecedent of dissociation. However, these authors also observed that the association between self-reported sexual abuse and dissociation disappears when a measure of family pathology (i.e., respondent's perceptions of their parents) is entered as a covariate in the analyses. This suggests that the connection between trauma and dissociation may be mediated by family pathology and is more complex than has previously been assumed. A similar conclusion can be drawn from a recent community study of Mulder, Beautrais, Joyce, and Fergusson (1998). That study was based on a randomly selected sample of over 1000 individuals. DES as well as data 
about psychiatric symptoms and childhood abuse were obtained and subjected to logistic regression modelling. The authors found that "any causal influence of childhood sexual abuse on dissociation is likely to be indirect and mediated by more general linkage between childhood sexual abuse and risk of mental disorder" (Mulder et al., 1998; p. 809). Thus, both the Nash et al. (1993) and the Mulder et al. (1998) findings call into question the simple trauma-dissociation model that is often advocated in clinical literature.

\section{IN CONSISTENCIES}

A third limitation of the trauma-dissaciation model has to do with its incompetence to explain some inconsistencies. In a study of Yehuda, Elkin, Binder-Brynes, Kahana et al. (1996) concerned with dissociative symptoms of Holocaust survivors, a low (and this time nonsignificant) correlation between exposure to traumatic experiences and dissociation was observed. Accordingly, these authors concluded that "in contrast to current dogma, dissociation in Holocaust survivors is not simply a consequence of having experienced severe trauma" (Yehuda et al., 1996; p. 938). In a study of Merckelbach, Dekkers, and Roefs (2003), which was based upon survivors of Japanese concentration camps during WW II, there was no relationship between Post Traumatic Stress Disorder (PTSD) and dissociative symptoms. These authors conclude: "Our results show that PTSD related symptoms and dissociative experiences do not necessarily overlap with each other".

Another example of a study that is difficult to reconcile with the traumadissociation model is the study of Sanders and Giolas (1991). They had a group of adolescent psychiatric patients $(N=47)$ complete the DES and retrospective selfreport measures of abuse and family atmosphere. In line with the DiTomasso and Routh (1993) study, the correlation between sexual abuse and DES was significant, but modest $(r=.26)$. The correlation between negative family atmosphere and the

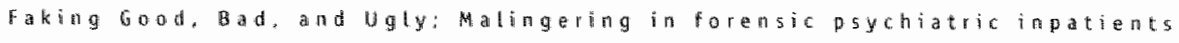


DES was considerably higher $(r=.50)$, a finding that accords well with the Nash et al. (1993) results. An interesting aspect of the Sanders and Giolas (1991) study is that these authors had access to the hospital records of the patients (including therapy notes and information concerning family background and history). An expert blind as to patients' scores on self-reported trauma and DES evaluated these patients" records in terms of indications for trauma. Curiously enough, a negative correlation emerged between sexual abuse ratings based on hospital records and DES scores $(r=-.21, p=.10)$. In other words, the less cues of sexual abuse were evident in the archive material of patients, the more dissociative symptoms were reported by the patients on the DES. Thus, trauma and dissociations are positively related to each other when one looks at the trauma self-reports, but when one looks at the abjective archive material, they are negatively related to one another.

In a German study of Brunner "Parzer, Schuld, and Resch (2000) that relied on a sample of 198 adolescent patients who filled out both the DES and a questionnaire regarding traumatic childhood experiences, the authors found that mild but not serious forms of physical abuse and neglect were related to elevated DES scores. In another German study of Gast, Rodewald, Nickel, and Emrich (2001), 115 psychiatric inpatients were administered the DES as well as a self-report measure of traumatic experiences to investigate the relationship between childhood trauma and dissociation. In this study, 25 out of the 115 patients abtained high DES scores. above the clinical cut-off. Of these 25 patients, 9 patients were discharged before interviewing could be completed and another 2 patients refused to participate. Thus, eventually only 14 patients were interviewed with the Structured Clinical Interview for DSM-IV Dissociative Disorders (SCID-D; Gast, Oswald \& Zundorf, 2000) for follow-up screening. Because one patient with a low DES score showed severe clinical depersonalisation symptoms, the authors decided to assign him/her to the final sample to which they administered the SCID D interview. Interestingly, only 5 of 15 patients met the criteria for a Dissociative Disorder. Of the 115 patients, 97 
(85\%) reported some sort of childhood trauma. Only 18 patients reported not having experienced traumatic events. In the final analysis, only 25 of the 97 patients who reported some sort of trauma also had a DES score above the cut-off. Thus „73 patients with self-reported traumatic experiences, failed to report a serious form of dissociation. What this shows is that the connection between trauma and DES is not that robust and uncomplicated as has often been suggested in clinical literature.

Another interesting aspect of the Gast et al. study (2001) is that those patients who were initially diagmosed with a Dissociative Disorder not otherwise specified as measured with the SCID-D, after one year of therapy showed full Dissociative Identity Disorder. According to McHugh (1993), Dissociative Identity Disorder is promoted by suggestion and maintained by clinical attention. During therapy, patients are actually coached in how to exhibit dissociative identities when therapists are digging for evidence. More specifically, during therapy sessions, the therapists asks such questions as: "With whom am I speaking now?" followed by the question what the name of this other person might be in order to be able to address him in the future. Persons diagnosed with a Dissociative Disorder tend to start to deteriorate as soon as they are diagnosed. It is an unusual mental health therapy that actually makes its client worse (Merskey, 1992). In other words, such practices justify the assumption that a "Dissociative Disorder" is not diagnosed in the traditional sense of the word but caused by the therapist. This hypothesis is called the "iatrogenese creation" of Dissociative Identity Disorder or Multiple Personality Disorder (for further explanation, see Crombag \& Merckelbach, 1997).

\section{CORRELATES OF THE DES AND THEIR IMPLICATIONS}

Several studies hawe been conducted to investigate different correlated of DES factors. One clearly established individual difference correlate of dissociation is fantasy proneness (e.g., Rauschenberg \& Lynn, 1995; Merckelbach, Muris \& Rassin.

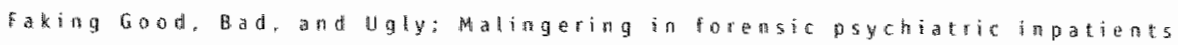


1999; Merckelbach, Rassin \& Muris, 2000d; Merckelbach, Devilly \& Rassin, 2002b). Fantasy proneness refers to a deep and profound involvement in fantasy and imagination (e.g., Lynn \& Rhue, 1988). It should be noted, though, that most fantasy prone individuals are well adjusted persons without overt psychopathology (Lynn \& Rhue, 1988). In samples of undergraduate students, Merckelbach and colleagues (1999; Merckelbach, Muris, Horselenberg \& Stougie, 2000b) found correlations ranging from. 43 to .63 between DES total scores and fantasy proneness as measured with the Creative Experiences Questionnaire (Merckelbach, Horselenberg \& Muris, 2001). Moreover, these authors documented that the significant assaciation between fantasy promeness and DES was not only evident for that particular factor of the DES that is assumed to measure relative benign experiences of absorption and imaginative involvement, but also for those factors that are thought to be powerful predictors of dissociative psychopathology (i.e.. depersonalisation-derealization and activities of dissociated states; Ross, Joshi \& Currie, 1991). The close relationship between dissociation and fantasy proneness was not only found among students samples, but was also evident within clinical samples (e.g., $r=.41$; Pekala, Kumar, Ainstie, Elliott, Mullen, et al., 1999/2000) and adolescent samples $(r=.65$; Muris, Merckelbach \& Peeters, in press). All in all, the connection between fantasy proneness and dissociation is a very close one.

The implication of the intimate link between dissociation and fantasy proneness is straightforward: fantasy proneness may compromise the veridicality of retrospective reports of traumatic events (e.g. Rauschenberg \& Lymn, 1995; Bryant, 1995). More specifically, fantasy proneness could either lead to a tendency to confuse memories that derive from real autobiographical episodes with those that derive from fantasies or it could lead to the adoption of a liberal criterion for reporting past events. The first possibility refers to source monitoring problems of the sort described by Johnson, Hashtroudi, and Lindsay (1993). The second possibility refers to a confabulatory tendency or, in other words, a false positive response bias of the 
type described by Roediger, Wheeler, and Rajaram (1993). To examine these alternatives, Merckelbach and colleagues (2000b; Study 1) exposed undergraduates to a series of slides. Some of the slides were photographs of common objects, while others consisted of werbal descriptions of an object. During a post-experimental recognition task, subjects had to indicate whether or not they had seen particular items and if so, whether the items had been presented as photographs or as verbal descriptions. Thus, two types of errors could occur during the recognition test: source monitoring errors (confusing photographs with werbal descriptions and vice versa) and false positive response errors (identifying an item as part of the previously seen slide series when it was not). Neither DES scores nor fantasy proneness scores were found to be related to source monitoring errors, a null finding that replicates the negative results of Koppenhaver, Kumar, and Pekala (1997) and of Van den Hout. Merckelbach, and Pool (1996). These authors also failed to find a relationship between elevated dissociation and unstable "source monitoring". However, in the Merckelbach et al. (2000b) study, both DES and fantasy proneness were significantly correlated with false positive response errors $(r=.40$ and $r=.26$, respectively). That is, high scores on DES and high scores on the fantasy proneness scale were accompanied by a high frequency of false recognition errors. Interestingly, partialling out the contribution of fantasy proneness attenuated the correlation between DES and false positive responses.

In a second experiment. Merckelbach and colleagues (2000b) sought to determine whether the positive response bias that characterizes high DES individuals also extends to autobiographical memory. In this second study, undergraduate subjects completed a so-called Life Events Inventory (LEI; Garry, Manning, Loftus \& Sherman, 1996), an inventory that consists of a large number of relatively neutral, but highty specific events (e.g., "I went with my school to Disney land"). Subjects indicated how certain they were that the LEI items had happened to them before the age of 10. Both DES and fantasy proneness were associated with a positive answer 
tendency on the LEI ( $r=.39$ and $r=.53$, respectively). Yet, controlling for fantasy proneness reduced the correlation between DES and positive responses on the LEI to practically zero. All in all, these findings suggest that individuals who score high on the DES exhibit a positive response bias that is strongly linked to their heightened levels of fantasy proneness. Two further studies support the connection between fantasy proneness and positive response bias. Firstly. Merckelbach and van de Ven (2001) found that participants who claimed to hear a music song while administered "white noise" exhibited elevated fantasy proneness scores. Secondly, Merckelbach and Smith (2003) showed that there is a significant connection between dissociation, fantasy proneness, and endorsement of atypical, bizarre, and/or nonexisting symptoms (e.g." "Sometimes my mussels go limp for no apparent reason"). Germane to this issue of response bias is also the work of Johnson, Edman, and Danko (1995). These authors had subjects complete a Bad Things Scale that contains items describing mildly aversive events like "I have been short changed in stores" and "I have helped friends and not been helped in return". A positive correlation was found between DES and scores on the Bad Things Scale $(r=.43)$, which, again, suggests that high DES scores are accompanied by a positive response bias.

A second research line that bears relevance to the idea that high levels of dissociation might be conducive to memory or report biases consists of studies that looked at the relationship between suggestibility and DES (Ost, Fellows \& Bull, 1997; Merckelbach, Muris, Wessel \& van Koppen, 1998; Wolfradt \& Meyer, 1998). These studies relied on the Gudjonsson Suggestibility Scale (GSS; Gudjonsson, 1992), which measures subjects" susceptibility to memory or report biases under conditions of post-hoc misinformation and social pressure. Briefly, the GSS consists of a short narrative that is read out to the subject. Next, the subject has to answer a set of questions about the narrative, some of which are misleading and contain misinformation about the narrative.. The tendency to give in to misleading questions 
is termed Yield score and gives a measure for suggestibility. The DES has been found to correlate with GSS scores, notably with the Yieid subscale of the G55. More specifically, correlations between DES and Yield subscale, range from .29 to .53 have been reported Merckelbach et al., 1998; Merckelbach, Muris, Rassin \& Horselenberg, 2000c) a significant link between dissociation and suggestibility was also reported in the older studies by Ost et al. (1997) and Wolfradt and Meyer (1998).

A third research line that should be considered, consist of studies showing that frontal dysfunctions are intimately linked to violent behaviour and dissociative states (e.g.. Evans \& Claycomb, 1999). Some authors have argued that dissociative symptoms are more prevalent in female than in male psychiatric patients (e.g., Ross, 1997; Putnam, 1989). These authors suggest that compared to women with dissociative symptoms, men with dissociative symptoms are more likely to engage in antisocial behaviour and, therefore, are more likely to be found in correctional institutions than in psychiatric treatment facilities. In line with this, Snow, Beckman, and Brack (1996) noted that their sample of male inmates exhibited higher mean scores on the DES than general population samples. Research in this domain is often guided by the more or less implicit assumption that dissociative symptoms in offenders and prison inmates must have a similar etiology as the dissociative symptoms seen in noncriminal psychiatric patients. Thus, it is often believed that in both populations, dissociative symptoms originate from traumatic childhood events (e.g., child sexual abuse). In a study of Cima, Mercketbach, Klein. Schellbach-Matties, and Kremer (2001), 30 criminal psychiatric patients were administered the DES along with the Behavioural Assessment of the Dysexecutive Syndrome (BADS; Wilson, Alderman, Burgess, Emslie \& Evans, 1996), which measures frontal lobe functioning. Briefly, the BADS consists of 6 tasks that all tap functions mediated by the frontal lobe (e.g.. cognitive flexibility, the ability to plan and monitor effective search strategies, reasoning about time durations, ability to plan a route). These authors found heightened levels of dissociations, which support the 
wiew that dissociative symptoms are quite common among male prison inmates (e.g., Ross, 1997). Self-reports of childhood trauma as indexed by the Chitdhood Trauma Questionnaire (CTQ: Bernstein, Fink, Handelsman, Fook, Lovejoy, et al., 1994) were also quite common among the criminal offenders. However, a simple version of the trauma-dissociation model according to which dissociative symptoms directly stem from traumatic childhood experiences (e.g., Snow et al., 1996) was not supported by the data $(r=.07)$. Interestingly, poor frontal functioning as indexed by the BADS was found to be linked to dissociative symptoms $(r=-.39)$. According to Bernstein and Putnam (1986), dissociation is thought to reflect an inability to integrate different psychological functions (e.g. memory, emotion, awareness). In line with the study of Cima et al., (2001), one could argue not only a traumatic background, but also frontal deficits may contribute to such an inability.

In summary, the studies cited in this section are relevant because they all show that dissociation overlaps with traits (e.g. fantasy proneness, suggestibility, and frontal lobe dysfunction) that may undermine the accuracy of retrospective measures of self-reported trauma.

\section{CAUSAL CONNECTION}

This brings us to a fourth remark about the trauma-dissociation link. The bulk of the evidence for the trauma-dissociation model comes from cross-sectional studies. More specifically. these studies obtained both self-reports of traumatic experiences and DES scores in cinical or nonclinical samples. Both types of information are then subjected to correlational computations and the resulting correlation is interpreted as a causal link between antecedent trauma and subsequent dissociation. Pope and Hudson (1995) have argued that such causal interpretations of cross-sectional data are notoriously problematic. However, often it is not possible to follow another strategy (e.g., longitudinal research). One should ask, therefore, how plausible rival 
interpretations of one and the same correlation are. As for the correlation between childhood trauma and dissociation, it seems almost self-evident to argue that childhood trauma is a developmental antecedent of dissociation (e.g., Brunner et al., 1997; Resch et al., 1998; Brunner et al., 2000). A concurrent and at first sight Less plausible interpretation would be that dissociation heavily contributes to a positive endorsement strategy on self-report instruments of childhood trauma. This interpretation becomes more plausible when one keeps in mind that the correlations involve not chilidhood trauma per se, but self-reports of childhood trauma. The accuracy of such self-reports may be compromised by personality features (e.g., fantasy proneness or suggestibility) that overlap with dissociation. The possibility that dissociation through its correlates will encourage self-reported traumatic experiences is a serious one (Tillman, Nash \& Lerner, 1994; Merckelbach \& Muris, 2001). Note that the study of Sanders and Giolas (1991) makes more sense when one considers this possibility. If dissociation can influence self-reports, it is understandable that dissaciation correlates positively with self-reported childhood trauma, but negatively with objective indices of trauma (i.e.. archives).

It would require a large-scale, longitudinal study to determine with a high degree of precision to what extent trauma contributes to dissociative tendencies and to what extent the reverse is true. For practical reasons such studies have not been conducted yet. In the absence of longitudinal research, the second best alternative to shed some light on the causality issue is provided by equation modelling performed on cross-sectional data (e.g., Schumacker \& Lomax, 1996). Basically, this approach combines several statistical techniques (e.g., path analysis) to examine how well an empirically derived correlational matrix fits with a particular causal model. In a recent study by Merckelbach, Rassin, Horselemberg, and Schmidt (2002d), the authors used this technique to test two models about the traumadissociation link. The sample consisted of 109 students who completed the DES and self-report measurements on absent-mindedness, fantasy proneness, and childhood 
trauma. Structural equation modelling was used to test two causal models about the link between self-reported trauma and dissociation. The first model was the widely accepted trauma-dissociation model which holds that trauma precedes dissociation. The second model was a dissociation-trauma model, which assumes that high DES scores go together with fantasy proneness and absent-mindedness and in this way, contribute to a positive endorsement strategy on self-reports of childhood trauma. The analyses showed that both the classical trauma-dissociation model and the concurrent dissociation-trauma model proved to be consistent with the observed data. Although limitations of this study include its cross-sectional design and its heavy reliance on self-reports of a non-climical sample, it makes clear that one should take seriously the possibility that causal directions flow from dissociation to trauma self-reports rather than vice versa.

\section{SELF-REPORT OF TRAUMA}

We certainly do not want to claim that dissociative persons all have high levels of absent-mindedness, fantasy proneness or frontal dysfunctions that elicit wildly inaccurate responses on self-report measures of trauma. The processes implicated by the dissociation-trauma model are probably more complex and subtle. Consider an often in Germany used (Gast et al., 2001) self-report index of childhood trauma (Childhood Trauma Questionnaire; CTQ. Bernstein et al. 1994). It consists of some fairly specific items (e.g. "When I was growing up. I got hit or beateri so badly that it was noticed by someone like a teacher, neighbour, or doctor"), but it also includes broadly formulated items (e.g." "When I was growing up, someone molested $\left.m e^{\prime \prime}\right)$. Both categories of items are scored on a frequency scale that ranges from "never true" to "very often true". According to the authors, the CTO is a valid "screening instrument" to access childhood trauma (Bernstein et al., 1994). By "valid", these authors mean a specific type of validity, namely concurrent validity. 
Bernstein and colleagues (1994) found that high Cra scores correspond with the judgement of therapists about the traumatic history of their patients. Sceptics have emphasized the limitations of this type of validity (e.g., Good, 1995). Their point has been strengthened by studies that compared the CTO to trauma questionnaires relying on a dichotomous response scale. About $25 \%$ of the cases showed inconsistencies between the instruments as to the question whether a participant had a history of sexual abuse or not (e.g., Lipschitz, Bernstein, Winegart \& Southwick, 1999). The CTO more often assumed the presence of abuse, while the dichotomous instruments were more conservative in their judgements.

Schwartz (1999) pointed out that vague items require disambiguation and one way in which respondents accomplish this is by using the information that is provided by quantifiers such as "very often". In his words, "the same expression denotes different frequencies in different domains. Thus, frequently suffering from headaches reflects higher absolute frequencies than frequently suffering from heart attacks" (Schwartz, 1999; p. 99). Perhaps, then, benign traits like fantasy proneness. promote an overinclusive disambiguation of vague trauma items and this might explain why dissociation, through its correlates, contributes to trauma self-reports. Apart from questionnaires, researchers have use other instruments for assessing traumatic youth experiences. For example, Draijer and Langeland (1999) conducted an interview with their patients in which the critical question was: "Nowadays it is clear that many women, but men as well, have had negative sexual experiences in their childhood. Do you know if something like this happened to you? Besides its suggestive nature ("many women"), this question is also vaguely formulated ("something like this"). One can easily imagine that because of their fantasy proneness and/or heightened suggestibility, dissaciative patients would respond with a "yes". 


\section{PSEUDO-MEMORIES}

Is it possible to recover long forgatten memories of childhood abuse under the influence of psychotherapy? And if so, how reliable are such memories? Questions like these have been the focus of an intense debate between clinically oriented authors and experimental psychologists (e.g., Crombag \& Merckelbach, 1997). The controversial issue of so-called recovered memories has been the driving force behind an enormous research activity in the domain of pseudo-memories. Basically, two types of pseudo-memories have been studied. The first type is, what one may call, naturally occurring pseudo-memories. A good example is provided by people who claim that they have detailed memories of abduction by space aliens, a traumatic event that seems extremely unlikely to have occurred. Systematic studies on this type of pseudo-memory have revealed that people with such memories suffer from minor sleep disturbances and frontal dysfunctions, but also thave heightened levels of dissociation and fantasy proneness (e.g., Clancy. McNally, Pitman, Schacter \& Lenzenweger, 2002; Banaji \& Kihlstrom, 1997; Persinger, 1992). Thus, a plausible: interpretation of the origins of such alien abduction memories is that the people who have them attribute their anomalous sleep experiences to external sources and under the influence of fantasy proneness, this takes the form of an elaborated pseudo-memory.

Another naturally occurring pseudo-memory develops when an individual mistakenly interprets a dream as a real event. Surveys (e.g., Rassin, Merckelbach \& Spaan, 2001 ) indicate that between 10 and $25 \%$ of the surveyed persons are familiar with the experience of confusing dream and reality. Again, those who report this type of experience have heightered levels of dissociation and fantasy proneness compared to those rat familiar with this type of experience. A more mundane form of pseudomemories occurs when people develop a memary illusion about an everyday event. Porter and Birt (2001) asked their 306 respondents whether they had ever 
experienced a memory for an entire event which they later discovered had definitely not occurred. About $20 \%$ of the respondents reported such a memory illusion and these people had considerably higher DES scores than those who did not report such memory üllusions.

A second type of pseudo-memories are memory illusions that are elicited by experimental manipulations. Thus, experimental research shows that one can elicit persistent pseudo-memories about autobiographical events in approximately $30 \%$ of the undergraduate participants by presenting to them a fictitious event, while telling them that this event has been provided by their parents (e.g., Hyman \& Billings, 1998; Porter, Birt, Yuille \& Lehman, 2000). Participants are then repeatedly and on several consecutive days encouraged to retrieve memories about the fictitious event. There is now convincing evidence that those participants who eventually come up with pseudo-memories about the false event have higher scores on the DES than those who do not come up with pseudo-memories. A similar conclusions was reached by authors studying the phenomenon of imagination inflation (e.g., Heaps \& Nash, 1999). This phenomenon occurs when participants are asked to imagine an event that they previously classified as unlikely to have accurred before their 10th birthday. (e.g., broke a window with your hand; found a silver ring). When participants are given detailed instructions to imagine the event, they subsequently increase their confidence ratings that the event did actually occur. Thus, the act of imagination can raise subjective confidence that an event happened and this imagination inflation effect is stronger in people with raised DES scores.

To sum up, then, the studies cited in this section leave little doubt that people who report relatively many dissociative symptoms (as indexed by the DES) are susceptible to develop pseudo-memories. This point is especially relevant to those studies that based their trauma-dissociation model on data obtained in patients undergoing psychotherapy (e.g., Chu, Frey, Ganzel \& Matthews, 1999). Plainly, in that situation. 
the joint influence of heightened dissociation and psychotherapy might produce pseudo-memories about childhood trauma.

\section{DISCUSSION}

The idea that traumatic experiences cause dissociative symptomatology is so widely accepted in clinical literature, that some take it as a validated part of psychology and psychiatry. In the currents chapter, we made an attempt to explain why this is problematic. To begin with, a simple trauma-dissociation model assumes a substantial connection between measures of trauma and dissociation, but not all studies have come up with robust correlations between these measures (e.g. DiTomasso \& Routh, 1993). Secondly, the trauma-dissociation model assume that the causal link between antecedent trauma and dissociation is fairly direct, but some studies have found evidence to suggest that a third variable (i...., family pathology) may be involved in the connection between trauma and dissociation (Nash et al., 1993). Moreover, some findings call into question the simple traumadissociation model (e.g., Sanders \& Giolas, 1991; Yehuda et al., 1996). Finally, studies that are cited as evidence for the idea that trauma causes dissociation often relied on the DES, but this measure is intimately related to personality features (e.g., fantasy proneness) that may compromise the accuracy of retrospective selfreports of trauma (Merckelbach et al., 2000b).

We conclude with 4 comments that complement the critical view outlined in this chapter (see also Merckelbach 8 Crombag, 2000). First, some authors (e.g., Ross, 1997) have recommended the DES as a screening instrument for severe dissociative pathology (e.g., Dissociative Identity Disorder). Yet, study of Sandberg and Lynn (1992) demonstrated that only a small minority $(6 \%)$ of individuals scoring in the upper $15 \%$ of the DES meet the criteria for a dissociative disorder. These authors concluded that "the DES, when used with nonclinical samples, is likely to yield a 
large number of false positives for dissociative disorder" (Sandberg \& Lynn, 1992: p. $722)$. On the basis of studies reviewed above, it is easy to see why this is the case: the overlap between the DES and a relatively benign trait such as fantasy proneness is considerable. Aside from its association with fantasy proneness, the DES has been found to be linked to cognitive failures ( $r=.53$; Merckelbach et al., 1999), neuroticism ( $r=66$; Wolfradt \& Meyer, 1998), and trait anxiety ( $r=.75$; Wolfradt \& Meyer, 1998). Thus, it is fair to conclude that the DES taps a wide diversity of traits that da not necessarily possess a pathological quality (e.g., Hacking, 1995; Frankel, 1990; 1996).

A. second point has to do with expert witness testimony. Sometimes expert witnesses argue that high DES scores of the victim provide evidence for the veridicality of sexual abuse charges. Such a line of reasoning is based on a strong version of the trauma-dissociation model. In its strong version, this model holds that heightened levels of dissociation do only and exclusively accur as a result of trauma. In logical terms, a weak implication (i.e., trauma causes dissociation) is translated into a strong implication (i.e., dissociation occurs solely as a result of trauma). This radical version of the trauma-dissociation model is subjected to the same critical points as its weak counterpart. Most importantly, it produces bad expert testimony.

Thirdly, the strong version of the trauma-dissociation model seems to be symptomatic for the dominant position of this model in current psychiatric literature. This is nicely illustrated by cross-sectional designs that include measures of dissociation and retrospective self-reports of childhood trauma. Research in this domain often adopts biased statistical procedures. That is, results of such studies are often subjected to regression analyses in which trauma is entered as the predictor variable and dissociation serves as the criterion (e.g., Draijer \& Langeland, 1999). This type of data analysis makes one blind to the possibility that the causal connection may flow in the opposite direction.

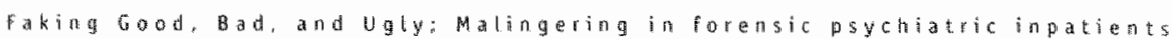


A related point has to do with studies that loosely employ vocabulary that suggests causality and objective measurement, when they do not reach such standards. For example, Lange, De Beurs, Doaln, Lachnit et al., (1999; p. 150) use the term "objective characteristics of abuse" when in fact, they mean participants" retrospective self-reports about the severity, duration, and frequency of the abuse. Likewise, Chu et al., (1999; p. 749) write about "independent corroboration of recovered memories of abuse ${ }^{\prime \prime}$ when referring to participants' reports that they had been able to find some kind of verification for the abuse. Researchers who interpret self-reports of childhood trauma as equivalents of childhood trauma feel very comfortable with the trauma-dissociative model, but easily ignore alternative explanations. The points raised here do not only apply to American, but also German studies. For example, in a study by Resch and colleagues (1998), trauma histories of 251 adolescent patients were assessed by an unpublished, half-structured checklist (Brunner \& Parzer, 1994), which clinicians filled out for their patients. The results thus obtained are misleading, not only because an objective rating of trauma was lacking, but also because the relationship between trauma and dissociation was subjected to a regression analysis in which trauma was entered as the predictor variable and dissociation served as the criterion.

A final remark has to do with alternative measures of dissociation. Over the past few years, new dissociation measures have been developed and published (e.g.* Vanderlinden, Van Dyck, Vandereycken \& Vertommen, 1991; Nijenhuis, Spimhoven. Vanderlinden, Van Dyck \& Van der Hart, 1998). It is difficult to evaluate whether these alternative measures have any additional value over and above the DES until studies have explored their intercorrelations with fantasy proneness, cognitive failures, neuroticism, and anxiety. To the extent that these alternative measures do correlate with these traits, they also suffer from the problematic features that were addressed in the current chapter. We agree with Hacking (1995: p. 112) who argued that, "the whole machinery of the DES has been constructed - quite literally 
constructed - in order to make it appear to be an objective fact that there is a continuum of one and the same kind of experience, the dissaciative experience. Once one dismantles that construction, it is not so clear that there is one kind of experience there to study". 


\section{CHAPTER 7}

\section{*The other side of malingering: Supernormality}

"This chapter has been accepted pending revision: Cima, M., Merckelbach, H., Hollnack, 5. Butt, C., Kremer, K., Knouer, E., Schellbach-Matties, R. \& Muris, P. The ather side of Malingering: Supernormality. The Clinical Neuropsychalogist. 


\section{SUMMARY}

Supernormality refers to the tendency to systematically deny the presence of common symptoms (e.g., intrusive thoughts). The current article describes the psychometric qualities of a 37 -item self-report measure of supernormality (ii.e., Supernormality Scale; SNS). The SNS was administered to nonclinical individuals ( $\mathrm{n}=$ 95), noncriminai psychiatric patients $(n=28)$, nonpsychiatric delinquents $(n=49)$. and a heterogeneous sample of forensic patients $(n=59)$. Within the healthy control sample, some employees were instructed to feign supernormal behaviour. while others were asked to respond honestly to SNS items. Findings indicate that the SNS demonstrates adequate test-retest stability and internal consistency. In the forensic patient sample, elevated SNS scores were significant related to denial of intrusive thoughts in a thought suppression paradigm. However, accuracy parameters for the SNS (i.e., sensitivity and specificity) showed that there is room for improvement. Nevertheless, our findings indicate that the SNS might be a useful research tool for measuring denial of common symptoms.

\section{INTRODUCTION}

Some authors (e.g., Hare, 1991) have suggested that psychopathic individuals are very successful in feigning a mental disorder because of their pathological lying and their use of manipulative behaviour to deceive others. Cleckley (1982) attributed psychopaths' success in deceiving others to their ability to hide traditional signs of falseness behind a facade of social charm. This often cited idea has fuelled the clinical intuition that psychopathic individuals are extremely good at feigning symptoms of mental disorder. Indeed, according to DSM-IV (American Psychiatric Association, 1994), the presence of an antisocial personality disorder is a primary consideration in the assessment of malingering (p. 683). Since pathological lying 
and manipulative behaviour are considered to be core features of psychopathy and are listed among the criteria for a DSM-IV (1994) diagnosis of antisocial personality disorder, an intimate link between psychopathy and malingering has been suggested (e.g., Rogers \& Cruise, 2000).

Although some studies (Gacone, Meloy. Sheppard, Speth \& Roske, 1995) have provided evidence for such link more recent studies failed to find support for the psychopathy-malingering association (e.g., Poythress, Watkins \& Edens, 2001; Cima, Merckelbach, Knauer \& Hollnack, in press b). One problem with the psychopathymalingering link is that it assumes that psychopathic individuals have a tendency to display one particular type of deception. Meanwhile, deception encompasses a broad variety of behaviours ranging from denial of psychiatric disorders to malingering (McCann, 1998). The latter involves exaggeration of symptoms, falsification of information, and/or fabrication of complaints motivated by external incentives (Ensalada, 2000). Whereas malingering is characterized by exaggeration of negative features (i.e., faking bad), denial refers to mimimization of symptoms and exaggeration of positive features (i.e., faking good) in order to manipulate others. Some authors (e.g. Hall \& Poirier, 2001) seern to assume that denial is an equivalent of, or at least closely linked to, social desirability. Social desirability is the tendency to deny minor faults or inadequacies that most persons would readily endorse. That is, social desirability is engagement in positive impression management by expressing social desirable answers according to the common norms and values of society (Edens, Buffington, Tomicic \& Riley, 2001).

It may well be the case that the link between psychopathy and deceptive behaviour is strongly affected by the context in which it occurs. Thus, a defendant who has a lengthy history of antisocial behaviour and who is facing a long prison sentence may be motivated to feign insanity in an attempt to avoid a long and harsh incarceration. Time spent in a mental health institution seems less difficult than being sent to prison, especially when the individual has prior experiences with 
incarceration. However, when this adult already serves his time in a mental institution, he may be motivated by different factors. Exhibiting signs of mental illness may prolong his stay in a mental hospital. Thus, in this context, deception may take the form of minimizing psychopathology.

In this particular context, faking good might imply more than just exhibiting a tendency to endorse "normal" answer options. For example, it is quite common for healthy people to report that they have experienced at least at some occasions intrusions (i.e., "normal obsessions"; Rachman \& de Silva, 1978), rituals (i.e., "normal compulsions": Muris, Merckelbach \& Clavan, 1997), worrisome thoughts (i.e., "normal worry"; Clark \& Claybourn, 1997), and mild persecutory delusions (Fenigstein \& Venable, 1992). Thus, many psychopathological phenomena have their mild counterparts in the general population, which is precisely the basis for dimensionality or continuum approaches to psychopathology (e.g., Claridge, 1997). Persons with a tendency to produce socilal desirable answers would not necessarily deny common, but slightly deviant human experiences. However, the psychopathic patient in a mental institution might try to deny these experiences in an attempt to make a healthy impression on his evaluators. We refer to this type of deception as "supernormality", so as to differentiate it from the type of social desirability that is measured with lie-scales.

In clinical treatment of forensic patients, malingering may provide therapists with a pessimistic view about treatment gains. In contrast, supernormality may lead to an erroneous impression that progress is being made when, in fact, the patient still has psychopathological symptoms. A case in point is a recent Dutch study by Nijman, de Kruyk, and van Nieuwenhuizen (2002) who found that personality disordered criminals showed significantly more treatment progress than did psychotic forensic patients. However, as these authors note, treatment improvement does not necessarily imply diminished risk for recidivism after release. The point is that indices of treatment progress heavily rely on self-reports of patients. Personality 
disordered patients and in particular antisocial or psychopathic patients might have a tendency to endorse non-symptomatic answer options.

There is a broad consensus in the literature that deceptive behaviour is difficult to detect (Ensalada, 2000). A number of authors have called into question clinicians" capacity to detect feigning (Heaton, Smith, Lehman \& Vogt, 1978; Faust, Hart \& Guilmette, 1988; Faust, Hart, Guilmette \& Arkes, 1988: Cima, Merckelbach, Nijman, Knauer \& Hollnack, 2002). Their studies show that dinicians are not very successful in identifying feigning when they have to rely on unstructured interviews and/or traditional tests. This observation served as an important impetus for the development of special tests and questionnaires intended to detect feigning (see, for overviews, Rogers, 1997; Hall \& Poirier, 2001). The majority of these tools focus. on malingering (i.e., fake bad). Although there are instruments for measuring the more benign forms of faking good (e.g., the Social Desirability Scale; Crowne \& Marlow, 1960), the questionnaire to be described below differs from such lie scate questionnaires in that it intends to tap specifically denial of common psychological symptoms. There is, to the best of our knowledge, no instrument for measuring supernormality.

In light of these considerations, we developed a self-report measure of supernormality. Below we address the construction of this Supernormality Scale (SN5). We also report on the basic psychometric properties (e.g., internal consistency, test-retest reliability) of the SNS. In an attempt to evaluate the construct validity of the SNS, we also collected data on how forensic patients attribute blame for their criminal behaviour. We argued that a correlation between SNS scores and a tendency to perceive external rather than internal (i.e., mental) justification for crimes would support the construct validity of the SNS. To further explore the validity of the SNS, we also examined whether SNS scores are related to a tendency to report no or only a few intrusive thoughts during a "white-bear" procedure (e.g., Wegner, Schneider, Carter \& White, 1987). We anticipated that 


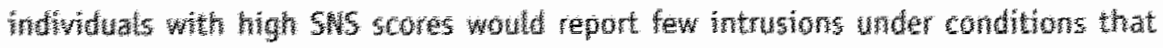

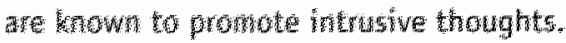

\section{ITEN CONSTUETION}

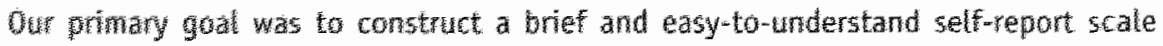

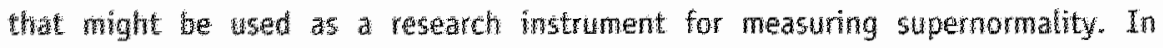

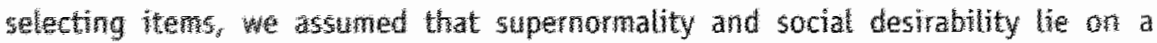
conthusm. Thus we first selected a set of 11 typical social desiability items from whely used insuments such as the Hinnesota Multiphasic Personality Inventory-2 (MMPI-2; Hathaway, Mexney Engel, 2000) and the Social Desirabitity Scale (SOS: Crowne Marowe, 1960), 萑ustrative examples are: "Lately, I have become a more sociable person" and "I atways show consideration for weaker people". We added a set of 28 supernomatity tems which intend to tap tendencies to portray oneself as an individuat who is completely free of anything that is even remotely related to psychopathology. We asked forensic psychiatrists and psychologists to generate a number of such supernomalty items. After eliminating social desirability items and items with overlapping content, 28 supernormality items were retained in the pool. After a second discussion round, 7 supernormality items were omitted because it was not clear whether they tapped supernormality, social desirability or preference for a nomal life.

Typical examples of the remaining 21 supernormality items are "I'am feeling physically and mentally extremely well" and "I have never had any mentall problems" "We added 5 bogus items to obscure the real purpose of the SNS (i.e." "I love to watch TV"; "I like it when the weather is hot"; "I like listening to music"; "I like to sleep in a darkened room"; and "I like to read". Thus, the final SNS version consisted of 37 items with a dichotomous (yes-no) scoring format (see table 7.1). Four items had a reversed scoring format (i.e., items 6, 13, 23, and 28). After

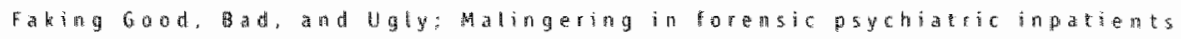


recoding these items, the number of yes-responses is summed to derive a total SNS score (range: 0-32).

Tabie 7.1: S.NS items, percentage of endorsement, corrected item-total correlations, and factor loadings in a mixed sample of healthy participants, (forensic) psychiatric patients, and criminals $(N=231)$
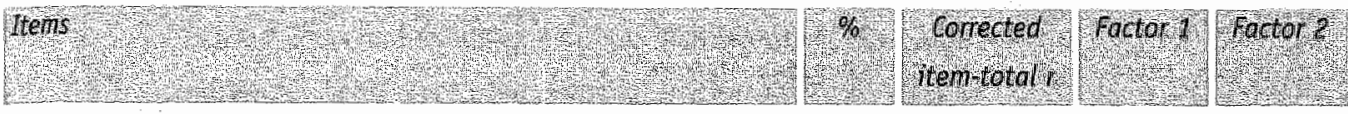

\section{SUPERNORMALITY}

1) I'm feeling physically and mentally extremely well.

$\begin{array}{llll}63 & .49 & .71 & .12 \\ 46 & .48 & .61 & .02 \\ 51 & .30 & .39 & .01 \\ 52 & .36 & .49 & .03 \\ 63 & .41 & .62 & .09\end{array}$

2) I have my problems under full control. .02

3) Without medicine, I'm feeling well ar even better.

5) I have felt well for a long time now.

7] Most people with whom I live today are obviously more mentally ill than I am.

9] My mental state is completely normal.

11] Even without the help of others, I can live my own life very successfully.

12] I do not have problems with negative thoughts, that influence my mind.

13] Sometimes, I feel unhappy without knowing why.

15] I'm never bored.

17) My sexual life is absolutely nomal.

19] I'm mentally doing so well that I can live on my own.

21) If I wanted to I could find a job easily.

23) I still have to work an myself.

24) I have never had any mental problems.

27] I'm my own best therapist. 


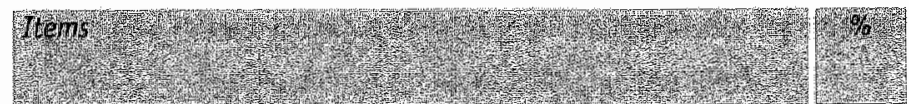

34) I do not have bizarre phanitasies.

37) In fact, I do not need any further help.
55

34

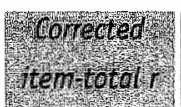

.41

.43

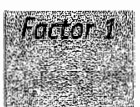

.29

.51

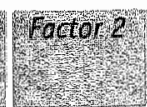

.35

.06

\section{SOCIAL DESIRABILITY}

10) Im convinced that I will never do anything that is forbidden.

16) If I was not in my present situation, I would do very well.

201 Under no circumstances, will I become aggressive again.

22) I try to help everybody who has problems.

26] I will always help people who are in need of something.

29] Even if I were to toke drugs or drink alcohol in the future, I would not do anything which was forbidden.

31] I always show consideration for weaker people.

66

.33

.01

.57

32) I'm convinced that I will never get mentally ill again.

33] Lately, I have become a mare sociable person.

43

35] I constantly try to understand other people.

36] Lately, I have become a more disciplined person.

\section{PARTICIPANTS}

The SNS was administered to 231 participants. There were 5 groups: (i) 45 healthy control participants (14 women), with a mean age of 35 years $(S D=11.7)$; (ii) 28 noncriminal psychiatric control patients ( 13 women), with a mean age of 35 years $(S D=11.7)$; (iii) 49 nonpsychiatric control criminals (only men), with a mean age of 42 years ( $5 D=11.2$ ); (iv) 50 healthy participants ( 30 women), with a mean age of 37 years $(50=11.3)$ who were instructed to "fake good" on the SNS; (v) 59 forensic patient (only men), with a mean age of 39 years $(S D=10.9)$. 
Healthy participants (i.e., groups $i$ and iw) were qualified nurses, therapists or medical doctors who were recruited from the Forensic Institute at Düren, Germany. They volunteered to complete the SNS, but were blind as to the purpose of the study. Noncriminal pisychiatric patients (ii) were recruited from closed or open-wards at Psychiatric Institute Düren, Germany. Most of them (i.e., more than $75 \%$ of the subsample) had a diagnosis of schizophremia or mood disorder. Nonpsychiatric criminals were recruited from a prison in Eusenkirchen, Germany (iii). Forensic patients (v) were recruited from the Forensic Institute at Düren, Germany. All of them had been convicted for severe criminal offences. Forensic and noncriminal patients as well as nonpsychiatric criminals completed the SNS after they had given their informed consent. In addition, forensic patients completed Gudjonsson's Blame Attribution Inventory (GBAI) during a second session.. Healthy participants (i). noncriminal psychiatric patients (ii), and nonpsychiatric criminals (iii) were pooled together to form a mixed control group.

\section{INSTRUMENTS}

To evaluate how forensic patients and nonpsychiatric criminals attribute blame for their offences, we administered the revised version of the Gudjonsson Blame Attribution Inventory (GBAI; Gudjonsson \& Singh, 1989). The 42-item GBAI consists of three subscales: external attribution, which relates to the extent to which the respondent blames others for his crime, mental element attribution, which relates to how much mental control a respondent believes he had at the time of the crime, and guilt attribution, which has to do with feelings of shame and remorse for the criminal act. The GBAI has been administered to psychiatric and prison populations in Britain, Iceland, and Northern Ireland and demonstrates adequate transcultural validity in the sense that all studies reported a robust relationship between severity of offence and certain blame attributions (Gudjonsson \& Petursson, 1991). Cima. Merckelbach, Butt, Kremer et al. (submitted) noted that the German translation of 
the GBAI possesses acceptable test-retest stability (e.g., $r=0.84$, for the mentalelement attribution scale) and good internat consistency (e.g., Cronbach's $\bullet=0.83$ for the mental-element attribution scale). The fact that forensic patients displayed higher scores on the mental-element and guilt-feeling attribution scales than honestly responding control individuals supports the construct validity of the GBAI (cima et al., submitted).

\section{PROCEDURE}

Healthy controls completed the SNS in groups of approximately 25 individuals. They were assigned to either one of 2 groups. One group (i.e., group i) was instructed to respond honestly to the SNS, while the other group (i.e., group iv) was instructed to respond so as to make an extremely healthy impression. Participants in this group were asked to imagine that they were forensic patients who were evaluated for probation. Psychiatric patients (i.e., group ii) and criminals (i.e., group iii) were instructed to respond honestly to the SNS and were tested in groups of approximately 10 persons. Forensic patients (i.e., group $v$ ) were also instructed to respond honestly to the SNS items and were tested individually.

Twelve forensic psychiatric patients from group $v$ (mean age: 39.5 years; $S D=13.8$ ) were invited to participate in a "white-bear" procedure (e.g. Wegner et al., 1987; Rassim, Merckelbach \& Muris, 2000). All of them were incarcerated because of crimes involving child abuse. The white-bear experiment consisted of 4 consecutive phases. During phase 1 (suppression), patients were instructed to "try not to think of a white bear" for a 5 min period. During phase 2 (expression), they were told that "you may think of everything, including white bears". Again, this phase lasted for 5 min. Phase 3 was a 5 min suppression phase in which patients were instructed to avoid thoughts of children. Phase 4 was a 5 min expression phase in which patients were allowed to think of everything, including children. During each phase, patients 
used a pen to mark on a paper every occurrence of the target thought (i.e., white bears or children).

\section{RESULTS}

\section{FACTOR ANALYSIS}

Because SNS scores were reasonably normally distributed (see figure 7.1), factor analysis was conducted on SNS data obtained in the mixed sample of 231 respondents ( $c$. supra). The 5 items that served as distracters were not included in this analysis. Since we assumed that supernormality and social desirability form a continuum, we expected the factors to be related. Hence, a principal component analysis with an oblique rotation was employed. This procedure revealed 9 factors with an eigenvalue $>1.0$. Of these 9 factors only 4 explained $5 \%$ or more of the variance in SNS variance. While this suggests a 4 -factor solution, inspection of the scree plot suggested the predicted 2-factor solution. The eigenvalues of these two factors were 6.2 and 3.1, respectively and together, they explained $29.1 \%$ of the total variance. With this in mind and given the interpretability of the factors, we decided to adopt the 2-factor solution, which is shown in table 7.1. Table 7.1 also presents endorsements rates and corrected item-total (i.e. total SNS scores) correlations. Correlation between the two factors was moderate $(r=.25, p<.01)$. As can be seen, factors reproduced the distinction between social desirability and supernormality. Thus, by and large, supernormality items primarily loaded on factor 1 , whereas social desirability items primarily loaded on factor 2 .

\section{INTERNAL CONSISTENCY}

Internal consistency of the total SNS in the mixed sample of 231 participants was adequate, with Cronbach's alpha being 0.86 . Internal consistencies of the two SNS 
subscales (i.e., supernormality and social desirability) for this sample were 0.85 and 0.78 , respectively.

\section{TEMPORAL STABILITY}

Test-retest stability ( 6 weeks) for the final SNS version was found to be high ( $\mathrm{r}=$ 0.90 ) in a sample of 18 forensic psychiatric patients (mean age: 39.2 years; $S D=$ 10.5), mean SNS scores on the two occasions being $19.6(S D=4.6)$ and $19.1(S D=$ 5.5), respectively.

Figure 7.1 shows the frequency distribution of total SNS scores in the sample $(N=$ 231). Skewness and kurtosis parameters indicated that scores followed a relatively normal distribution ( kewness $=.10 ; \mathrm{SE}=.16$; kurtosis $=-.48 ; \mathrm{SE}=.32$ ). Mean total SNS score of the total sample was $16.18(S D=6.4)$.

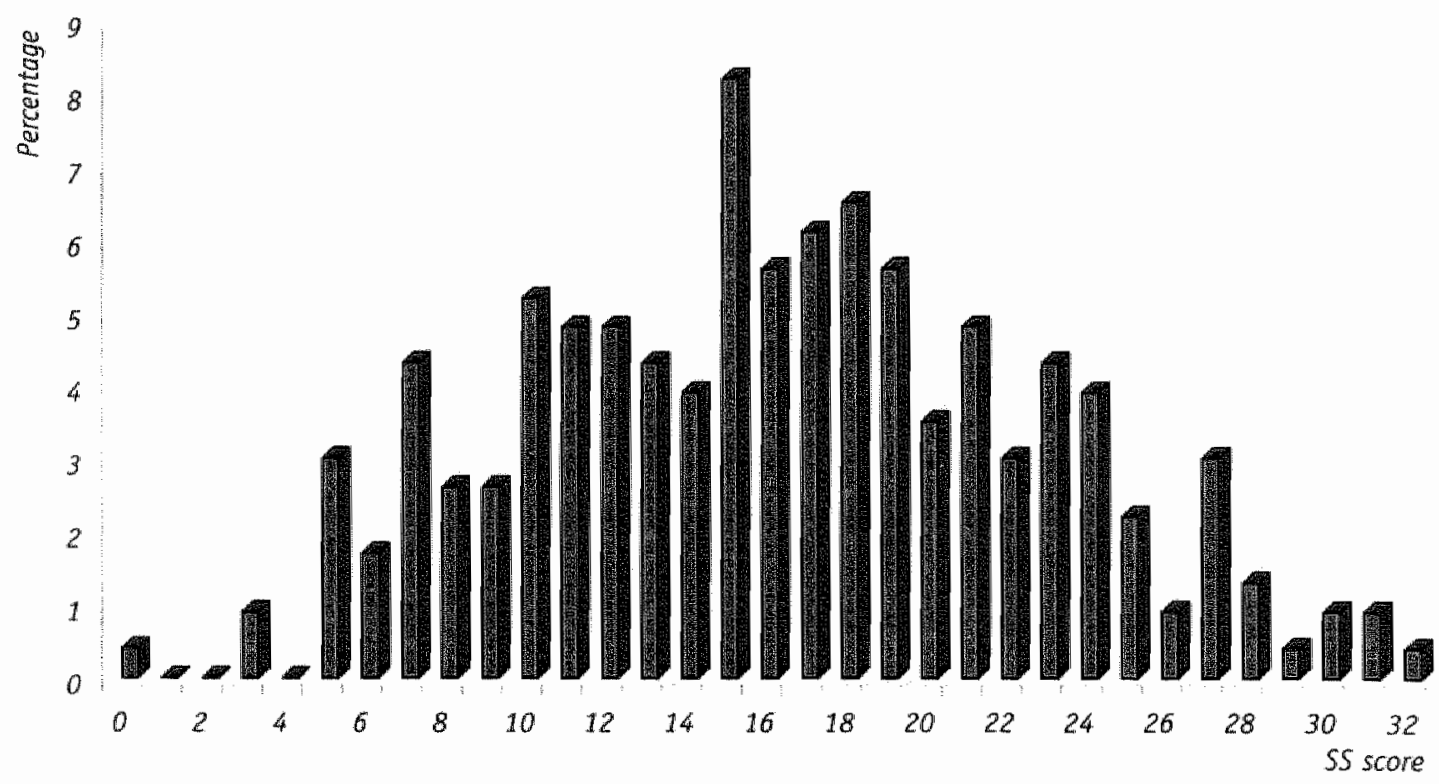

Figure 7.1: Distribution of tatal Supernormality Scale (SNS) scores in 231 participants. 


\section{VALIDITY}

To evaluate the validity of the SNS, we compared SNS scores of 5 groups. The first group ( $n=45$ ) consisted of honestly responding control participants ( $c f$. supra). The second group $(n=28)$ consisted of noncriminal psychiatric patients. The third group $(n=49)$ were the nonpsychiatric control criminals. The fourth group $(n=50)$ consisted of normal controls who were insitructed to feign supernormal behaviour and a fifth group inwolved 59 forensic psychiatric patients.

Table 7.2 shows mean total SNS scores for these groups. A one-way Analysis of Variance (ANOVA) made clear that the groups differed significantly with regard to their mean total SNS scores, even when age and sex were entered as covariates: $F(4$, $224)=11.43, p<.001$. Follow-up t-tests were conducted to evaluate pairwise differences between the groups. Noncriminal psychiatric patients had significantly lower total SNS scores than all other groups [all $t^{\prime} s>3.80$, all $p^{\prime} s<0.001$ ]. In terms of effect size, these differences were large: all Cohen's $d^{\prime} s>0.91$. Forensic patients had significantly higher total SNS scores than honestly responding controls [ $\mathrm{t}(102)$ $=2.61, p<0.01]$ r a difference that was in the medium range $(d=0.50)$. However, forensic patients did not significantly differ from nonpsychiatric criminals and instructed participants [Bonferroni corrected p's > 0.01]. As well, honestly responding controls had significantly lower total SNS scores than instructed normal controls $[t(93)=2.66, p<0.01 ; d=0.54]$. They did not differ from the nonpsychiatric criminal group $[\mathrm{t}(92)<1.0$, NS]. Likewise, instructed normal controls did not differ from nonpsychiatric criminals $[t(97)=2.16, p>0.01]$. 
Table 7.2: Mean totol SNS Scores, SD, and range of total SNS scores of the honestly responding cantrols (n=45), noncriminal psychiatric patients $(n=28$ ), nonpsychiatric criminals $(n=49)$, instructed normals ( $n=50$ ). and forensic patients $(n=59)$.

\begin{tabular}{|c|c|c|c|}
\hline Groups & Mean & $(S D)$ & Range \\
\hline Controls & 15.33 & 4.81 & $5-27$ \\
\hline Psychouric patients & 1018 & 5.29. & 525 \\
\hline Criminals & 15.67 & 6.45 & $3-30$ \\
\hline Instructed & 18,48 & 6.50 & 032 \\
\hline Forensic patients & 18.15 & 5.90 & $5-31$ \\
\hline
\end{tabular}

As another exploration of the construct validity of the SNS, we computed Pearson product-moment correlations between SNS scores and GBAI subscale scores for the subsample of forensic psychiatric patients $(n=59)$. SNS was found to be modestly, but significantly related to external attribution of blame $(r=.24, p<0.05)$. In addition. SNS was negatively associated with mental-element attribution. Again. although this correlation reached significance, it was modest $(r=-.26, p<0.05)$. The correlation between SNS and guilt attribution remained non-significant $(r=$ $0.10)$.

As a third approach to the construct validity of the SNS, we calculated for a subset of forensic psychiatric patients $(n=12)$ correlations between SNS scores and expression of target thoughts. Mean total SNS score for this subsample was 17.91 $(S D=5.82$; range: $7-25)$. During phase 2 , patients exhibited the typical rebound effect in that they reported $33.75(S D=42.56)$ target thoughts about white bears against 0.42 ( $S D=0.90)$ white bear thoughts during phase 1 (i.e., suppression): $F(1,11)=7.28, p<0.05$. During phase 4 , no rebound effect for reports of target thoughts occurred: $\mathbb{F}(1,11)=1.93, p=0.19$. That is, during phase 4 , patients reported a mean number of 3.58 target thoughts about children $(\mathrm{SD}=6.16)$ against 0.92 target thoughts about children ( $S D=1.98$ ) during phase 3 . SNS scores were not 
related to white bear targets during phase $2(r=0.18, p=.58)$, but they were significantly and negatively related to reports of target thoughts about children during phase $4(r=-0.59, p<0.05)$. Apparently, the higher the SNS scores, the lesser the willingness to report target thoughts about children, a finding that supports the validity of the SNS.

\section{DIAGNOSTIC ACCURACY}

To evaluate whetiner the SNS can be used as a screening tool, sensitivity and specificity were determined. They refer to the proportion of individuals with the target behaviour (i.e., supernormality) who test positive (sensitivity) and the proportion of individuals without the target behaviour who accordingly test negative (specificity). To calculate these parameters, we only included honestly responding healthy controls $(n=45)$ and instructed normal controls $(n=50)$ in our analyses. The precise relationship between sensitivity and specificity depends on the selected cut-off point (Hsiao, Bartko \& Potter, 1989). For example, sensitivity can be increased by setting the cut-off at a lower point in the SNS distribution, but the cost of doing so will be a decrease in specificity (i.e., an increase in false positives). Table 7.3 demonstrates how diagnostic accuracy parameters vary with different SNS cut-off points. As can be seen, with the most optimal cut-off point of 15 , sensitivity is 0.74 , but specificity is only 0.42 . In other words, a cut-off of 15 correctly identifies $74 \%$ of the instructed participants (sensitivity) and $42 \%$ of the honestly responding participants (specificity). Thus, corresponding false negative and false positive rates are $26 \%$ and $58 \%$, suggesting that the SNS is not very good as a diagnostic screening instrument. Within the subsample of forensic patients $(n=59)$, $45(76.3 \%)$ patients had a total SNS score exceeding the cut-off of 15 . 
Table 7.3: Sensitivity and specificity rates for different SNS cut-off points $(n=95)$.

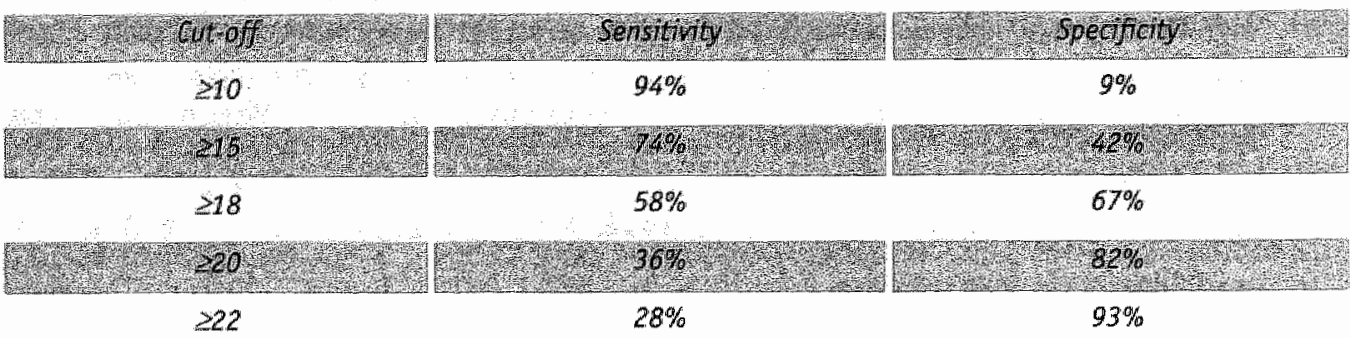

\section{DISCUSSION}

Evaluation of deceptive behaviour within the forensic context often relies on instruments measuring malingering. The SNS was designed to tap the other side of the coin: supernormality. The results presented above indicate that the SNS is a promising research tool for assessing this type of behaviour. To begin with, the SNS displays adequate reliability in terms of internal consistency and test-retest stability. Secondly, the SNS possesses predictive validity in the sense that certain categories of individuals who are known to exhibit supernormal characteristics (i.e. people who were instructed to feign supernormal behaviour) display higher scores on this scale than do control individuals. Thirdly, the significant correlations between SNS and GBAI subscales suggests that supernormality is related to minimalizing responsibility for crime (i.e., externalization of blame) and denial of mental illness. Admittedly, these correlations remained modest and further research is warranted to investigate in more detail the links between supernormality and blame attribution. Finally, instructions to suppress target thoughts resulted in more target thoughts later on (i.e., rebound effect) when targets were white bears, but not when targets were children. The absence of a rebound effect for target thoughts involving children correlated significantly with forensic patients' SNS scores. In sum, 
then, the current results suggest that the SNS possesses a reasonable preliminary construct validity.

Having said this, we also have to acknowledge that the accuracy parameters for the SNS were poor. With the optimal cut-off of 15 , false negative and false positive rates were considerable. While honestly responding controls had significantly lower SNS scores than either controls instructed to fake good or forensic patients, the distribution data indicated that there was a substantial overlap between SNS scores of these three groups. As things stand, it would be premature to use the SNS as a diagnostic screening tool. The primary reason for presenting the current data is to encourage researchers and clinicians to develop practical tools for detecting supernormality. The SNS might serve as a starting point for this endeavor. One way in which the SNS can be improved is by identifying more symptoms that are common in the normal population, but that might be readily denied by forensic patients who want to fake good. Once such symptoms have been identified, one could increase the number of SNS items thereby improving its diagnostic accuracy.

It would also be informative to collect SNS data in forensic patients with psychopathic traits. Recent studies (e.g., Poythress et al., 2001; Cima et al., in press b) noted that there is no close relationship between psychopathic traits and the tendency to fake bad (i.e., malingering). On the other thand, depending on the precise context, there might be a relationship between psychopathy and fake good (i.e., supernormality). Of course, the SNS has to be optimalized before the relationship between supernormality and psychopathic personality characteristics can be investigated. Another research area that might benefit from the SNS is the evaluation of forensic treatment programs. In as far as outcome studies in this domain are not concerned with recidivism rates, they often have to rely on selfreports of forensic patients (e.g., prognostic questionnaire, Part B; Seifert, Jahn, Bolten \& Wirtz, 2002). An optimalized SNS might be used to correct for positively biased reports in this group. 
Pritchard (1997; p. 98) noted that "most of the recent attention to performance distortion has focused on "malingering", that is the false production of signs and symptoms of pathology. Little attention has been given to the minimization of signs and symptoms of genuine deficits. There is currently no available research on the detection of denial or minimization during neuropsychological evaluations". As far as we can see, Pritchard's conclusion does not only apply to neuropsychological, but also to psychiatric evaluations. The construction of the SNS was an attempt to remedy this omission. However, in its current form, it is only a first step in the direction of a diagnostic tool. 


\section{CHAPTER 8}

*It wasn't me: Attribution of blame for criminal acts in psychiatric offenders

"This chapter has been submitted as: Cima, M. Merckelbach, H., Butt, C. Krener. K., Knawer, E. \& Schellbach-Matties, R. It wasn't me: Attribution of blame for criminal acts in psychiatric offenders. 
146 CHAPTER

\section{SUMMARY}

The current chapter addresses the psychometric qualities of the German Version of Gudjonsson's Blame Attribution Inventory (GBAI), a self-report scale for measuring attribution of blame for crime. The GBAI was administered to a heterogeneous sample of forensic and criminal inmates $(n=107)$, noncriminal psychiatric patients $(n=29)$, and healthy control participants $(n=81)$. Within the healthy control sample, some participants $(n=16)$ were instructed to complete the GBAI while imagining that they had committed a violent crime, others $(n=21)$ were instructed to imagine that they had committed a non-violent crime, and still others $(n=44)$ were asked to complete the GBAI in relation to a "serious act" that they had to recall before filling in the questionnaire. Noncriminal psychiatric patients $(n=29)$ also completed the questionnaire in relation to a "serious act". Findings indicate that the German wersion of the Gudjonsson Blame Attribution Inventory possesses acceptable test-retest stability and good internal consistency. Forensic patients had higher mental-element attribution and guilt-feeling attribution scores than honestly responding controls, but forensic patients' GBAI scores were not related to their scores on an instrument measuring malingering tendencies. All in all, our data show that the German version of the GBAI is a valuable tool for measuring attributional styles of offenders.

\section{INTRODUCTION}

Individuals permanently attempt to construct causal explanations for their own behaviour and the behaviour of others and the nature of these attributions may, in turn, influence their future behaviours (Heider, 1958). According to Wortman (1976) and Storms and McCaul (1976), attribution may function to enhance the individual's

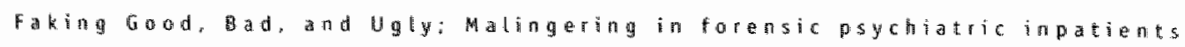


feelings of control over the environment, help to protect self-esteem and a sense of personal worth, and in these ways, attributions may reduce anxiety and guilt.

White attribution has been primarily studied in the domain of social psychology, it also bears strong relevance to forensic issues. For example, attribution of blame for crime is different in offenders who committed violent crimes and those who committed crimes against properties, with the former group more often blaming external factors (e.g., society, other people) than the latter group (e.g., Gudjonsson \& Singh, 1988). Attribution theory, as ariginally developed by Heider (1958), emphasizes that there are two possible ways in which people may interpret the causal antecedents of their behaviour, mamely internal and external attribution. Internal attribution occurs when the cause for the behaviour is attributed to individual qualities. External attributions occur when social and envirommental pressures are believed to be the cause of behaviour. Gudjonsson (1984) argued that when people attribute their own undesirable act to an external force, they reduce their feelings of guilt about the act. Individuals who committed a crime during a state of mental illmess may attribute blame to internal factors. This type of attribution may also have the effect of reducing feelings of responsibility. Whether such internal attributions reduce feelings of responsibility depend on a third type of attribution, which is largely independent of the internal-external dimension and which concerns the perception of self-determination or perceived freedom to act (Snyder, 1976). Thus, this attributional dimension has to do with the extent to which the causes of the behaviour are perceived as being beyond self-control. Gudjonsson and Singh (1988, 1989) developed and subsequently revised the Gudjonsson Blame Attribution Inventory (GBAI), which intends to measure these three dimensions of attribution of blame: external attribution (e.g.. blaming the crime on society); mental-element attribution (e.g.x blaming the crime on mental illness); and guilt-feeling attribution (e.g., feelings of regret concerning the offence). Although the internal- external and guilt-feeling dimensions are 
forensically relevant concepts, relatively few studies have systematically addressed their role in criminal behaviour (Gudjonssom, 1984). Gudjonsson and Singh (1988) examined the relationship between type of offence and attribution of blame in a sample of 239 criminals. Among the different groups of offenders, participants who were incarcerated for sexual affences reported the strongest feelings of remorse as measured with the GBAI, followed by offenders who had committed violent acts against other persons. In addition, violent offenders (e.g., homicide) had the highest mental-element scores on the GBAI, followed by sexual offenders. With regard to external attribution, violent offenders exhibited the highest scores, while sex offenders displayed the lowest scores. In a follow-up study (Gudjonsson \& Petursson, 1991a), these findings were replicated in a sample of 98 Icelandic criminals, suggesting that attributional interpretations tapped by the GBAI show cross-cultural stability.

The way in which offenders attribute blame for their criminal acts may be related to a range of important factors, including their mental state (Gudjonsson, 1984), their personality (Gudjonsson, 1984; Gudjonsson \& Singh, 1989), and the reason why they confess to the police (Gudjonsson \& Petursson, 1991b). For example, excessive guilt about the criminal act may be associated with depressive illness requiring treatment (Gudjonsson \& Petursson, 1991a). Mental-element attribution may be relevant to issues surrounding criminal responsibility, whereas external attribution of blame, at least in extreme cases, may be indicative of a personality disorder (Gudjonsson \& Singh. 1989). Lack of remorse and a strong tendency to externalise blame are often considered to be predictors of reoffending (Horne, 1999; Nedophil, 1992). There are. indeed, good reasons to assume that externatisation of blame is related to impulsivity (Gudjonsson. Petursson, Sigurdardottir \& Skulason, 1991c) and high psychoticism scores on the Eysenk Personality Questionnaire (EPQ; e.g. Fox, De Koning \& Leicht, 2002). Both impulsivity and psychoticism are considered to be closely related to antisocial personality (e.g., Fox et al., 2002).

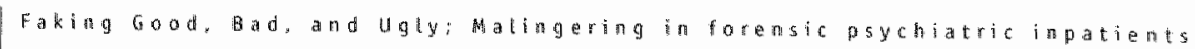


Although it is widely recognized in Germany that the way in which offenders talk about their offences and the extent to which they have feelings of remorse might be important predictors of their criminal career (e.9. Nedopil. 1992), there are no standardized scales for measuring such predictors. Therefore, we translated the GBAI into German. The first goal of the present study was, then, to collect and evaluate psychometric data on this German version of GBAI (Gudjonsson \& Singh, 1989). A subsidiary aim of the current study was to examine whether attribution of responsibility to a mental dysfunction is positively related to a tendency to feign symptoms as measured with the Structured Inventory of Malingered Symptomatology (SIMS; Smith \& Burger, 1997: Cima, Hollnack, Kremer, Knauer, Schellbach-Matties, Klein \& Merckelbach, in press, a; chapter 2). Germane to this issue is the observation that in criminal samples, lie scale scores are generally found to be raised (e.g., Fox et al., 2002; Gudjonsson \& Moore, 2001). With this in mind, we explored how sensitive the GBAI is to malinger tendencies.

\section{METHODS}

\section{PARTICIPANTS}

The GBAI was administered to a mixed sample of 217 participants. There were 6 groups. Table 8.1 provides demographic details of these groups. Healthy participants (i.e., groups 1,4 and $5 ; n=81$ ) were qualified nurses, therapists or medical doctors who were recruited from the Forensic Institute Düren, Germany. They volunteered to complete the GBAI, but were blind as to the purpose of the study. Noncriminal psychiatric patients (i.e., group $2 ; n=29$ ) were recruited from closed or open-wards at Psychiatric Institute Düren, Germany. The majority of them (i.e., more than $75 \%$ of this subsample) had a diagnosis of schizophremia or mood disorder. Nonpsychiatric criminals (i.e., group $3 ; n=48$ ) were recruited from a prison in Eusenkirchen, Germany. Forensic patients (i.e., group $6 ; n=59$ ) were recruted from 
the Forensic Institute Dïren, Germany. Noncriminal patients, nonpsychiatric criminals, and forensic patients completed the GBAI after they had given their informed consent.

\section{INSTRUMENTS}

GBAI. All participants completed the German translation ${ }^{5}$ of the Blame Attribution Inventory (GBAI; Gudjonsson \& Singh, 1989). As a check on the quality of the translation, the scale was back translated and ambiguous formulations were removed. The GBAI consist of 42 items that tap 3 attributional dimensions: external attribution ( 15 items; e.g.. "Other people are to blame for my crimes"), mentalelement attribution ( 9 items; e.g. "I would certainly not have committed the crime(s) I did, if I had been mentally well"), and guilt-feeling attribution (18 items; e.g.. "I feel very ashamed of the crime(s) I committed"). Responses are made on 5point scales ranging from $0=$ "I do not at all agree" to $4=$ "I fully agree". Scores. are summed for the 3 subscales, resulting in an external attribution score, a mentalelement score, and a guilt-feeling score.

5IMS. The subsample of forensic patients $(n=59)$ also completed the German translation of the Structured Inventory of Malingered Symptomatology (SIMS; Smith \& Burger, 1997: Cima et al., in press a). This 75-item self-report questionnaire intends to screen for malingering of psychopathology. It consists of 5 subscales tapping 5 different clusters of symptoms that are sensitive to malingering (i.e., amnesia, psychosis, neurological complaints, low intelligence, and depression). The yes-no items listed by the SIMS refer to bizarre (e.g. "Sometimes, when I'm writing down a phone number, I notice that although I do not want this to happen, the numbers come backwards on the paper"), atypical (e.g. "I have noticed for some time now, that there are days on which I can not remember anything because my

\footnotetext{
${ }^{3} A$ copy of the German version of the GBAI con be obtained from the first author.
}

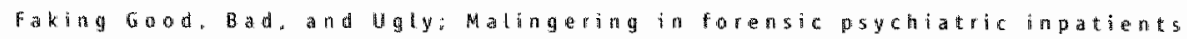


memory has become so bad") or near good (e.g." "A week consist of 6 days") symptoms or responses. The idea behind this test is that patients suffering from a genuine mental disorder will rarely respond positively to these items. In contrast, patients trying to feign mental disorder, will respond positively to these bizarre, atypical, and exaggerated items resulting in a total SIMS score that exceeds the cutoff of 16 (Smith \& Burger, 1997).

\section{PROCEDURE}

Participants were told that data obtained with the GBAI and SIMS would be treated confidentially. Healthy participants completed the GBAI in groups of approximately 20 persons. Noncriminal psychiatric patients and monpsychiatric criminal participants completed the questionnaire in groups of 5 to 10 patients. Forensic patients completed both the GBAI and the SIMS during an individual session.

Participants in the honestly responding control group (group 1) and the psychiatric control group (group 2) were instructed to recall a "serious act" they had committed in the recent past. They were then told to fill out the GBAI in relation to this act. Normal control participants of group 4 and 5 were instructed to imagine that they had committed either a non-violent crime (e.g., theft) or a violent crime (e.g., manslaughter), respectively, and to complete the GBAI with this imagined crime in mind. Participants in the criminal (group 3) and forensic (group 6) subsamples were instructed to respond honestly to GBAI items. 
Table 8.1: Demagrophic dato of the subgroups

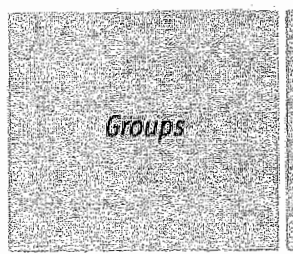

N

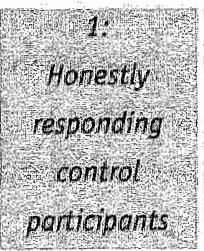

44

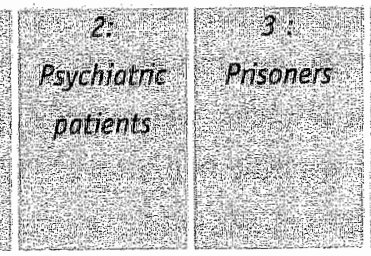

29

48

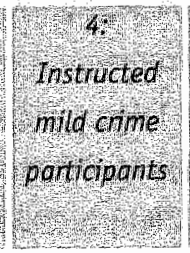

21

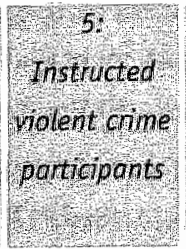

16

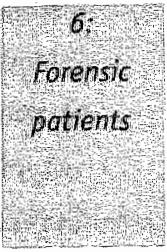

59

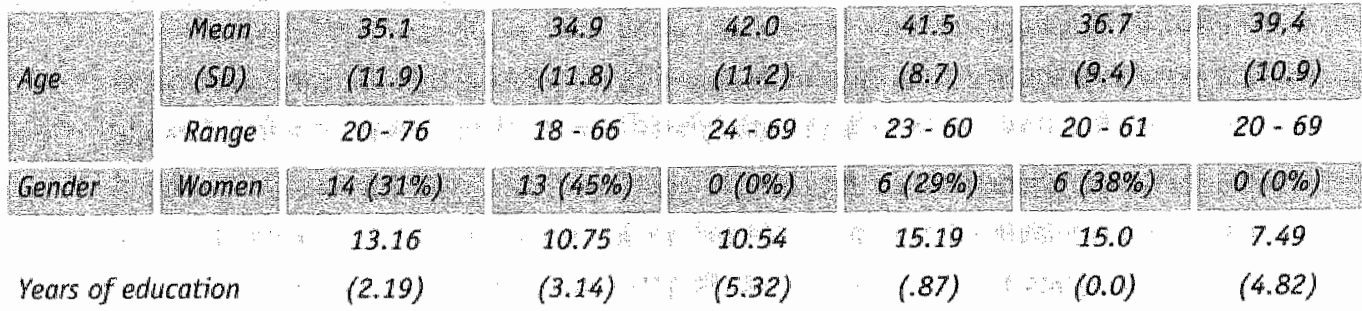

\section{RESULTS}

\section{RELIABILITY}

Test-retest reliability was evaluated by administering the GBAI to a fresh sample of 18 male forensic patients on 2 separate occasions, 6 weeks apart. The patients all had committed serious crimes and were recruited from the Forensic Hospital Düren, Gemany. Mean age of this sample was 39.56 years $(50=10.29)$. Test-retest correlation for the external-attribution factor was .62, means at the two occasions being $4.28(S D=2.93)$ and $3.22(S D=3.19)$, respectively. For the mental-element attribution factor this correllation was .84 , means being $4.56(S D=2.50)$ and 4.72 $(S D=2.24)$. respectively. Finally, for the guilt-feeling attribution factor the correlation was .62, means being $9.56(\mathrm{SD}=4.10)$ and $11.0(\mathrm{SD}=2.54)$, respectively. 
To evaluate internal consistency, we analysed GBAI scores of the total sample $(N=$ 217). Internal consistency (Conbrach's alpha coefficient) was .80 for the externalattribution scale, .83 for the mental-element attribution scale, and .84 for the guiltfeeling attribution scale. These alpha coefficients are similar to those that have been reported in other studies (e.g., Fox et al., 2002). The Pearson correlation between external attribution and mental-element attribution was $-.14(p<.05)$. that between mental-element attribution and guitt-feeling attribution was . $54(p<$ .01 ), while that between external attribution and guilt-feeling attribution was -.35 $(\mathrm{p}<.01)$.

\section{VALIDITY}

To explore the validity of the German version of the GBAI, 3 groups were compared to each other. The first group $(n=121)$ consisted of a mixed sample of honestly responding participants (group 1,2 , and 3 ). The second group $(n=59)$ involved forensic patients (group 6), while the third group $(n=37)$ consisted of hospita! employees (group 4 and 5) who were instructed to imagine that they had committed a certain type of crime. As said before, there were 2 different instructed crime conditions: one in which participants had to imagine they had committed a non. violent crime and one in which they had to imagine that they were incarcerated for a violent crime.

Table 8.2 shows mean scores of honestly responding participants, forensic patients. and instructed participants. One-way Analyses of Variance (ANOVA's) were conducted to evaluate differences between groups with regard to the GBAI subscales. The three groups differed significantly with regard to mental-element attribution scores $\mathbb{E}(2$, $214)=25.99, p<.01]$ and guilt-feeling attribution scores $[F(2,214)=19.26, p<$ .011. For the external-attribution scale, there were no significant group differences $[F(2,214)<1.0]$. Follow-up t-tests were conducted to evaluate pairwise comparisons among the groups. Forensic patients had higher mental-element 
attribution scores than either the honestly responding controls $[t(178)=6.93, \mathrm{p}<$ $.01]$ or the instructed group $[\mathrm{t}(9.4)=4.52, \mathrm{p}<.01]$, while there was no difference in this respect between the instructed and honestly responding control group $[t(156)=$ 1.21, $\mathrm{p}=.23 \mathrm{]}$. As to guilt-feeling attribution scores, forensic patients scored significantly higher than honestly responding controls $[t(178)=5.89, p<.01]$, whereas they did not differ from the instructed group $[t(94)=1.28, p=.20]$. As well, honestly responding contrals had significantly lower guilt-feeling attribution scores than the instructed group $[t(156)=3.53, p<.01]$.

Table 8.2: Mean scores (and SO"s) of honestly responding control participants ( $n=121$ ), forerisic patients $(n=59)$, and instructed participants $(n=37)$ on the 3 GBAI subscales.

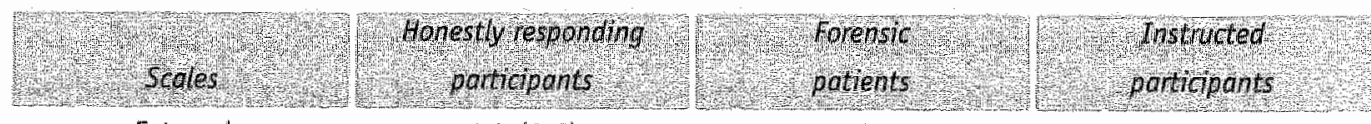
External
$4.2(2.6)$
$4.1(2.9)$
$4.7(3.9)$

attribution

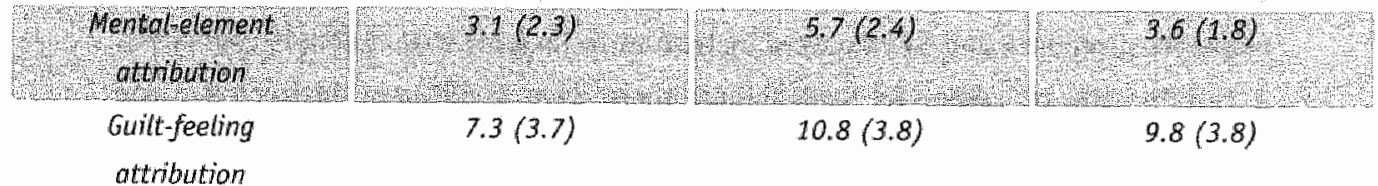

\section{TYPE OF CRIME AND ATTRIBUTION}

As another exploration of the validity of the German GBAI, we performed two further repeated measurement ANOVA's. First, healthy controls (group 1), healthy controls instructed to imagine that they had committed a mild crime (group 4), and those instructed to magine that they had committed a violent crime (group 5) were compared with regard to their GBAI subscale scores via a 3 (group) $\times 3$ (subscales) ANOVA with repeated measures on the last factor. As expected, there was a main effect of group $[F(2,78)=34.21, p<.011$, which made it clear that the groups differed significantly with regard to their GBAI scores. A main effect of subscales 
$[F(2,77)=133.19, p<.01]$ indicated that participants scored significantly higher on some GBAI subscales (e.g., guilt-feeling) than on other GBAI subscales (e.g.* mental-element). A significant interaction $[F(4,154)=4.80, p<.01]$ showed that groups exhibited a differential pattern with regard to the subscales. More specifically, post-hoc tests with Bonferroni adjustment showed that there was no significant difference between the three groups with regard to the externalattribution scores [all $t^{\prime} s<1.50$, all $p^{\prime \prime} s>.01$ ]. With respect to both the mentalelement attribution score as well as the guilt-feeling attribution score, honestly responding controls had significantly lower scores than both instructed groups [all $t^{\prime} s>3.00$, all $\left.p^{\prime} s<.01\right]$. However, the instructed groups did not differ on any of the three subscales [all t's $<1.59$, all p's $>.01$ ].

Next, we inspected the criminal records of participants in groups 3 and 6 . On the basis of this, participants were reassigned to a violent crime group (e.g., murder; $n$ = 49). a non-violent crime group (e.g. fraud; $n=14$ ), and a sexual offence group (e.g., rape; $n=44$ ). Again, a 3 (group) $\times 3$ (subscales) ANOVA with repeated measures was conducted. There only was a main effect of subscales $[F(2,103)=$ 81.10, $p<.01]$, demonstrating that overall, groups had raised scores on certain subscales. More specifically, all groups showed heightened guilt-feeling attribution scores (see figure 8.1). Post-hoc tests with Bonferroni adjustment made it clear that groups differed only with regard to mental-element attribution scores, such that offenders who had committed vialent crimes had higher scores compared to offenders who had committed sexual crimes $[t(91)=2.95, p<.01]$. 

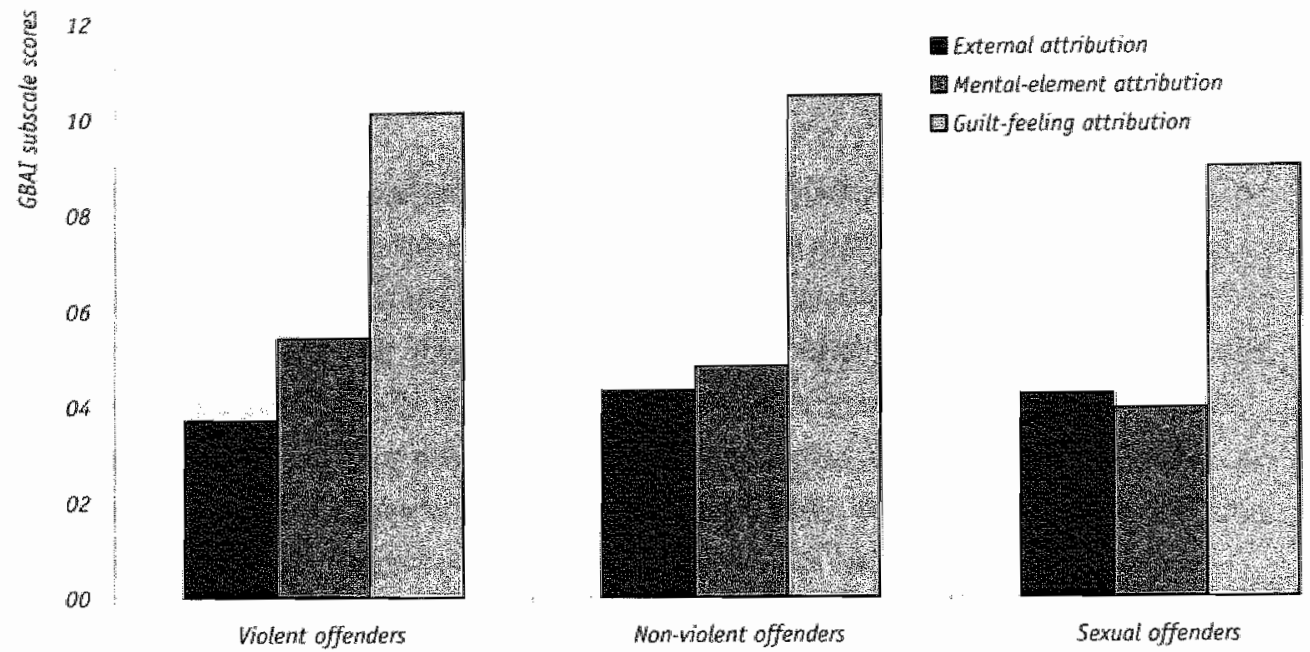

Figure 8.1: GBAI subscale scores of violent offenders $(n=49)$, non-violent offenders $(n=14)$, and serual offenders $(n=44)$.

\section{ATTRIBUTION AND MALINGERING}

The subsample of forensic patients (group 6) consisted of 31 violent offenders, 9 non-violent offenders and 19 sexual offenders. Their mean SIMS scores were 11.0 $(S D=7.10), 15.0(S D=9.3)$, and $17.3(S D=15.5)$, respectively. A one-way ANOVA performed on these data yielded a borderline significant effect $[F(2,56)=2.08, p=$ $.07]$.

For the subsimple of forensic patients, we also computed Pearson product-moment correlations between SIMS and GBAI subscale scores. All correlations remained nonsignificant (all $r^{\prime} s<.22 ;$ all $p^{\prime} s>.30$ ). Similarly, when Pearson correlations were calculated for violent, non-violent, and sexual offenders separately, nome of the associations between GBAI subscale scores and SIMS attained significance (all $r^{t} s<$ $.39 ;$ all $p^{\prime} s>.25$ ). 


\section{DISCUSSION}

The results presented above show that the German version of the GBAI possesses satisfactory psychometric properties. To begin with, overall, test-retest stability of the German GBAI was acceptable with the mental-element attribution scale displaying good stability and the external attribution and guiltafeeling subscales having somewhat lower stability. Compared to the test-retest stability data reported by Gudjonsson (1984), aur test-retest correlations are relatively low. We suspect that this has to do with our sample of forensic patients. Given the fact that they received treatment, it may well be the case that their causal interpretations of the crime they had committed changed over time. The German GBAI also has good internal consistency. In fact, Cronbach alpha's for the subscales were higher than those reported by, for example, Dolan (1995).

Secondly, we obtained evidence for the validity of the GBAI in that forensic patients displayed higher scores on the mental-element and guilt-feeling attribution scales than honestly responding control individuals. Furthermore, in keeping with earlier work (Gudjonsson \& Singh, 1988; Gudjonsson \& Petursson, 1991a), those who had committed a violent crime displayed higher scores on mental-element attribution than those who had committed a sexual crime. The relationship between certain blame attributions and type of crime suggests that the more interpersonal the offence (e.g., violent and sexual crime), the more guilt-feelings (i.e., remorse) offenders claim to experience and/or the more they tend to attribute blame to mental factors. Overall, this pattern is consistent with findings of previous studies (Gudjonsson \& Singh, 1988; Gudjonsson \& Petursson, 1991a).

Thirdly, a further indication for the validity of the GBAI is provided by the nonsignificant correlations between GBAI subscale scores and malingerning tendencies as measured by the SIMS. Apparently, the GBAI is not sensitive to malingering. Interestingly, our finding that sexual offenders showed the most pronounced 
tendency to endorse bizarre and atypical responses on the SIMS replicates the results of a previous study on malingering in forensic patients (Cima et al., in press $a_{*}^{*}$ chapter 2). While the absence of a significant correlation between malingering and GBAI scores underlines the validity of the GBAI, we should add that GBAI scores do correlate with faking good tendencies as measured by the SNS (chapter 7). In other words, the GBAI is not sensitive to fake bad, but it might be sensitive to fake good.

All in all our findings demonstrate that the German version of the GBAI is a valuable tool for measuring attributional styles that offenders use when interpreting the cause of their criminal behaviour. In more general terms, the current study supports the notion that individuals who have committed violent crimes often suffer or claim to suffer from a mental illness (Hodgins, 1998). This is in line with a study by Nijman, Cima, and Merckelbach (submitted) that showed that compared to nonpsychotic patients, psychotic patients more often had committed severe criminal acts. In that study, of the 111 index offences committed by psychotic patients, 33 $(30 \%)$ had had lethal consequences. Thus, it seems that patients with a mental illness are, indeed, more prone to commit violent crimes. The attribution data of the present study suggest that those patients with high mental-element scores also have high guilt-feeling scores, while these scores are not related to malingering. of course, the exact relationship between type of crime, blame attributions, and mental illness is far from clear and further research is necessary to clarify this point. 
CHAPTER 9

General discussion 


\section{INTRODUCTION}

This thesis started with a critical review of climical judgements in the forensic context. It was argued that in this context, such judgements may lead to unreliable diagnoses (Zimmerman \& Mattia, 1999), in the sense that manifestations of malingering (e.g., falsely claiming crime related amnesia) will be readily accepted as. authentic symptoms, while forms of pathology that are difficult to detect (e.g." personality disorders) will remain unnoticed. And, of course, the clinical orientation is not very sensitive to the phenomenon of supernormality. Thus, exclusive reliance on clinical judgement will promote both overestimation of pathology (e.g.* accepting manifestations of malingering) and underestimation of pathology (e.g.. accepting supernormality). Using psychometrically sound instruments (e.g. SIMS, SNS and so on) offers an alternative to dinical judgement. In this chapter, this issue will be further illustrated with case examples.

\section{CASE 1}

Mister $X^{6}$ arrived at a forensic hospital after having been in regular prison for 1 year. According to a psychiatric evaluation, he suffered from a Borderline Personality Disorder. Mister X often talked about death, because he said he couldn"t stand life in prison. The psychiatrist assumed that Mister $X$ had a low intelligence. However, there were no IQ test data available in his personal file, neither were there indications that Mister $X$ had been subjected to a structured psychiatric interview. Mister $X$ was incarcerated because of multiple sadlistic murders. More specifically, he sexually molested several women who were then subsequently killed. According to the psychiatric report, Mister $X$ could not be held fully responsible for his crimes, because he suffered from a personality disorder as well as a mood disorder (i.e.,

\footnotetext{
This wignette is based on a real case.
} 
depression). Also, because of his low intelligence level, it was argued that he did not fully understand the consequences of his actions.

The psychiatric court report in this case was entirely based on clinical experience. None of the conclusions in this report were based on test results. How should this case be interpreted when actuarial methods are used? First, let us consider which tests should have been administered to inform the court about the issue of criminal responsibility.

As mentioned in the first chapter, forensic practitioners should preferable use a test-battery in which different types of tests are combined (e.g., self-reports including items controlling for deception, collateral information, standardized instruments measuring risk factors, structured interviews: de Ruiter, 2000). Thus, Mister $X^{\prime}$ s personality should have been evaluated with a structured interview measuring DSM-IV Axis I and Axis II disorders (e.g., Structured Clinical Interview for DSM-IV personality disorder; Spitzer, Williams, Gibbon \& First, 1992), personality questionnaires controlling for deceptive response patterns (e.g., MMPI-2; Hathaway \& Mckinley, 1983), and an impulsivity test (e.g. BIS-10; Patton, Stanford \& Barratt, 1995). Such an approach would have revealed evidence for the presence of a personality and/or mood disorder, if there is any. As well, to test whether Mister $\chi^{\prime \prime} s$ intelligence was, indeed, below the population mean, one should have administered an I0 test (e.g., HAWIE-R; Wechsler, 1991). Finally, the forensic experts in this case should have asked themselves whether Mister $X$ was malingering his depressives symptoms (e.g., SIMS; Smith \& Burger, 1997; chapter 2) and to what extent he was feeling responsible for his own actions (e.g. GBAI; Gudjonsson \& Singli, 1989; chapter 8 ). Because Mister $X$ had brutally murdered several women, one should also have looked for psychopathic traits using the Psychopathic Checklist-Revised and/ar the Psychopathic Personality Inventory (PCL-R; Hare, 1991; PPI; Lilienfeld \& Andrews, 1996), respectively. Similarly, administering the Supermormality Scale (SNS; Cima, Merckelbach, Hollnack, Butt, Kremer, Schellbach-Matties \& Muris, see 
atso chapter 7) would have been helpful in this case as it is conceivable that Mister $X$ feigned depression, but tried to fake good with regard to other mental problems (e.g., obsessive thinking).

One year later, Mister $x$ returned to regular prison. The reason for this was a new psychiatric evaluation. This new evaluation was based on psychometrically sound tools. The new report concluded that Mister $X$ did not suffer from a mental disorder, a conclusion that was based on a structured interview and MMPI-2 results. Additionally, it turned out that Mister $X$ had faked his depressive symptoms, because his SIMS score was above the cut-off. Neuropsychological tests revealed no signs of brain abnormalities and on an intelligence test, Mister $X$ displayed an intelligence level far above the population mean (I0:130).

So, the idea that Mister $X$ could not be held fully responsible for his actions because of a mental illness and low intelligence was not supported by the tests results. Mister $X$ 's case is just one example of the failure to use well-calibrated instruments and reliance on clinical judgement alone. In this case, clinical experience and actuarial methods lead to different conclusions. Based on clinical judgement, Mister $X$ was send to a forensic hospital in order to receive treatment for a mental disorder he did not suffer from. Based on the results of psychometric testing. Mister $X$ was send back to regular prison, making room for someone who might really benefit from a treatment program.

\section{SUPERNORMALITY, MALINGERING, AND AMNESIA}

In the intraductory chapter, we argued that there are three different perspectives on malingering: malingering as a disease, malingering as a psychopathic trait, and malingering as a strategy (Rogers, 1990a). The first two interpretations assume that malingering is a stable phenomenon, but various case examples demomstrate that it is not. Thus, Augusto Pinochet faked demential problems when British judges had to decide whether he was fit to stand trial, but as soon as he was back in Chili, the old

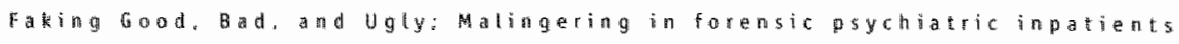


man turned out to be alive and kicking. This example illustrates that malingering is a form of role behaviour that people adopt to attain certain benefits. Accordingly. within the legal domain, offenders may choose to fake bad (malinger) when they think that this reduces their criminal responsibility. During subsequent phases, the same offenders may choose to fake good (supernormality) in order to get out of a high secure forensic hospital.

One might counter that when this adaptional interpretation of malingering is correct one would not expect cases of feigned amnesia in a forensic hospital. After all. feigning amnesia is faking bad rather than faking good. However, there are two points that should be considered here. First, throughout this dissertation we have used the terms feigning and malingering as exchangeable concepts, but things are much more subtle than that. As DeClue (2002) argues, feigning is a prerequisite for malingering, but it is not the same. More specifically, a person who is feigning is distorting or misrepresenting psychological symptoms, regardless of intent. In contrast, malingering occurs in cases in which there is unequivocal evidence of intentionally exaggeration or fabricating psychological symptoms, motivated for external gain (DeClue, 2002). Thus, because of their desire to adopt the patient role, forensic patients may feign, but necessarily malinger amnesia. Second, even in a high secure forensic hospital, it might be beneficial for patients to malinger amnesia. Telling your therapist that you can't remember the crime you committed makes it impossible for you and your therapist to discuss what happens and gives you a much more comfortable time in hospital. Even in this context it is important to test the status of crime-related amnesia. Talking extensively about the crime is an important component of therapy in forensic hospitals. Feigned or malingered amnesia may obstruct such therapy and so it may jeopardize therapeutic progress. Therefore, it is important to use psychometrically sound tools to evaluate claims of amnesia. One such tool is the SIMS. Another tool is Symptom Validity Testing (SVT; chapter 3). The next paragraphs illustrate how SVT may inform forensic experts. 


\section{CASE $2^{\prime}$}

A middle aged man ( 44 years), incarcerated for murdering a 16 year old girl, claimed to have no memory of the crime what so ever. He was diagnosed with a DSM-IV (APA, 1994) Axis II antisocial personatity disorder, but also suffered from epilepsy. The offender claimed that his memory probilems were a result of his epilepsy. However, as his seizures had declined over the years, forensic experts believed that the offender malingered his crime-related amnesia. This clinical judgement was based on decreasing seizure activity and a kind of "feeling" that the offender was a habitual liar. Again, no tests had been administered to support these clinical impressions. Additionally, no tests were performed to evaluate his memory loss in more detail. In this case, we used a Symptom Validity Test (SVT; see also chapter 3) to do just that.

SVT is an objective procedure for detecting malingered amnesia (Frederick. Carter \& Powel, 1995; Denney, 1996; Cercy, Schretlen \& Brandt, 1997). This test was developed as a means to evaluate perceptual and memory complaints. It is based on the binomial distribution which implicates that when an individual with no knowledge is asked questions with only two possible answers of equal probability, test results will fall within a predictably random range and distribution. Knowledge affects the test results by raising them above the random range. Knowledge is also demonstrated when results fall significantly below random chance as the person must have the ability to select the incorrect answer more often than would occur by random chance alone. For conducting this test, it is important to acquire specific information regarding the details of events for which amnesia is claimed. This can be done by intensively searching through the file records. On the basis of the information that is gathered in this way, items and answers options are formulated. In doing so, it is important to find the right balance in the detailedness of the

\footnotetext{
'This vignette is based on a real case.
}

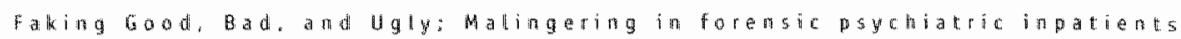


questions. Questions must have enough details, but they should be created in such a manner that it is reasonable to expect that an individual without significant memory loss would likely to remember these details. Using questions that are too detailed lessens the power of the test by increasing the likelihood of a random response pattern when memory loss is feigned. Therefore, it is wise to have the items reviewed by another clinician to help validate the details of the question. The next step is to create a reasonable number of questions. Each question is accompanied by two reasonably plausible answer options, one of which is correct. Before the questionnaire is administered to the offender, one must validate the questions. This can be done by administering the questionnaire to a naive control panel consisting of people who have no knowledge of the crime event. When this control sample is performing at chance level, one may use the items to examine the status of the amnesia claimed by the offender. The offender is instructed that his memory for specific events is tested so as to more fully understand the nature of his memory problem. If the individual says that he has no memory for the information depicted in the item and does not invalidate the item through reason, the item is given with instructions to choose the correct item or simply quess if he cannot remember (Denney, 1996). Correct responses are totalled and subjected to the formula given by Siegel (1956, p. 41). Frederick and colleagues (1995) noted the difficulty of creating alternative answers which are as plausible as the correct answer. It is unlikely that correct and alternative answer options always have a 0.50 probability. The authors suggest that the robustness of the test statistic would minimize such error given an adequate number of questions and the randomness of bias. More specifically, to avoid creating alternative answer options which actually appears

${ }^{3} Z=[(x \pm .5)-N P] /$ APQ: where $Z$ is the test statistic, $x$ is the number of correct responses, $N$ is the number of jtems administered. $P$ is the probability of a correct discrimination given no thue ability (0.50), and $Q$ represents $1-p$. 
more likely than the correct answer, should guarantee that any inappropriate test bias would not occur.

In the case of the murderer claiming to have no memory of the crime-event because of his epilepsy, we developed 15 questions. Of course, the more questions one creates, the more reliable the SVT will be. However, it has been demonstrated that a SVT of 10 items can be reliable and valid as well (Denney, 1996). Examples of questions we developed for this case were 1) What date did the crime take place? (a. Oktober 21*; b. Oktober 5th); 2) Did the offender use a pistol? (a. Yes; b. $\mathrm{No}^{*}$ ); 3) Did the victim die? (a. Yes*; No); 4) What was the name of the victim? (a. Sue; b. Michel $\left.{ }^{*}\right)^{2}$. Before administering this SVT to the offender and in an effort to calibrate the probaloility of answer options used in this case, we administered the same items to sample of 32 adults who had no knowledge of the event in question. Subjects were drawn from the clinical staff of the forensic hospital Düren. Germany and had a mean age of 35.7 years ( $S D=7.7 ; 9$ women). As can be seen in figure 9.1 (left side), mean number of correct answers in this normative sample was 10.31 (SD = .82), with scores ranging from 9 to 12 .

The offender correctly answered 7 of the 15 questions $(z=.516$; one tailed $p=$ 0.30). This suggests that he did not feign his amnesia. Thus, it may well be the case that he suffered from an organic amnesia related to his epilepsy.

\section{CASE $3^{10}$}

In this case, we administered the SVT to a man who was convicted for arson. His age was 33 years and he had a DSM-IV (APA, 1994) diagnoses of pyromania and antisocial personality disorder. The offender was incarcerated for burning down his landlord's house. He claimed that his nnemory loss for the crime event was due to

\footnotetext{
For reason of anomynnity names are invented. * correct answer option.

"This wignette is based on a real case.
} 
excessive alcohol use. Because of his amnesia, the court reasoned that he must have committed his crime unconsciously and unintentionally. It was assumed that an alcohol-blackout could have lead to the development of a limited amnesia, which, in turn, was taken as evidence that he could not be held fully responsible for his crime. However, as has been discussed in chapter 3 , an alcohol-blackout is an organic form of amnesia as a consequence of excessive alcohol use within a very short time span. In other words, consuming 5 glasses of whisky or 20 glasses of beer within 4 hours of time, may lead to an alcohol-blackout (Goodwin, 1995). In the case of the arsonist, there was no indication that he had consumed such an amount of alcohol.
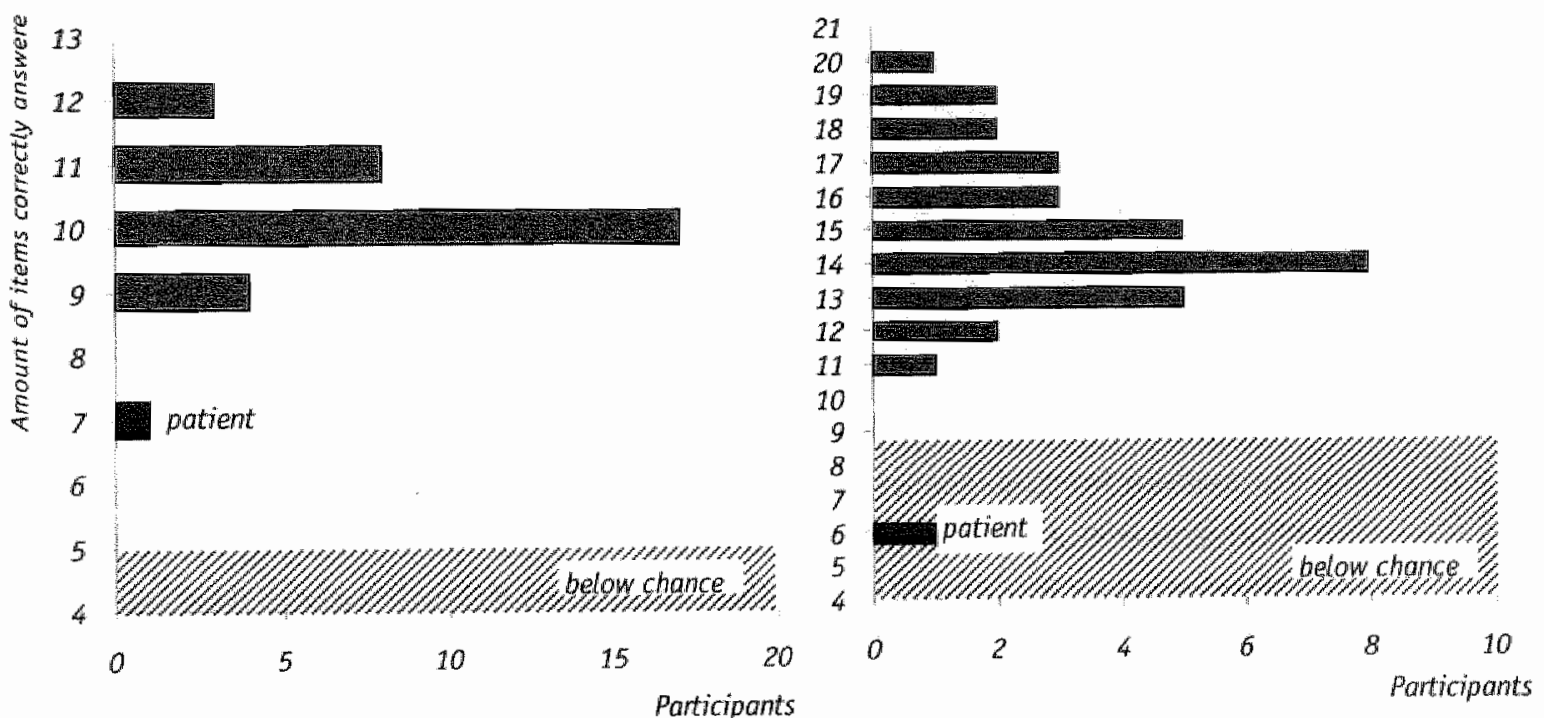

Figure 9.1: Results of the control sample $(n=32)$ on two different SVT's, Left side: SWT results of case 2 (murderer); Right side: SWT results of case 3 (arsonist).

In this case, we were able to develop 25 questions based on file information. Examples were 1) Where was the garage? (a. Beside the house; b. Behind the 
house*; 2) How was the garage set on fire? (a. Using a lighter*; b. Using matches; 3) Did the offender help the accomplice to reach the garage roof? (a. Yes*; b. No).

As with the first case, we administered the 25 items to the same panel of 32 adults who had no knowledge of the event in question. As can be seen in figure 9.1 (right side), mean number of correct responses in this normative sample was 15.0 (5D= 2.21 ), with scores ranging from 11 to 20 .

In this case, the offender correctly answered 6 of 25 questions $(z=-2.40$; ome tailed $p<0.008$ ). Such a performance would only occur less than 8 times out of 1000 by chance alone. Given these SVT results and the absence of any evidence that the man had consumed enormous amounts of alcohol prior to the crime, one has every reason to suspect that the offender did feign his amnesia.

\section{CASE $4^{11}$}

Mister $Z_{*}$ a forensic patient incarcerated in a Dutch high security facility for an explosion that he created and that caused casualities, claims that his crime was an accident. He changes his version of the crime quite regularly. For instance, he has stated that the explosion was caused because of a fallen candle. At other moments he claimed that a burning cigarette caused the explosion. He has also claimed hearing voices that sometimes order him what to do. However, in fact, there was technical evidence that his crime was professionally planned and carried out. More specifically, around the building that exploded, there were traces of bottles filled with gasoline, which had lead to a powerful explosion. In order to examine the credibility of Mister $Z^{*}$ s story we administered some standardized tests.

The following tests were used:

\footnotetext{
"This vignette is based on a real cose.
} 
1. Creative Experience Questionnaire (CEQ)

2. Childhood Trauma Questionnaire (CTO)

3. Dissociative Experience Scale (DES)

4. Structured Inventory of Malingered Symptomatlogy (SIMS)

5. Gudjonsson Blame Attribution Inventory (GBAI)

Briefly, the CEO (Merckelbach, Horselenberg \& Muris, 2001) is a 25-item measure of fantasy proneness that is scaled in the true/false form. The number of yes-answers is summed to yield a total CEQ score. There is solid evidence for the reliability and validity of the CEQ (Merckelbach et al., 2001).

The CTO (Bernstein, Fink, Handelsman, Fook, Lovejoy, Wenzel, Saparetor \& Ruggiero, 1994) is a 25-item self-report instrument that asks about negative treatment by parents and negative home atmosphere. Respondents indicate on a 5 -point scale how frequently particular events or situations occurred during his or her childhood and adolescence. The 25 questions cover five general areas of child abuse and trauma: physical abuse, emotional abuse, sexual abuse, emotional neglect, and physical rueglect.

The DES (Bernstein \& Putnam, 1996) is a self-report instrument containing 28 items that address dissociative experiences such as disturbance in memory, awareness, and cognition. The test-retest and split-half reliability coefficient indicate that the test is reliable, while item-scale score correlation indicate good internal consistency and scale construct validity (Bernstein \& Futnam, 1986).

The SIMS (Smitin \& Burger, 1997; chapter 2) is a 75-item inventory designed to screen for malingering of psychiatric symptoms (e.g., depression and psychosis) and/or cognitive impairments (e.g., low intelligence and memory complaints). The SIMS consists of 75 dichotomous (i.e., true-false) items that can be grouped into five subscales, each subscale containing 15 items. Severat studies found relatively 
high sensitivity and specificity rates (e.g., Smith \& Burger, 1997; Rogers, Hinds \& Sewell, 1996). which suggests that the SIMS is a promising instrument. The GBAI (Gudjonsson \& Singh, 1989; chapter 8) consist of three independent factors: external attribution (i.e., blaming the crime on social circumstances, victims of society), mental element attribution (i.e., blaming responsibility for the crime on mental illness or poor self-control), and guilt-feeling attribution (i.e.r feelings of regret and remorse concerning the offence). Factor analysis of the revised version of the GBAI revealed three independent factors similar to those found for the original inventory (Guidjonsson \& Singh, 1989).

Table 9.1: Test scores of Mister $Z$.

\begin{tabular}{|c|c|c|}
\hline Tests & Popularon mean & Ponent rore \\
\hline CEQ & $7.9(3.8)$ (Merckelbach et al. 2000b) & 24.0 \\
\hline חTa & 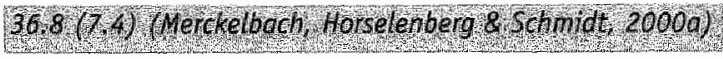 & 61.9 \\
\hline DES & 11.57 (10.63) (Wan IJzendoorn \& Schuengel, 1996) & 66.4 \\
\hline MIS & 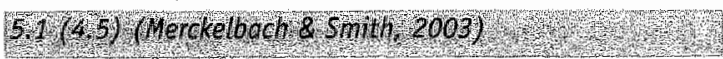 & 40. \\
\hline GBAI-external attribution & $2.8(3.0)$ (Gudjonsson \& Singh 1989 ) & 6 \\
\hline 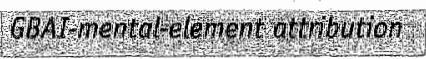 & 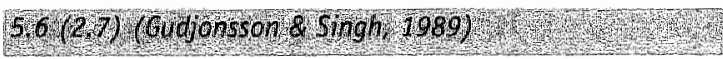 & \\
\hline GBAI-guilt-feeling attribution & 10.1 (4.6) (Gudjonsson \& Singh, 1989) & 12 \\
\hline
\end{tabular}

Results show first, that Mister Z has CEQ scores far above the population norm. This indicates that he is a very successful storyteller. Secondly, his childhood trauma score is well above that of a large sample of young adults $(N=109)$ reported by Merckelbach et al. (2000a). Thirdly, his DES scores are very high compared to a large sample study $(\mathbb{N}=1458)$ of Van Ijzendoorn, and Schuengel (1996), suggesting that he claims a wide variety of dissociative experiences. However, because of the elevated SIMS scores, which brings us to the next point these results should be interpreted with caution. Mister Z's total SIMS score of 40 certainly exceeds the cut- 
off point of 16 (as indication that malingering might be present: Smith \& Burger. 1997).

Finally. Mister $Z$ shows no extreme remarse or guilt-feeling attributions and does not blame society or other people for his crime (i.e. external attribution). However, he attributes his criminal behaviour to mental-elements like having no control over the situation.

All in alt, one has to be careful with regard to the patient"s version of the crime story and his explanation of what guided his behaviour. Reliable test results, especially the CEQ, may shed some lights on the credibility of Mister Z's version of the story. This is especially relevant with regard to crime scenario therapy. In order to be successful, this therapy requires the patient to talk about his crime. When there is a discrepancy between the real scenario of the crime and the way the patient perceives it, it will be difficult to develop a finetuned therapy program. With the case of Mister $Z_{s}$ we have tried to illustrate this point.

\section{DIRECTION FOR FUTURE RESEARCH}

The different concepts we have addressed (e.g., malingening, supernormality, crimerelated amnesia, and feelings of crime responsibility) have only attracted the attention of a handful of researchers. Compared to other topics in psychiatry and clinical psychology, these concepts are clearly under-researched. Below, we briefly address research lines for future studies.

\section{PSYCHOPATHY AND DECEPTION}

In the wards of Porter, Birt, Yuille, and Hervé (2001): "Psychopaths use a high degree of manipulation, deception and malingering relative to other offenders and would be likely to use a false claim of amnesia if any personal gains were

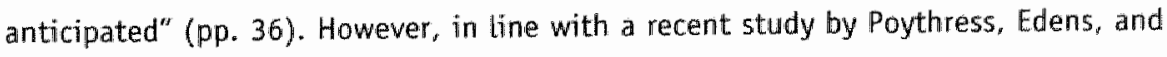


Watkins (2001) who failed to find a link between psychopathic personality features and malingering, we have demonstrated in chapter 4 that there is no clear connection between malingering amnesia and psychopathy. We suggested two alternative explanations for this finding. First, one might argue that in our sample, most instances of claimed amnesia involved genuine memory loss. If true, one would not expect to detect a link between claims of amnesia and psychopathy (see Porter et al., 2001). However, we suspect that this possibility is not very plausible given the raised SIMS scores of those who claimed amnesia. Secondly, it may well be the case that malingered amnesia is different from the more subtle types of manipulative behaviour found among psychopathic individuals. Perhaps, then, malingered amnesia is more typical for those with relatively low IO's, while other and more subtle forms of deception are typical for psychopathic individuals with relatively normal or above normal IO's. Clearly, the precise links between different types of malingering (e.g., feigning amnesia, feigning psychotic features, feigning mood disorders), IQ, and psychopathy is one of the avenues for future studies and warrants systematic investigation.

The concept of supemormality that we discussed at length in chapter 7 appears to be useful. Meanwhile, there is room for improvement: the SNS questionnaire requires further calibration in order to be of sufficient diagnostic quality. In a follow-up study, that is on its way, those patients who feign normal behaviour by denying psychopathology will be identified by performance below rather than above a cut-off score. To this end, we have developed a revised version of the SNS (SNS-R), which contains more items (72). Examples of typuical SNS-R items are: "I always check whether I have closed the door properly"; "I love children"; and "I'm afraid of

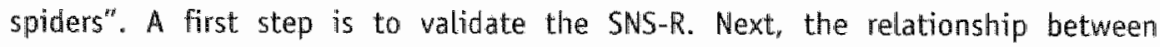
psychopathy and supernormality warrants further study. In chapter 2 , we noted that the prevalence of malingering varies between 18 and $27 \%$ in forensic samples. However, the supernormality study (chapter 7) does suggest that this form of 
deception (i.e., supernormality) might even be more common within the forensic field. The ultimate goal of the whole enterprise is to test whether malingering and supernormality do, indeed, depend on the context in which participants find themselves. More specifically, a thorough examination of both malingering and supernormality within different criminal settings (e.g., forensic hospital, prison, pre-trial arrest) would clarify this point.

In two of our studies (see chapter 4; Cima, Merckelbach, Klein, Schellbach-Matties \& Kremer, 2001), we found clear evidence that poor executive functions are related to claims of crime-related amnesia and self-report of dissociative symptoms. One could argue that poor executive functions precede endorsement of symptoms that are easily faked. Another distinct possibility is that poor executive functions might be malingered as well. The neuropsychological tests that we used in previous studies (Behavioural Assessment of Dysexecutive Syndrome: BADS; Wilson, Alderman, Burgess, Emslie \& Evans, 1996) do not control for response bias. In order to investigate whether poor BADS scores of forensic patients are a genuine indication of poor executive (frontal. Lobe) functioning, one would have to conduct studies in which forensic patients with poor BADS scores and control participants with normal or high BADS scores are compared with regard to anterior electroencephalographic (EEG) activity and tasks tapping executive functions (e.g.. Go-No-Go task: Winconsin-card-sort test: Cognitive Estimation Task).

\section{PSYCHOPATHY AND THE BRAIN}

Psychopathic individuals have been described as persons who use charm, intimidation, and violence to control others and to satisfy their own needs. Underlying their propensity to violate social norms and expectations is a profound lack of empathy, guilt or remorse, affective processes that have long resisted scientific investigation (Intrator, Hare, Stritzke, Brichtswein, Dorfman et. al., 1997). As already mentioned in the first chapter, there are by now several studies that have 
found biological factors that trigger and mediate violence (Raine, 1993). That biological parameters of violence were not addressed in this thesis thas to do with the simple fact that crucial cancepts such as malingering, supernormality, blame attribution, and psychopathy first require clarification and quantification, before one is able to address their neurobiological underpinning.

Meanwhile, the development of effective treatment programs for persistent violence of psychiatric patients would profit from more knowledge of specific neurotransmitter systems involved in aggression. In the words of Brown, Botsis, and van Praag (1994): "decreased serotonin function has consistently been shown to be highly correlated with impulsive aggression" ( $p p .27)$. In line with this, Johrson (1996) noted that the relationship between violence and neurotransmitting systems is carried by serotonin. Both the insanity defence and the defence of automatism depend on disorders of the mind, and psychiatry is now able in many cases to produce evidence that mental disorders are consequent upon disorders of the brain (Fenwick, 1993). However, a common misconception is that biological factors are static and determined at birth. Indeed, social environmental factors do also play a role in how biological predispositions manifest themselves (Altman \& Das, 1964; Coleman \& Riesen, 1968; LeDoux, Romanski \& Xagoris, 1989; LeDoux, Cicchetti, Xagoraris \& Romanski 1990; Sapolsky, Krey \& McEwen, 1984: Sapolsky, Una, Rebert \& Finch, 1990). Of course, well-controlled research is urgently needed to evaluate brain structures and neurotransmitters controlling violence. The promise that this line of research holds is that it may offer forensic tools that do not depend on selfreports. Whether this goal can be reached in the years to come is difficult to say. In any case, it is now too early to offer abnormal brain scans (Kulynych, 1996) or reduced serotonine levels. (Berman \& Coccaro, 1998) of defendants as evidence for insanity or automatism in court. There are even critics who argue that the legal concept of automatic behaviour and its counterpart "free will" can never be backed up by neuroscientific evidence, simply because these legal terms are completely 
outside the neuroscientific realm. In the words of Waldbauer and Gazzaniga (2001* p. 363): "assertions about an individual's responsibility for actions cannot be justified (though they may be supported, in an inferential sense) by results from the neurosciences. To use empirical investigation in this way is a misleading and possibly dangerous misapplication of sciencer.

The presence of certain electroencephalographic (EEG) abnormalities may also provide a neurobiological underpinning to psychopathy, but the available data are somewhat mixed (Millon, Simonsen, Birket-Smith \& Davis, 1998). Numerous studies have focused on the EEG of aggressive psychopathic individuals, which may reveal temporal spike activity (Monroe, 1978). There have been several studies that recorded EEG's of psychopathic individuals in the context of emotional stimuli (e.g., words; Dgloff \& Wong, 1990), altered attentional deployment (Yochelson \& Samenow, 1976; Jutai \& Hare, 1983), baseline attention (Wood, McCarthy Squires Vaughan, Woods \& MCCallum, 1984), and auditory evoked potential (Jutai \& Hare, 1983). However, few studies have looked at the relationship between an inhibition deficit at the behavioural level and executive functioning at the EEG level in psychopathic individuals. More specifically, since psychopathic individuals seem to have difficulties in inhibiting wrongful behaviour and react with indifference to punishment (Cleckley, 1976; Millon, 1981; Hare, 1993), which has been interpreted as a disbalance in the BIS/BAS systems (Gray, 1982), the question of underlying frontal brain mechanisms arises. The behavioural activation or approach system (BAS) activates motor response to reward signals ("conditioned appetitive stimuli") and active avoidance behaviour in response to nonreward or punishment. It is mediated neurally by ascending domaminergic fibers in the rewand or appetitive system of the brain. These fibers project from subcortical structures to the prefrontal cortex. The behavioural inhibition or withdrawal system (BIS) inhibits motor responses to signals of punishment or nonreward. According to Gray's theory (1982), the BIS is mediated by the subcortical septal-hippocampal structure and circuits 
associated with this structure. Children with conduct disorder $(C D)$ seem to have $a$ reward-dominant response style (O'Brien \& Frick, 1996), which suggests that their BIS system is hypoactive. Given the continuum between CD and psychopathy, it would be worthwhile to explore the relationship between BIS functioning and executive functions in psychopathic individuals. In more general terms, future studies should rely on experimental paradigms to measure inhibitory functioning in psychopathic individuals. Thus, for example, it would be interesting to examine whether psychopathic participants (indicated by elevated Psychopathic Personality Inventory scores: PPI; see Lilienfeld \& Andrews, 1996; Jelicic, Merckelbach, Nijman, Timmermans \& Candel, in preparation) will have more difficulties with a stopparadigm (e.g., stopping signal paradigm; e.g., Logan, Schachar, \& Tannock, 1997) than participants with low PPI scores. Subsequently, in order to find support for underlying frontal lobe dysfunction, it would be interesting to subject psychopathic individuals to the stop-paradigm while monitoring their EEG. To the extent that one would find clear indications of inhibitory abnornalities related to frontal areas, this would argue against a malingering interpretation of poor executive performance typically found among many forensic patients.

As was mentioned in the first chapter, hyperactivity, impulsivity, and conduct problems in childhood, predict criminal careers (Babinsky, Hartsough \& Lambert (1999). Furthermore, the forebrain has been related to inhibitory control (Schlag \& Scheibel, 1967). A reward-dominant response style, which is common in CD children, is a manifestation of approach behaviour (Gray, 1982). Gray assumes that the reward-dominant style is not only a concomitant, but also a risk factor for $C D$. According to Kreusi, Rapoport, Hamburger, Hibbs, Potter et al. (1990), children with $C D$ display biological correlates such as lower levels of serotonin, epinephrine, and higher levels of testosteron. Evidence for this view comes from studies that foumd a decreased autonomic reactivity in terms of reduced skin conductance (Schmidt, Solant \& Bridger, 1985), heart rate (Raine, Venables \& Wiliams, 1990), and event- 
related potentials (ERP's; Raine et al, 1990). Reduced autonomic functioning may constitute the physiological basis of the reward-dominant response style found in many children with CD (Gray, 1982). According to O'Brien and Frick (1996) children with this reward-dominance response style form a subgroup of $C D$ children who are said to be cold-hearted, insensitive, unsympathetic, and unresponsive, characteristics which $0^{\prime} B$ rien and Frick (1996) have termed Callous-Unemotional traits. This subgroup shows normal IO's, instrumental aggression, and has no deficits in sociat information processing. O'Brien and Frick (1996) believe that this subgroup of children are at the highest risk for the development of psychopathy. The investigation of childhood precursors of psychopathic traits, deserves closer attention and is an interesting avenue for future research.

There is some evidence that psychopathic patients display certain interesting Laterality effects (Hare \& McPherson, 1984; Jutai \& Hare, 1983; Hare \& Jutai 1988). Indeed, some studies have reported that normal functional brain asymmetries reflect specialization for approach and withdrawal processes in the left and right fromtal regions, respectively. For example, Sobotka, Davidson, and Senulis (1992) found that in healthy participants, reward trials are associated with strong left frontal alpha power suppression than punishment trials. In contrast, during punishment trials, there is stronger night sided frontal atpha power suppression than during reward trials. The findings in this study support the idea that approach-related processes can be differentiated from withdrawal-related processes on the basis of asymmetrical shifts in alpha power in the frontal region. Given the fact that psychopathic individuals do not react fearfully to aversive stimuli (e.g., Cleckley, 1976), one might speculate about increased right frontal alpha power in these individuals when they are confronted with pumishment (Sobotka et al.., 1992). More systematic research into this issue is important because it directly bears relevance to behavioural therapy which is based on punishment and reward systems. 
In a study of Raine, Buchsbaum, Stanley, Lottenberg, Abel, and Stoddard (1994), 22 murderers were compared to a matched control sample. Almost all murderers showed diminished prefrontal activity. However, the only serial killer in the sample displayed heightened prefrontal brain activity. Since the prefrontal cortex is involved in activities like planning, one might speculate that in contrast to impulsive murderers, a more systematic serial killer has to rely on intact prefrontal processes. Consequently, in their follow-up study, Raine, Brennan, and Farrington (1997) divided the group of murderers into a group of affective murderers versus a group of predatory murderers. Compared to a control group, the latter showed excessive subcortical activity in their left brain hemisphere, and no abnormalitities in prefrontal functioning. In contrast, affective murderers displayed a lower prefrontal brain activity and higher right subcortical activity relative to a control group. According to the authors, the increased subcortical activity in the right brain hemisphere of affective murderers is quit important: "while predatory violent offenders have sufficient left prefrontal functioning to modulate such aggressive behaviour in a way to bully and manipulate others to achieved desired goals, affectively violent offenders lack this prefrontal modulatory control over their impulses, resulting in more unbridled, dysregulated, aggressive outbursts (Rain et al., 1997: Raine, Meloy, Bi|arle, Stoddard, LaCasse \& Buchsbaum, 1998).

\section{CORTISOL LEVELS AND IMPULSIVITY}

One measure that responds to certair stressors is the concentration of cortisol in the saliva. This parameter reflects activity in the hypothalamic-pituitary-adrenal (HPA) axis and mirrors the level of free circulating cortisol in blood that can engage brain receptors (Kirschbaum \& Helthammer, 1992). In addition to serotomin, cortisol Levels have been related to aggression (Salvador, Simon, Suay \& Llorens, 1987; Christiansen \& Knussman, 1987). Previous studies reported that low hypothalamicpituitary-adrenal axis activity (i.e., reduced cortisol reactivity) is a correlate of 
severe and persistent aggression in boys and male adolescents (e.g., McBumett, Lahey, Frick, Risch, Loeber et al., 1991; van Goozen. Matthys, Cohen-Kettenis, Gispen- de Wiet, Wiegant \& wan Engeland, 1998; McBurnett, Lahey, Rathouz \& Loeber, 2000).

As chapter 1 pointed out, psychometric measures of impulsivity have been related to a wide range of biological measures (Barratt, 1963, 1972, 1985; Barratt, Pritchard, Faullk \& Brandt, 1987). Overall, studies in this domain suggests that: 1) frontal lobe dysfunctions are related to impulsivity and; 2) serotonin levels are inversely related to impulsivity scores (Brown, Kent, Bryant, Gevedon, Campbell et al., 1989; Kent, Brown, Bryant, Barratt, Felthous \& Rose, 1988). There is also evidence that impulsivity is partially genetically determined (e.g., Pedersen, Plomin, Mclearn \& Friberg, 1988). Serotonin levels are also known to have a genetic basis (Meltzer \& Arora, 1988), which may account for the temperamental predisposition towards impulsivity. Also, high levels of impulsivity have been found to be negatively correlated with plasma cortisol levels (King, Jones, Scheuer, Curtis, Zargone, 1990). Although we did not address this issue in more detail, it would be interesting to investigate the precise roles of saliva cortisol levels and impulsivity in criminal behaviour. Another interesting research line consists of studies showing that high cortisol levels associated with stress have neurotoxic effects on the hippocampus, a brain structure involved in memory (e.g., Bremner, Randall, Scot, Bronen, Seibyl, Southwick, Delaney, McCarthy, Charney \& Innis, 1995; but see Jelicic \& Merckelbach, submitted). Generally, the hypothalamic-pituitary-adrenal axis (HPA-axis) serves to arganize essentially adaptive responses to stress (O'Brien, 1997). Thus, it would be interesting to examine whether a history of stressful events (e.g., traumatic childhood experiences) might infuence HPA axis functioning such that habitually reduced cortisol levels develop. This, in turm, could lead to low fear and unresponsiveness to punishment. Plainly, the precise causal connections between trauma, cortisol, dissociation, amnesia, and violence are an interesting field to 
study in more detail. As well, it would be interesting to examine whether a disregulation in HPA axis at birth might form a risk factor in the development of antisocial behaviour.

\section{FINAL REMARKS}

The discussion above makes clear that in the domain of "Faking Good, Bad, and Ugly", the issues of criminal responsibility and brain function have to be investigated in more detail. Obviousty, clinical judgement in the forensic domain too often lacks validity and seldomly makes use of psychometrically sound instruments. In this thesis, several tests and their psychometric qualities have been described in an attempt to remedy this serious shortcoming. However, given the resistant and substantial ignorance in this field, this thesis is only a modest starting point for future research. Especially questions regarding the neuropsychology of criminal behaviour (e.g., executive functions and psychopathy: frontal brain activity and malingering) should be further explored.

Furthermore, clinical judgements about criminal responsibility have been shown to be strongly related to clinicians' perceptions of defendant's ability to distinguish right from wrong (Durat, Jabotinsky-Rubin \& Ginath, 1993). In a study of Heinik. Kimlii, and Hes (1994), it was reported that personality disordered defendants were Judged as being more responsible for their criminal behaviour, psychotics were judged as being less responsible, while individuals diagnosed with dementia fell somewhere in between. Most law systems dictate that mentally itl offenders should not be held responsible for their crime. However, what exactly constitutes a severe mental disorder? A large scale study compared offenders diagnosed with a personality disorder to offenders with other diagnoses (Kullgren, Grann \& Holmberg, 1996). The researchers found that $49 \%$ of all offenders were deemed by clinicians to meet the criteria for severe mental disorder, compared to only $10 \%$ among the

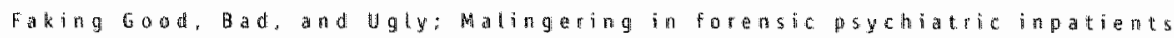


personality disordered offenders. Apparently, a disorder per se is not viewed as a severe mental illness undermining criminal responsibility. A potential drawback of this type of clinical judgement, is that the type of crime may influence the diagnosis. More specifically, individuals who are charged with serious offences against other persons (e.g., murderer, sexual offences) are less likely to be found severely mentally disordered (Kullgren et al., 1996) and, instead, are often judged to suffer from a personality disorder of the cluster B (APA, 1994) type.

To conclude, there are cases in which a crime will depend an a brain malfunction of which the person is not aware or a brain malfunction of which he/she is aware, but cannot control its behavioural consequences (Fenwick, 1993). As knowledge of brain functioning increases and imaging facilities become more available, the exact relationship between biological factors, mental illness, and violence will be better understood. For now, we may state that the issue of faking bad, good or ugly should be raised in each forensic case and that it should be addressed with help of psychometrically sound instruments. Valid tests should guide forensic practitioners in judgements and conclusions. 


\section{SUMMARY}

In the first chapter, we briefly reviewed several key concepts (e.g.. malingering. psychopathy, supernormality) on which the other chapters were based. We pointed out that despite the availability of valid tests, they are rarely used by professionals. Instead, psycholagists and psychiatrists often base their judgement on clinical experience alone (Borum \& Grisso, 1995). However, research literature clearly indicates that prediction based on clinical judgement leads to less precise results. compared to prediction based on measurement of factors that are known to be related to criminal behaviour (Lidz, Mulvey \& Gardner, 1993).

Using several case examples, the importance of valid tests in forensic psychiatry was illustrated in more detail in chapter 9. Since deception is common within the forensic settings, one should be prepared that self-reports might be unreliable, unless one controls for these manipulative behaviours. In line with Rogers, et al. (1994). we found that malingering within forensic patients is not uncommon. More specifically, the study reported in chapter 2 shows that 17 out of 62 patients had elevated malingering scores as measured with the German version of the SIMS. The results indicated that endorsement of bizarre, atypical and strange symptoms was mostly present among sexual offenders who were also diagnosed with an antisocial personality disorder. Furthermore, this study showed that the German version of the SIMS is a practical and reliable instrument to screen for malingering tendencies.

In the literature, all kinds of taxonomies have been proposed to distinguish between different types of amnesia (e.g.. Schacter, 1986; Loewenstein, 1991; Kopelman, 1995; Kihlstrom \& Schacter, 1995). Most taxonomies agree that at the very least, three types should be considered: dissociative amnesia (formerly termed psychogenic or functional amnesia), organic amnesia, and feigned amnesia ("malingered amnesia"). Organic ammesia is always caused by a neurological defect. This defect may be structural (e.g., epilepsy, brain trauma), but. it may also be 
momentarily such as in the case of alcohol-or drug intoxication. Kopelman (1995) assumes that memory loss in arganic amnesia has to do with storage-problems rather than retrieval-problems: due to an epileptic seizure, brain damage or intoxication, offenders would not be able to store their memories in the first place, which would eventually lead to a total "blackout" for their crime. Dissociative amnesia is thought to originate from extreme emotions that accompany such behaviour. The idea behind this is that extreme levels of arousal during crime may hamper memory retrieval at a later point in time. Thus, a failure in so called retrieval processes, would underlie dissociative amnesia. Finally, amnesia might be malingered in an attempt to obstruct police investigation and or to avoid criminal responsibility. As DeClue (2002) angues, feigning is a prerequisite for malingering. but it is not the same. More specifically. a person who is feigning is distorting or misrepresenting psychological symptoms, regardless of intent. In contrast. malingering occurs in cases in which there is unequivocal evidence of intentionally exaggeration or fabricating psychological symptoms, motivated for external gain. Thus, because of their desire to adopt the patient role, forensic patients may feign, but one has to consider the possibility of malingering in crime-related amnesia claims. To be able to evaluate the status of such amnesia claims, several tests have been developed. In the last chapter, we demonstrated how certain tests (e.g.. Symptom Validity Test) may contribute to clarify the status of crime-related amnesia.

In line with earlier research (e.g., Kopelman, 1995), the study described in chapter 4 demonstrated that amnesia occurs in $27 \%$ of the cases. Those offenders who claimed amnesia for their crime displayed heightened frequencies of antisocial personality disorder symptoms, accompanied by low intelligence, frontal lobe dysfunction, and higher scores on a malingering device. Although the prevalence of an antisocial personality disonder within this group was raised, there was no relationship between psychopathy and malingering crime-related ammesia. We 
suspect that malingered amnesia is more typical for those with relatively low IO's, while other and more subtle forms of deception are typical for psychopathic individuals with relatively normal or above normal IO"s. The finding in this study that patients claiming amnesia exhibited more evidence of executive dysfunctions and more frequently scored above the cut-off of a malingering scale (SIMS) than controls, is reminiscent of a previous study (Cima, Merckelbach, Klein, SchellbachMatties \& Kremer, 2001). which showed that poor executive functions occur with high self-reports of dissociative symptomatology.

Dissociation is often considered a psychological defence mechanism used by victirus of stressful events such as sexual abuse, physical punishment, or emotional abuse. In line with this, amnesia is commonly seen as a dissociative symptom. In chapter 5 a large sample of forensic inpatients was divided into those who claimed amnesia (about one fourth) and those who did not. The two groups were then compared on a number of variables in order to determine which of the three mechanisms adwanced to explain amnesia would be most plausible: stress-dissociation, state-dependency in relation to alcohol or psychosis, or malingering. A learning process in line with the malingering hypothesis was found to fitt the data best.

The trauma-dissociation model was discussed in chapter 6. Briefly, this model assumes that traumatic childhood experiences constitute a direct pathway to dissociative symptoms (Classen, Koopman \& Spiegel, 1993; Putnam, Carlsen, Ross, Anderson, Clark, Torem et al., 1996). That this connection is not a direct and robust: as is often assumes in the literature, was explored in chapter 6.

The hypothesis that psychopathic persomality disordered offenders may not only 'fake bad' to be admitted to a mental hospital as is often assumed in the literature (e.g., Clark, 1997; Edens, Buffington \& Tomicic, 2000), but instead, might also Take good or deny all mental disorders (including symptoms found in the normal population such as intrusive thoughts) in order to facilitate early release from such mental institutions, was a motive for developing a new scale introduced in chapter 
7. This pilot questionnaire, aimed to measure 'supernormality', was administered to a large number of participants $(n=231)$ across a variety of groups (i..e., nonclinical individuals, nonpsychiatric delinquents, noncriminal psychiatric patients, and forensic patients). The number of participants in each group was between 29 and 96. The accuracy parameters in terms of sensitivity and specificity were relatively poor. This poor discriminatory ability implies that the questionmaire needs to be revised to improve its positive predictive power and negative predictive power. Furthermore, given the hypothesis that personality disorder, and psychopathy in particular, is related to supernormality, it is especially important to investigate the scores of different patient groups on a revised version.

Studying the relationship between certain blame attributions (e.g., mental-element, external, guilt-feeling attribution) and different crime graups, is relevant to risk assessment. It is known that violent offenders attribute blame for crime more often to mental-element attribution than sexual offenders who committed non-violent crimes. However, as reported in chapter 8 , this was not found to be related to a tendency of matingering major mental illness. This has led to the suggestion that mentally ill persons may, indeed, be more prone to commit violent crimes. This is in line with research of Hodgin, Mednick, Brennan, Schulsinger, and Engberg (1996) who reported an association between psychiatric hospitalization and criminal conviction. The findings also concur with results that patients discharged from psychiatric wards are more likely than other persons living in the same community to commit crimes (Link, Andrews \& Cullen, 1992; Steadman, Monahan, Robbins, Applebaum, Grisso, Klassen, Mulvey \& Roth, 1993) and with findings from US prison inmates (Collins \& Schlenger, 1983; Daniel, Robins, Reid \& Wilfley, 1988; Hyde \& Seiter, 1987; Neighbors, Williams, Gunnings, Lipscomb, Broman \& Lepkowski, 1987) and Canadian peritentiary inmates (Hodgin \& Côté, 1990) showing elevated rates of major mental disorders. However, especially in the catogory of sexual offenders with an antisocial personality disorder (which may include violent offenders like for 
instance sadistic rapists), one should screen for malingering of major mental illness (chapter 2). Whether mentally ill persons are, indeed, more prone to commit a violent act or just are very successful malingerers has to be investigated in more detail. For now, we can conclude that in the forensic field, one should hold all scenarios in mind. With help of valid tests, it should be possible to come closer to the truth.

In chapter one we briefly discussed several models regarding the relationship between mental illness and violent behaviour. In one model it is assumed that this relationship is a by-product of malingering psychiatric symptoms. In sum, then, the considerations on which this approach is based (Hare, 1995), can be partially addressed: First, we did not find that the most violent crimes (e.g., murder, manslaughter) are more often committed by offenders with psychopathic or/and antisocial personality characteristics. Indeed, in a study of Nijman, Cima, and Merckelbach (submitted) it was reported that crimes with lethal consequencs are mostly committed by psychotic patients. However, violent crimes like sexual sadistical offences were associated with elevated rates of an antisocial personality disorder. Secondly, we could partially support the second point of Hare (1995) that such personality characteristics (e.g., psychopathic or/and antisocial personality) incite malingering of psychiatric symptoms. More specifically, an antisocial personality disonder was found in both malingering of major mental illness as well as within the group of claimed amnesia. However, there was no relationship between malingering and psychopathy. Finally, the last point, in which such personality characteristics might be related to poor executive functioning, has to be investigated in follow-up studies.

All in all, then, a large correlational analysis of how malingering, amnesia, dissociation, psychopathy, impulsiveness, supernormality, and blame attribution relate to eachother might be able to shed some light of the exact relationship between criminal behaviour and mental illness. The psychometric qualities of the 
instruments used in the studies reported in this thesis, have shown promising results. However, a lot of research has still to be done and our contribution of new tests is only a starting point in this domain of forensic psychiatry. We concluded that neuropsychological investigations of the criminal mind will be the next area of interest, in which detailed and systematic studies are needed. 


\section{SAMENVATTING}

Dit proefschrift handelt over simulatie van psychiatrische symptomen en hoe dit met behulp van valide testinstrumenten is vast te stellen. Simulatie, ofwel malingering, is het met opzet voorwenden of overdrijven van psychiatrische symptomen. In het eerste hoofdstuk worden naast malingering ook andere concepten behandeld, waaronder psychopathie en supernormaliteit. Ondanks de bestaande tests en de huidige psychometrische ontwikkelingen op forensisch psychiatrisch gebied, blijkt dat slecht weinig professionals uit het vakgebied hier gebruik van maken. Veelal berusten hun oordelen op klinische ervaring (Borum \& Grisso, 1995). Hoewel onderzaek laat zien dat voorspellingen gebaseerd op klinisch oordeel tot minder nauwkeurige resultaten leiden dan voorspellingen gebaseerd op metingen van factoren waarvan bekend is dat ze met crimineel gedrag samenhangen (Lidz, Mulvey \& Gardner, 1993), lijken psychologen en psychiaters tach moeiljkk hiervan te overtuigen. Het belang wan valide meetinstrumenten wordt in hoofdstuk 9 verder geillustreerd. Vanwege het feit dat in een forensische context bedrog niet ongewoon is, zou men op onbetrouwbare antwoordtendensen voorbereid moeten zijn, tenzij men dit soort van manipulatief gedrag controleert. Met name claims betreffende geheugenverlies voor het delict zouden op zijn minst siceptisch benaderd moeten worden. Zoals in hoofdstuk 2 wordt aangetoond, is malingering van psychiatrische symptomen bij forensische patiënten niet ongewoon. De belangrijkste resultaten uit hoofdstuk 2 kunnen als volg worden samengevat. Van de 62 patiënten die zich vrijwillig voor dit onderzoek hadden aangemeld, behaalden 17 patiënten een verhoogde malingering-score, gemeten middels de Duitse versie van de SIMS. Bovendien bleek dat het optreden van bizarre, atypische en vreemde symptomen zich vooral voordeed bij sexuele delinquenten die tevens met een antisociale persoonlijkheidsstoornis volgens het DSM-IV gediagnostiseend wareh. Daarbij laat de studie uit hoofdstuk 2 zien dat de Duitse versie van de SIMS een geschikt en 
betrouwbalar meetinstrument is woor het screenen wan malingering. Behalve het vaststellen van de betrouwbaarheid van psychiatrische symptomen bij delinquenten, zouden ook de betrouwbaarheid van geheugenverlies, ofwel amnesie, voor het delict vastgesteld moeten worden. Op het moment dat jemand een begrensd geheugenverlies heeft, kan dat het gevolg zijn van verschillende oorzaken. Amnesie kan optreden bij een klap op het hoofd, waardoor de persoon een tijdelijk geheugenverlies heeft voor de gebeurtenis voorafgaand aan de klap. In de regel komt dit geheugen na een bepaalde tijd weer terug. Een andere mogelijkheid van beperkt geheugenverlies, is dat vanwege een traumatische of stressvolle gebeurtenis het geheugen voor die gebeurtenis niet goed wordt opgeslagen, hetgeen tot een zogenaamde psychogene ofwel dissociative amnesie kan leiden. Ten slotte, maar zeker niet minder belangrijk, kan de geclaimde amnesie gefaked zijn. Volgens DeClue (2002) is veinzen een vereiste voor het optreden van malingering, maar zijn dit twee verschillende dingen. Specifieker gezegd, een individu die veinst is iemand die psychologische symptomen vervormt, ongeacht het doel. Van malingering is pas sprake zodra er overduidelijk bewijs voorhanden is dat iemand intentioneel psychologische symptomen overdrifft en fabriceert, gemotiveerd door een extern doel. Vanuit hun wens de patiënten-rol over te nemen, kunnen forensische patiënten dus psychologische en psychiatrische symptomen veinzen, maar kan men miet uitsluiten dat malingering van delict-gerelateerde amnesie optreedt. $0 \mathrm{~m}$ tot een betrouwbaar oordeel te komen betreffende de status van dergelijke claims, zijn er inmiddels verschillende soorten tests waar gebruik van kan worden gemaakt. In hoofdstuk 9 wordt een woorbeeld gegeven van $20 " n$ test die een bijdrage kan leveren aan het ophelderen van oorzaken van delict-gerelateerde amnesie (Symptom vatidity) Test).

Overeenkomstig eerder onderzoek (b.v., Kopelman, 1995), laat de studie, beschreven in hoofdstuk 4 , zien dat claims betreffende geheugenverlies voor het delict in $27 \%$ van de gevallen optrad. Binnen de groep van patiënten met dergelijke claims, was er 
een verhoogde frequentie van de antisociale persoonlijkheidsstoomis hetgeen samenging met een lage intelligentie, frontale hersenfuncties en een hoge score op de simulatie-vragenlijst. Hoewel de frequentie van antisociale persoonlijkheidsstoomis binnen de amnesie-groep hoog was, werd er geen relatie gevonden tussen psychopatie en amnesie claims. Wellicht is gesimuleerde amnesie typischer voor mensen met een lage intelligentie, terwijl de meer subtiele vormen van bedrog en manipulatief gedrag typischer voor psychopatische individuen met een relatief normaal IQ is...

De bevinding dat patiënten, die amnesie woor het delict claimen, tevens meer problemen laten zien betreffende hun executieve functies en vaker boven de cut-off van een mallingering schaal (SIMS) scoorden dan de controle groep, doet aan een eerdere studie denken (Cima, Merckelbach, KLlein, Schellbach-Matties \& Kremer, 2001). In die studie werd aangetoond dat slechte executieve functies samen gaan met hoge zelf rapportage van dissociatieve symptomen.

In de literatuur is het gebruikelijk om dissociatieve symptomen op te vatten als een psychologisch afweermechanisme. Zulke symptomen zijn uitwoerig bestudeerd bij slachtoffers van traumatische gebeurtenissen zoals sexueel misbruik, lichamelijke straf of emotionele misbruik. Aanhangers van het trauma-dissociatie model menen dat een delict als een traumatische ervaring woor de delinquent gezien kan worden. Dit zow dientengevolge tot een dissociatieve amnesie kurnen leiden (b.v. Kopelman, 1995). Amnesie wordt dan als een dissociatief symptoom beschouwd. In hoofdstuk 5 wordt een grote steekproef van forensische patiënten onderverdeeld in diegenen die amnesie voor het delict claimden en diegenen die dat miet deder. Er werden 3 hypothesen aangehaald die ammesie voor het delict zouden kunnen verklaren. Ten eerste de stress-dissociatie hypothese die stelt dat stresswolle gebeurtenissen tot de ontwikkeling van dissociative amnesie kunnen leiden. Ten tweede, de "state-dependent theory" in samenhang met alcohol af psychose, waarin gesteld wordt dat wanneer een gebeurtenis tijdens een bepaalde "state" (b.v. 
alcohol of tijdens een psychose) opgeslagen wordt, deze gebeurtenis alleen in diezelfde "state" herinnerd kan worden. Ten derde, de simulatie-hypothese, waarin gesteld wordt dat de amnesie geveinsd is. Om te bepalen welke van deze 3 hypothesen het meest waarschijnlijk zou zijn, werden de twee groepen op een aantal variabelen met elkaar vergeleken. Het belangrijkste resultadt in deze studie was, in overeenstemming met de laatste hypothese, dat een leerproces de meest warschijnlijke verklaring was voor de delict-gerelateerde amnesie.

In hoofdstuk 6 wordt het trauma-dissociatie model kritisch besproken. Kort gezegd, houdt dit model in dat traumatische ervaringen tot de ontwikkeling van dissociatieve symptomen leiden (Classen, Koopman \& Spiegel, 1993; Putnam, Carlsen, Ross, Anderson, Clark, Torem et al., 1996). Dat dit verband niet zo direct en robuust is, als in de literatuur vaak wordt aangenomen, werd aan de hand van een aantal punten in hoofdstuk 6 duidelijk gemaakt.

Vanuit de hypothese dat delinquenten met een psychopathische persoonlijkheidsstoornis ter vermijding van een gevangenisstraf, zich niet enkel slechter voordoen dan ze zijn ("fake bad"), maar misschien ten behoeve van eerdere vrijlating wit een forensisch psychiatrische instelling, zich eerder beter voordoen dan zie zijn, werd een nieuwe wragenlijst ontwikkeld. Deze wordt in hoofdstuk 7 behandeld. Deze pilot* vragenlijst, die supernormaliteit beoogt te meten, werd bij een grote steekproef van 233 deelnemers uit verschillende groepen (gezonde deelnemers, niet psychiatrische daders, niet criminele psychiatrische patiënten, en forensische patäënten) afgenomen. Het aantal deelnemers in elke groep verschilde van 29 tot 96 . De nauwkeurigheidsparameters van deze vragenlijst in termen van sensitiviteit en specificiteit, waren niet in alle opzichten bemoedigend. Dit impliceert dat de vragenlijst gereviseerd moet worden om haar positieve en negatieve voorspellingskracht te verbeteren. Bovendien, vanwege de hypothese dat persoonlijkheidsstoornissen en psychopatie in het bijzonder, gerelateerd zouden zijn 
aan supernormaliteit, is het van belang de antwoorden op een gereviseerde versie van deze vragenlijst voor verschillenden diagnose-groepen te onderzoeken. De manier warop delinquenten hun delict attribueren (externe factoren, interne factoren) is van belang voor de risicotaxatie. In hoodstuk 8 wordt de relatie tussen bepaalde schuld-attributies en verschillende delict-groepen onderzocht. In overeenstemming met eerder onderzoek (Gudjonsson \& Singh, 1989) attribueren meer gewelddadige delinquenten de schuld van hun delict eerder aan een psychisch element (b.v. bevelende stemmen horen; geen controle gehad hebben). Deze tendens is echter niet gerelateerd aan malingering van psychiatrische of psychologische symptomen. Dit leidt tot de suggestie dat psychisch zieke mensen mogelijk meer vatbaar zijn voor de ontwikkeling van gewelddadig gedrag. Dit is in overeenstemming met onderzoek van Hodgin. Mednick, Brennan, Schulsinger en Engberg (1996) die een associatie rapporteerden tussen psychiatrische opnames en veroordelingen. Het resultaat is in overeenstemming met bevindingen dat patiënten die van de psychiatrische afdeling ontslagen worden, vaker een misdrijf plegen dan andere personen uit dezelfde samenlevingsgroep (Link. Andrews \& Cullen, 1992: Steadman, Monahan, Robbins, Applebaum, Grisso, Klassen, Mulvey \& Roth, 1993). De resultaten gaan verder samen met bevindingen van US gevangenen (Collins \& Schlenger, 1983; Daniel, Rabins, Reid \& Wilfley, 1988; Hyde \& Seiter, 1987; Neighbors, Williams, Gunnings, Lipscomb, Broman \& Lepkowskii, 1987) en Canadese gevangenen (Hodgin \& Coté, 1990) die een verhoogde prevalentie van een psychische stoornis laten zien. Men moet echter altijd screenen voor malingering van psychiatrsiche symptomen, met name in het geval van sexuele delinquenten met een antisociale persoonlijkheidsstoornis, die eveneens vanwege zeer gewelddadige delicten zoals sadistische verkrachting kunnen vastzitten (hoofdstuk 2). of psychisch zieke mensen inderdaad vatbaarder zijn voor het plegen van een gewelddadig misdrijf ofwel dat deze groep delinquenten zeer succesvolle malingerers zijm. zal in meer gedetailleerd onderzoek verder onderzocht moeten worden. We 
kunnen op dit moment conciuderen dat op het gebied van de forensische psychiatrie men altijd met alle scenario's rekening moet houden. Met behulp van gestandaardiseerde tests is het mogelijk dat men dichter bij de waarheid kan komen.

In hoofdstuk 1 , bespraken we kort een aantal modellen betreffende de relatie tussen een psychische stoornis en gewelddadig gedrag. Het model warin gesteld wordt dat deze relatie magelijk tot stand komt vanwege het simuleren van psychiatrische symptomen, is op een aantal uitgangspunten gebaseerd (Hare, 1995). Op basis van onze bevindingen kunnen we een aantal uitspraken doen over de merites van deze uitgangspunten. Ten eerste, wonden we geen aanwijzingen dat de meest gewelddadige delicten (b.v., moord, doodslag) vaker door delinquenten met psychopatische en/of antisociale persoonlijkheidskenmerken gepleegd worden. In een studie van Nijman, Cima en Merckelbach (ter publicatie aangeboden) werd dienovereenstemmend gerapparteerd dat de delicten met een dodelijke afloop het meest door psychotische patiënten werd gepleegd. Desalniettemin. waren gewelddadige delicten zoals seksueel sadistische misdrijven geassocieerd met verhoogde mate van een antisociale persoonlijkheidsstoornis. Ten tweede, het idee dat bepaalde persoonlijkheids-kenmerken (b.v. psychopatische en/of antisociale persoonlijkheid) aanzetten tot het simuleren van psychiatrische symptomen, kunnen wij ten dele ondersteunen. Specifieker gezegd laten de resultaten zien dat een antisociale persoonlijkheid veel voorkomt in aanwezigheid van malingering van psychiatrische symptomen als ook binnen de groep personen die delict-gerelateerde amnesie claimt. Er werd echter geen samenhang tussen amnesie claims en psychopatie gevonden. Tot slot, de veronderstelling dat zulke persoonlijkheidskenmerken mogelijk samenhangen met slechte executieve functies zal in toekomstig onderzoek verder onderzocht moeten worden.

Betreffende de relatie tussen crimineel gedrag en psychiatrische sitoormis zou een grote correlationele analyse van de samenhang tussen malingering, amesie, dissociatie, psychopatie, impulsiviteit, supernormaliteit en attributie van schuld 
meer duidelijkheid kumnen verschaffen. De psychometrische kwaliteit van de instrumenten gebruikt in beschreven studies, laten veelbelovende resultaten zien. Er is echter nog veel onderzoek nodig waarbij onze bijdrage van vertaalde en nieuw ontwikkelde tests slechts een startpunt is op dit gebied van de forensische psychiatrie. We concluderen dat neuropsychologisch onderzoek van de 'criminal mind" het volgend gebied van interesse zal zijn, waarin gedetailleerde en systematische studies noodzakelijk zijn. 



\section{ZUSAMMENFASSUNG}

In dem ersten Kapitel haben wir verschiedene Konzepte (wie z.B., Simulation, Psychopathie, Supernormalität), die in den anderen Kapiteln verwendet werden, kurz besprochen. Wir haben darauf hingewiesen, dass, obwohl es valide Tests gibt, diese selten durch Professionelle benutzt werden. Stattdessen, stuitzen Psychologen und Psychiater ihr Urteil häufig nur auf klinische Erfahrung (Borum \& Grisso, 1995). Die wissenschaftliche Literatur zeigt jedoch deutlich, dass Voraussagen, welche nur auf klimische Erfahrung gestützt sind, zu schlechteren Ergebnissen führen als Voraussagen, die sich auf Messungen von Faktoren stützten, welche einen empirisch nachgewiesenen Zusammenhang mit kriminellem Verhalten zeigen (Lidz, Mulvey \& Gardner, 1993).

Die Wichtigkeit valider Tests in der forensischen Psychiatrie wurde anhand verschiedener Fallbeispiele in Kapitel 9 detailliert dargestellt. Weil innerhalb der forensischen Umgebung Täuschung üblich ist, soll man darauf vorbereitet sein, dass Selbsteinschätzung unzuverlässig ist, es sei denn, dass für dieses manipulative Verhalten kontrolliert wird. In Übereinstimmung mit Rogers et al. (1994) haben wir gefunden, dass Simulation bei forenischen Patienten nicht ungewöhnlich ist. Genauer gesagt, deut die Studie aus Kapitel 2 an, dass won den 62 Patienten bei 17 ein erhöhter Simulationswert mittels der deutschen Version des SIMS gemessen wurde. Die Ergebnisse zeigen, dass die Darstellung bizarrer, atypischer und merkwürdiger Symptome überwiegend bei sexualdelinquenten Patienten mit einer Antisozialen Persönlichkeitsstörung vorzufinden war. Weiterhin zeigt diese Studie, dass die deutsche Version des SIMS eine praktische und wertwalle Sreening-Methode zur Entdeckung vorgetäuschter psychiatrischer Symptome ist.

Um eine Unterscheidung zwischen den verschiedenen Amnesiearten machen zu können, sind in der Literatur verschiedene Taxonomien vorgestellt worden (z.B., Schacter, 1986; Loewenstein, 1991; Kopelman, 1995; Kihlstrom \& Schacter, 1995). 
Die meisten Taxonomien stimmen darin überein, dass mindestens drei verschiedene Amnesiearten zu unterscheiden sind: dissoziative Amnesie (früher bezeichnet als. psychogene oder funktioneller Amnesie), arganische Amnesie, und simulierte Amnesie ("malingered amnesia"). Organische Amnesie wird immer durch einen neurologischen Defekt verursacht. Dieser Defekt kann strukturell sein (z.B., Epilepsie, Gehirntrauma), kann aber auch von kurzer Dauer sein wie bei Alkohol oder Drogenintoxikation. Kopelman (1995) nimmt an, dass die Gedächtnisprobleme bei organische Amnesie mit Problemen der Einspeicherung zu tun haben, statt mit Zugriffsproblemen: wegen eines epiletischen Anfalls, eines Gehirntraumas oder ein Intoxikation sind Täter erstens nicht in der Lage ihre Erinnerungen zu speicheren, was zu einem gesammter "Black-out" hinsichtlich ihrer Delikte führt. Bei dissoziative Amnesie wird angenommen dass der Ursprung in den extremen Emotionen, die solches Verhalten begleiten, liegt. Die Idee dahinter ist, dass das 'arousal system' während des. Delikt ein extremes Niveau hat und so der Zugriff auf das Gedächtmis später behindert ist. Also, ein Fehler bei den Zugriffsmöglichkeiten bedeutet die Ursache für eine dissoziative Amnesie. Als letztes, kann eine Amnesie simuliert sein als Versuch, z.B. eine Polizeiuntersuchung zu behindern und/oder kriminelle Verantwortung zu vermeiden. Simulation ist nach DeClue (2002) eine erste Bedingung für Täuschung, aber nicht dass Gleiche. Genauer gesagt, eine Person die simuliert verdreht oder stellt psychologische Symptomen falsch dar ohne auf das Ziel zu achten. Täuschung tritt nur in den Fällen auf bei denen es eindeutig Beweise dafür gibt, dass psychologische Symptomen, motiviert durch ein externes Ziel, übetrieben oder fabriziert werden. Wegen ihres Wunsches die Patientenrolle einzunehmen, wäre es möglich dass forensische Patienten psychologische und psychiatrische Symptome simulieren, aber kann man nicht ausschließen, dass Täuschungen won delïktbezogener Amnesie auftreten. Um in der Lage zu sein, den Status solcher Amnesieansprüchen evaluieren zu können, sind verschiedene Tests entwickelt worden. In dem letzten Kapitel werden wir demonstrieren, wie bestimmte 
Tests (z.B., Symptom Validity Testing) einen Beitrag zur Aufklärung deliktbezogener Amnesie liefern können.

In Übereinstimmung mit früherer Forschung $\left(Z_{*} B\right.$. Kopelman, 1995) zeigt die Studie beschrieben in Kapitel 4 dass Amnesie in $27 \%$ der Fälle auftritt. Die Täter, die eine Amnesie für ihre Delikte angeben zeigen eine niedrige Intelligenz, häufiger eine Antisoziale Persönlichkeitsstörung, häufiger gestörte frontale Gehirnfunktionen und. erhöhte Werte auf einer Simulationsskala. Tratz der erhöhte Häufigkeit einer Antisoziale Persönlichkeitsstörung in diese Tätergruppe, zeigt sich keine Zusammenhang zwischen Psychopathie und Täuschung von deliktbezogene Amnesie. Wir vermuten, dass simulierte Amnesie typischer für diejenigen mit ein relativ niedriger Intelligenz ist, während andere und subtilere formen von Täuschung vielleicht typischer für psychopathische Persönlichkeiten mit eine relativ normalen oder erhöhten Intelligenz sind. Die Ergebnisse diese Studie, dass Patienten mit deliktbezogene Amnesie mehr Hinweisen für gestörte frontale Gehirnfunktionen zeigen und häufiger erhöhte Werte auf einer Simulationsskala (SIMS) erhalten, zeigte auch eine frühere Studie (Cima, Merckelbach, Klein, Schellbach-Matties \& Kremer, 2001). In dieser Studie zeigt sich, dass schlechte Exekutive Funktionen in Zusammenhang mit erhöhten Angaben von dissoziativen Symptomen stehen.

Dissoziation wird häufig konzeptualisiert als ein Abwehrmechanismus für stressvolle Erfahrungen sowie z.B. sexuellen und kiorperlichen Mißbrauch, emotionale und elterliche Vernachlässigung. In Übereinstimmung damit, wird Amnesie häufig als ein dissoziatives Symptom beurteilt. In Kapitel 5 wird eine große Stichprobe von forensischen Patienten unterteilt in diejenigen, die Amnesie für ihr Delikt angeben (ungefähr $1 / 4$ ) und diejenige die dass nicht angeben. Drei Hypothesen, welche Amnesie für ein Delikt erklären können, werden angeführt. Erstens, die StressDissoziations-Hypothese, die beinhaltet, dass Streßsituationen zur Entwicklung dissoziativer Amnesien führen können. Zweitens, die "State-Dependent Theory", die besagt dass sich nur dann an ein Ereignis erinnert werden kann, wenn man sich in 
dem gleichen Zustand befindet wie zum Zeitpunkt des Ereignisses. Orittens, die Simulationshypothese, die behauptet dass Amnesie für ein Delikt vorgetäuscht ist. Um entscheiden zu können, welche dieser drei Hypothesen eher zutrifft, sind die zwei Gruppen in einer bestimmten Anzahl von Variablen mit einander verglichen. Das wichtigste Ergebnis dieser Studie ist, in Übereinstimmung mit der letzte Hypothese, dass ein Lernprozess die wahrscheinlichste Erklärung der deliktbezogenen Amnesie ist.

In Kapitel 6 wird das Trauma-Dissoziations-Modell besprochen. Kurz gesagt, nimmt dieses Modell an, dass traumatische Erfahrungen während der Jugend eine direkte Verbindung zur dissoziativen Symptomen darstellen (Classen, Koopman \& Spiegel, 1993; Putnam, Carlsen, Ross, Anderson, Clark, Torem et al., 1996). In diesem Kapitel wird die These vertreten, dass eine direkte kausale Verbindung zwischen Trauma und Dissoziation nicht nachgewiesen ist. Die Interpretation der Korrelation zwischen Trauma und Dissoziation wird weiter diskutiert.

Von der Mypothese aus, dass Täter mit einer psychopathische Persönlichkeitsstörung wegen Vermeidung einer Gefängisstrafe nicht nur negative Merkmalen übertreiben ("faking bad"), sondern auch zugunsten einer vorzeitigen Entlassung aus einer forensischen Klinik, eher Positive Markmalen übertreiben ("faking-good"), ist ein neue Fragenbogen entwickelt worden. Diese wird in Kapitel 7 eingeführt. Diese Fragebogen, welche Supernormalität misst, wurde an einer großen Stichprobe von 233 Teilnehmern verschiedener Gruppen durchgefüht (gesunder Teilnehmer. gesunde Täter, psychiatrische Patienten, und psychiatrische Straftäter). Das Anzahl der Gruppenteilnehmer war Unterschiedtich (29 bis 96). Die Genauigkeit der Parameter für die diagnostische Qualität (Sensitivität und Spezifität) war relativ klein. Dieses impliziert, dass der Fragebogen revidiert werden muss, damit die Positive Predictive Power und Negative Predictive Power verbessert werden kamn. Wegen die Hypothese, dass Persönlichkeitsstörungen, ins besondere Psychopathie, mit Supernormalität in Zusammenhang stehen, ist es weiterhin wichtig die Werte der 
revidierten Version dieses Fragebogens für unterschiedliche Diagnosegruppen zu untersuchen.

Das Erforschen der Beziehung zwischen Schuldzuweisung und Tätergruppen ist wichtig für die Risokoeinschätzung. In Kapitel 8 wird der Zusammenhang zwischen Schuldzuschreibung und unterschiedlichen Deliktgrüppen untersucht. In Übereinstimmung mit früheren Forschungen (Gudjonsson \& Singh, 1989) schreiben Gewalttäter die Schuld häufiger psychischen Zuständen zu (z.B., imperative Stimmen hören; Kontrollverlust). Diese Tendenz ist jedoch nicht in Verbindung mit Simulation psychischer oder psychiatrischer Symptome zu setzen. Dieses führt zu der Vermutung, dass psychisch Kranke möglicherweise eher bereit sind für die Entwicklung von gewalttätigem Verhalten. Dieses ist in Übereinstimmung mit Forschung von Hodgin, Mednick, Brennan, Schulsinger und Engberg (1996) die über eine Verbindung zwischen psychiatrischen Aufnahmen und Verurteilungen berichten. Dieses Ergebnis stimmt mit Befunden überein, die zeigen, dass Patienten, die aus psychiatrischen Abteilungen entlassen werden, häufiger Verbrechen begehen als andere Personen aus der gleichen Gesellschaftsgruppe (Link, Andrews \& Cullen, 1992: Steadman, Monahan, Robbins, Applebaum, Grisso, Klassen, Mulvey \& Roth, 1993). Es stimmt weiter mit den Befunden überein, dass US -Häftlinge (Collins \& Schlenger, 1983; Daniel, Robins, Reid \& Wilfley, 1988; Hyde \& Seiter, 1987; Neighbors, Williams, Gunnings, Lipscomb, Broman \& Lepkowski, 1987) und kanadische Häftlinge (Hodgin \& Cötë, 1990) eine erhöhte Häufigkeit einer psychischer Störung zeigen. Man soll aber immer wieder die Simulation psychiatrischer Symptome überprüfen, insbesondere bei Sexulstraftätern mit einer Antisozialen Persönlichkeitsstörung (Kapitel 2). Ob psychisch kranke Personen tatsächlich bereiter sind gewalttätige Verbrechen zu begehen ader hat sehr erfolgreiche Simulanten sind, muss in zukünftigen Studien weiter untersucht werden. In Moment können wir daraus schlussfolgern, dass man innerhalb der 
forensichen Psychiatrie immer müt allem Szenarien rechnen soll. Mithilfe valider Tests ist es möglich, etwas näher an die Wahrheit zu kommen.

In dem ersten Kapitel haben wir kurz verschiedene Modelle zur Erklärung des Zusammenhangs von psychischer Krankheit und gewalttätigem Verhalten behandelt. Eines dieser Madelle nimmt an, dass dieser Zusammenthang eine Nebenprodukt won Simulierung psychiatrischer Symptome ist. Die Beobachtungen, auf denen diese Behauptung basiert (Hare, 1995), können teilweise besprochen werden: Erstens, haben wir nicht gefunden, dass die gewalttätigsten Delikte (d.h., Mord oder Totschlag) häuffiger durch Täter mit einer Psychopathischen und/ oder Antisozialen Persönlichkeitsstörung begangen werden. In einer Studie von Nijman, Cima und Merckelbach (eingereicht) wird berichtet, dass Delikte mit tödlichem Verlauf meistens durch psychotische Patienten verübt werden. An gewalttätigen Delikten sowie sexual-sadistischen Taten waren jedoch anteilmäßig vermehrt Personen mit einer Antisozialen Persönlichkeitsstörung beteiligt. Zweitens können wir die Ictee, dass bestimmte Persönlichkeitsmerkmale (z.B., psychopathische und/oder antisoziale Persönlichkeit) zur Simulation psychiatrischer Symptome antreiben, zum Teil unterstützen. Genauer gesagt zeigen die Ergebnisse, dass bei Personen mit einer Antisozialen Persönlichkeitsstörung sowohl das Vorhandensein von Simulation als auch von deliktbezogener Amnesie auftritt. Es ist jedoch kein Zusammenhang zwischen Imanspruchnahme von Amnesie und Psychopathie gefunden worden. Zum Schluss sei gesagt, dass die Vermutung, dass solche Persönlichkeitsmerkmale möglicherweise mit schlechten exekutiven Funktionen zusammenhängen, in zukünftiger Forschung weiter untersucht werden muss.

Eine grosse Korrelationsanalyse zwischen Simulation, Amnesie, Dissoziation. Psychopathie, Impulsivität, Supernormalität und Schuldattribution würde für mehr Deutlichkeit hinsichtlich der Verbindung von gewalttätigem Verhalten und psychischer Krankheit sorgen. Die psychometrische Qualität der Messinstrumente, die in diesen Studien benutzt worden sind, haben vielversprechende Ergebnisse 
gezeigt. Es ist aber noch viel Forschungsarbeit erforderlich und unsere Beiträge sind nur ein Anfang im Bereich der forensischen Psychiatrie. Wir erschließen den Bereich neuropsychologischer Untersuchungen des "criminal mind", dem unser Interesse gelten soll und in dem detaillierte und systematische Studien notwendig sind. 



\section{REFERENCES}

Adshead, G. (1997). Ethical issues raised by the discussion of "false" and "fecovered" memories. In J.B. Read \& D.S. Lindsay (Eds.), Recollection of trauma: Scientific evidence and clinical practice (pp. 435-439). New York: Plenum.

Allen, J.G. (1993). Dissociative processes: Theoretical underpinnings of a working model for clinician and patient. Bulletin of the Menninger Clinic. 57, 287-308.

Altman, J. \& DaS G.D. (1964). Autoradiographic examination of the effects of enriched enwironment on the rate of glial multipication in the adult rat brain. Nature, 204, 1161-1165.

American Psyctiatric Association. (1994). Diagnostic and Statistic Manual of Mental Disorders (4th ed.). Washington, DC: Author.

Minnon, is. (1988). Detection of deception and search for truth: A proposed model with particular reference to the witness, the victim, and the defendant. Forensic Reports, $1,301-359$.

Appelbaum, P.S., Robbins, P.C. \& Monalian, J. (2000). Wicience and delusions: Data from the MacArthur violence risk assessment study. American Journal of Psychiatu, 157, $566-572$.

Babunski, L.M. Hartsough, C.S. \& Lambert, N.M. (1999). Childhood conduct problems, hyperactivity impulsivity, and inattention as predictors of adult criminal activity. Journal of Child Psychology and Psychiatry, 40, 347-355.

Bagby. R.M., Gillis, J.R. \& Dickens, S.E. (1990). Detection of dissimulation with the new generation of objective personality measures. Behavioral Sciences and the Law, 8, 93-102.

Bagby, R.M., Rogers, R. \& Buis, T. (1994). Detecting malingered and defensive responding on the MMPI-2 in a forensic inpatient sample. doumal of Parsonality Assessment, $62,191-203$.

Banaji, M.R. \& Kihlstrom, J.F. (1997). The ordinary hature of alten abduction memories. Bsychological Inquiry, $7,132-135$.

Barbey, I.(1990). Postdeliktische Erinnerungsstörungen: Ergebnisse einer retrospektiven Erheburig Blutalkohol, 27, 241-259.

Barratt, E.S. (1963). Behavional variability related to stimulation of the cats anygdala. Journal of the American Medical Association, $185,773-775$.

Barratt, E.S. (1972). Anxiety and impulsiveness: Toward a neuropsychological rnodel. In C.D. Spielberger (Ed.). Anxiety: Courent trends in theory and research (pp. 195-222). New York: Academy Press.

Barratt, E.5. (1985). Impulsiveness subtraits: Arousal, and information processing. In J. Spence \& C. lzard (Eds.). Motiwation, emotion and personality (pp. 137-14.6). Ansterdam: Elserier. 
Barratt, E.5. (1993). Impulsivity: Integrating cognitive, behavioral, biological, and enwirommental data. In W. MCLowan \& M. Shure (Eds.). Ihe impulsive dient: Theory researich and treatment (DP. 39-56). Washington DC: American Psychological Association.

Barratt. E.S. (1994). Impulsiweness and aggression. In J. Monahan \& H.J. Steadman (Eds.), Violence and mental disorder (pp. 61-79). Chicaga: Uniwersity af Chicago Press.

Baratt, E.S. Pritchard, W.S., Faulk, 0.M. \& Brandt, M.E. (1987). The relationship between ilupulsiveness subtraits, trait anxiety, and visual $N 100$ augmenting/ reducing: A topographic analysis. Personality and Individual Differences, 8, 43-51.

Bartels, S.3., Drake, R.E. Wallach, M.A. \& Freeman, D.H. (1991). Characteristic hostility in schizophrenic outpatients. Schizophrenia Bulletin, 17, 163-171.

Berman, M.E. \& Coccaro, E.F. (1998). Neurobiologic correlates of violence: relevance to criminal responsibility. Behavioral Sciences and the Law. 16, 303-318.

Bermstein, E.M. \& Putram, F.W. (1986). Development, reliability, and validity of a dissociative scalle. Joumal of Nervous and mental Disease, 174, 727-735.

Bernstein, D.P., Fink, L., Handelsman, L., Fook, J., Lovejoy, M., Wenzel, K., Saparetor, E. \& Ruggiero, J. (1994). Initial retiability and walidity of a new retrospective measure of child abuse and neglect. American Joumal of Psychiatry, 151, 1132-1136.

Berry, D.T.R. Bear, R.A. \& Harris, M.J. (1991). Detection of malingering on the M.MPI: a meta. analysis. Clinical Psvchological Review, 11, 585-589.

Beveridge, M., Janold, C. \& Pettit, E. (2002). An experimental approach to executive fingerprinting in young children. Infant and Child Development, 11, 107-123.

Brinder, L.M. \& Rohling, M.L. (1996). Money matters: A metamanalytic review of the effects of financial incentives on recovery after closed-head injury. American Journal of Psychiatry. $153,7-10$.

Birnbaum, I.M. \& Parker, E.S. (1977). Alcoholand menon. Hillsdale, NJ: Erbaum.

Eonta, J. Law, M. \& Hansson, K. (1998). The prediction of criminal and violent recidivism amang mentally disordered offenders: A meta-analysis. Psychalogical Bulletin, 123, 123-142.

Borum, R. \& Grisso, T. (1995). Psychological test use in criminal forensic evaluations. Professional Psychology: Research and Practice, 26, 465-473.

Bourget, 0. \& Badford, J.M.W. (1995). Sex offenders who claim amnesia for their atleged offense. Bulletin of the American Academy of Psychiatry and Law, 23, 299-307.

Bower, 6.H. (1981). Mood and memory. American Psvchologist, 36, 129-148.

Bradford, J.W. \& Sinith, S.M. (1979). Amnesia and homicide: The Padola case and a study of thirty cases. Bulletim of the American Academy of Psychiatry and Law, Z, 219.231. 
Braun, B.6. (1988). The BASK modiel of dissociation, Dissociation, 1. 4-23.

Bremmer, J.D., Randall, P., Scot, T.M., Bromen, R.A., Seibyl, J.P., Southwick, S.M., Delaney, R.C. MCCarthy, G. Charney, D.S. \& Imnis, R.B. (1995). MRI-based measurenent of hippocampal volume in patients with combat-related posttraumatic stress disorder. American Jownal of Psychiatry, 152, 973-981.

Brown, S., Botsis, A. \& van Praag. H.M. (1994). Serotonin and aggression. In M.Hillbrand \& N.J. Pallone (Eds.). The pswchobiology of aggression (pp. 27-39). New York: The Haworth Press inc.

Brown, C.S., Kent, T.A., Bryant, S.G., Gevedon, R.M., Campbell, J.L., Felthous, A.R., Barratt E.S. \& Rose. R.M. (1989). Blood platelet uptake of serotonin in episodic aggression. Psychatry Research, 27, 5-12.

Brunner, R. M. \& Parzer, P. (1994). Checkliste zur Erhebung traumatischer Lebensereignisse in der Kindheit und Jugend. Unpublished Instrument: University Heidelberg.

Brunner, R., Parzer, P., Schuld. V. \& Resch, F. (2000). Dissociative symptomatology and traumatogenic factors in adolescent psychiatric patients. Journal of Nervous and Mental Disease, 188,71277 .

Brunner, R., Resch, F., Parzer, P. \& Koch, E. (1997). Dissoziation und Trauma: Psychotherapeutische Gesichtspunkte. In: P. Hoffmann, M. Lux, Ch. Probst, M. Steinbauer, J. Tauchler, \& H.G. Zapotoczky (Eds.), Klinische pswchotherapie (pp. 312-318). Vienna: Springer.

Bryant, R.A. (1995). Fantasy-proneness and recall of childhood abuse. In G.D. Burrows \& R.0. Stanley (Eds.). Contemporary International Hypnosis (pp. 109-117). New York: Wiley.

Burkett, B. G. \& Whitley, G. (1998). Stolen valor: How the Vietnam generation was robbed of its heroes and its thistory, Dallas, TX: Werity Press.

Carliste. A.L. (1991). Dissociation and violent criminat behavior Journal of Contemporary Criminal Justice, $4,273-285$.

Cercy, S.P., Schretlen, D.J. \& Brandt, J. (1997). Simulated amnesiza and the pseudomemory phenomenon. In Rogers, R. (Ed.), Clinical assessment of malingening and deception (pp. 85107). New York: Guitdiford.

Christianson, S-A. \& Bylin, 5. (1999). Does simulating amnesia mediate genuine forgetting for a crime event? Applied Cognitive Psychology 13, 495-511.

Christiansen, K. \& Kaussman, R. (1987). Androgen levels and components of aggressive behavior in men. Hormones and Behavior, 21, 170-180.

Chu, J.A., Frey, L.M., Ganzel, B.L. \& Mathews, J.A. (1999). Memories of childhood abuse: Dissociation, amnesia, and corroboration. American Journal of Psvchiatry, 156, 749.755.

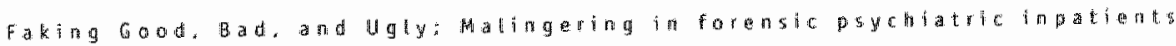


Chu, J.A. (1990). Trauma, dissociation, and multiple personality. Comprehensive Therapy. 16, 35-40. Cima, M., Hollnack, S., Kremer, K., Knäuer, E., Schellbach-Matties, R., Klein, B. \& Merckelbach, H. (in press a). Strukturierter Fragebogen Simulierter Symptome. Die deutsche Version des. Structured Inventory of Malingered Symptomatology: SIMS IStructured Inwentory of Simulated Symptoms: The German wersion of the Structured Inventory of Malingered Symptomatology: SIMSI. Nervenarzt.

Cima, M., Merckelbach, H., Butt, C., Kremer, K., Knauer, E. \& Schellbach-Matties, R. (submitted). It wasn't me: Attribution of blame for criminal acts in psychiatric offenders.

Cima, M., Merckelbach, H., Hallnack, S., Butt, C., Kremer, K., Schellbach-Matties, R. \& Muris, P. (accepted pending revision). The other side of malingering: supernormality. The Clinical Neuropsychologist.

Cima, M., Merckelbach, H., Hollnack S. \& Knauer, E. (in press b). Correlates of amnesia in psychiatric prison inmates. Personality and Individual Differences.

Cima, M., Merckelbach, H., Klein, B., Schellbach-Matties, R. \& Kremer, K. (2001). Frontal lobe dysfunctions, dissociation, and trauma self-reparts in forensic psychiatric patients. Journal. of Nervous and Mental Disease, 189, 1.88-190.

Cima, M., Merckelbach, H., Nijman,. H., Kmauer, E. \& Holnack, S. (2002). I can't remember your honour: Offenders who claim amnesia. German Journal of Psychiatry, 5, 24-34.

Clancy, S.A., McNally, R.J., Pitman, R.K., Schacter, D.L. \& Lenzenweger, M.F. (2002). Memory distortion in people reporting abduction by aliens. Journal of Abnormal Psychology, 111, 455-451.

Claridge, G. (1997). Schizotypy: Implications for illness and health. Oxford: Oxford University Press.

Classen, C., Koopman, C. \& Spiegel, D. (1993). Trauma and dissociation. Bulletin of the Menninger Clinic, 27, 178-194.

Clark, C.R. (1997). Sociopathy, malingering and defensiveness. In R. Rogers (Ed.), Clinical assessment: of malingering and deception (pp.68-84). Mew York: Guilford.

Clark, D.A. \& Claybouirn, M. (1997). Process characteristics of worry and obsessive intrusive thoughts. Behaviour Research and Therapy, 35, 1139-1141.

Cleckley, H. (1982). The mask of sanity (5th ed.). St. Louis: Mosby.

Cliffe, M.J. (1992). Symptom-walidity testing of feigned sensory or memory deficits: A further elaboration for subjects who understand the rationale. British Journal of Clinical Psychology, 31, 207-209.

Coccaro, E. (1989). Central serotonin and impulsiwe aggression. British Joumal of Psychiatry. 155, 52.62 . 
Cochrane, H.J., Baker, G.A. \& Meudell, P.R. (1998). Simulating a memory inpairment: can amnestics implicity outperform simulators: British Joumal of Clinical Psychology, 37, 31-48.

Cohen, 1. (1992). A power primer. Psychological Bulletin, 112, 155-159.

Coleman, P.D. \& Riesen, A.H. (1968). Emvirommental effects on cortical dendritic fields: 1. reaning in the dark. Journal of Amatomy, 102, 3693-3374.

Cornell. D.G. \& Hawk, G.L. (1989). Clinical presentation of malingerers diagnosed by experuenced forensic psychologists. Law and Human Behevior, 13, 374-383.

Critchlow, B. (1986). The powers of John Barleycom: Betiefs about the effects of alcohol on social behaviour. American Psychologist, 41, 751-764.

Crombag. H. (2002). Over opzet en schuid. In P.J. van Koppen, D.J. Hessing. H.L. G.J. Merchelbach \& H.F.M. Crombag (Eds.), Het recht van himnen: Psychologie van het recht (pp. 737-760). Deventer: Kluwer.

Crombag, H. F. M. \& Mercketbach, H. (1997). Misbrauch vergilst man micht. Enirnerh und VerdrängenFehldiagnosen und Fehlurteile. Berlin: Ullstein Buchverlage GmbH.

Crombag, H. F.M., Van Koppen, P.J. \& Wagenaar, W.A. (1994). Dubiewze zaken: De psychologie van

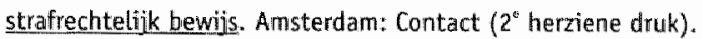

Crowne, D.P. \& Marlowe, D. (1960). A new scale of social desirability independent of psychopiathology. Journal af Consulting Psycholocy, 24, 349-354.

Declue, G. (2002). Feigning not equat malingering: a case study. Behavioral Sciences and the Law. $20,717-726$.

Denney, R.L. (1996). Symptom validity testing of remote memory in a criminal forensic setting., Archives of Clinical Nemropsychology. 11 , 589-603.

Denney, R.L. \& Wyncop, T.F. (1995). Exaggeration of neuropsuchological deficits in pretrial evaluation: A case oresentation. Paper presented at the 103 rd annual meeting of the American Psycholagical assiociation, New York.

de Ruiter, C. (2000). Forensische psychodiagnostiek en risocotaxatie: Ontwerp van een forensisch psychologisch testinstrumentarium. In I.I. Dei \& M.S. Groenhuijsen (red.) Forensische psychiatrie anno 2000: Actuele ontwikkelingen in breed perspectief (pp. 301-315). Deventer: Gouda Duntrt.

de Ruiter, C. \& Greeven, P.G.J. (1999). Persoontijkheidsstoomissen bif forensisch psychiatrische patiēnten: intemiew - en zelfrapportagemethoden. Diagnostiekwijzer, 2. 51-59.

de Ruiter, C. \& Hildebrand, M. (2002). Over toerekeningsvatbaarheid. In P.J. van Koppen. D.J. Hessing. H.L.6.J. Merckelbach \& H.F.M. Crombag (Eds.), Het recht wan birnen: Psycholagie van het recht (pp. 687-607). Deverter: Kluwer.

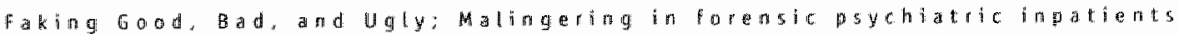


DeLoache, J.5. \& Brow15, A. (1984). Where do I go next? Intelligent searching by very young children. Development Psychology, $20,37-44$.

Diamond, A. (1988). Abilities and neural mechanisms underlying A not B performance. Child Development, 59, 523i-527.

Diamond, A. (1991). Developmental time course in human infants and infant monkeys, and the neural bases of inhibitory control in reaching. Annals of the New York Academy of Sciences, $608,637-704$.

Diamond, A, Prevor, M.B., Callender, G. \& Druin, D.P. (1997). Prefrontal cortex cognitive deficits in children treated early and continuously for PKU. Monographs of the Society for Research in Child Development, 62, $1-205$.

DiTomasso, M.J. \& Routh, D.K. (1993). Recall of abuse in childhoad and three measures of dissociation. Child Abuse \& Aleqlect, 17, 477-485.

Dolan, B. (1995). The attribution for criminal acts: Relationship with personality disorder and mood. Criminal Behaviour and Mental Health, $5,41.51$.

Draijer, N. \& Langeland, W. (1999). Childhood trauma and perceived parental dysfunction in the etiology of dissociative symptoms in psychiatric inpatients. Amenican Joumal of Psychiatry. 156. $379-385$.

Durat, R., Jabotinsky-Rubin, K. \& Ginath, Y. (1993). A look at court appointed psychiatric evaluations in Israel with special reference to criminal livability. Medicine and Law, $\underline{12}, 153-163$.

Edens, J.F., Buffingtion, J.K. \& Tomicic, T.L. (2000). Arl investigation of the melationship between psychopathic traits and malingening on the Psychopathüc Personality Inventory. Assessment Z. $281-296$.

Edens, J.F., Buffington, J.K., Tomicic, T.L., Riley. B.D. (2001). Effects of positive impression mamagement on the Psychopathic Personality Inventory. Law and Human Behavior, 25, 235. 256.

Edens, J.F, 0tto, R.K. \& Dwryer. T. (1999). Utility of the Structured Inventory of Malingered Symptomatology in identifying persons motivated to malinger psychopathology. Journal of the American Academy of Psychiatry ard the Law, 127, 387-396.

Eich, J.E. (1980). The cue-dependent nature of state-dependent retriewal. Memory and Cognition, 8. $157-173$.

Eich, J.E., Weingartner, H., Stilman, R.C. \& Gillin, J.C. (1975). State-dependent accessibility of retrieval cues in the retemtion of a categonized list. Journal of Verbal Learning and Verbal Behavior, 14, 408-417. 
Eissler, K. R. (1951). Malingering. In G.B. Withur \& W. Muensterberger (Eds.). Psychoanalysis and culture (pp. 218-253). New York: International Universities Press.

Ekman, P. (1985). Telling lies: Clues to deceit in the marketplace, politics, and , marriage. New York: W.W. Norton.

Elwoad, R.W. (1993). Psychological tests and clinical discriminations: beginning to address the base rate problem. Clinical Psychological Review, 13, 409-419.

Ensatada, L. H. (2000). The importance of illness, behavior in disability management. Occupational Medicine, 15, 739- 753.

Evans, J.R., \& Claycomb, S. (1999). Abnormal EEG patterns associated with dissaciation and violence. Journal of Neurotherapy, 3, 21-27.

Farkas, G.M., DeLeon, P.H. \& Newman, R. (1997). Sarity examiner certification: An evolving national agenda. Professional Psychology: Research and Practice. 28, 73-76.

Faust, D. (1995). The detection of deception. Neurologic Clinics, 13, 255-255.

Faust, D., Guilmette, T,J., Hart, K., Arkes, H.R., Fishburne, F.J. \& Davey, L. (1988). Neuropsychologists' training, experience, and judgment accuracy. Archives of Clinical Neuropsychology, $3,145-163$.

Faust, D. (1996). Assessment of brain injuries in legal cases: Neuropsychological and neuropsychiatric considerations. In B.S. Fogel, R.B. Scheffen \& S.M.. Rao (Eds.). Neuropsychiatiry (pp. 973990). Pennsylvania: Willians \& Wilkins

Faust, D., Hart, K. \& Guilmette, T.J. (1988). Pediatric malingering: The capacity of children to fake believable deficits on neuropsychological testing. Journal of Consulting and Climical Psychology, 56, 578-582.

Faust, D. Hart, K., Guilmette, T.J. \& Arkes, H.R. (1988). Neuropsychologists" capacity to detect adolescent malingerers. Professional Psychology: Research and Practice, 19, 508-515.

Faust, D. \& Ziskin, J. (1988). The expert witness in psychology and psychiatry. Science. 241, 31-35.

Fenigstein, A. \& Vanable, P. (1992). Persecutory ideation and self-consciousness. Journal of Personality and Social Psychology, 62, 124-138.

Fenwick, P. (1993). Brain, mind, and behaviour: Some medico-legal aspects. British Journal of Psychiatry, 163, 565-573.

Fishbein, M. \& Ajzen, I. (1973). Attribution of responsibility: A theoretical note. Joumal of Experimental Social Psychology. 2, 148-153.

Frankel, F.H. (1990). Hypnotizability and dissociation. American Journal of Psychiatry, 147. 823-829. 
Fox, S., De Koning, E. \& Leicht, 5. (2002). The relationship between attribution of blame for a wiolent act and EPQ R sub-scales in male offenders with memtal disorder. Personality and Individual Differences, $33,1-9$.

Frankel, F.H. (1996). Dissociation: The dinical realities. American Joumal of Psychiatry, 153, 64; 70. Fiederick, R.I. \& Carter, M. (1993). Detection of malingered amnesia in a competency evaluee. Paper presented at the annual meeting of the American Psychological Association, Toranto.

Frederick, R.I., Carter, M. \& Powel, J. (1995). Adapting symptom validity testing to evaluate. suspicious complaints of amnesia in medicolegall evaluations. Bulletin of the Amenican Academy of Psychiatry and the Law, 23, 227-233.

Freyberger, H. J., Spitzer, C., Stieglitz, R. D., Kuhr, G., Magdeburg, N. \& Bernstein $\times$ Carlson, E. (1998). Fragebogen zu dissociativen Symptonen (FDS). Deutsche Adaptation, Reliabilität und Validität der amerikanischen Dissociatiwe Experience Scale (DES). Psychotherapie Psychosomatik Medizinische Psycholagie, 48, 223-229.

Frick, P.J. (1998). Conduct disorder and severe antisocial behaviors, New York: Plenum.

Gaconio, C.B. \& Meloy. J.R. (1994). The Rorschach assessment of agqressive and psychopathic persomalities. Hillsdale, NY: Erbaum.

Gacono, C.B., Meloy, J.R., Sheppard, K., Speth, E. \& Roske, A. (2995). A clinical investigation of malingering and psychopathy in hospitalized insamity acquittees. Bulletin of the American Academv of Psychiatty and the law, 23, 387-397.

Garry, M., Mamning, C.G., Loftus, E.F. \& Sherman, S.J. (1996). Imagination inflation: Imagining a childhood event inflates confidence that it occurs. Psychomomic Bulletin \& Review, 3,208 214.

Gast, U., Oswald, T. \& Zündorf, F. (2000). Das Strukturierte Klinische Interview für DSM-IV Dissoziative Stöumgen (SCDO-D). Deutsche Fassung. Göttingen: Hogrefe.

Gast, U., Rodewald, F. Nickel, V. E Emrich, H. M. (2001). Prevalence of dissociative disorder among psychiatric inpatients in a German university dinic. Journal of Nervous and Mental Disease. 139. 249-257.

Gerson, A.R. (2002). Beyond DSM-IV: A meta-review of the literature on malingering. American Jounal of Forensic Pswchology 20, 57-69.

Gilbert, 6.M. (1971). Nuirnberger Tagebuch: Gespräche der Angek lagten mit dem Gerichtspsychologen. Frankfurt am Main: Fischer.

Gillis, J.R., Rogers, R. \& Bagby, R.M. (1991). Validity of the M test: Simulation-design amd naturatgroup approaches. Journal of Personality Assessment. 57, 130-140.

Faking Good. Bad, and Ugly: Matingering in forensic psychiatsic inpatients 
Goldberg. L. R. (1968). Simple models or simple processes? Some research on clinical judgment. American Journal of Psychology, 23, 483-496

Golden, C.J. (1981). The Luria-Nebraska children's battery: theory and formulation. In G.W. Hynd \& G.E. Obrzut (Eds.). Neuropsychological assessment and the school-aged child (pp. 277-302). New York: Grune \& Stratton.

Good, M.I. (1995). Validity of childhood abuse measurements. American Joumal of Psychiatry 152. 1533-1534.

Goodwin, D.W. (1995). Alcohol ammesia. Addiction, 90, 315-317

Goodwin, D.W., Crane, J.B. \& Guze, S.B. (1969). Phenomenologital aspects of the atcoholic "blackout." British Journal of Psychiatny, 115, 1033-1038.

Goodwin, D.W. Othmer, E., Malikas, J.A. B Freeman, F. (1970). Loss of short-term unemory as a predictor of the alcoholic "blackout." Nature, 22.27, 201-202.

Graharn, J.R., Watts, D. \& Tïmbrook, R. (1991). Detecting fake-good and fake-bad MMPI-2 profiles. Journal of Personality Assessment, $57,264-277$.

Green, R.L. (1988). Assessment of malingering and defensiveness by objective personality measures. In R.Rogers (Ed.). Clinical assessment of malingering and deception (pp. 169-207). New York: Guilford.

Gireen, R.J. (1991). The MMPI-2/MMPI: An interpretive manual. Boston: Allyn \& Bacon.

Greeven, P.G.J. (1997). De intramurale behandeling van forensische patiënter met een persoonlijkheidsstoornis. Een empirische studie. Amhem: Gouda Quint.

Gross, H. \& Kaltenbäck, E. (1974). Amnesie für deliktisches Verhattem [Amnesia for criminal behavior]. Arztliche Praxis, 26. 2156-2161.

Grossman, L.5. \& Wasyliw, 0.E. (1988). A psychometric study of stereotypes: Assessment of malingering in a criminal forensic group. Journal of Personality Assessment, 52, 549-563.

Grow, R. McVaugh, W. \& Eno. T.D. (1980). Faking and the MANP. Joumal of cinical Pychology. 35. 910-917.

Gudjonsson, G.H. (1984). Attribution of blame for criminal acts and its relationship with personality. Personality and Individual Differences, $5,53-58$.

Gudjonsson, G.H. (1992). The psychology of interrogations, confessions, and testimony. Chichester: Wiley.

Gudjonsson, G.H., Hannesdattir, K. \& Peturssan, H. (1999). The relatianship between amnesia and crime: The role of personality. Personality and Individual Differences, 26, 505-5.10. 
Gudjonsson, G.H., Kopelman, M.D. \& Mackeith, J.A.C. (1999). Unreliable admissions to homicide: A case of misdiagnosis of ammesia and misuse of abreaction technique. British Joumal of Psychiatry, $174,455-459$.

Gudjonsson, G.H. \& Moore, E. (2001). Self-deception and ather-deception among admissions to a maximum security hospital and a mediun secure unit. Psychology, Crime and Law I, 25-31.

Gudjonsson, G.H. \& Petursson, H. (1991a). The attribution of blame and type of crime committed: Transcultural validation. Journal of the Fouensic Society, 31, 349-3.52.

Gudjonsson, G.H. \& Petursson, H. (1991b). Custodial interragation: Why do suspects confess and how does it relate to their crime, attitude and personality? Personality and Individual Differencess, $12,295-306$.

Gudjonsson, G.H., Petursson, H. Sigurdardottir, H. Skulason, X. (1991c). The personality of Iceland prisonars: Some normative data. Nordisk Psykatrisk Tidssknift, 45, 151-157.

Gudjonsson, G.H., Petursson, H., Skulason, S. \& Sigurdardottir, H.(1989). Psychiatric evidence; A study of psychological issues. Acta Psychiatrica Scandinavica, 80, 165-169.

Gudjansson, G.H. \& Singh. K.K. (1989). The revised Gudjonsson Blame Atribution Inventory. Personality and Indiwidual Differences, 10,67-70.

Gudjonsson, G.H. \& Singh, K.K. (1988). Attribution of blame for criminal acts and its relationship with type of offence. Medicine, Science and the Law, 28, 301-303

Guttmacher, M. S. (1955). Psychiatry and the Law. New York, NY: Grune \& Stratton.

Gray, J.A. (1982). The neuropsychology of anxiety. Oxford: Oxford Uniwersity Press.

Haber, L. \& Haber, R.N. (1998). Criteria for the admissibility of eyewitness testimony of long past ovents. Pychology, Public Policy, and Law, 4, 1135-1159.

Hacking, I. (1995). Rewriting the soul: Multiplesersonality and the sciences of memory. New Jersey: Princetorn.

Hall. H.V. \& Poirier, J.G. (2001). Detecting malingering and deception: Forensic distortion analysîs. Washington: CRC Press.

Hankins, (G.C., Barnard, G.W. \& Robbins, L. (1993). The waltitity of the M test in a residential forensic facility. Bulletin of the American Academy of Psychiatry and the Law, 21, 111-121.

Hanson, R.K. \& Bussière, M.T. (1998). Predicting relapse: A meta-analysis of sexulal offender recintivism studies. Journal of Consulting and Clinical Psychology, 66, 348-362.

Hare, R. D. (1980). A research scale for the assessment of psychopathy in criminal populations. Personality and Individual Differences, $1,111 \mathrm{~m} 117$.

Hare, R.D. (1991). Markal of the Psuchopathy Checklist-Revised (PCL-R). North Tonawanda, NW: Multi. Health Systens. 
Hare, R.D. (1993). Without conscience: The disturbing world of the psychopattus among ns. New York: Pocket books.

Hare, R.D. (1995). Psychopathy: theory, research and implications for society. A introduction. Igsues in Criminological \& Legal Psychology 24, 4-5.

Hare, R. (1999). Without conscience: The disturbing wortd of the psychonaths among us. New York: The Guilford Press.

Hare, R.D. \& Jutai, 3.W. (1988). Psychopathy and cerebral asymmetry in semantic processing. Personality and Individual Differences, $9,329-337$.

Hare, R.D. \& McPherson, L. (1984). Psychopathy and perceptual asymmetry during verbal dichotic listering. Journal of Abnormal Psychology, 93, 141-149.

Hare, R.D., Vertomnen, H.s van den Brink, W. \& de Ruiter,C. (in press). Handleiding bij de Nederlandse Psychopathie Checklist-Revised.

Hart, S.D. Cox, D.N. \& Hare, R.D. (1996). Manual of the Screening Version of Psychopathy Checklist Revised (PCL-R:5W). Toronto, ON: Mullti-Health Systerns.

Harpur, T.J., Hakstian, A.R. \& Hare, R.D. (1988). Factor structure of the Psychopathic Checklist. Jounal of Consulting anid Cinical Psychology, 56, 741-747.

Harpur, T.J., Hare, R.D. \& Hakstian, R. (1989). Two-factor conceptualisation of psychopathy" Construct validity and assessment implications. Psychological Assessmenti A Journal of Consulting and Clinical Psychology. 1, 6-17.

Harvey, J.H. \& Smith, W.P. (1977). Social psychology: An attribution approacth. Mosby, St. Louis, Mo. Hathaway, S.R. \& Mckinley, J.C. (1983). Mantual for the Minnesota Multinhasic Personality Inventory. New York: The Psycholagical Corporation.

Heaps, C, \& Nash, M. (1999). Individual differences in imagination inflation. Psychonomic Bulletin i Review, 6. 313-318.

Heaton, R. K., Smith, H.H., Lehman, R.A.W. \& Vogt, A.T. (1978), Prospects for faking betievable deficits on neuropsychological testing. Journal of Consulting and clinical Psyctology, 46, 892-900.

Heider, F. (1958). The psychology of interpersonal relations. New York: Wiley.

Heitburn, K. (1992). The role of psychological testing in forensic assessment. Law and Hurnan Behavior, $16,257-272$.

Heilburn, K. Bennett, W.S., White, A.J. \& Kelly, J. (1990). An MMPI-based empinical model of malingering and deception. Behavioral Sciences and the Law, 8, 45-53. 
Heinik, J., Kimbi, R. \& Hes, J. (1994). Dementia and crime: A forensic psychiatry unit study in Israel. International Journal of Geriatric Psychiatry, 2, 491-494.

Hermann, D.H.J. (1986). Criminal defenses and pleas in mitigation based on amnesia. Behavional Sciences and the Law , 4. $5 \times 26$.

Hodgirs, S. (1998). Epidemiological investigations of the association between major mental disorder and crime: Methodological limitations and validity of the conclusions. Social Psychiatry and Psychiatric Epidemiologye $33.29-37$.

Holcomb, W. R. \& Daniel, A. E. (1988). Homicide without an apparent motive. Behavioral Sciences and the Law, 6, 429-437.

Hopwood, J.5. \& Snell, H.K. (1933). Amnesia in relation to crime. Journal of Mental Science, 29, 27 . 41.

Horne. A.S. (1999). Reflections on remorse in forensic psychiatry. In: M. Cox (Ed.). Remorse and reparation ( $p$ p. 21-31). London, UK: Jessica Kingsley Publishers.

Hsiao, J.K., Bartko, J.J. \& Potter, W.Z.(1989). Diagnosing Diagnoses: Receiver operating characteristics methods and psychiatry. Archives of General Psychiatry, 46, 664-667.

Hughes, C. (1998). Executive function in preschoolers: links with theony of mind and verbal ability. British Journal of Dewelopmental Psychology. 16, 233-253.

Hughes, c. (2002). Executive functions and development: Why the interest? Infant and child Development, $11,67-71$.

Huls, F.W.M., Schreuders, M.M., ter Horst-van Breukelen, M.H. \& wan Tulder, F.P. (2000). Criminaliteit en rechtshandhawing 2000. Centraal Bureau voor de Statistiek: Justitie.

Hyman, I. E. Billings, F. J. (1998). Individual differences and the creation of false childhood memaries. Memory, 16, 313-318.

Intrator, J., Hare, Ru, Stritzke, P., Brichtswein, Ko, Dorfmain, D., Harpur, T., Bernstein。 D. Handelsman, L., Schaefer, C., Keilp, J., Rosen, J. \& Machac, J. (1997). A brain imaging (single photon emission computerized tomography) study of semantic and affective processing in psychopaths. Biological Psychiatry, 42. 96-103.

Jackson, M.A. \& Giffiths, C.T. (1991). Eanadian criminalogy: Perspectives on crime and criminality. Tononto, Ontario: Harcourt Brace Jovamovich.

Jelicic, M. \& Merckelbach, H. (submitted). Does traumatic stress lead to structural brain changes and memory deficits? A critical note.

Jelicic, M., Merckelbach, H. Nijnman,H., Timmerfnans, M. \& Candel, I. (in preparation). Reliability and validity of the Dutch version of the Psychopathic Personality Inwentory.

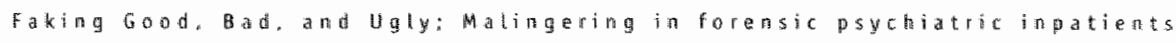


Johnson, H.C. (1996). Violence and biology: a review of the literature. Families in Society. The Joumal of contemporary human services. 17, 3-18.

Johnson, R.C., Edman, J.L. \& Danko, G.P. (1995). Self reported negative experiences and dissociation. Personality and Individual Differences, 18, 793-795.

Johnson, M.K., Hashtroudi, S. \& Lindsay, D.S. (1993). Source momitoring. Psychological Bulletinn, 114 , $3-28$.

Junginger, J. (1996). Psychosis and wiolence: The case for a content analysis of psychotic experience. Schizophrenia Bulletin, 22, 91-103.

Jutai, J.W. \& Hare, R.D. (1983). Psychopathy and selective attention during performance of a complex perceptual-motor task. Psychophysiology, 20, 146-151.

Kalant, H. (1996). Intoxicated automatism: Legal concept vs. scientific evidence. Contemporary Drug Problems. 23, 631-648.

Kanzer, M. (1939). Amnesia: A statistical study. American Joumal of Psychiatry, 96, 711-716.

Kelk, C. (1999). De veelzijdige functies van het Pieter Baan Centrum In F.A.M. Bakker, F.A.M.M. Koenraadt \& A.W.M. Mooij (red.), Om ernstige zaken (pp. 63). Devenyer: Gouda Quint.

Kent, T.A., Brown, C.S., Bryant, S.G., Barratt, E.S., Felthous, A.R. \& Rose, R.M. (1988). Blood platelet. uptake of serotonin in episodic aggression: correlation with red blood cell proton $T 1$ and impulsivity. Psychopharmacology Bulletin, 24, 454-457.

Kiblstrom, J.F. \& Schacter, D.L. (1995). Functional disorders of autobiographical memory. In In A.D Baddeley, B.A. Wilson \& F.N. Watts (Eds.). Handbook of Memory Disorders (pp. 337-364). New York: Wiley.

King, R.J., Jones, J., Scheuer, J.W., Curtis, D. \& Zargone, W.P. (1990). Plasma cortisol correlates of impusivity and substance abuse. Personality and Individual Differences, $11,287-291$.

Kirschbaum, C. \& Hetlhammer, D.H. (1992). Methodological aspects of salivary cortisol measurement. In C. Kirschbaum, G.F. Read \& D.H. Hellhammer, (Eds.). Assessment of hormones and drugs in saliva: Biobehavioral Research (pp. 19-32). Seattle, Wash: Hogrefe \& Huber.

Kopelman, M.D. (1987). Amnesia: Organic and psychogenic. British Journal of Psychiatry. 150, 428442.

Kopelman, M.D. (1995). The assessment of psychogenic amnesia. In A.D Baddeley, B.A. Wilson \& F.N. Watts (Eds.). Handbook of memory disorders ( $p$ p. 427-448). New York: Wiley.

Kopelman, M.D., Green, R.E.A., Guinan, E.M., Lewis, P.D.R. \& Stanhope, N. (1994). The case of the amnestic intelligence officer. Psychological Medicine, 24, $1037-1045$.

Koppenhawer, J. M. Kumar, V. K. \& Pekala, R. J. (1997). Dissociativity. imagery vividness, andi reality monitoring. Dissociation, $10,21-28$. 
Kreusi, M.4., Rapoport, J.L., Hamburger, S., Hibbs, W., Potter, M.Z., Lenane, M. \& Brown, G.L. (1990). Cerebrospinat fluid monoamine metabolites, aggression, and impulsivity in disruptive behavior disorders of children and adolescents. Archives of Gemeral Psychiatry. 47, 419-426.

Kröber, H.L. \& Lauff, 5. (2000). Bad or mad? Personality disorders and legal responsibility-The Germam situation. Behavioral Sciences and the Law, 18, 679-690.

Kuch, K. \& COX B.J. (1992). Symptoms of PTSD in 124 sumivors of the Holocausit. American Journal of Psychiatry, $149,337-340$.

Kullgren, G.., Gurann, M. \& HoLmberg, G. (1996). The Swedish Forensic concept of severe mental disorder as related to personality disorders: An amalysis of forensic psychiatric investigations. of 1498 male offenders. International Journal of Law and Psychiatry, 19, 191-200.

Kullynych, J. (1996). Brain, mind, and criminal behavior: Neuroimages as scientific evidence. Jurimetrics, $36,235-244$.

Kvavilashwili, L. \& Ellis, J.A. (1999). The effects of positive and negatiwe placebos on human memory performance Memory, $2,421-437$.

Lahey. B.B. \& Loeber, R. (1997). Attention-deficit/hyperactivity disorder, oppositional defiant. disorder, conduct disorder, and adult behavior: A Lifespan perspective. In D.M. Stoff (Ed.). Handbook of antisocial behawior (pp. 51-59). Chicago: Chicago Press.

Langle, A., De Beurs, E., Dolan, C., Lachnit, T., Sjollema, S. \& Hanewald, G. (1999). Long-term effects of chillahood sexual abuse: Objective and subjective characteristics of the abuse and psychopathology in later life. Journal of Nerwous and Mental Disease, 187, 150-158.

LeDoux, J.E, Cicchetti, P.. Xagoraris, A. \& Romaniski, L.M. (1990). The lateral amygdaloid nucleus: sensory interface of the amygdala in fear conditioning. Journal of Neuoscience, 10,1062 1069.

LeDous, J.E., Romanski, L.M. \& Xagoris, A.E. (1989). Indelibility of subcortical emotional memories. Joumal of Cognitiwe Neuroscience, $1,238-243$.

Leitch. A. (1948). Notes on amnesia in crime for the general practitioner. The Medical Press, 26, 459 463.

Lees-Haley, P.R. Fox, D.D. \& Courtney, J.C. (2001). A comparison of complaints by milld brain injury clamants and ather chamants dfescribing subjective experiences immediately following their injury. Archives of Clinical Meuropsychology, 17, 1-9.

Lennox, W.G. (1943). Amnesia, real and feigned. Amenican Jourmal of Psychiatry, 99, 732-742.

Lidz. 6. W., Mulvey, E.P. \& Gardner. W. (1993). The accuracy of predictions of violence to others. Journal of the American Medical Association, 269, 1007-1011. 
Lilienfeld, S.0. \& Andrews, B.P. (1995). Dewelopment and preliminary validation of a self-report measure of psychopathic personality traits in noncriminal populations. Journal of Personality Assessment, 66, 488-524.

Link, B. \& Stueve, A. (1994). Psychotic symptoms and the violent/illegall behavior of mental patients compared to community controls. In J. Monahan \& $\mathrm{H}$. Steadman (Eds.). Violence and mental disorder: Developments in risk assessment ( $p$. 137-160). Chicago: University of Chicago Press.

Link, B. G. Stueve, A. \& Phelan, J. (1998). Psychotic symptoms and violence behaviors: probing the ncomponents of "threat/control-override" symptoms. Social Psychiatry and Psychiatric Epidemiology, 33, 55-60.

Lipschitz, D., Bernstein, D.P., Winegar, R.K. \& Southwick, S.M. (1999). Haspitalized adolescents' reports of sexual and physical abuse: a comparison of two self-report measures. Jounal of Traumatic Stress, 12, 641-654.

Lisman, S.A. (1974). Alcoholic "blackout": State dependent learning? Archives of General Psychiatry, 30, $45 \cdot 5.3$.

Loeber, R. \& Farrington, D.P. (1998). Serious and violent juvenile offenders. London: Sage Publiocations.

Loewenstein, R.J. (1991). Psychogenic amnesia and psychogenic fugue: A comprehensive review. American Psychiatric Press Review of Psychiatry. 10, 189-222.

Logan, 6.D., Schachar, R.J. \& Tannock, R. (1997). Impulsivity and inhibitory control. Psychological Science, $8,60-64$.

Lymburner. J.A. \& Roesch, R. (1999). The insanity defense: Five years of research (1993-1997). International Journal of Law and Psychiatry. 22, 213-240.

Lynam, D.R. (1996). Early identification of chronic offenders: who is the fledging psychopath? Psychotogical Bulletin. 120, 209-234.

Lynch, B.E. \& Bradford, J. (1980). Amnesia: Its detection by psychophysiological measures, Anerican Aadeny of Psychiatry and Law. $8,288-297$.

Lynn, 5.J. \& Rhue, J.W. (1988). Fantasy proneness: Hypnosis, developmental antecedents, and psychopathology. American Psychologist, 43, 350-354.

Martin, G.A. (1981). Mental disorder and criminal responsibility in Canadian Law. In S.J. Hucker, C.D. Webster \& M.H. Ben-Aron (Eds.), Mental disorder and criminal responsibility (pp. 15-31). Toronto: Butterworths. 
McBumet, K., Lahey, B.8., Frick, P.J., Risch, C., Loeber, R., Hart, E.L., Christ, M.A. \& Hanson, K.S. (1991). Anxiety, inhibition, and conduct disorder in children.. Relation to salivary cortisol. Jowrmal of Amenican Acaderny of Child and Adolescent Psychiatry, 30, 192-196.

McBurmett, K., Lahey, B.B., Rathouz, P.J. \& Loeber, R. (2000). Low salivary cortisol and persistent aggression in boys referred for disruptive behavior. Archives of General Psychiatry, 57. 38 43.

McCain m, J.T. (1998). Mallingering and deception in adolescents: Assessing credibility in dinical and forensic settings. Washington DC: American Psychological Association.

Mctught, P. R. (1993). Multiple personality disorder. New York: Harvard Mental Health Newstetter.

McNiel, D. (199.4). Hallucinations and wiolence. In J. Monahan \& H. Steadman (Eds.) Violence and mental disorder: Developments in risk assessment (pp. 183-202). Chicago: University of Chitcago Press.

McNiel, D.E. 8 Binder, R.L. (1994). The relationship between acute psychiatric symptoms, diagnosis, and short-term risk of wolence. Hospital and Community Psychiatry, 45, 830-831

McNulty, C. \& Wardle, J. (1994). Adult disclosure of sexual abuse: A primary cause of prychological distress? Chilld abuse and Neglect. 18, 549-555.

McSherry, B. (1998). Getting away with murder: Dissociative states and criminail responsibility. International Journal of Law and Psychiatry, 21, 163-176.

Meehl, P.E. (1996). Clinical versus statistical prediction. Minneapolis: Uniwersity of Minnesota Press.

Meltzer. H.Y. \& Arora, R.C. (1988). Genetic control of serotonin uptake in blood phatelets: a twin study. Psychiatry Research, 24, 253-269.

Merckelbach, H., Cima, M. \& Nijman, H. (2002a). In P.J. valu Koppen, D.J. Hessing, H.L.G.J. Merckelbach \& H.F.M. Crombag (Eds.), Het recht yan binnen: Psychologie wan het recht (pp. $667-685$ ). Deventer: Kluwer.

Merckebach, H. \& Crombag, H. (2000). Trauma en dissociatie: hoe hangen ze samen? De Psycholoog, 35. 4294634 .

Merckelbach, H., Dekkers, Th. Wessel, II. \& Roefs. A. (2003). Amnesia, flashbacks, nightmares, and dissociation in aging concentration camp survivors. Behaviour Research and Therapy. 41. $351-360$.

Merckelbach, H., Devilly, G. J1. \& Rassin, E. (2002b). Alters in dissociative identity disorder: Metaphors or genüne entities? Ginical Psychology Review, 22, 481-497.

Merckelbach, H., Hater. B. \& Rassin, E. (2002C). Symiptom validity testing of feigned dissociative amnesia: A simulation study. Psychology, Crime \& Law, 8, 311-318.

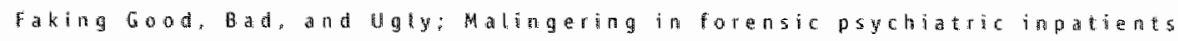


Merckelbach, H., Horselenberg, R. \& Muris, P. (2001). The Creative Experiences Questionnaire (CEQ): A brief self-report measure of fantasy proneness. Personality and Individual Differences. 32. 987.99 .5

Merckelbach, $H_{*}$ Horselenberg, R. \& Schmidt. H. (2000a). Modelling the connection between selt: reported trauma and dissociation in a student sample. Personality and Individual Diferences. Q0., $1-25$.

Merckelbach, H. \& Muris, P. (2001). The causal link between self-reported trauma and dissociation: a critical review. Behavioural Researcin and Therapy, 39, 245-254.

Merckelbach, H., Muris, P., Horselenberg, R. \& Stougie, S.(2000b). Dissociation, reality monitoring. and response bias. Personality and Individuai Differences, 28, 49-58.

Merckelbach, H., Muris, P. \& Rassin, E. (1999). Fantasy proneness and cognitive failures as correlates of dissociatives expierences. Persanality and Individial Differences, 26, 961-967.

Merckelbach, H., Muris, P., Rassin, E. \& Horselenberg, R. (2000c). Dissociative experiences and interrogative suggestibility in college students. Personality and Individual Differences. 29. $1133-1140$.

Merckelbach, H., Muris, P., Wessel. I. \& van Koppen, P.J. (1998). The Gudjonsson Suggestibility Scale (GSS): Further data on ist reliability, validity, and metacognition correlates. Social Beloviour and Personality, 26, 203-210.

Merckelbach, H., Rassin, E., Horselenberg. R. \& Schmidt, H. (2002d). Modelling the connection between self-reported trauma and dissociation in a student sample. Personalite and Individual Differences, 29, 1133-1140.

Merckelbach. H., Rassin, E. \& Muris, P. (2000d). Dissociation, schizotypy and fantasy proneness in wndergraduate students. Jowrnal of Nervous and Mental Disease, $188.428-431$.

Merckelbach, H. \& Snith, 6.F. (2003). Diagnostic accuracy of the Structured Inventory of matingered Symptomatology (SIMS) in detecting instructed malingering. Archives of Clinical Neuropsychology, $18,145-152$.

Merckelbach, H. \& van de Ven, V. (2001). Another White Christmas: Fantasy proneness and reports of "hallucinatory experiences" in undergraduate students. Joumal of Behaviour Theraps and Experimental Fsychiativ, 32, 137-14.4.

Merskey. H. (1992). The manufacture of personalities: The production of multiple personatity disorder. British Journal of Psychiatry, $160,327-340$

Merydit, S.P. \& Walbrown. F.H. (1991). Recansidering response sets, test-taking attitudes. dissimulation, self-deception, and social desirability. Psychological Reports, 69, $891-905$.

Millom. T. (1981). Disorders of personality. Mew York: Wiley. 
Millon, T., Simonseri, E., Birket-Smith, M. \& Davis, D. (1998). Psychopathy: Antisocial, criminaL, and violent behavior. New York: Givilford Press.

Monahan, J. \& Steadman, H. (1983). Crme and mental disorder: An epidemiological approach. In M. Tonry \& N. Morris (Eds.), Crime and justice: An annual review of research (pp. 145-189). Chicago: University of Chicago Press.

Monahan, J. \& Steadman, H.J. (1994). Wiolence and mentat disorder, Develapments in risk assessment. Chicago: University of Chicago Press.

Monroe, R.R. (1978). The medical model in psychopathy and dyscontral syndromes. In W.H. Reid (Ed.). The psychopath: A comprehensive study of antisocial disorder and behaviors (pp. 190208). New York: Brunner/ Mazel.

Mooij, A.W.M. (1995). Het psychiatrisch onderzoek. In A.W.M.Mooij, F. Koenraadt \& J.M.J.: Lommenvan Alphen (red.). De persoon wan de verdachte: De rapportage pro justitia vanuit het Pieter Baan Centrum ( $p p .85-94$ ). Arnhem: Gouda Quint.

Mulder, R.T., Beautrais, A.L.* Joyce, P.R. \& Fergusson, D.M. (1998). Relationsinip between dissociation, childhood sexual abuse, childhood physical abuse, and mental illiness in a general population sample. American Journal of Psychiatry, 155, 806-811.

Muris, P., Merckelbach, H. \& Clavan, M. (1997). Abnormal and normal compulsions. Behaviour Research and Therapy $35,249-252$.

Muris, P. Merckelbach, $H_{*} \&$ Peeters, E. (in press). The links between the adollescent Dissociative Experiences Scale (A-DES), fantasy proneness, and anxiety symptoms. Journal of Nervous and Mental Disease.

Nash, M.R., Hullsey, T.L., Sexton, M.C.. Harralson, T.L. \& bambert, W. (1993). Longuterm sequelae of childhood sexual abuse: perceived fambly environment, psychopathology, and dissociation. Journa of Consuling and Clinical Psvehology, 61, 276-283.

Nedophil, N. (1992). Die Bewährung won Prognoseknterien in Maßsregelvollzug. In: C. Frank, \& G. Harret (Eds.), Kriminalprognose. Forensia- Jahrbuch, Vol 3. Berlin: Springer.

Newman . J.P. (1998). Psychopathic behavior" An hinformation processing perspective. In 0.J. Cooke, A. E. Forth \& R.D. Hare (Eds.), Psychopatity: Theon, research, and implications for society (pp. 81-104). Dordrecht: Kluwer Academic Pubhishers.

Nigenduis, E.R.S. Spinhovem, P., Vanderlinden, J., Van Dyck, R. \& Van der Hart, 0. (1998). Somatoform dissociative symptoms as related to animal deferasive reactions to predatory ithminence and injury. Journal of Abnormal Psychology. 107, 63-73.

Nijman, H. (1999). Aggressive behavior of psychiatric ingatients; Measurement, prevalence, and determinants. Unpublished doctoral dissertation, University of Mastricht, the Netherlands.

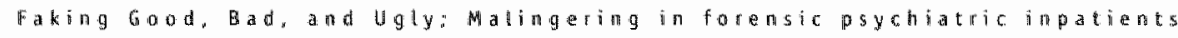


Nijman, H., Cima, M. \& Merckelbach, H. (submitted). Nature and antecedents of psychotic patients cringes.

Nijman. H., Dautzenberg, M., Merckelbach, H., Jung. P. Wessel. I. \& a Campo, \#. 1999). Selfmutilating behawour of psychiatric inpatients. European Psychiatr, $14,4-10$.

Nijmagn, H.L.I, de Kruyk, C. \& van Nieuwenhuizen, Ch. (2002). Ijidschrift voor Psychiatrie [Dutch Joumal of Psychiatry], $44,334-339$.

O'Brien. J.T. (1997). The glucoconticoid cascader hypothesis in man:. prolonged stress may cause permanent brain damage. British Joumal of Psychiatry, 120, 199-201.

O'Brien, B.S. \& Frick, P..J. (1996). Reward dominance: associations with anxiety, conduct problems, and psychopatiny in children. Journal of Abromal Child Psychology, 24, 223-240.

o'Conneli, B.A. (1960). Amnesia and homicide. British youmal of Dielinquency, $10,262-276$.

Ogloff, J.R. \& Wong. S. (1990). Electrodermal and cardiovascular evidence of a coping response in psychopaths. Criminal Justice and Behavion, 17, 231-245.

Ost, J., Fellow, B, \& Bull, R. (1997). Individuat differences and the suggestibility of human memony. Cantemporary Hypnosis, 14, 132-137.

Parkin, A.3. (1987). Memonu and amnesia. An introduction. (2nd ed.) Oxford: Btackwell.

Parwatikar, 5.D., Holcomb. W.R. \& Menninger, K.A. (1985). The detection of malingered annesia in accused murderers. Bulletin of the American Academy af Psychiatry and Law, 13, 97-103.

Patton, J.H. Stanford, M.S. \& Barratt, E.S. (1995). Factor structure of the Barratt Impulsivity Scale. Jourral of Clinical Psychology, 51,768-774.

Pedersen, N.L., Plomin, R., McLeam, G.E. \& Friberg, L. (1988), Neuroticism, extraversion, and related traits in adult twins reared apart and reared together. Journal of Personality and Social Psychology. 55, 950-957.

Pekala, R. J. Kumar, W. K. Ainstie, 6., Ettott. N. C., Mullen, K. J., Salinger, M. M. \& Masten, E. (1999/2000). Dissociation as a function of child abuse and tantasy proneness in a substance abuse population. Imagination Cogntion and Personality 19, 105-129.

Pennington, B.F. \& Ozonoff, 5. (1996). Executive functions and dewelopmental psychopathology. Journal of Child Psychology, 32, 51-87.

Persunger, M.A. (1992). Neuropsychological profiles of adults who report sudden remembering of tearly childhood memories: Implications for clains of sex abuse and atien visitation/abduction experiences. Perceptual and Motor Skills, 75, 259-266.

Philipge, M., de Ruiter, C., Hildebrand, M. \& Bouman, Y. (2000). HCR-20: Risicotaxatie yan geweldadig gedrag. Utrecht/Ningegen: Van der Hoeven Stichting/Pompestichting.

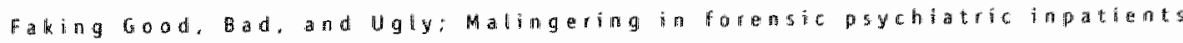


Picknett, L., Prince, C. \& Prioir, S. (2001). Double standards: The Rudolf Hess Cover-Up. London: Littlle, Brown \& Compamy.

Pope, H.6. \& Hudson, J.I. (1995). Does childhood sexual abuse cause adult psychiatric disorders? Essentials of methodology. Journal of Psychiatry and Law, 23, 363-381.

Pope, H.G., Hudson, D.L., Bodkin, J.A. \& Oliva, P. (1998), Questionable validity of dissociative amnesia in trauma victims. British Journal of Psychiatn, 172, 210-215.

Porter, S. B Birt, A.R. (2001). Is traumatic unemory special?' A comparison of traumatic memory characteristics with memory for other emotional life experiences. Applied Cognitive puchology, 15, 1-17.

Porter, S, Birt, A.R., Yuille, J.C. \& Herve, H.F. (2001). Memory for murder: A psychologicall perspective on dissociative amnesiz in legal contexts. Intermational Jouinal of Law and Psychiatry, 24, 23-42.

Porter, S., Birt, A. R., Yuille, J. C. \& Lehman, 0. R. (2000). Negatiating false memories: Interviewer and rememberer characteristics relate to memory distortion. Psychological Science, 11, 507 . 510.

Poytress, M.G., Edens, J.F. \& Watkins, M.M (2001). The relationship between psychopathic personality features and malingering symptoms of amjor mental illmess. Law and Human Behavior. 25. $567-582$.

Pritchard, D.A. (1997). Forensic neuropsychology. In M.E. Maruish \& J.A. Moses (Eds.), Clinical neuropsychology: Theoretical foundations for practicioners (pp. 81-118). Mahwah NJ, Erlbatum:

Putnam, F.W. (1989). Diagnoses and treatment of multiple personallity disorder. New York: Guilford.

Putnam, F.W., Carlson, E. B., Ross, C.A., Anderson, G. Clark, P., Torem, M., Bowman, E.S., Cons, PH., Chw, J.A., Dill, D.L., Loewenstein, R.J. \& Braun, B.G. (1996). Patterns of dissociation in clinical, and mondinical samples. Joumal of Nerwous and Mental Disease, 184, 673-679.

Rabiti, P. (1997). Methodology of frontal and execurive function. Hove, East Sussex: Psychology Press.

Rachiman, S. de Silva, P. (1978). Abnormal and nomal obsessions. Behaviour Research and Therapy, 16, 233-248.

Raine. A. (1991). The SPQ: A scale for the assessment of schizotypal personality based on DSM IV criteria. Schizophrenia Bulletin, $17,555-564$.

Raine, A. (1993). The psuchopathologu of crime. Califormia: Academic Press. 
Raine, A. Brennan, P.A. \& Farnington, D.P. (1997). Biosocial bases of violence: Conceptual and theoretical issues. In A. Raine, P.A. Brenman, D.P. Famington \& S.A. Mednick (Eds.), Biosocial bases of vidence (pp. 1-20). New York: Plenum.

Raine, A., Buchsbaum, M.5., Stanley, J., Lottenberg, S., Abel, b. \& Stodrard, J." (1994). Selective reductions in prefrontal glucose metabolism in murderers. Biological Psychiatry. 36. 365373.

Raine, A., Meloy, J.R., Bihrle, S., Stoddard, J., LaCasse, L. \& Buchsbaum, M.S. (1998). Reduced prefrontal and increased subcontical brain functioning assessed using pasitron emission tomography in predatory and arfective murderers. Behavional Sciences and the Lawa, 16,319 . 332 .

Raine, A., Venables, P.H. \& Wiliams. M. (1990). Relationship between central and autonomic measures of arousal at age 15 years and criminality at age 24 years. Archives of General Psychiatry, 47, 1003-1007.

Rakic, P., Bourgeois, J.P., Zecevic, N., Eckenhoff, M.F. \& Goldman-Rakic, P.5. (1986), Concurrent averproduction of synapses in diverse regions of the primate cerebral cortex. Science. 232. $232-235$.

Rasch, W. (1966). Das Amnesie-Problem in der forensischen Psychiatrie The amnesia problem in forensic psychiatry]. In J. Genchow (Ed.). An den Grenzen von Medizin und Recht. Festschrift für W. Hiallermann. Stuttgart: Enke.

Rassin, E. \& Merckelbach, H. (1999). Special perspectives: The potential conflict between clinical and judicial decision making heuristics. Behavioral Sciences and the Law, 17, 237-268.

Rasin, E., Merckelbach, H. \& Muris, P. (2000). Paradoxical and less paradoxical effects of thought suppression: A critical review. Clinical Psychology Review, 20, 973-995.

Rassin, E., Merckeibach, H. \& Spaan, V. (2001). When dreams become a royal raad to contuston: realistic dreams, dissociation, and fantasy pronenes5. Journal of Nervous and Mental Disease, 189, $478-481$.

Rauschenberg. S.L. \& Lynn, 5.J. (1995). Fantasy proneness, OSM-III-r axis I psychopathology. and dissociation. Jounnal of Abnormal Psychology, 104, 373-380.

Reichlin, S.M., Bloom, J.O. \& Wiltans, M.H. (1993). Excluding personality disorders from the insantity defense: A follow-up study. Bulletin of the American Academy of Psychiatry and the Law. 21. $91-100$.

Renaud, H. \& Estess. F. (1961). Life history interwiews with one hundred nomal Amenican males: "Pathogenicity" of childhood. American Journal of Onthopsychiatry, 31, 786-802. 
Resch, F., Brunner, R. M. \& Parzer, P. (1998). Dissoziative Mechanismen und Persönlichkeitsentwicklung. In: J. Kllosterkötter (Ed.). Frühdiagnostik und Frühbehandlung (pp. 125-141). Berlin: Springer.

Resnick, P.J. (1984). The detection of malingered mental allness. Behavioral Sciences and the Lavk, 2 $20-38$.

Resnick, P.J. (1988). Malingered Psychosis. In R.Rogers (Ed.). Clinical assessment of malingering and deception (pp. 34-53, 1st ed.). New York: Guilford.

Resnick, P.J. (1997), Malingered Psychosis. In R.Rogers (Ed.). Clinical assessment of malingering and deception (pp. 47-67, and ed.). New York: Guilford.

Roediger, H. L. III., Wheeler, M. A. \& Rajaram, 5. (1993). Remembering, knowing and reconstructing the past. In: D.L. Medin (Ed.). The psychotagy of learning and motivation: Adwances in theory aind research (pp. 97-103). New York: Academic Press.

Rogers, R. (1984). Towards an empirical model of malingering and deception. Behavioral Sciences and the Law $2,93-112$.

Rogers, R.(1990a). Development of a new classificatory model of malingering. Bulletin of the American Academy of Psychiatry and Law, $\underline{1}$, 323-333.

Rogers, R. (1990b). Models of feigned mental illness. Professional Psychology. 21, 182-188.

Rogers, R. (1997). Structured interwiews and dissimulation. In R. Rogers (Ed.), Climical assessment of malincering and deception (pp. 301-327, $2^{\text {ms }}$ ed.). New York: Guilford.

Rogers, R. (1997). Clinical assessment of malingering and deception ( $2^{\text {nil }}$ ed.). New York: Guilford.

Rogers, R., Bagby, R.M. \& Dickens, S.E. (1992). Structured Interview of Reported Symptoms (SIRS) and professional manual. Odessa. FL: Psychological Assessment Recources.

Rogers, R. \& Cruise, K. (2000). Malingering and deception among psychopaths. In C.B. Gacono, C.B. (Ed.). (2000). The clinical and forensic assessment of psvehopathy: A practitioner's guide (pp. 269-284). Mahwah, New York: Erlbaum.

Rogers, R. Gillis, J.R., Dickens, S.E. Bagby, R.M. (1991). Standardized assessment of malingering: Validation of the Structured Interview of Reported Symptoms. Psychological Assessment, 4. 89.96.

Rogers, R., Hinds, J.D. \& Sewell. K.W. (1996). Feigning psychopathollogy among adolescent offenders: Validation of the SIRS, MMPI-A, and SIMS. Journal of Personality Assessment, 67 . $244-257$.

Rogers, R., Kropp, P.R., Bagby, R.M. \& Dickens, S.E. (1992). Faking specific disorders: A study of the Structured Interview of Reported Symptoms. (SIRS). Joumal of Climical Psychology, 48, 643in 648 .

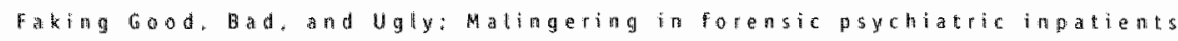


Rogers, R., Sewell, K.W. \& Goldstein, A. (1994). Explanatory models of malingering: A prototypical analysis. Law and Human Behavior, 18, 543-552.

Roman, D.D., Tuley. M.R., Villanueva, M.R. \& Mitchell, W.E. (1990). Evaluating MMPI validity in a forensic psychiatric population: Distinguishing between malingering and genuine psychopathology. Criminal Justice and Behavior, 17, 186-198.

Room, R. (2001). Intoxication and bad behaviour: Understanding cultural differences in the link. Social Science and Medicine, 53, 189-198.

Roserifeld, B., Sands, S.A. \& van Gorp. W.G. (2000). Have we forgotten the base rate problem? Methodological issues in the detection of distortion. Archives of Climical Meurapsychology. 15. 349-359.

Rosenhan. O.L. (1973). On being sane in insane places. Science 179, 250-258.

Ross. C.A. (1997). Dissociative identity disorder: Diagnosis, clinical features, and treatment of multiple personality. New York: Wiley.

Ross, C.A., Jashi, S. \& Currie, R. (1991). Dissociative experiences, in the general population: A factor analyses. Hospital and Community Psychiatry, 42, 297-301.

Sadoff, R.L. (1974). Evaluations of amnesia in criminal-tegal situations. Journal of Forensic Sciences, 19, 98-101.

Salvador, A,s Simon, V., Suay, F. \& Llorens, L. (1987). Testasterone and cortisol responses to competitive fighting in human males: A pilot study. Aggressive Behavior, 13, 9-13

Sandberg, D.A. \& Lymn, S.J. (1992). Dissociative experiences, psychopathology and adjustment, and child and adolescent maltreatment in female college students. Journal of Abmornall. Psychology, 101, 717-723.

Sanders, B. \& Giolas, M. H. (1991). Dissociation and childhood trauma in psycholagical disturbed adolescents. American Journal of Psychiatry, 148. $50-54$.

Sapolsky, R.M.. Krey. L.C. \& McEwen, B.S (1984). Glucocorticoid-sensitive hippocampal neurons are involved in terminating the adrenocortical stress response. Broceedings of the National Academy of Sciences of the United States of America, 81, 6174-6177.

Sapolskiky, R.M., Uno, H., Rebert, C.S. \& Finch, C.E. (1990). Hippocampal damage associated with protonged glucocorticoid exposure in primates. Joumal of Neuroscience, 10, 2897-2902.

Sawyer, J. (1966). Measurement and prediction, clinical and statistical. Psychological Bultetin, 66 , 178-200.

Schacter D.L. (1986). Amnesia and crime: How much do we really know? American Psychologists 42. $286-295$. 
Schacter, D.L. (1986). Feeting-of knowing ratings distinguish between genuine and simulated forgetting. Journal of Experimentad. Psychology: Learning Memory and Cognition, 12, 30-41.

Schacter, D.L., Wang. P.L., Tulving, E. \& Freedman, M. (1982). Functional retrograde amnesia: A quantitative case study. Ne:uropsychologia, 20, 523-532.

Schlag, J. Scheibel, A. (1967). Forebrain in inhibitory mechanisms [special issue]. Brain Research, 6 .

Schmidt, K., Solant M.V. \& Bridger, W.H. (1985). Electrodermal activity of undersocialized aggressive children: a pilot study. Joumal of Child Psychology and Psychiatry, 26, 653-660.

Schretlen, $D_{2}$ J. (1988). The use of psychological tests to identify malingered symptoms of mental disorder. Cinical Psychologicat Review, 8, 451-4.76.

Schreten, D., Neal, J. \& Lesikar, 5. (2000). Screening for malingered mental illness in a court clinic American Journal of Forensic Psychology, $18,5-16$

Schretien, D., Wilkens, S.5., Wan Gorp. W.G. \& Brobholz, J.H. (1992). Cross-validation of a psychological test battery to detect faked insanity. Psychological Assersment, $4,77-83$.

Schumader, R. E. \& Lomax, R. G. (1996). A beginner's guide to structural equation modelling. Mahwah N]: Erlbaum.

Schwartz, N. (1999). Self-reports: How the questions shape the answers. American Psychologist: 54 , 93-105.

Shallice, T. (1998). From neuropsycholagy to mental structure. Cambridge: C.U.P.

Seamons, D.T. Howell, R.J., Carlisle, A.L. \& Roe, A.V. (1981). Rorschach simulation of mental illness and normality by psychotic and nonpsychotic legal offenders. Journal of Personality Assesment, $45,130-135$.

Seifert, D. Jahn, K. Bolten, S. \& Wirtz, M. (2002). Prediction of dangerousness in mentally disordered offenders in Germany. International Jounal of Psychiatry and Law. 25, $51-66$.

Siegel, 5. (1956). Nonparamatnic statistics for the behavioral sciences. Mew York: MicGraw-Hill.

Sierles, F.S. (1984). Correlates of natingering. Behavioral Sciences and the llaw, 2, 113-118.

Sigmon, S.T. \& Snyder, C.R. (1993). Looking at oneself in a rose-colored mirror: The role of excuses in the negotiation of a personal reality. In M. Lewis \& C.Saani (Eds.), Lying and deception in everyday life (pp. 148-165). New York: Guilford Press.

Silva, J.A., Leong, G.B., Weinstock, R. \& Kein, R.L. (1995). Psychiatric factors associated with dangerous misidentificaton delusions. Bulletin of the American Academy of Pswchiatry and the Law, $23,53-61$.

Smith, G.P. (1997). Assessment of malingering with self-report instruments. In R.Rogers (Ed.), ClinicaL assessment of malingering and deception (pp. 351-370). New York: Guilford.

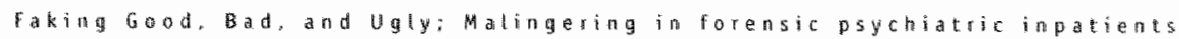


Smith G.P. Burger, G.K. (1997). Detection of Malingering: Validation of the Structured Irventory of Malingered Symptomatology (5IMS). Jowmal of American Academic Psychiatry and the Lawe, 25, $183-189$.

Snow, M.S., Beckman, D. \& Brack, G. (1996). Results of the Dissociatiwe experiences Scate in a jail population. Dissociation, 9, 98-103.

Snyder, M. (1976). Attribution and behaviour: Social perception and social causation. In Jith. Harvey, W.3. Ickes \& R.F. Kidd (Eds.). New Directions in Attribution Research (pp. 53-72). New York: Eribaum, Hillsdale.

Sobotka, SuS., Davidson, R.a. \& Senulis, J.A. (1992). Anterior brain ellectrical asymmetries in response to reward and pumishment. Electroencephalograpliy and Clinical Neurophysiology, 83. 236 . 247.

Spanos, . N.P., Weekes, J.R. \& Bertrand, L.D. (1986). Multiple personality: A sacial psychological perspective. Journal of Abnormal Psychology, $24,362-376$.

Spiegel, D. (1994). Dissociative Disorders. In R.E. Hales, 5.C. Yudofsky \& J.A.Talbott (Eds.). The American psychiatric press textbook of psychiatry (pp.633-652) Washingtom: APA.

Spiegel, D. \& Cardena, E. (1991). Disintegrated experimece: The Dissaciative Disorders revised. Journal of Abnormal Psychology, 100, 366-378.

Spitzer, R.L., Williams, J.B., Gibbon, M. \& First, M.B. (1992). The Structured Clincal Interview for DSM-III-R (SCID). I: History, rationale, and description. Archives of General Psychiatry. 49. $624-629$

Stalentheim, E.G. \& von Knorring, L. (1996). Psychopathy and Axis I and Axis. II psychiatric disorders in a fomensic prychiatric population in Sweden. Acta Psychiatrica Scandinavica, 94, 217-223.

Stevens, J.P. (1992). Applied multivanate statistics for the social sciences (2nd ed.). Hillsdale. NJ: EHLaนm.

Stoms, M.D. \& MCCauL, K.D. (1976). Attribution processes and whotional exacerbation of dysfunctional behaviour. In J.H. Harvey, W.J. Ickes \& R.F. Kidd (Eds.). Mew directions in attribution research (pp. 143-164). New York: Erlbaum.

Stibner, S., Wolk, G. \& Soyka, M. (1989). Zur Differenthialdiagmose der dissoziativen Identitatsstorung (multiple Persönlichkeitsstörung). Mervenarat, $69,440-445$.

Stuss, D.T. \& Bensan. D.F. (1986). The frontal Labes. New York Raven Press.

Swanson, J. (1994). Mental disorder, substance abuse, and community viotence: An wepidemiological approach. In 3. Monahan \& H. Steadman (Eds.). Violence and mental disoider: Developments: in risk assessment (pp. 101-136). Chicago: Uniwersity of Chicago Press.

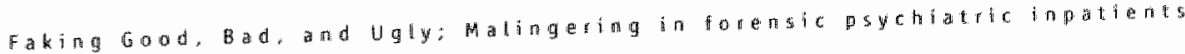


Swhart, G., Yuille, J. \& Porter, 5. (1999). The role of 5 tatemdependent menory in red-outs. Intermational Journal of Law and Psychiatry 22, 199-212.

Tanay, E. (1969). Psychiatric study of thomicide. Americen Joumal of Psychiatry, 125, 1252-1258.

Tarter, R.E. \& Schneider, D.U. (1976). Blackouts. Relationship with memory capacity and alcoholism history. Acchives of General Psychiatry, 33, 1492-1496.

Taylor, P.J. \& Kopelman, M.D. (1984). Amnesia for criminal offences. Psychological Medicine, 14, $581-588$.

Taylor, P.J., Leese, M., Williams, D., Butwell. M. Oaly, R. \& Larkin, E. (1998). Mental disorder and violence: A special (high security) hospital study. British Joumal of Psychiatry, 172.218 226 .

Thamas. W.I. \& Thomas, D.S. (1928). The child in america: Behaviour problems and programs. New York: Knopf

Tiltman, 1.G., Nash, M.R \& Lerner, P.M. (1994). Does trauma cause dissociative psychopathology? In S.J. Lynn \& J.W. Rhue (Eds.), Dissociation: Clinical and theoretical perspective (p. 395-413). New York: Guilford.

Quinsey, V.L., Harris, G.T., Rice, M.E. \& Cormier, C.A. (1998). Violent offenders. Appraising and managing risk. Washington, DC: American Psychological Assiociatior.

Van den Hout, M.A., Merckelbach. H. \& Pool, K. (1996). Dissociation, reality monitoring, trauma, and thought suppression. Behawioural and Cognitive Psychatherapy, 24, 97-108.

Wan der Kolk, B.A. \& valn der Hart, 0. (1989). Pierre Janet and the brealkdown of adaptation in psychological trauma. American Journal of Psychiatry. 146, 1530-1540.

Vanderlimden, J., Van Dyck, R., Vandereycken, W. \& Ventommen, H. (1991). Dissociative experiences. in the general population in the Netherlands and Belgium. Dissociation, 4, 180-184.

Van Goozen; S.H.M., Matthys, W., Cohen-Kettenis, P.T., Gispen-de Wiet, C., Wiegant, V.M. \& wan Engetand, H. (1998). Salivary cortisol and cardiovascular activity during stress in oppositional-defiant disorder boys and nomal controls. Biological Psychiatry. 43, 53-11-539.

Van Ijzendoom. M.H. \& Schuenget, C. (1996). The measurement of dissociation in normal and clinical populations: Meta-analytic validation of the Dissociative Experience scale (DES). Clinical Psychology Revew, 16, 365-382.

Waldbatier, J.R. \& Gazzaniga, M.S. (200)). The divergence of neuroscience and Law. Junimetrics, 41 , $357-364$.

Walters. G.D. (1988). Assessing dissimulation and denial on the MMPI in a sample of maximum security, male innates. Joumal of Personality Assessiment, 52, 465-474.

Faking Good, Bad, and Ugly: Maliagering in forensic psychiatric inpatients 
Wechsler, D. (1991). Hamburq-Wechsler Intelligenztest für Erwachsene Revison (HAWIE-R) [Hamburg-Wechsler Intelligence Scale for Adults Revised]. Bern: Huber.

Wegner, D.M., Schneider, D.J., Carter, 5.R. \& White, T.L. (1987). Paradoxical effects of thought suppression. Jourmal of Personatity and Socjal Psycthology. 53, 5-13.

Wiggins, 3.5. (1959). Interrelationship among MMPI measures of dissmulation under standard and social desirability instructions. Joumal of Consulting Psychology, $23,419-427$.

Wilson, B.A., Aldernan, N., Bungess, P.W., Enslie, H.E., \& Evans, 3.3. (1996). Behaviourat assessment of dysexecutive syndrome. Bury 5t. Edmumds: Thames Valley.

Woif, A.S. (1980). Homiride and blackout in Alaskan natives. Journal of Studies on Alcohol. 41. 456462.

Wolfradt, U. \& Meyer, T. (1998). Interogative suggestibility, anxiety, and dissociation among anxious patients and nomal controts. Personality and Individual Differences, $25,425-432$.

Wong, C.K. (1990). Too shameful to remember: A 17 -year-old Chinese boy with psychogenic amnesia. Australian and New Zealand Jounal of Psychiatry $24,570-574$.

Wood, C.C. MCCarthy, G., Squires, N.K., Vaughan, H.G., Woods, D.L. \& McCallum, W, (1984). Anatomical and physiological substrates of event-related potentials. Annals of the New York Acaidemv of Sciences, 425, $681-721$.

Wortman, C.8. (1976). Causal attribution and personal control. In J.H. Harvey. W.J. Ickes \& R.F. Kidd (Eds.). New directions in attribution researchy (pp. 23-52). New York: Eribaum.

Tehuda, R., Elkin, A., Binder-Brynes, K., Kahana, B., Southwick, S.M., Schmeidler, J. \& Gitler, En. (1996). Dissociation in aging Holocaust survivors. American Journal of Psychiatry, 153, $935-$ 940.

Yochelson, 5. \& Samenow, 5. (1976). The criminal personality. New York: Jason Aronson.

Youngjohn, J.R., Burrows, L. E Edat, K. (1995). Brain damage of compensation meurosis? The controversial post-concussion syndrome. The Clinical Neuropsychologist. $2,112-123$.

Zimmerman. M. \& Mattia, J.I. (1999). Differences between chinical and research practices in diagnosing bordertine personatity disorder. American Journal of Psychiatry. $155,1570-1574$.

Zlotnick, C., Shea, M.T. Pearlstein. T., simpson, E., Costello, E. \& Begin, A. (1996). The relation between dissociative symptoms, alexithymia, impulsiwity, sexual abuse, and self-mutilation. Comprehensive Psychiattr. $37,12-16$. 



\section{DANKWOORD}

Ik zou heel veel mensen kunnen bedanken die in mijn leven iets voor me betekenen. Maar ik zal me beperken tot diegene die iets met mijn proefschrift te maken hebber.

Harald, ik dank je voor je geduld, je enthousiasme en je positieve instelling. Vooral dank ik je dat ik altijd bij je terecht kan als dat nodig is. Ik heb veel van je kritische blik (c.q. bekende rode teksten) geleerd. Je hebt me opgeleid tot wetenschapper en ik ben trots dat ik jou als promotor mocht hebben.

Beste IRP leden, ik dank jullie voor de wetenschappelijke discussies en gesprekken. Elke bijeenkomst is steeds opnieuw weer vruchtbaar en motiverend. Ingrid, Kim, Harald, Marko, Henk, Robert, Ineke, Timo, Sander, Hans, Han en Maarten, ik geniet ervan met jullie samen te werken.

Aan mijn collega's in Duitsland: Doktor Knauer und Herr Schellbach-Matties, vielen dank dass Sie mir die Möglichkeit gegeben haben meine Doktorarbeit in die Rheinische Klinik Düren durchzuführen. Icl danke alle Mittarbeiter für ihren Unterstiutzung. Karl und Sabine, vielen dank für dass Korrektur lesen. Auch danke ich alle Patienten die Freiwillig an meine Arbeit teilgenommen haben.

ou collega's, jullie bedank ik voor jullie belangstelling en interesse in mijn werk. Birgit en Daantje, dank voor jullie ondersteuning.

Sietse en Robert, dank dat jullie op deze dag aan mijn zijde willen staan. 
Lieve Reem, ik dank je voor de mooie lay-out en de prachtige kaft. Dat je me altijd ondersteunt en met je humor maakt dat alles leuk blijft. Maar boven alles, dank ik je dat je aan elke dag uit mijn leven steeds opnieuw weer betekenis geeft. 


\section{CURRICULUM VITAE}

Maaike J. Cima werd op 25 December 1973 geboren te Heerlen. In 1996 ging zij biologische psychologie studeren in Maastricht, met als afstudeerrichtingen Neuropsychologie en Psychopathologie. Sinds haar afstuderen is zij als wetenschappelijk onderzoekster werkzaam in de Forensische Psychiatrie van de Rheinische Kliniken Düren (D). Vanaf 2000 is zij tevens als honorair docent verbonden aan de faculteit Psychologie van de Universiteit Maastricht. Tevens is zij lid van de Interfacultaire Werkgroep Recht en Psychologie (IRP) te Maastricht. Sinds 1 Juni 2002 is zij voor de periode van 4 jaar aangesteld als universitair docent aan de faculteit Psychologie van de Open Universiteit Nederland. 


\section{LIST OF PUBLICATIONS}

Cima, M. Hollnack, S., Kremer, K., Knauer, E. \& Merckelbach, H. (2002). Untersuchungen zur Simulation, Dissimulation und Supernormalität bei forensisch-psychiatrischen Patienten. In M. Osterheider. Whe sicher kamn Prognose sein? (p. 112-123) . Brilon: Hecker.

Cima, M., Hollnack, 5., Kremer, K., Knauer, E., Schellbach-Matties, R., Klein, B. \& Marckelbach, H. (in press). Strukturienter Fragebogen Simulierter Symptome. Die deutsche Version des "Structured Inventory of Malingered Symptomatology: SIMS". Nervenarzt.

Cima, M., Merckelbach, H., Butt, C., Kremer, K., Knauer, E. \& Schellbach-Matties, R* (submitted). It wasn't me: Attribution of blame for criminal acts in psychiatric offenders.

Cima, M., Merckelbach, H., Hollnack, S, Butt, C., Kremer, K., Knauer, E., Schellbach-Matties, R. \& Muris, P. The other side of Malingering: Supernormality. The Clinical. Neuropsychologist.

Cima, M., Merckelbach, H. Holnack, S. \& Knauer, E. (in press). Die Zusammenhang zwischen Trauma und Dissoziation: Eine kritische Betrachtung. Fortschritte der Neurologie und Psychiatrie.

Cima, M. Merckelbach. H., Hollnack, S. \& Knauer, E. (in press). Characteristics of psychiatric prison unmates who claim amnesia. Personality and Individual Differences

Cima, M., Merckelbach, H., Klein, B., Schellbach-Matties, R. \& Kremer, K. (2001). Frontal Lobe dysfunction, dissociation, and trauma self-reports in forensic psychiatric patients. The Journal of Nervous and Mental Disease, 189, 188-190.

Cima, M., Merckelbach, H. Nijman, H., Knauer. E. \& Hollnack, S. (2002). I can't remember Your Honor: Offenders who claim amnesia. The German Journal of Psychiatry, $5,24-$ 34. 
Cima, M., Nijman, H., Merckelbach, H., Kremer, K. \& Hollnack, S. (accepted pending revisionj. Claims of crime-related amnesia in Forensic Patients. International Journal of Law and Psychiatry.

Jeticic, M., Merckelbach, H. \& Cima, M. (submitted). Over het simuleren van cognitieve stoornissen.

Merckelbach, H. Cima, M. \& Nijman, H. (2002). Daders met geheugerverlies. In P.J. van Koppen, D.J. Hessing, H.L.G.J. Merckelbach \& H.F.M. Crombag. Het recht van binmen: Psychologie van het recht (p. 667-685). Deventer: Kluwer.

Merckelbach, H., Koeywoets, N., Cima, M. \& Nijman, H. (2001). De Nederlandse versie van de SIMS. De Psycholoog, 36, 586-591

Nijnaan, H., Cima. M. \& Merckelbach, H. (accepted pending revision). Nature and antecedents of psychotic patients" crimes. The Jourral of Forensic Psychiatry and Psychalogy. 
